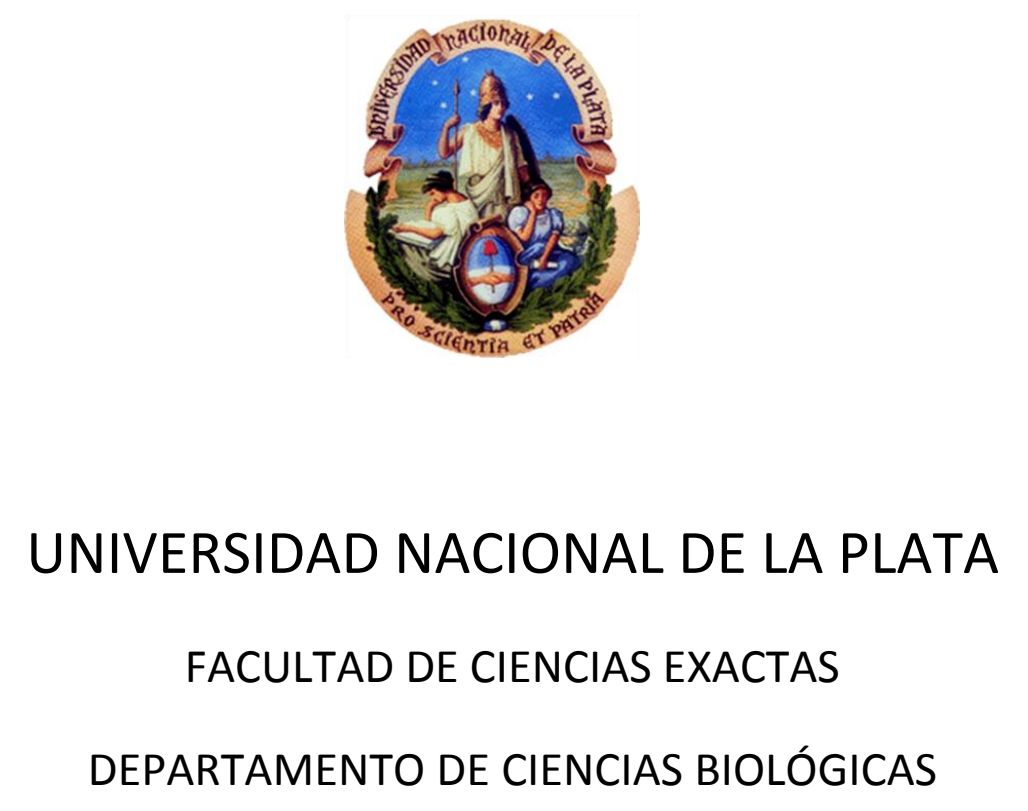

Trabajo de Tesis Doctoral:

\title{
DESARROLLO Y CARACTERIZACIÓN DE MATRICES COMPUESTAS QUITOSANO/POLÍMERO SINTÉTICO PARA REGENERACIÓN DE TEJIDO ÓSEO.
}

\author{
Carla Florencia Berghoff \\ Director: Dra. María Susana Cortizo \\ Codirector: Dra. Ana María Cortizo
}


El presente trabajo de tesis, para optar por el título de Doctor de la Facultad de Ciencias Exactas de la Universidad Nacional de La Plata, fue realizado en el Instituto de Investigaciones Fisicoquímicas Teóricas y Aplicadas (INIFTA-Departamento de Química) y en la Cátedra de Bioquímica Patológica (Departamento de Ciencias Biológicas) de la Facultad de Ciencias Exactas, Universidad Nacional de La Plata.

I N I F T A

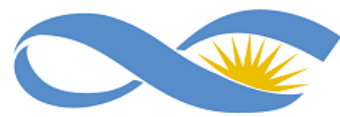

CON I CET

U $\quad \mathrm{N} \quad \mathrm{L} \quad \mathrm{P}$

Facultad de Ciencias Txactas Departamento de Quimica
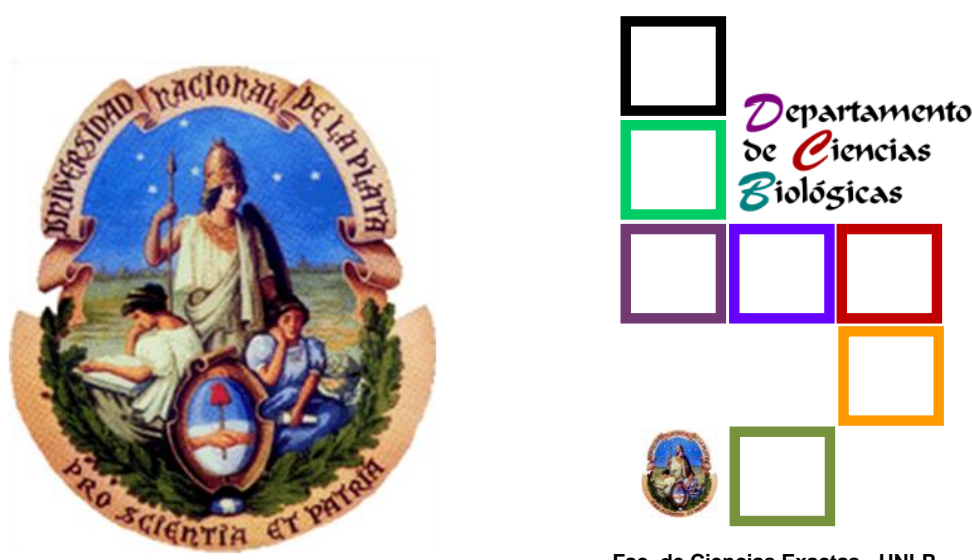

Fac. de Ciencias Exactas - UNLP 
Al Doc...a la distancia, pero cerca del corazón. 


\section{AGRADECIMIENTOS}

La presente Tesis Doctoral es el producto de varios años de trabajo, a lo largo de los cuales, he contado con la colaboración, el apoyo y la compañía de varias personas. Por esto, quisiera expresar en las siguientes líneas mi agradecimiento a todas aquellas personas que de una manera u otra, han hecho posible llevar a cabo este trabajo.

En primer lugar, mi agradecimiento a las Dra. Susana Cortizo y Dra. Ana Cortizo por su dirección, por darme la oportunidad de formar parte de los grupos de investigación que dirigen y por permitirme desarrollar mi trabajo de tesis.

Deseo expresar mi más sincero agradecimiento a aquellos con quien he compartido de forma más cercana estos años de trabajo, mis compañeros del Grupo Macromoléculas y Giomm, en especial a María José Tolosa, Verónica Arnol, Juan Manuel Fernandez, María Virginia Gangoiti, Juan Ignacio Felice y Maria Laura Sbaraglini, Juan Giussi, Marcos Coustet, Fernando Amarilla y Adolfo Pesce por su amabilidad, disponibilidad y valiosos consejos así como paciencia, conocimiento y gran apoyo en la realización de esta investigación.

A mis padres y mi hermano, por sus esfuerzos de cada día, que siempre me han transmitido su apoyo y optimismo, por haberme dado siempre lo mejor y por enseñarme como ser una buena persona, en especial a mi madre por su amor, confianza y por ser todo un ejemplo para mí.

A María Laura, Verónica y Eugenia, mis compañeras y amigas incondicionales de carrera, de las cuales tengo muy buenos recuerdos que guardaré siempre, gracias por preocuparse y aconsejarme en los momentos más difíciles.

Quisiera agradecer de forma especial a Federico, María Laura y a Noelia por su paciencia, su apoyo y por animarme siempre; gracias por brindarme su amistad.

A Paula, Daniela, Mariela, Dolores, Judith, Agustín, Diego, Lucas y Juan Manuel por el cariño y por ser lo que somos, muy buenos amigos.

A mi familia en general y en especial a mi prima Mara y mi tía Delia por su cariño, apoyo y confianza.

A mis profesores y compañeros de los talleres de plástica Edo Eki y el Gato Imán por ser mi cable a tierra y enseñarme que la vida es un bello arte que hay que disfrutar.

Asimismo, agradezco a Ethel Flores, Dr. José Caram, Edgardo Fertitta, Jorge Llanos y Dra. María F. Rozas, que me recibieron como uno más de su gran familia, en especial a la Dra. Esther L. Svartman, por su preocupación constante, por darme fuerza y dedicación para afrontar los momentos difíciles y a la Dra. M. Virginia Mirifico por su disponibilidad para responder mis múltiples dudas, por sus sabios comentarios, y por haber puesto a mi disposición todos los equipos con los que cuenta en su grupo de trabajo, por sus consejos y preocupación; gracias por brindarme su apoyo y amistad. 
También quisiera extender este agradecimiento a la Dra. Sandra Gomez de Saravia y Dra. Patricia Giamet, Paola Lavin, Dra. Mónica Mele, Dra. Claudia Grillo y Florencia Álvarez quienes a pesar de no haber contribuido de forma directa, han sido de gran ayuda para que esta Tesis Doctoral llegase a buen término. Agradezco especialmente a Patricia Battistoni por brindarme su apoyo y amistad, por sus consejos y su optimismo aún en los momentos más arduos.

A la Dra. Cecilia Milazzo, quien me abrió camino en el mundo de la química y por estimularme a llevar a cabo un trabajo de investigación en esta área.

Asimismo, debo dar las gracias a mis compañeros de la cátedra de Química Orgánica de la Facultad de Ciencias Naturales, en especial a la Dra. Adriana Mauri, Dra. Paula Aphalo, Dr. Guillermo Blustein y Dr. Juan Girotti por compañerismo y amistad, por compartir sus conocimientos de forma desinteresada y brindar grandes consejos.

También quisiera agradecer a todo el personal de Taller Mecánico, Vitroplastía, Departamento de Informática y Biblioteca del INIFTA por brindar su ayuda en todo momento.

Al Lic. Mario Sánchez y Lic. Mariela Theiller del Servicio de Microscopía Electrónica de Barrido y Microanálisis Químico por Sonda de Electrones por facilitar la preparación y el análisis de las muestras.

A Jackeline Muñoz Zuñiga, Silvina Ramos, Waldemar Marmisollé, Natalia Fagali y Luciano Carlos por su compañerismo y amistad.

A todos y cada uno de los integrantes del INIFTA, por nuestro tiempo de trabajo compartido.

A la Universidad Nacional de La Plata por haberme brindado formación de excelencia en forma gratuita.

A la Sociedad Iberoamericana de Quitina, a la European Chitin Society y a la Universidad Nacional de La Plata por haberme brindado apoyo económico en la participación de jornadas y congresos.

Finalmente, debo agradecer a la Comisión de Investigaciones Científicas de la Prov. de Buenos Aires por la concesión de las Becas de Estudio y Perfeccionamiento que habilitaron mi formación doctoral durante el período 2007-2011.

"The more that you read, the more things you will know. The more that you learn, the more places you'll go." Dr. Seuss. 


\section{RESUMEN}

Enfermedades tales como osteoporosis, osteonecrosis, osteogénesis imperfecta y tumores óseos se caracterizan por pérdida de masa ósea con deterioro de la microarquitectura lo que se asocia con riesgo de fractura en la población general. Las terapias convencionales para la reparación de lesiones óseas incluyen la reconstrucción quirúrgica, el trasplante, y el reemplazo por prótesis artificiales. En la actualidad el tratamiento de dichas enfermedades es un área de gran interés, a tal punto que la ingeniería de tejidos, ciencia que aplica los principios de la ingeniería y las ciencias de la vida para desarrollar sustitutos biológicos que reparen o mejoren la función biológica de un tejido u órgano, se ha convertido en una terapia alternativa para tratar la pérdida de hueso por medio de la utilización de productos biomédicos obtenidos a partir de biomateriales con aplicaciones en reparación de tejidos dañados.

La búsqueda de nuevos materiales que puedan ser empleados en el campo de la ingeniería de tejidos ha permitido que en los últimos años surja un especial interés en la investigación de las sustancias poliméricas, fundamentalmente de origen natural. Los biopolímeros han presentado un papel primordial en el desarrollo de nuevos materiales por no presentar limitaciones en cuanto a biocompatibilidad, biodegradabilidad y toxicidad, además de ser naturalmente abundantes y renovables.

El enfoque de la ingeniería tisular se basa en el uso de tres elementos fundamentales: las células, las biomoléculas y las matrices tridimensionales (scaffolds). En este sentido, los scaffolds poliméricos desempeñan un papel muy importante, y para ello deben cumplir una serie de requisitos con el fin de favorecer la integración y vascularización del tejido, deben ser biocompatibles, biodegradables, tener adecuadas propiedades mecánicas y una superficie química apropiada que favorezca la adhesion, proliferación y diferenciación celular. 
En este contexto, el quitosano, biopolímero obtenido por desacetilación de la quitina de caparazones de crustáceos y más recientemente pluma de calamar, es un candidato con un gran potencial, utilizado en una amplia gama de aplicaciones, ya que posee propiedades biológicas únicas, entre las que se incluyen su biocompatibilidad, su biodegradación, su marcada actividad antibacteriales, entre otras y además posibilita el desarrollo de scaffolds en una gran variedad de formas como polvos, micropartículas y filmes.

Debido a que las características de este biopolímero extraído de fuentes marinas encajan perfectamente con aquellas cualidades necesarias para el diseño de soportes poliméricos biocompatibles que pueden ser utilizados en ingeniería tisular regenerativa del tejido óseo y con el fin de ofrecer una alternativa para el procesamiento de la pluma de calamar generado en las zonas pesqueras del Mar Argentino, el gran reto de este trabajo de tesis fue el desarrollo de scaffolds biodegradables basados en quitosano obtenido a partir de quitina extraída de la pluma del calamar Illex argentinus. Hasta la fecha esta fuente no ha sido reportada como materia prima para la obtención de los mencionados polímeros.

Como primer etapa (Sección A de este trabajo de tesis) se adecuaron las condiciones de aislamiento, purificación de la $\beta$-quitina a partir de la pluma del calamar Illex argentinus y se llevó a cabo la obtención de quitosano por desacetilación de la misma obteniéndose quitina y quitosano de alta calidad. Por último se realizó una caracterización fisicoquímica de los biopolímeros, investigándose las propiedades en estado sólido (estructura cristalina, grado de acetilación) y en solución (estimación del peso molecular promedio y evaluación de las propiedades reológicas) de la quitina y quitosano.

En una segunda etapa (Sección B de este trabajo de tesis) se desarrollaron y caracterizaron scaffolds biodegradables basados en los polímeros biodegradables quitosano y el poliéster sintético poli-ع-caprolactona, mediante la técnica de evaporación de solvente con el agregado de la droga con actividad osteogénica alendronato de sodio y compatibilizados mediante el uso del entrecruzante no tóxico tripolifosfato de sodio, dirigido a aplicaciones de liberación de fármacos en ingeniería de tejidos que favorezcan el crecimiento de células del tejido óseo para su utilización en reparación y regeneración del tejido óseo y posterior aplicación en implantes óseos. 
Se evaluaron las características fisicoquímicas y biológicas de los scaffolds con las diferentes composiciones el objetivo de seleccionar los más adecuados para su posterior aplicación como futuro material de aplicación en el tratamiento de lesiones óseas.

La caracterización fisicoquímica y estructural de los scaffolds utilizando técnicas de microscopía (electrónica y óptica) y por espectroscopía FTIR reveló diferencias de acuerdo a su composición en alendronato y tripolifosfato. La evaluación de la respuesta biológica (biocompatibilidad y posible citotoxicidad) de los diferentes scaffolds se realizó con un modelo experimental in vitro de osteoblastos en cultivo.

La evaluación del crecimiento y la diferenciación osteoblástica de las células crecidas en los diferentes scaffolds basados en mezclas de quitosano y poli- $\varepsilon$ - caprolactona, permitió observar que dichos materiales presentan una buena biocompatibilidad. Las células crecieron bien mostrando una morfología tetraédrica normal y fueron capaces de adherirse y proliferar en todas las matrices poliméricas. En los cultivos in vitro de osteoblastos lleva a concluir que se obtienen mejores resultados en cuanto a proliferación celular y diferenciación en los scaffolds que contienen bajos dosajes de la droga bisfosfónica alendronato, ya que la inclusión de altas concentraciones de alendronato induce un efecto inhibitorio dosis-dependiente sobre la progresión celular. Por otra parte aquellos scaffolds entrecruzados con tripolifosfato resultaron ser tóxicos para el crecimiento y diferenciación de los osteoblastos. Los estudios de caracterización fisicoquímica y biológica sugieren que los scaffolds basados en quitosano-PCL adicionados con dosis de alendronato entre 0,1 y 0,5\% $\mathrm{p} / \mathrm{p}$ poseen un enorme potencial y serían los candidatos más adecuados en aplicaciones de ingeniería de tejido óseo. 


\section{DEDICATORIA.}

\section{AGRADECIMIENTOS.}

\section{RESUMEN.}

\section{INDICE DE CONTENIDO.}

\section{SECCIÓN A: QUITINA Y QUITOSANO.}

I. QUITINA Y QUITOSANO. FUENTES DE OBTENCIÓN, PROPIEDADES Y APLICACIONES.

1. QUITINA

1.1. Generalidades

1.2. Fuentes de obtención de quitina

1.2.1. Desechos quitinosos en Iberoamérica

1.2.2. Obtención de calamares en argentina 7

1.2.3. Pluma de calamar $\quad 10$

1.3. Métodos de obtención de quitina 11

1.3.1. Acondicionamiento de la materia prima $\quad 12$

$\begin{array}{lll}\text { 1.3.2. Aislamiento y purificación de quitina } & 13\end{array}$

$\begin{array}{ll}\text { 1.3.2.1. Desproteinización } & 13\end{array}$

$\begin{array}{ll}\text { 1.3.2.2. Desmineralización } & 14\end{array}$

1.3.2.3. Decoloración 14

2. QUITOSANO 15

2.1. Generalidades 15

2.2. Obtención de quitosano por desacetilación 17

3. PROPIEDADES Y APLICACIONES DE QUITINA Y QUITOSANO

31. Propiedades químicas y biológicas de quitina y quitosano 20

3.2. Derivatización de quitina y quitosano 21

3.3. Aplicaciones de quitina y quitosano 22

II. MÉTODOS DE CARACTERIZACIÓN FISICOQUÍMICA DE QUITINA Y QUITOSANO.

1. CARACTERIZACIÓN ESTRUCTURAL DE QUITINA Y QUITOSANO

1.1. Difracción por Rayos X 2

1.2. Determinación del Grado de Acetilación 3

1.2.1. Espectrometría Infrarroja 3

1.2.2. Espectrometría ${ }^{13} \mathrm{C}$ RMN CP-MAS en estado sólido 5

2. CARACTERIZACIÓN DE LA MACROMOLÉCULA EN SOLUCIÓN

2.1. Estudios en régimen diluido. Evaluación del peso molecular promedio por viscosimetría capilar

2.2. Evaluación de propiedades reológicas en régimen no diluido mediante viscosimetría rotacional 11

2.3. Propiedades de quitina en solución 13

$\begin{array}{ll}\text { 2.4. Propiedades del quitosano en solución } & 14\end{array}$

III. HIPÓTESIS DE TRABAJO Y OBJETIVOS.

Hipótesis de trabajo 1

Objetivos 1 
IV. EXPERIMENTAL.

1. OBTENCIÓN DE QUITINA 1

1.1. Acondicionamiento de la materia prima 1

1.2. Aislamiento y purificación de la quitina 2

1.2.1. Extracción de lípidos y lipoproteínas 2

1.2.2. Desproteinización 2

2. OBTENCIÓN DE QUITOSANO 3

3. CARACTERIZACIÓN FISICOQUÍMICA DE QUITINA Y QUITOSANO

3.1. Caracterización de la pluma de calamar 4

3.2. Caracterización de $\beta$-quitina purificada 4

3.2.1. Caracterización estructural 5

3.2.1.1. Espectroscopía Infrarroja 5

3.2.1.2. Determinación del grado de acetilación por espectroscopía ${ }^{13}$ C NMR CP-MAS en estado sólido 5

3.2.1.3. Difracción por Rayos $X$

3.2.2. Caracterización de la molécula en solución 7

3.2.2.1. Evaluación del peso molecular promedio viscosimétrico de la quitina 7

3.2.2.2. Modelización de la quitina como una macromolécula flexible

$\begin{array}{ll}\text { 3.3. Caracterización de quitosano } & 10\end{array}$

3.3.1. Caracterización estructural. Determinación del grado de acetilación 10

3.3.2. Propiedades del quitosano en solución 11

3.3.2.1. Evaluación del peso molecular promedio viscosimétrico 11

3.3.2.2. Reología de quitosano 12

v. RESULTADOS Y DISCUSIÓN.

1. CARACTERIZACIÓN DE LA PLUMA DE CALAMAR 1

2. CARACTERIZACIÓN DE LA QUITINA PURIFICADA 4

2.1. Espectroscopía Infrarroja 4

2.2. Espectrometría ${ }^{13} \mathrm{C}$ RMN CP-MAS en estado sólido 5

2.2.1. Determinación del grado de acetilación 6

2.3. Difracción por Rayos $X \quad 7$

2.4. Evaluación del peso molecular promedio viscosimétrico de la quitina 9

2.5. Modelización de la quitina como una macromolécula flexible

3. CARACTERIZACIÓN DEL QUITOSANO 15

3.1. Caracterización estructural del quitosano y determinación del grado de acetilación 15

3.2. Propiedades del quitosano en solución 17

3.2.1. Evaluación del peso molecular promedio de quitosano por viscosimetría capilar $\quad 17$

3.2.2. Medidas de quitosano por reometría rotacional 20

VI. CONCLUSIONES, RECOMENDACIONES Y PERSPECTIVAS. 1 Conclusiones 1 
Recomendaciones $\quad 2$

Perspectivas 3

VII. REFERENCIAS BIBLIOGRÁFICAS DE LA SECCIÓN A.

\section{SECCIÓN B:BIOMATERIALES}

PARA INGENIERÍADE TEJIDO ÓSEO.

I. BIOMATERIALES EN INGENIERÍA DE TEJIDOS. GENERALIDADES, DEFINICIONES Y APLICACIONES.

1. INGENIERÍA DE TEJIDOS EN SISTEMA ÓSEO 1

1.1. Ingeniería de tejidos. Generalidades 1

1.2. Matrices poliméricas tridimensionales o scaffolds 2

1.3. El tejido óseo 4

1.3.1. Estructura arquitectónica del hueso 5

1.3.2. Estructura microscópica del hueso 6

1.3.2.1. La matriz ósea 6

1.3.2.2. Osteoblastos 8

1.3.2.3. Células osteoprogenitoras 9

$\begin{array}{ll}\text { 1.3.2.4. Osteocitos } & 10\end{array}$

1.3.2.5. Osteoclastos 12

1.3.3. Fisiología del hueso 12

1.3.3.1. Osteogénesis y remodelamiento óseo 12

1.3.3.2. Mecanismos biológicos de reparación y regeneración ósea

1.4. Ingeniería de tejidos para reparación y regeneración ósea

2. POLÍMEROS BIODEGRADABLES COMO BIOMATERIALES PARA REGENERACIÓN ÓSEA 16

2.1 Métodos de biofabricación y procesamiento de scaffolds 18

2.2. Quitosano como biomaterial 20

2.2.1. Quitosano en aplicaciones de ingeniería en tejido óseo 24

2.3. Mezclas de quitosano con otras sustancias 24

2.3.1. Mezclas poliméricas $\quad 25$

2.3.1.1. Poli- $\varepsilon$-caprolactona 26

2.3.2. Refuerzo de la estructura del scaffold por entrecruzamiento

3. SISTEMAS DE LIBERACIÓN CONTROLADA DE DROGAS Y SU RELACIÓN CON INGENIERÍA DE TEJIDOS ÓSEO 31

3.1. Sistemas de liberación controlada de drogas e ingeniería de tejidos 31

3.2. Sistemas de liberación controlada en ingeniería de tejido óseo

3.3. Bisfosfonatos 36

3.3.1. Relación estructura-actividad de los bisfosfonatos 37

3.3.2. Mecanismos de acción y efectos celulares en sistema óseo

3.3.3. Bisfosfonatos en sistemas de liberación controlada de drogas

II. HIPÓTESIS DE TRABAJO Y OBJETIVOS. 
Justificación 1

Hipótesis de trabajo $\quad 1$

Objetivos 2

III. EXPERIMENTAL.DESARROLLO Y CARACTERIZACIÓN DE SCAFFOLDS BIODEGRADABLES QUITOSANO/POLI- $\varepsilon-$ CAPROLACTONA PARA REGENERACIÓN ÓSEA.

1. ELABORACIÓN DE SCAFFOLDS BASADOS EN QUITOSANO/ POLI-E-CAPROLACTONA POR LA TÉCNICA DE EVAPORACIÓN DE SOLVENTE

2. CARACTERIZACIÓN FISICOQUÍMICA DE LOS SCAFFOLDS 5

2.1. Análisis de la micromorfología superficial 5

2.2. Análisis de las interacciones moleculares 6

3. ESTUDIOS DE BIOCOMPATIBILIDAD IN VITRO 6

3.1. Cultivos celulares e incubación $\quad 7$

3.2. Estudios de biocompatibilidad 9

3.2.1. Ensayos de morfología y crecimiento celular 9

3.2.2. Ensayos de diferenciación celular 10

3.2.2.1. Actividad enzimática específica 10

3.2.3. Análisis estadístico de los datos 11

IV. RESULTADOS Y DISCUSIÓN. 1

1. ELABORACIÓN DE SCAFFOLDS BIODEGRADABLES BASADOS EN QUITOSANO/ POLI- $\varepsilon$-CAPROLACTONA 1

2. CARACTERIZACIÓN FISICOQUÍMICA DE LOS SCAFFOLDS 3

2.1. Análisis de la micromorfología superficial 3

2.2. Análisis de las interacciones moleculares 8

3. ESTUDIOS DE BIOCOMPATIBILIDAD IN VITRO 11

3.1. Estudios en la línea celular UMR-106 derivada de osteosarcoma de rata $\quad 11$

3.2. Estudios en la línea celular MC3T3-E1 derivada de calvaria de ratón 18

$\begin{array}{ll}\text { 3.3. Discusión } & 19\end{array}$

V. CONCLUSIONES, RECOMENDACIONES Y PERSPECTIVAS. 1

Conclusiones 1

Recomendaciones 3

Perspectivas 4

VI. REFERENCIAS BIBLIOGRÁFICAS DE LA SECCIÓN B. 1

TRABAJOS PUBLICADOS Y PRESENTACIONES A CONGRESOS

EN EL MARCO DEL TRABAJO DE TESIS. 
Sección A.

Quitina Y Quitosano. 
I.

Quitina Y Quitosano.

Fuentes de Obtención,

Propiedades

$y$

Aplicaciones. 


\section{QUITINA Y QUITOSANO. FUENTES DE OBTENCIÓN, PROPIEDADES Y APLICACIONES.}

\section{QUITINA.}

\subsection{Generalidades.}

La quitina es un polisacárido lineal nitrogenado, de origen natural, blanco, duro y cristalino. Fue aislado por primera vez por Braconnot en 1811, a partir de hongos superiores, y por su origen la denominó "fungina" (Braconnot H., 1811). El nombre quitina - vocablo griego $\chi \imath \tau \varpi v$ (xitwuv, chiton), que significa túnica, cubierta o envoltura-se debe a Odier, que en 1923 la aisló a partir de escarabajos en soluciones alcalinas (Odier A., 1823). Químicamente se trata de un polímero de alto peso molecular compuesto por unidades de $\mathrm{N}$-acetil-2-amino-2-desoxi-D-glucosa unidas entre sí por enlaces glicosídicos $\beta(1 \rightarrow 4)$ formando una cadena lineal. Algunas de las de unidades monoméricas se encuentran desacetiladas.

La quitina se diferencia estructuralmente de la celulosa en la presencia de un grupo $\mathrm{N}$-acetamida $\left(-\mathrm{NH}-\mathrm{CO}-\mathrm{CH}_{3}\right.$ ) en lugar del grupo hidroxilo $(\mathrm{OH})$ en el carbono en posición 2 de la unidad de glucosa de la celulosa (Gardner K. et al., 1975). La gran similitud estructural existente entre la quitina y la celulosa se muestra en la figura 1.1.

Si bien la quitina y la celulosa desempeñan un rol semejante como materiales de soporte y defensa en los organismos que los contienen, la celulosa es sintetizada preferentemente en plantas, mientras que la quitina se encuentra presente en varios grupos taxonómicos, principalmente en animales inferiores. Comúnmente se la encuentra en el exoesqueleto o cutícula de varios invertebrados (artrópodos y moluscos entre otros), así como también en las paredes celulares de la mayoría de hongos y algunas algas. 

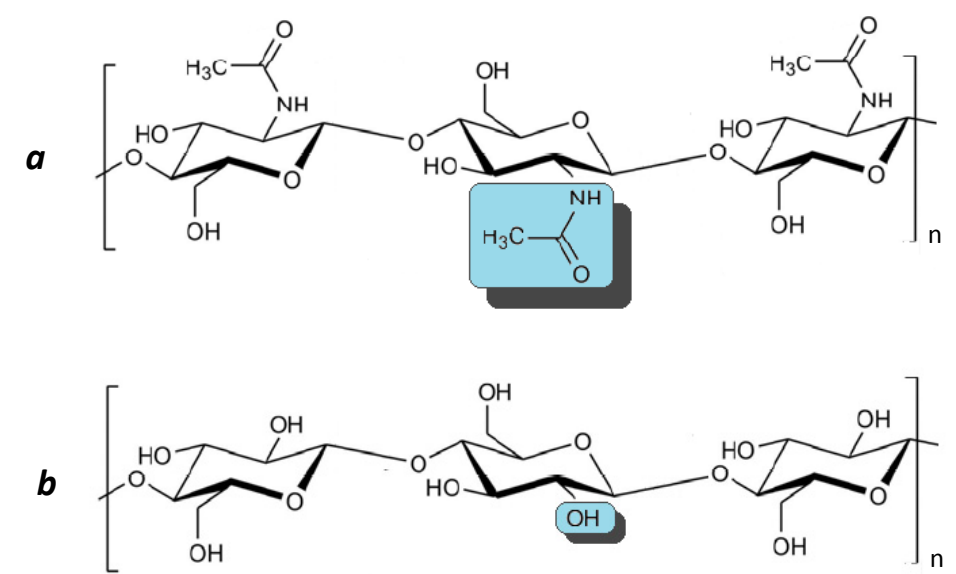

Figura 1.1. Estructura química de la quitina (a) y celulosa (b).

Estos dos biopolímeros poseen la ventaja de ser conocidos en la naturaleza desde hace millones de años. En efecto, es posible asignarle a la quitina una edad de al menos 570 millones de años, al haber sido encontrada en el exoesqueleto de trilobites, artrópodos acuáticos fósiles que datan de la era Paleozoica (Lárez Velásquez C., 2006).

La quitina se produce por biosíntesis y las enzimas involucradas en su formación y degradación están identificadas (Koide S., 1998). En la naturaleza la función de la quitina, como forma nativa, está bien definida como un polisacárido estructural que actúa como material de soporte y defensa en una gran variedad de organismos. Se encuentra asociada de distintas maneras en las diversas matrices biológicas de los tejidos que compone: unida a proteínas formando complejos entre sí, asociada a otros polisacáridos o hidroxifenoles, lípidos, pigmentos y sales inorgánicas. Entonces, es evidente que para aislar el biopolímero de su matriz biológica original serán necesarios sucesivos procesos de extracción y purificación.

La quitina es el polisacárido natural más abundante en términos de ocurrencia estática luego de la celulosa y primero por su tasa de regeneración en la biósfera, que se estima el doble de la celulosa $\left(2,3.10^{9}\right.$ toneladas/año sólo para crustáceos) (Dutta $K$. et al., 2002). Si bien constituye un importante recurso renovable, estadísticamente se ha demostrado que su acumulación constituye la mayor fuente de polución superficial en áreas costeras. El aprovechamiento de estos desechos constituye una oportunidad de desarrollo industrial, y a la vez, una solución inteligente para el problema ambiental que los mismos generan. 
A diferencia de los polímeros sintéticos la quitina y su principal derivado, el quitosano, no presentan limitaciones en cuanto a la biocompatibilidad, biodegradabilidad y toxicidad, además de ser naturalmente abundantes y renovables. La quitina y el quitosano pueden considerarse como un nuevo tipo de materiales poliméricos biofuncionales que son ambientalmente benignos (Kurita K., 2006) y que poseen mayor número de potenciales aplicaciones que la celulosa en varios campos.

Si bien la quitina es uno de los polímeros más abundantes, su utilización como material polimérico es limitado debido a su elevada cristalinidad, lo que le confiere una pobre solubilidad tanto en medios acuosos como solventes orgánicos y por tanto pobre reactividad. De ahí el hecho de que la mayoría de los estudios orientados a su utilización estén dirigidos a lograr modificaciones químicas para obtener derivados con propiedades más convenientes, de los cuales el más notorio es el quitosano producido por desacetilación.

Los estudios de difracción por rayos $\mathrm{X}$ han identificado tres formas polimórficas de quitina en la naturaleza, denominadas alfa $(\alpha)$, beta $(\beta)$ y gamma $(\gamma)$ quitina. Las mismas difieren no sólo por su arreglo en la región cristalina (empaquetamiento, disposición u ordenamiento y en las polaridades de las cadenas adyacentes dentro de la celda cristalina) sino también en su origen biológico. Sus disposiciones se aprecian en la figura 1.2 .
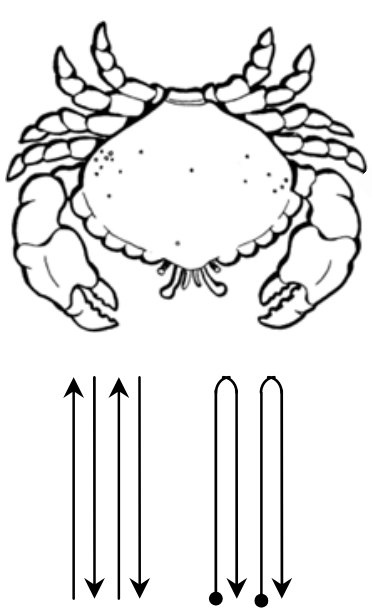

$\alpha$-quitina
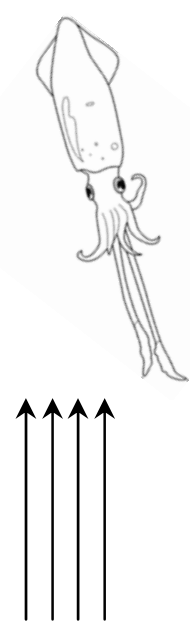

B-quitina
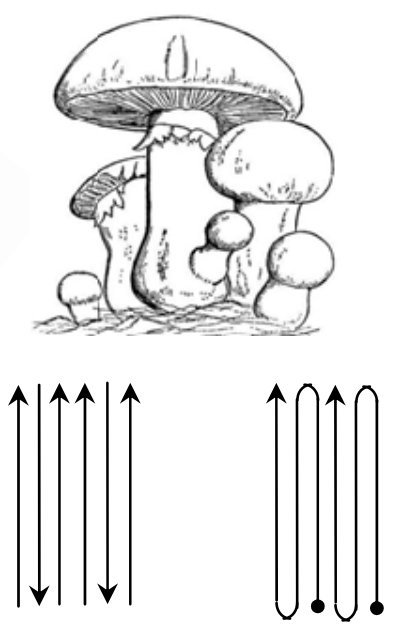

$\gamma$-quitina

Figura 1.2. Polimorfos de la quitina en la naturaleza y ejemplos biológicos de cada uno de ellos. Las "flechas" representan la disposición de las cadenas poliméricas. Basado en Onar N. et al., 2004. 
Las formas más comúnmente estudiadas son la $\alpha$ - y $\beta$-quitina. La $\alpha$-quitina es la más abundante y prevalece en cutícula de artrópodos, pared celular de hongos y algas, quistes de Entamoeba y rádula y cutícula esofágica de cefalópodos dibranquiados, entre otros. Presenta una disposición antiparalela de las cadenas poliméricas, las cuales se estabilizan por fuertes interacciones por puentes de hidrógeno intercatenarios e intracatenarios (Blackwell J. et al., 1980). El polimorfo $\beta$-quitina consiste en un ordenamiento paralelo y más abierto de las cadenas, que se caracteriza por interacciones intermoleculares por puentes de hidrógeno, más débiles (Gardner K. et al., 1975). Debido a esta diferencia estructural la $\beta$-quitina exhibe un mejor comportamiento de solubilidad, mayor capacidad de absorción de agua así como mayor afinidad frente a solventes orgánicos. Estas propiedades se traducen en una mayor reactividad en comparación con la $\alpha$-quitina, siendo importante para su derivatización en posteriores aplicaciones. La $\beta$ quitina, menos abundante, ha sido estudiada en pluma de calamar, espinas de ciertas diatomeas, braquiópodos, tubos de pogonóforos y vestimentíferos, así como también en otros pocos organismos. La $\beta$-quitina de pluma de calamar es semicristalina, pero una forma casi completamente cristalina se aisló de tubos del pogonóforo Tevnia jerichonana (Gaill F. et al., 1992). Datos abundantes únicamente se encuentran en relación a las formas $\alpha$ - y $\beta$ - de la quitina. Respecto al alomorfo $\gamma$-quitina, que presenta una disposición de dos cadenas paralelas en un sentido y la siguiente en sentido opuesto (figura 1.2.), existen pocos datos publicados en la literatura debido a la naturaleza inusual de este tipo de quitina (Jang M. et al., 2004). Inclusive algunos autores se inclinan por considerar este polimorfo como una variante de la familia $\alpha$-quitina (Rinaudo M., 2006; Roberts G., 1992). La forma $\alpha$-quitina es la más estable; ello se ve confirmado por la tendencia de transformación, mediante tratamientos químicos, de la forma $\beta$ - en $\alpha$ - y de igual manera la forma $\gamma$ - en $\alpha$-. Rudall y Kenchington (Rudall K. et al. 1973) asocian diferentes funciones biológicas a cada forma polimórfica.

Por ser un producto natural, no es posible esperar una composición única para la quitina. Debe entenderse por esto que las diferentes moléculas del polímero presentan variabilidad entre ellas. La variabilidad abarca el tamaño molecular, el porcentaje de grupos amino-acetilos y la secuencia de estos a lo largo de la cadena. Es así entonces que la quitina aislada se caracteriza más específicamente evaluando el grado de acetilación (DA), definido como la fracción molar de unidades glicosídicas $\mathrm{N}$-acetiladas (Roberts $\mathrm{G}$., 
2008) (unidades A en la figura 1.3.). Este valor refleja el efecto de la solubilidad y propiedades en solución de la quitina y sus derivados.

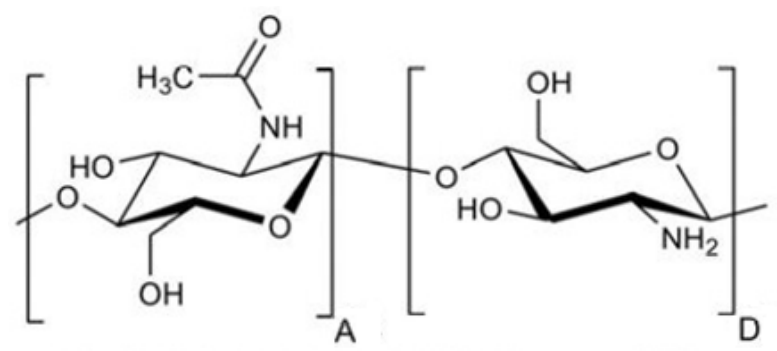

Figura 1.3. Grado de acetilación de la quitina. Las unidades repetitivas de monosacárido en la quitina se hallan representadas por $\mathrm{N}$-acetil-2-amino-2-desoxi-D-glucosa (A) y 2-amino-2-desoxiD-glucosa (D). Basado en Aranaz I. et al., 2009.

Algunos autores argumentan que la quitina natural posee un grado de acetilación de 0,66 , es decir, que una de cada tres de sus unidades se encuentran desacetiladas (Peniche Covas C., 2006), otros (Ravi Kumar M., 2000) que el DA típico de la quitina es 0,90; de acuerdo a los datos bibliográficos no se observa una conformidad entre los diferentes autores. La quitina obtenida a partir de diatomeas constituye una excepción ya que todos los grupos amino están acetilados (Blackwell J., 1967).

\subsection{Fuentes de obtención de quitina.}

A pesar de que la quitina está ampliamente distribuida en la naturaleza (Fungi, Algae, Protozoa, Cnidaria, Aschelminthes, Endoprocta, Bryozoa, Phoronida, Brachiopoda, Echiurida, Annelida, Mollusca, Onycophora, Arthropoda, Chaetognatha, Pogonophora, Tunicata), desde el punto de vista práctico, los exoesqueletos de diversos tipos de crustáceos acuáticos (camarones, langostas, cangrejos y krill) y más recientemente pluma de calamar, son las fuentes más accesibles de quitina por ser materiales de desecho de plantas procesadoras de la industria pesquera (Kurita K., 2006).

La actividad de procesado industrial de los productos de la pesca, especialmente de crustáceos (langostino, camarón, centolla, entre otros) y moluscos cefalópodos (calamar), genera actualmente una gran cantidad de residuos, que suponen a nivel 
mundial, un grave problema medioambiental. Cerca del 10 por ciento de los productos acuáticos pesqueros mundiales consisten en especies ricas en material quitinoso.

Se estima que la industria mundial de captura, la acuicultura y el procesamiento de crustáceos y moluscos genera anualmente aproximadamente $144.10^{4}$ toneladas de desechos quitinosos sólidos, donde Iberoamérica produce aproximadamente un $12 \%$ de esa cifra (Goycoolea F. et al., 2004). En la década del '70 la necesidad de dar una respuesta a la creciente concentración de los desperdicios de las industrias pesqueras, estimularon investigaciones en torno a las distintivas propiedades de la quitina y sus derivados y el potencial de estos polímeros naturales.

Actualmente las principales fuentes de desechos mundiales aprovechadas para producir quitina comercialmente son los crustáceos.

\subsubsection{Desechos quitinosos en Iberoamérica.}

Las distintas especies de crustáceos y moluscos que abundan en Iberoamérica y que son comercialmente importantes, difieren según la región. En conjunto los camarones y langostinos son el grupo más importante de materia prima potencial para la producción industrial de quitina en Iberoamérica. Goycoolea y colaboradores (Goycoolea F. et al., 2004) realizaron una revisión detallada de los principales géneros y especies. Dichos autores presentan además los datos experimentales de composición química de los principales desechos quitinosos industriales de importancia comercial en Iberoamérica. Como se observa en la tabla 1.1., la composición química varía con la especie y la época del año.

Para los crustáceos la composición del desecho en base seca está dada típicamente por proteína (13-58 \%), carbonatos y fosfatos de calcio (20-72\%), lípidos (0,8-12 \%) y quitina (14-35 \%). El contenido en humedad varía entre 50-80\% dependiendo del origen biológico y el manejo de los desechos previo a su procesamiento.

Tal como se esbozó anteriormente, la quitina ha sido identificada bajo diferentes formas en varios grupos de moluscos (Peters W., 1972) y se han realizado estudios comparativos acerca de las composiciones de los complejos quitinosos en cefalópodos (Hunt S. et al., 1981). Si bien los calamares dentro de los cefalópodos poseen los tres alomorfos de quitina, la pluma de calamar constituye el principal desecho quitinoso. A 
pesar de no ser la fuente más comúnmente utilizada, la pluma de calamar es una fuente potencial alternativa por poseer el alomorfo $\beta$-quitina, y por estar compuesta principalmente de quitina y proteínas, se observa un mayor rendimiento en quitina respecto a la fuente crustáceo, con un porcentaje de quitina mayor al $40 \%$ y una mínima cantidad de material mineral (menor al $1 \%$ ).

\begin{tabular}{lccccc}
\hline \multirow{2}{*}{ Origen } & \multicolumn{5}{c}{ Composición Química (\%) } \\
\cline { 2 - 6 } & Humedad & Proteínas & Cenizas & Lípidos & Quitina \\
\hline $\begin{array}{l}\text { Caparazones de jaiba y cangrejo } \\
\quad \text { Callinectes sapidus }\end{array}$ & 46,8 & 7 & 38,5 & 0,4 & 7,3 \\
$\quad \begin{array}{l}\text { Paralithodes camtschaticus } \\
\quad \text { Chionectes opilio }\end{array}$ & 50 & 11 & 23 & 0,5 & 15,5 \\
$\begin{array}{l}\text { Camarón (langostino) Penaus sp. } \\
\quad \text { cabeza }\end{array}$ & $n . r$. & 10,3 & 57,9 & 1,35 & 26,65 \\
$\quad$ cáscara & 77,04 & 12,9 & 5,2 & 2,06 & 2,8 \\
$\begin{array}{l}\text { Krill Euphasia superba } \\
\text { Langosta }\end{array}$ & 65 & 22,1 & 9,2 & 0,5 & 6,2 \\
$\quad$ Linuparus trigonus & $n . r$. & 41 & 23 & 11,6 & 24 \\
$\quad \begin{array}{l}\text { Palinurus argus } \\
\text { Pluma de calamar }\end{array}$ & 13,5 & 17 & 54,7 & $n . r$. & $n . r$. \\
$\quad \begin{array}{l}\text { Dosidicus gigas(calamar gigante) } \\
\text { Loligo sp. (calamar común) }\end{array}$ & 11,8 & $11,0-14,0$ & 55 & $n . r$. & 10,6 \\
\hline
\end{tabular}

Tabla 1.1. Composición química porcentual de las principales fuentes de materia prima de quitina. (n.r.: valor no registrado). Tomado de Goycoolea F. et al., 2004.

\subsubsection{Obtención de calamares en Argentina.}

Los moluscos cefalópodos constituyen un grupo de 700 especies marinas distribuidas en todos los océanos del mundo que se caracterizan por poseer una cabeza bien desarrollada rodeada por diez apéndices móviles con hileras de ventosas con anillos quitinosos. La boca se abre en el interior de la corona de brazos y lleva un par de mandíbulas quitinosas. El cuerpo o manto lleva internamente una conchilla quitinosa denominada pluma o gladio.

El comercio mundial de cefalópodos ha experimentado un considerable crecimiento en las últimas décadas, constituyendo en el año 2002 una de las principales pesquerías de invertebrados. Las capturas registradas para dicho año fueron cercanas a 
los 3,2 millones de toneladas, dentro de las cuales alrededor de 2,2 millones de toneladas corresponden a calamares (FAO, 2005). Las principales zonas de pesca (figura 1.4.) se encuentran en el Pacífico Noroccidental (Área 61, FAO) y Atlántico Sudoccidental (Área 41, FAO), las cuales aportan cerca de las dos terceras partes del total de las capturas mundiales. Los cefalópodos representan el $27 \%$ de los desembarques totales del Atlántico Sudoccidental. Por el volumen de pesca $(80 \%)$, los calamares constituyen el grupo más importante dentro de los cefalópodos. Entre los calamares, los omastréfidos (potas) y los loligínidos (calamaretes) incluyen el mayor número de especies explotadas comercialmente (Brunetti N. et al., 1999).

Los calamares de aleta corta de la Familia Ommasthephidae se distribuyen mundialmente en la región nerítica y oceánica. Esta Familia es la más importante desde el punto de vista pesquero, ya que cerca del $70 \%$ de las capturas mundiales de cefalópodos corresponden a ella (FAO, 2005; Roper C. et al., 1984; Caddy J., 1995). El calamar argentino Illex argentinus y Todarodes pacificus, son las principales especies de omastréfidos y constituyen el 46 \% de las capturas mundiales de cefalópodos (FAO, 2005).

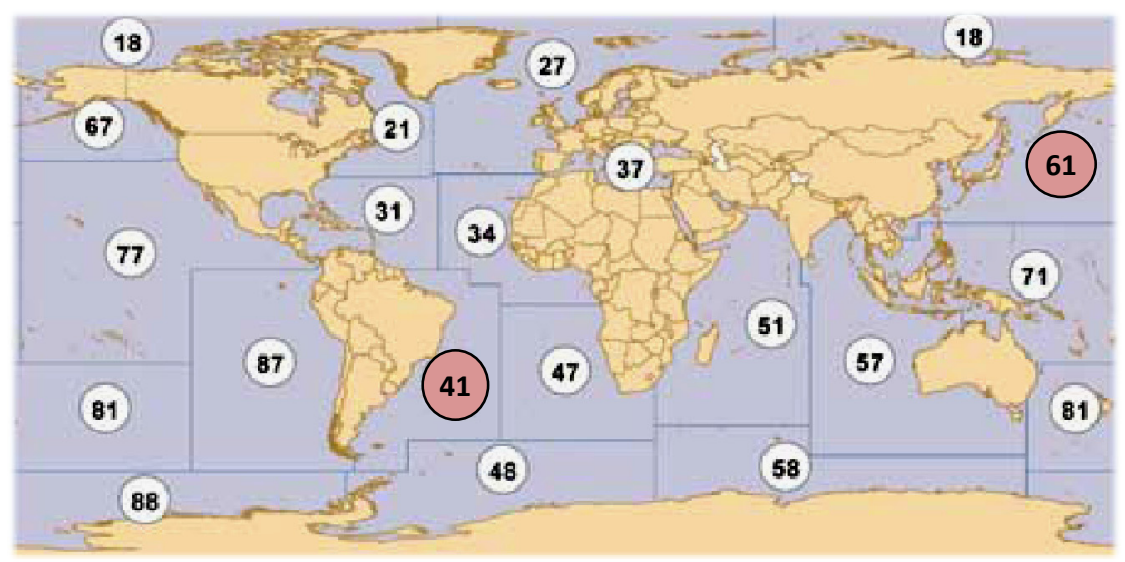

Figura 1.4. Mapa de zonas de pesca mundiales según $F A O$. Resaltadas se encuentran las principales áreas pesqueras. Tomado de $F A O, 2005$.

Seis especies de calamares omastréfidos habitan en la región del Mar Argentino y/o región oceánica adyacente. La más importante, debido a su elevada abundancia, es Illex argentinus, la cual se distribuye especialmente sobre la plataforma y talud continental. La especie soporta una gran presión pesquera, la cual ha aumentado considerablemente en la última década, lo que la convierte en la segunda especie de 
interés económico del Mar Argentino. Martialia hyadesi (calamar negro) y Ommastrephes bartrami (calamar rojo) son la base de pesquerías locales o en desarrollo y por lo tanto potencialmente explotables, si bien no existe actividad pesquera dirigida a ellas en el presente. Ornithoteuthis antillarum y las especies restantes solo son capturadas ocasionalmente en la región (Brunetti N. et al., 1998).

Illex argentinus (figura 1.5. a) es una especie de calamar de mediano tamaño y de ciclo anual que se encuentra desde los $54^{\circ} \mathrm{S}$ hasta los $23^{\circ} \mathrm{S}$, con presencia frecuente entre los $52^{\circ} \mathrm{S}$ hasta los $35^{\circ} \mathrm{S}$. Su distribución está limitada a aguas templado-frías de la corriente de Malvinas (figura 1.5. b). La temporada de pesca se extiende entre el $1^{\circ}$ de febrero y el 31 de agosto, cuando la especie se encuentra migrando sobre la plataforma continental; en tanto que entre septiembre y enero se aplica una veda destinada a proteger los juveniles. En la Argentina la mayor parte del calamar es congelado a bordo en buques y una menor proporción es conservada a bordo en hielo. Se comercializa enfriado o congelado (entero, vaina, tubo, anillos, tentáculos, aletas) y en conserva.

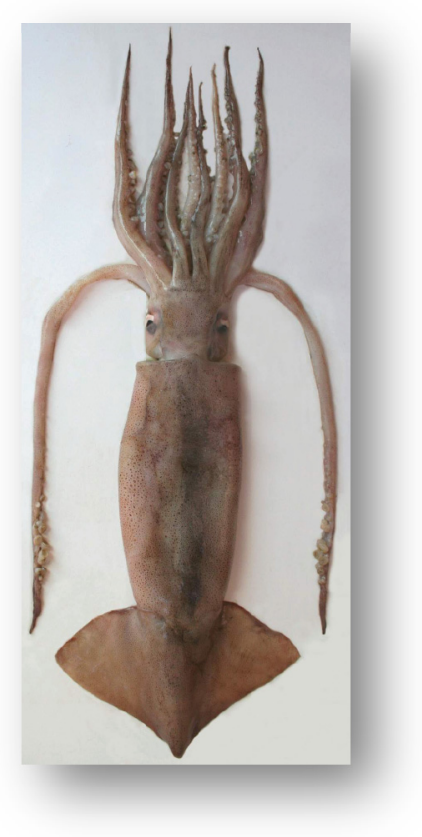

a

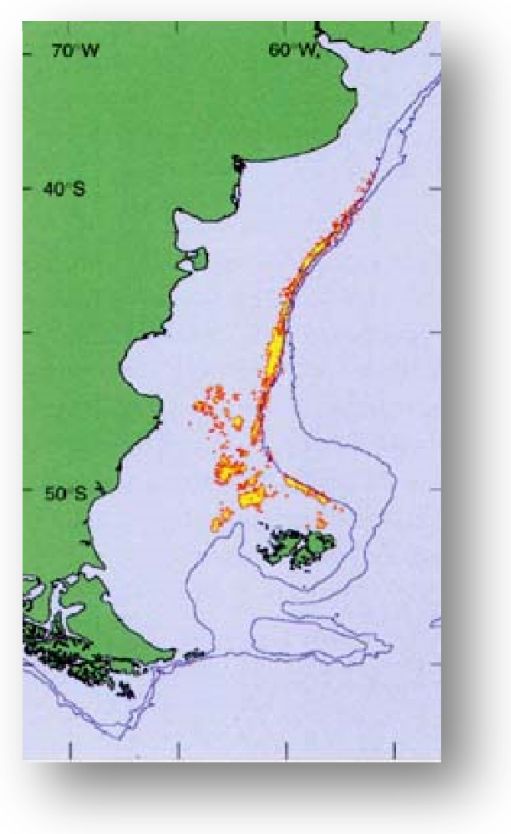

$\boldsymbol{b}$

Figura 1.5. Vista dorsal (a) y distribución (b) geográfica de calamar omastréfido Illex argentinus. Tomado de FAO, 2005. 
Por otra parte los calamaretes de la familia Loliginidae, representados en el Mar argentino por Loligo sanpaulensis y Loligo gahi, tienen importancia económica a nivel regional por ser la base de pesqueras locales (Brunetti N. et al., 1999).

\subsubsection{Pluma de calamar.}

La pluma o gladio es la conchilla interna presente en calamares y sepiólidos (figura 1.6. a). A diferencia de las estructuras calcáreas características de las sepias, la pluma de los calamares posee una estructura que está principalmente compuesta por $\beta$-quitina en asociación con proteínas (Hunt S. et al., 1981; Hunt S. et al., 1990; Wu S. et al., 2003). Se ubica en un saco de la conchilla y corre a lo largo de la línea dorsal del manto. Se forma tempranamente en la ontogenia y crece desde la parte posterior del cuerpo hacia adelante por adición de capas de quitina. Su forma varía con el estilo de vida de la especie, pero en general consiste de un raquis central, expansiones laterales y un cono terminal (figura 1.6. b).
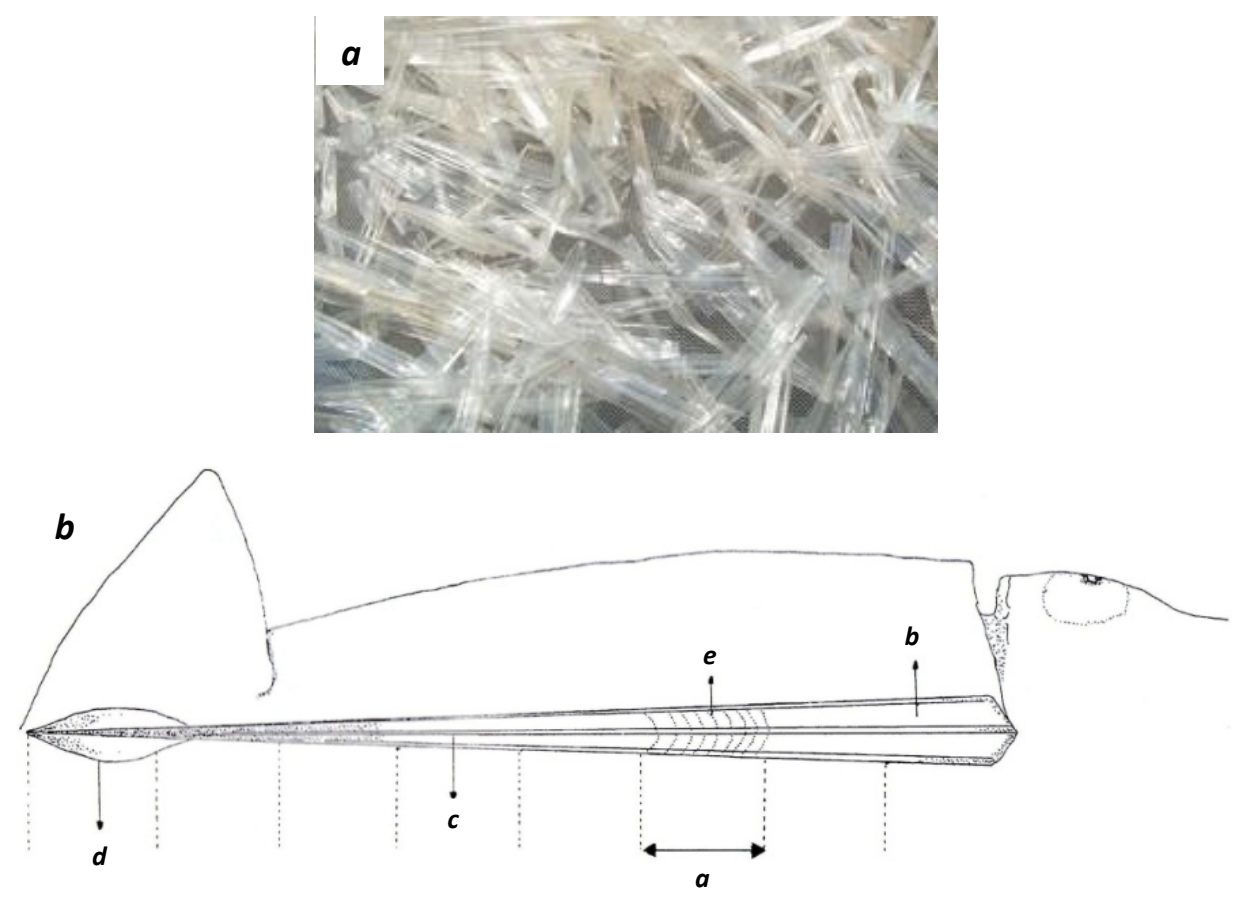

Figura 1.6. Morfología general de la pluma de calamar. a) Vista general de la pluma de Illex argentinus. b) Vista dorsal de la pluma y posición en relación al manto del omastréfido lllex Illecebrosus (especie emparentada a Illex argentinus) a-intervalo de un $\mathrm{cm}$. de longitud, $b$ expansiones o costillas laterales, c-raquis, d-cono, e-líneas de crecimiento. Tomado de Perez J. et al., 1996. 
Bizikov (Bizikov V., 1991a) describió la estructura interna de la pluma y demostró que es filogenéticamente homóloga a la conchilla de otros moluscos, y que consiste de tres capas: una capa intermedia (ostraco), una capa interna (hipostraco) y una capa externa (periostraco), con diferentes planos de crecimiento.

En la mayoría de los omastréfidos como Illex argentinus y en los loligínidos, la pluma consiste en un raquis estrecho con 2 costillas laterales y un cono terminal figura 1.6 b). El ostraco está bien desarrollado y es responsable del crecimiento longitudinal de la pluma, desde el extremo posterior hacia el anterior, de manera casi periódica y paralela al crecimiento del manto; el periostraco e hipostraco no están bien desarrollados. El hipostraco crece en la superficie ventral de la región posterior del ostraco y el periostraco se encuentra reducido a un cono o espina al final de la pluma (Perez J. et al., 1996; Bizikov V., 1991b; Arkhipkin A. et al., 1998).

\subsection{Métodos de obtención de quitina.}

Las características de la quitina tales como el grado de polimerización y su grado de acetilación están fuertemente afectadas por los tratamientos empleados en su extracción desde la biomasa (Lavall R. et al., 2007). Las técnicas de extracción de quitina reportadas son muy variadas, pues dependen en gran medida de las características de la fuente y la composición del material de partida, los cuales varían notablemente de una especie a otra. Por lo tanto, es posible obtener polímeros con diferentes propiedades, tanto desde el punto de vista químico como funcional, dependiendo de la fuente de obtención materia prima y de las condiciones de aislamiento.

A su vez, la selección del biodesecho a utilizar como materia prima varía dependiendo las cantidades disponibles, la composición química, las impurezas incluidas, la zona geográfica de captura, la época del año y la aplicación deseada. Estas variables condicionan los protocolos de procesamiento empleados.

En general los procesos de obtención de quitina requieren pasos consecutivos de acondicionamiento de la materia prima, aislamiento y purificación de la quitina (figura 1.7.). El aislamiento y purificación involucra la extracción de proteínas (desproteinización), la eliminación de las impurezas inorgánicas (desmineralización) y la separación de pigmentos (decoloración) de la quitina obtenida. 


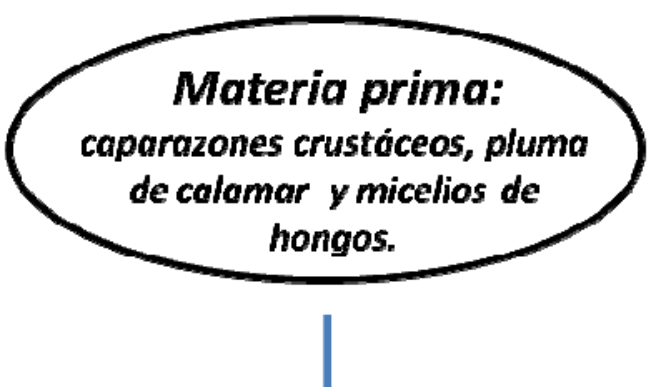

ACONDICIONAMIENTO

Lavado, secado y

reducción de tamaño

( molienda y tamizado)

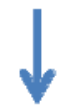

DESPROTEINIZACIÓN

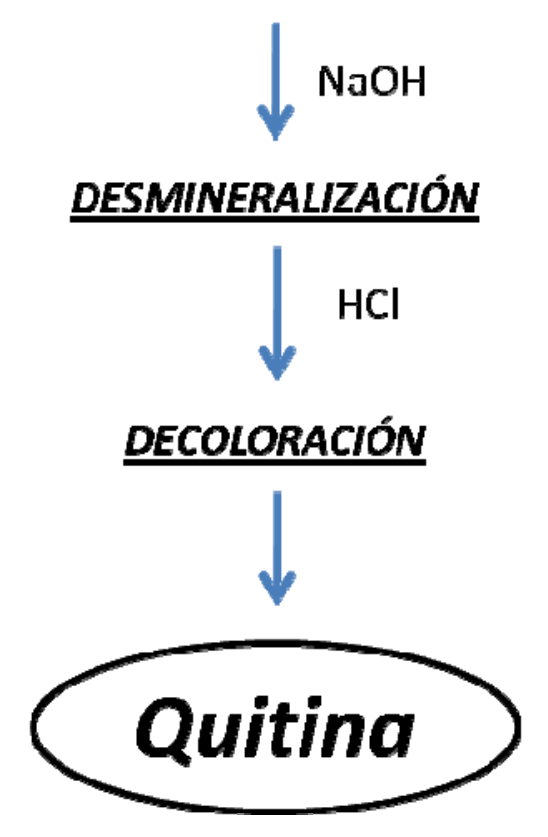

Figura 1.7. Esquema destacando las principales etapas en la obtención de quitina.

\subsubsection{Acondicionamiento de la materia prima.}

Debido a su composición química y su alto contenido en humedad, los desechos o materia prima para producir quitina y quitosano constituyen una biomasa altamente perecedera desde el punto de vista microbiológico. Su manejo previo requiere atención, para reducir el deterioro durante el transporte, almacenamiento y triturado de la 
biomasa antes de ser procesada. Para preservar las características de la materia prima existen distintas alternativas, tales como el enfriamiento (congelación o refrigeramiento) y secado (Goycoolea F. et al., 2004).

El acondicionamiento consiste en el lavado de la muestra a procesar con agua y separación de la materia orgánica u otro material extraño que pueda quedar adherida a los mismos. Posteriormente se procede a su molienda hasta el tamaño de partícula adecuado para la extracción, que generalmente es de varios milímetros.

\subsubsection{Aislamiento y purificación de la quitina.}

Uno de los mayores problemas relacionados a la purificación de la quitina es la de mantener la estructura lo más cercana posible a su forma nativa, minimizando la desacetilación parcial y la degradación de cadena causada por los tratamientos de desmineralización, desproteinización y blanqueado aplicados durante el procesamiento de la materia prima (Roberts G., 1992).

La mayor parte de las técnicas desarrolladas consisten en procesos químicos de hidrólisis de la proteína y la remoción de la materia inorgánica. Dependiendo de la estructura del material a extraer, el proceso inicial es la extracción de proteínas y luego la de minerales, como es el caso de materiales con importante cantidad de proteínas y material soluble, aunque esta secuencia puede invertirse en el caso de materiales con estructura calcárea densa.

A continuación se brinda una reseña breve sobre cada uno de estos procesos.

\subsubsection{Desproteinización.}

La desproteinización puede llevarse a cabo por métodos químicos o enzimáticos. El procedimiento más comúnmente utilizado consiste en tratar químicamente las muestras con una solución acuosa diluida de $\mathrm{NaOH}$ con el fin de disolver la proteína. Los métodos de desproteinización por extractos enzimáticos o enzimas aisladas y fermentaciones microbiológicas constituyen una alternativa y se han probado con relativo éxito, pero tienen la desventaja de emplear largos tiempos y suelen dejar de $1-7 \%$ de 
proteína residual, que resulta difícil de eliminar (Wu S. et al., 2003; Hackman R., 1954; Brine C. et al., 1981).

En la actualidad la mayoría de los tratamientos químicos convencionales emplean $\mathrm{NaOH}$ a temperaturas entre $65^{\circ} \mathrm{C}$ y $100^{\circ} \mathrm{C}$, con una gran variación no sólo en el intervalo de concentraciones $(0,25-2,5 \mathrm{M})$ sino también en tiempos de duración (0,5-72 horas) y número de operaciones (1 a 5 veces).

Percot y colaboradores (Percot A. et al., 2003) realizaron un estudio completo de la cinética de desproteinización en muestras de crustáceos y concluyen que la utilización de $\mathrm{NaOH}$ en una concentración $1 \mathrm{M}$, con una temperatura menor a $70{ }^{\circ} \mathrm{C}$ y tiempo de reacción de 24 horas no produce efectos en el peso molecular ni el grado de acetilación del polímero. Chaussard y colaboradores (Chaussard G. et al., 2004) posteriormente aplican estos estudios al aislamiento del biopolímero desde la pluma de calamar de Loligo sp., llegando a las mismas conclusiones. El tratamiento alcalino prolongado, bajo condiciones severas, causa depolimerización, desacetilación y modificaciones indeseables a las proteínas.

\subsubsection{Desmineralización.}

El contenido mineral de los residuos de origen crustáceo conforma entre el 30 y el $55 \%$ y está constituido principalmente por carbonato de calcio $\left(\mathrm{CaCO}_{3}\right)$ y fosfato de calcio $\left(\mathrm{Ca}_{3}\left(\mathrm{PO}_{4}\right)_{2}\right)$ en menor proporción. La eliminación del componente inorgánico se realiza por tratamiento ácido y se suelen emplear soluciones diluidas de ácido clorhídrico $(\mathrm{HCl})$ de hasta $10 \% \mathrm{v} / \mathrm{v}$ a temperatura ambiente. De todas maneras la concentración de ácido clorhídrico, el volumen utilizado y el tiempo de tratamiento varían de acuerdo con la materia prima, pero deben evitarse los tratamientos a temperaturas más elevadas, que provocan la degradación del polímero (Brzeski M., 1982; Kurita K. et al., 1993).

\subsubsection{Decoloración.}

Los exoesqueletos de crustáceos, muchos de ellos fuertemente coloreados, contienen pigmentos como astacina, astaxantina, cantaxantina, luteína y $\beta$-caroteno. Los 
tratamientos previamente explicados generalmente no son capaces de eliminar estos compuestos. Los pigmentos suelen extraerse a temperatura ambiente con acetona, cloroformo, éter, etanol, acetato de etilo o mezcla de solventes (No H. et al., 1997).

La pluma de calamar, como se comentó previamente, está compuesta principalmente por $\beta$-quitina y proteínas. Además se caracteriza por carecer de pigmentos y por poseer un bajo contenido en minerales, especialmente por la ausencia de carbonato de calcio (presente en abundancia en la principales fuentes de $\alpha$-quitina) (Lavall R. et al., 2007; Chaussard G. et al., 2004; Tolaimate A. et al., 2003). Como consecuencia se puede obviar el blanqueado y la desmineralización, responsables de una disminución en el peso molecular promedio.

Como consecuencia de lo detallado más arriba, se hace notable la importancia de la selección de las condiciones experimentales en el proceso de obtención de quitina, así como la necesidad de su realización o no según el interés que se persiga con el producto a obtener.

\section{QUITOSANO.}

\subsection{Generalidades.}

El quitosano (figura 1.8.) es un polisacárido lineal que se obtiene por desacetilación extensiva de la quitina. Si bien no existe una especificación comúnmente aceptada, se lo describe como un copolímero compuestos por dos tipos de unidades estructurales, la N-acetil-D-glucosamina y la D-glucosamina, unidas entre sí por enlaces glicosídicos del tipo $\beta(1 \rightarrow 4)$, las cuales se distribuyen de manera aleatoria (distribución Bernouliana) y varían en su proporción a lo largo de la cadena.

Lo que usualmente se conoce como quitosano no es una entidad química única y definida sino que es una familia de quitinas que varían entre sí su composición y tamaño molecular y poseen diferente grado de desacetilación.

La capacidad del quitosano de disolverse en soluciones acuosas diluidas de ácidos tales como el ácido acético $\left(\mathrm{CH}_{3} \mathrm{COOH}\right)$ es el criterio comúnmente aceptado para diferenciarlo de la quitina (Peniche Covas C., 2006). De acuerdo a la nomenclatura 
propuesta por la Sociedad Europea de Quitina (European Chitin Society, EUCHIS) quitina y quitosano deben clasificarse en base a su solubilidad en ácido acético 0,1M (Roberts G., 2007). El material soluble es llamado quitosano mientras que la quitina es insoluble.

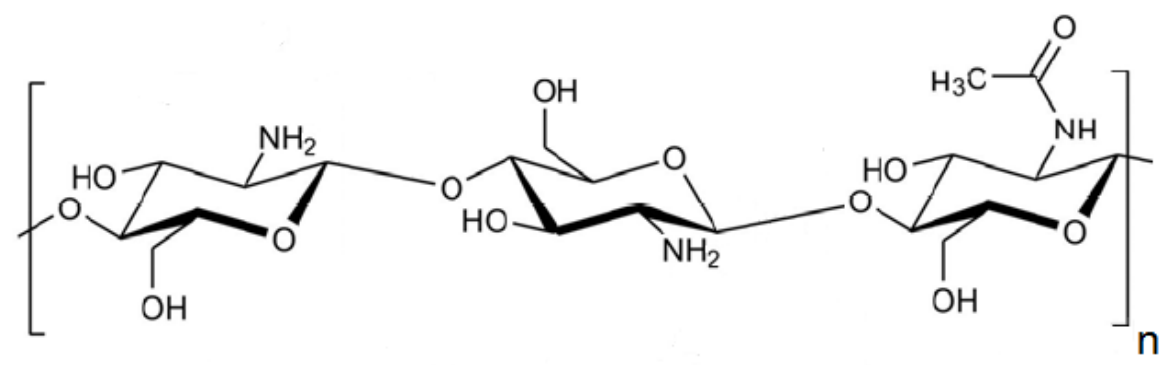

Figura 1.8. Estructura química del quitosano.

El quitosano, en contraste a la quitina, se encuentra muy raramente presente en la naturaleza. Se puede hallar de forma natural en las paredes de algunas plantas y hongos (por ejemplo en Mucor rouxii y Choanephora cucurbitarum, donde llega a representar hasta un tercio de su peso). Sin embargo, la fuente más importante de quitosano, a nivel industrial, lo constituye la quitina, la cual, mediante un proceso de desacetilación química o enzimática, ha permitido producirlo a gran escala (Lárez Velásquez C., 2006).

El quitosano es el único polisacárido catiónico pseudonatural; al poseer en su estructura una amina alifática primaria es básico, forma sales con ácidos y origina polielectrolitos a pH menores que 6,5. Ello le confiere características especiales que lo hacen útil en una amplia gama aplicaciones. Ha sido descrito como el biomaterial más versátil de la naturaleza (Sandford P., 1989), debido a que posee propiedades únicas como lo son su biocompatibilidad, biodegradabilidad, baja toxicidad y bajo costo (Shahidi F. et al., 2005), lo que se traduce en casi 200 aplicaciones en ramas como biomedicina, biotecnología e industria alimenticia.

Quitina y quitosano tienen masas molares de hasta varios millones $\mathrm{g} / \mathrm{mol}$. El quitosano comercialmente disponible posee un peso molecular promedio de entre $3800 \mathrm{y}$ $500.000 \mathrm{~g} / \mathrm{mol}$ y un grado de acetilación (DA) entre 2-40\% (Ravi Kumar M., 2000).

En el caso del quitosano para identificar el porcentaje relativo de grupos amino en el polímero se puede utilizar tanto el grado de acetilación (DA) como el grado de desacetilación (DD). 


\subsection{Obtención de quitosano por desacetilación.}

La principal reacción de derivatización de la quitina es la hidrólisis de las funciones químicas acetamida para generar el polímero desacetilado quitosano (figura 1.9.a). Aunque las amidas, en principio pueden hidrolizarse en condiciones ácidas o alcalinas, se excluye el uso de la hidrólisis ácida debido a la susceptibilidad de los enlaces glicosídicos de la quitina a dicho tratamiento.

La reacción de $\mathrm{N}$-desacetilación se corresponde con una hidrólisis en la que el ión hidróxido, fuertemente nucleofílico, ataca inicialmente al átomo de C carbonílico de la función química amida mediante un mecanismo de adición nucleofílica-eliminación (Streitwieser A. et al., 1989) (figura 1.9.b).
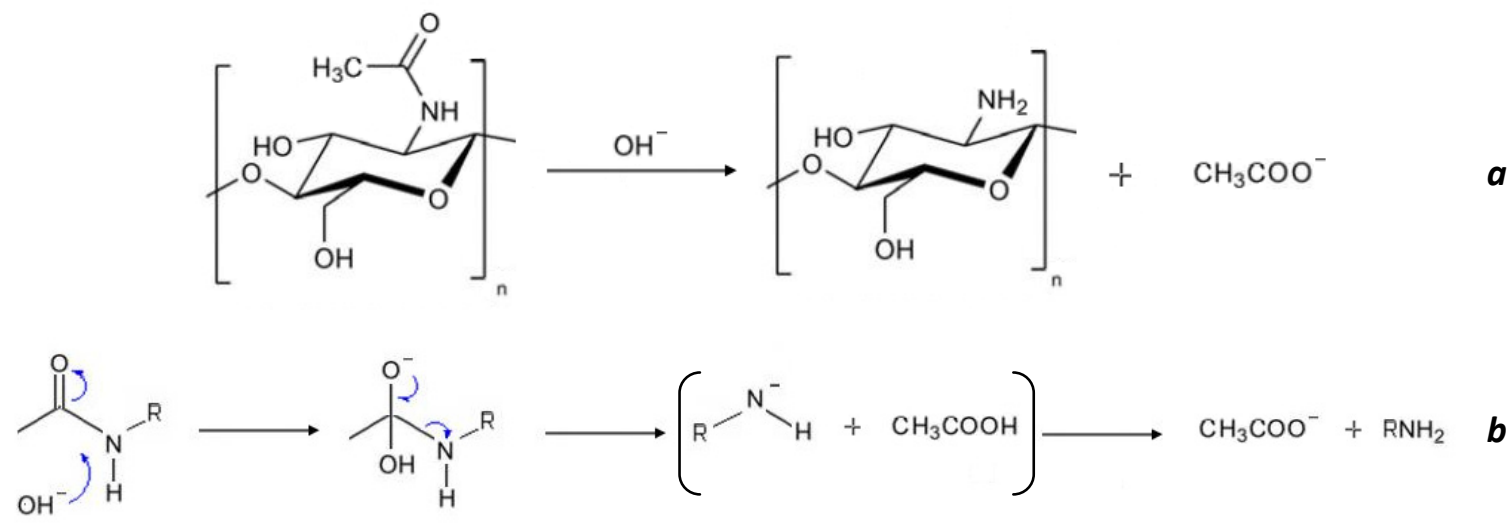

Figura 1.9. Mecanismo de reacción que interpreta a la reacción de desacetilación de la quitina para obtener quitosano. a) Reacción generalizada. b) Detalle del mecanismo de reacción.

La desacetilación se conduce bajo condiciones alcalinas severas, debido a la combinación de tres factores: 1) la baja reactividad debida a la configuración trans de los sustituyentes acetamida con respecto al grupo $\mathrm{OH}$ unido al átomo de $\mathrm{C} 3$ del anillo piranósico de la unidad monomérica (Horton D. et al., 1965); 2) la presencia de puentes de hidrógeno entre los grupos hidroxilo y carbonilo y amida de cadenas adyacentes; y 3 ) el denso empaquetamiento de las cadenas en el enrejado cristalino de la quitina, que previene el acceso del álcali a los sitios reactivos.

Normalmente son necesarios tratamientos térmicos de la quitina en soluciones acuosas muy concentradas con el objetivo de desacetilar parcialmente el polímero y 
obtener quitosano (Goycoolea F. et al., 2004). La desacetilación puede ser parcial o casi total.

Actualmente, el quitosano es producido por la desacetilación termoalcalina de la quitina. Las condiciones específicas de la reacción dependerán de diversos factores, tales como el material de partida, el tratamiento previo, y el grado de desacetilación deseado. La concentración de álcali, la temperatura y tiempo de reacción afectan la distribución de los grupos acetilos remanentes (Peniche C. et al., 1984). Otros factores que afectan el grado de desacetilación son los tratamientos previos, el tamaño de partícula y la densidad de la quitina. Estos dos últimos afectan la velocidad de penetración del álcali en las regiones amorfas del polímero y, en cierta medida, también en las regiones cristalinas, lo que es necesario para que tenga lugar la hidrólisis (Aranaz I., 2009).

La desacetilación de quitina a quitosano se puede llevar a cabo por dos metodologías diferentes: desacetilación en fase heterogénea o en fase homogénea. Independientemente de la metodología, la reacción de desacetilación se lleva a cabo en soluciones concentradas de álcali $(40-50 \% \mathrm{p} / \mathrm{v} \mathrm{NaOH})$ y tiempos relativamente largos.

El tratamiento más comúnmente utilizado consiste en la desacetilación heterogénea de la quitina sólida empleando soluciones concentradas de hidróxido de sodio $(\mathrm{NaOH})$ o hidróxido de potasio $(\mathrm{KOH}) 40-50 \% \mathrm{p} / \mathrm{v}$ a temperaturas superiores a 100 ㄷ y tiempos de reacción cortos, preferiblemente en atmósfera inerte o en presencia de sustancias reductoras como el borohidruro de sodio $\left(\mathrm{NaBH}_{4}\right)$ o el tiofenol $(\mathrm{PhSH})$ para evitar la depolimerización de la macromolécula. Sannan y colaboradores (Sannan T. et al., 1976) sugieren que la desacetilación en fase heterogénea de la quitina, por ser un polímero semicristalino, tiene lugar preferentemente en las regiones amorfas, dejando casi intactas las regiones cristalinas de la quitina nativa y luego ocurre desde el exterior hacia el interior de la región cristalina y que, como resultado se obtienen copolímeros en bloque.

La reacción en condiciones homogéneas permite una modificación más uniforme del polímero, y se realiza sobre la quitina previamente solubilizada bajo presión reducida. La misma se obtiene sometiendo una suspensión alcalina de quitina a tratamientos de congelación-descongelación hasta producir una solución acuosa de quitina en hidróxido de sodio. La desacetilación homogénea se lleva a cabo con concentraciones de álcali más moderadas (alrededor del $30 \% \mathrm{p} / \mathrm{v}$ ), a $25-40$ ㅇ C por tiempos de 12 a 24 horas. Estas 
condiciones permiten que la reacción no se localice en determinados lugares de la cadena y que el ataque a los grupos amino sea más uniforme, resultando en residuos acetilados aleatoriamente distribuidos (Aiba S., 1991). Así es que los productos obtenidos por los procesos homogéneo y heterogéneo, aún con el mismo grado de acetilación, por lo general muestran comportamientos diferentes que se deben a la variación en la distribución de las diferentes unidades repetitivas. Se ha demostrado que mientras que los quitosanos obtenidos en el proceso heterogéneo presentan polidispersión en cuanto al grado de acetilación de sus cadenas, los obtenidos por vía homogénea tienen la misma composición (Roberts G., 1998). Recientemente Lamarque y colaboradores (Lamarque G. et al., 2004) estudiaron el mecanismo de desacetilación en profundidad y proponen que no debe utilizarse la terminología homogénea o heterogénea sino localmente homogénea o heterogénea.

Kurita y colaboradores (Kurita K. et al., 1993) determinaron las condiciones experimentales óptimas para la desacetilación heterogénea de $\beta$-quitina de pluma de calamar utilizando $\mathrm{NaOH} 40 \% \mathrm{p} / \mathrm{v}, 80^{\circ} \mathrm{C}$ y una duración del tratamiento de 3 horas. Inclusive demostraron que la desacetilación de la $\beta$-quitina en estas condiciones ocurre más rápidamente que para la $\alpha$-quitina. Debido a las diferencias estructurales existentes entre ambos polimorfos, la forma $\beta$ - es más reactiva por su menor cristalinidad (dada por la debilidad de sus fuerzas intermoleculares) y por lo tanto se requieren condiciones menos severas. Numerosos investigadores (Tolaimate A. et al., 2003; Lamarque G. et al., 2004; Tolaimate A. et al., 2000; Rhazi M. et al., 2000; Methacanon P. et al., 2003; Chandumpai A. et al., 2004; Lamarque G. et al.,2007; Chen C. et al., 2004; Jiang C. et al., 2006) se basaron en este trabajo y estudiaron el rol de la fuente de quitina, del grado de acetilación y de los distintos parámetros de reacción que conllevan a la obtención de un quitosano derivado de $\beta$-quitina con elevado peso molecular y elevado grado de deacetilación. Tolaimate, Rhazi y colaboradores (Tolaimate A. et al., 2003; Tolaimate A. et al., 2000; Rhazi M. et al., 2000) bajo condiciones de desacetilación suaves obtuvieron valores de peso molecular promedio de $500.000 \mathrm{~g} / \mathrm{mol}$ para una muestra de $\beta$-quitina completamente desacetilada en atmósfera inerte de $\mathrm{N}_{2}$.

En la actualidad se exploran métodos alternativos para reducir los tiempos de desacetilación de la quitina y la cantidad de álcali utilizado; éstos hacen uso de la 
radiación con microondas (Goycoolea F. et al., 1998) o de tratamientos termo-mecánicos (Pelletier A. et al., 1990), entre otros.

\section{PROPIEDADES Y APLICACIONES DE QUITINA Y QUITOSANO.}

Existen numerosísimos artículos respecto a las propiedades y aplicaciones de quitina y quitosano, por lo que en esta sección se nombrarán brevemente las propiedades y aplicaciones más relevantes.

\subsection{Propiedades fisicoquímicas y biológicas de quitina y quitosano.}

Quitina y quitosano son un recurso natural de elevado peso molecular con propiedades polielectrolíticas y que presentan grupos funcionales reactivos (amida, amino e hidroxilos) química o enzimáticamente modificables (Tharanathan $R$. et al., 2003).

Entre las propiedades fisicoquímicas más destacables se hallan la capacidad de formación de películas, geles (Kurita K., 2006; Rinaudo M., 2006) y fibras, la capacidad de adsorción de iones metálicos, hidrocarburos aromáticos y proteínas (Kurita K., 2006), la coagulación de suspensiones o solutos (Kurita K., 2006) y su comportamiento como agentes quelantes (Dutta P. et al., 2004; Kurita K., 2006).

Además poseen interesantes propiedades biológicas, fisiológicas y farmacológicas, en su mayor parte relacionadas con el comportamiento catiónico del quitosano (Aranaz l. et al., 2009) como ser no tóxicos, biodegradables, biocompatibles en plantas y animales, presentando una importante actividad biológica en relación a sus efectos analgésicos, antimicrobianos (Aranaz I. et al., 2009; Kurita K., 2006), hemostáticos (Dutta P. et al., 2004; Aranaz I. et al., 2009), antioxidantes, mucoadhesivos, hemostáticos, fungistáticos, antitumorales (Dutta P. et al., 2004), hipocolesterolémico (Kurita K., 2006), por presentar actividad inmunológica (Kurita K., 2006) y por poseer propiedades regenerativas (Dutta P. et al., 2004).

Todas estas propiedades son ciertamente ventajosas para aplicaciones biotecnológicas e industriales. Es por ello que los productos de quitina, en particular 
quitosano y sus derivados, están comenzando a encontrar un amplio rango de aplicaciones en varios campos.

\subsection{Derivatización de quitina y quitosano.}

Químicamente quitina y quitosano son bases débiles que grupos funcionales reactivos, sin embargo debido a la naturaleza cristalina, la limitada solubilidad y pobre reactividad de la quitina, es necesario preparar derivados mediante modificaciones químicas de modo de utilizar dicho polímero (Kurita K., 2001; Kurita K., 2006). Por otro lado el quitosano es más accesible a reactivos presumiblemente por que es menos cristalino y se disuelve en ácidos (Tharanathan $R$. et al., 2003). Es por ello que, si bien estas reacciones son llevadas a cabo tanto sobre quitina como sobre quitosano, la mayoría de las derivatizaciones por modificación química se dan sobre el quitosano.

La cationicidad neta del quitosano así como la presencia de grupos reactivos funcionales, un grupo amino y dos grupos hidroxilo por residuo monomérico, hacen que sea una molécula muy interesante a la hora de su derivatización (Dutta P. et al., 2004; Prashanth H. et al., 2007).

La mayoría de las reacciones de derivatización del quitosano involucran reacciones específicas del grupo amino primario, un nucleófilo potente que puede experimentar $\mathrm{N}$ acilación, cuaternización, aminación reductiva y reacciones Schiff entre otras, lo que permite incluir grupos funcionales diferentes (Tharanathan R. et al., 2003; Dutta P. et al., 2004; Rinaudo M., 2006). También pueden darse modificaciones por reacciones inespecíficas en los hidroxilos particularmente aquel en C-6 y C-3, siendo éstas generalmente esterificaciones y eterificaciones (Tharanathan R. et al., 2003; Rinaudo M., 2006).

Las modificaciones de quitina y quitosano en materiales con funciones específicas eficientes permite la manipulación y la preparación de un amplio espectro de derivados para usos en aplicaciones de una gran diversidad de áreas (Kurita K., 2006; Prashanth H. et al., 2007). 


\subsection{Aplicaciones de quitina y quitosano.}

Tal como se comentó previamente, la pobre solubilidad de la quitina es el principal limitante para su utilización. Sin embargo se utiliza como derivatizado en columnas cromatográficas de afinidad; para inmovilizar enzimas y células y como fibras de sutura absorbibles, como cicatrizante de heridas; como biosensores; como polutantes industriales; como fibras en papel y aplicaciones biomédicas; como excipiente y carrier de drogas en film, gel o en polvo y en aplicaciones para el tratamiento de aguas (Ravi Kumar M., 2000; Rinaudo M., 2006).

Es importante resaltar que dependiendo de las aplicaciones son requeridas una o más de las diferentes propiedades de quitina y quitosano y que además dichas propiedades varían con el grado de acetilación y el peso molecular (Dutta P. et al., 2004; Kurita K., 2006). Por ejemplo, el carácter catiónico del quitosano, sus propiedades filmogénicas y su bioactividad son importantes en aplicaciones biomédicas, cosméticas y farmacéuticas (Rinaudo M., 2006).

Las aplicaciones industriales del quitosano incluyen desde su uso como ingredientes de productos cosméticos relacionados con el cuidado de cabello y piel, pastas de dientes y enjuagues bucales, debido a sus propiedades fungicidas y fungistáticas (Dutta P. et al., 2004; Kurita K., 2006; Tharanathan R. et al., 2003); aplicaciones en el tratamiento de aguas se deben a la naturaleza catiónica del quitosano, siendo utilizado como agente floculante y quelante y adsorbiendo proteínas, compuestos orgánicos y metales pesados (Dutta P. et al., 2004; Kurita K., 2006; Ravi Kumar M., 2000; Aranaz I. et al., 2009; Tharanathan R. et al., 2003); aplicaciones en relación con la industria textil y papelera, donde se utiliza como pulpa de papel así como para el acabado del papel y papel reciclado, textiles higiénicos, para impartir estaticidad y como repelente de suciedad, para decoloración de efluentes textiles, hilados y fibras(Dutta P. et al., 2004; Kurita K., 2006; Ravi Kumar M., 2000; Tharanathan R. et al., 2003; Rinaudo M., 2006).

Además presenta interesantes en agricultura como agente antifúngico acelerante del crecimiento de semillas y aplicaciones en alimentos $e$ industria alimenticia ya sea como oligosacáridos, ingredientes de alimentos, suplementos dietarios como también como agente emulsificante y antioxidante y para preservamiento de productos 
alimenticios del deterioro microbiano (Dutta P. et al., 2004; Kurita K., 2006; Ravi Kumar M., 2000; Aranaz I. et al., 2009; Tharanathan R. et al., 2003; Rinaudo M., 2006).

Otras aplicaciones incluyen su utilización en biocatálisis para inmovilización y atrapamiento de enzimas y células, su uso en fotografía (por su habilidad para formar films) y como baterías en estado sólido (Dutta P. et al., 2004; Kurita K., 2006; Ravi Kumar M., 2000; Tharanathan R. et al., 2003; Rinaudo M., 2006).

En relación a sus aplicaciones biomédicas, farmacéuticas y en biotecnología se destacan sus aplicaciones en el tratamiento y cicatrización de heridas (Dutta P. et al., 2004; Ravi Kumar M., 2000; Aranaz I. et al., 2009; Tharanathan R. et al., 2003) (ya que el quitosano activa inmunocitos y células inflamatorias además de servir como agente anticoagulantes, antitrombogénicos y hemostáticos), como dispositivos médicos tanto en implantes, suturas, oftalmología, y bajo la forma de hidrogeles, films, tabletas, microcápsulas, microesferas y nanopartículas en ingeniería de tejidos y sistemas de liberación controlada de drogas (Dutta P. et al., 2004; Kurita K., 2006; Ravi Kumar M., 2000; Aranaz I. et al., 2009; Tharanathan R. et al., 2003; Rinaudo M., 2006). Estas dos últimas aplicaciones serán desarrolladas más adelante en la sección B de este trabajo de tesis.

Por último y tal como lo indica Hirano (Hirano S., 1999) "Quitina y quitosano se encuentran circulando en la atmósfera, biósfera, hidrósfera y litósfera, y la función de autodefensa del cuerpo para seres humanos animales y plantas está potenciada por contacto celular con estos biopolímeros. Quitina y quitosano son biológicamente renovables, biodegradables, biocompatibles, no-antigénicos, casi no tóxicos y biofuncionales. Sin embargo, es importante el uso de estos biopolímeros en beneficio de toda la vida sobre la tierra, como materiales biotecnológicos ecológica y ambientalmente amigables, sin perturbar su circulación natural". 
II.

Métodos de Caracterización

Fisicoquímica de Quitina y Quitosano. 

1

\section{MÉTODOS DE CARACTERIZACIÓN FISICOQUÍMICA DE QUITINA Y QUITOSANO}

Tanto la composición de las cadenas de quitina y quitosano como sus dimensiones varían en dependencia con el material de partida y la rigurosidad del método de obtención. La determinación del grado de acetilación y su masa molecular son parámetros de obligatorio conocimiento para caracterizar una muestra de dichos polisacáridos, ya que ambos tienen una gran incidencia en sus propiedades. Otras características, tales como la polidispersidad de su masa molecular, cristalinidad, propiedades en solución, el contenido de humedad, proteínas y cenizas son también de obligado conocimiento.

Existen numerosas técnicas para caracterizar ambos polímeros, tal como se observa en la tabla 2.1., las cuales se encuentran bien descritas en las referencias señaladas, además de estar revisadas en diversos libros. A continuación se reseñan y se discuten los métodos empleados en esta tesis para caracterizar estos biopolímeros.

\begin{tabular}{|c|c|}
\hline $\begin{array}{l}\text { Características } \\
\text { Fisicoquímicas }\end{array}$ & Métodos de determinación \\
\hline Grado de acetilación & $\begin{array}{l}\text { Espectroscopía IR (Sannan T. et al., 1978; Baxter A. et al., 1992; } \\
\text { Brugnerotto J. et al., 2001a), Espectroscopía UV (Muzzarelli R. et al., } \\
\text { 1985; Wu T. et al., 2008), Espectroscopía RMN }\left({ }^{1} \mathrm{H} \mathrm{y}{ }^{13} \mathrm{C}\right) \text { (Duarte M. } \\
\text { et al., 2001; Van de Velde K. et al., 2004; Vårum K. et al., 1991), } \\
\text { Conductimetría (Raymond L. et al., 1993), Potenciometría (Jiang X. } \\
\text { et al., 2003), DSC (Guinesi L. et al., 2006; García l. et al., 1983), } \\
\text { Análisis elemental (Roberts G., 1992), Cromatografía GPC (Aiba S., } \\
\text { 1986), Dicroísmo circular (Domard A., 1987). }\end{array}$ \\
\hline $\begin{array}{l}\text { Peso molecular promedio } \\
\text { y/o distribución de peso } \\
\text { molecular }\end{array}$ & $\begin{array}{l}\text { Viscosimetría (Rinaudo M. et al., 1993), Cromatografía GPC } \\
\text { (Brugnerotto J. et al., 2001b), Dispersión de Luz (Terbojevich M. et } \\
\text { al., 1997). }\end{array}$ \\
\hline Cristalinidad & $\begin{array}{l}\text { Difracción por rayos X (Jang M. et al., 2004; Kurita K. et al., 1993; } \\
\text { Yui T. et al., } 1994 \text { Okuyama K. et al., 1997). }\end{array}$ \\
\hline Contenido en humedad & $\begin{array}{l}\text { Gravimetría (Tolaimate A. et al., 2000; Kim S. et al., 1996; ASTM. } \\
\text { F2103-01, 2001). }\end{array}$ \\
\hline Contenido en cenizas & $\begin{array}{l}\text { Gravimetría (Lavall R. et al., 2007; Chandumpai A. et al., 2004; } \\
\text { ASTM. F2103-01, 2001). }\end{array}$ \\
\hline Contenido en proteínas & Bradford (Bradford M., 1976; Chaussard G. et al., 2004). \\
\hline
\end{tabular}

Tabla 2.1. Características fisicoquímicas de quitina y quitosano y métodos de determinación. 


\section{CARACTERIZACIÓN ESTRUCTURAL DE QUITINA Y QUITOSANO}

\subsection{Difracción por Rayos $X$.}

La cristalinidad de la quitina ha sido investigada por largo tiempo. Los estudios por difracción de rayos $X$ demostraron que la quitina, al igual que la celulosa, se encuentra en la naturaleza formando una matriz sólida hidratada compuesta por regiones amorfas en las que coexisten porciones cristalinas y altamente ordenadas. El patrón típico de la quitina muestra fuertes reflexiones cercanas a $2 \theta=9-10^{\circ}$ y $2 \theta=20-21^{\circ}$ junto con reflexiones menores a valores de $2 \theta=26,4^{\circ}$ o superiores (Abdou E. et al., 2008).

Tal como se comentó anteriormente, dependiendo de su fuente de origen, la estructura cristalina de la quitina se halla presente en tres polimorfos diferentes denominados $\alpha-, \beta-$, y $\gamma$ - quitina (figura 1.2.). Estas formas difieren entre sí en la disposición de las cadenas dentro de las regiones cristalinas y por lo tanto pueden ser diferenciadas mediante el análisis de sus difractogramas de rayos $X$ (Jang M. et al., 2004). Kurita y colaboradores (Kurita K. et al., 1993) estudiaron los cambios en los difractogramas de quitinas y quitosanos de diferentes fuentes y observaron que los picos de la $\beta$-quitina a $2 \theta=19^{\circ}$ y $8^{\circ}$ son más anchos que los correspondientes a la $\alpha$-quitina, comportamiento que indica una menor cristalinidad (figura 2.1.).

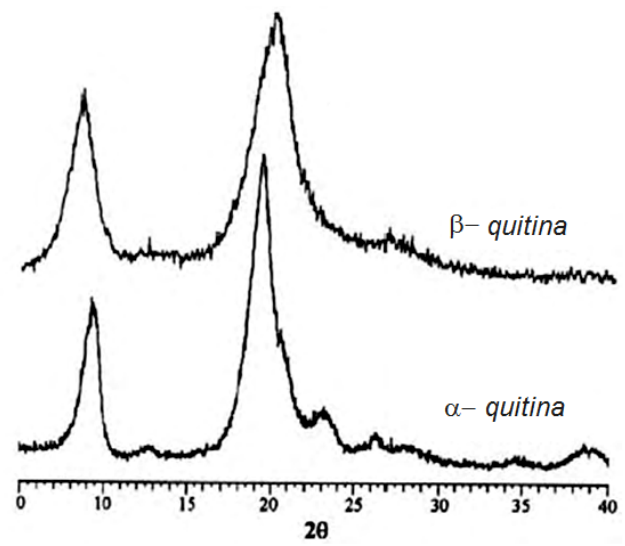

Figura 2.1. Patrones de difracción de rayos $X$ de $\alpha$ y $\beta$-quitina de camarón (Penaus sp.) y pluma de calamar (Dosidicus gigas) respectivamente. Tomado de Goycoolea F. et al., 2000. (Una comparación detallada de los patrones de difracciones por rayos $X$ de $\alpha$-, $\beta$ - y $\gamma$-quitina se puede hallar en Jang M. et al., 2004). 
Como en el caso de la quitina, el quitosano también es cristalino y muestra polimorfismo, tal como se evidencia por sus patrones de difracción de rayos X. Su estructura es diferente de los alomorfos de la quitina y han sido refinadas las estructuras cristalinas de varias formas incluyendo formas anhidras e hidratadas, así como de varios tipos de sales (Yui T. et al., 1994; Okuyama K. et al., 1997). Se ha observado que la estructura cristalina depende en alguna extensión del método utilizado en la preparación de la muestra, ya que presentan estructuras de diferente estabilidad y nivel de hidratación.

\subsection{Determinación del grado de acetilación.}

La determinación del valor del grado de acetilación, definido anteriormente como la fracción molar de unidades glicosídicas $\mathrm{N}$-acetiladas, se refleja en la solubilidad y propiedades en solución de la quitina y sus derivados.

Para la determinación del grado de acetilación se han reportado distintas técnicas, tales como la espectroscopia de infrarrojo (Sannan T. et al., 1978; Domszy J. et al., 1985; Baxter A. et al., 1992; Brugnerotto J. et al., 2001), la espectroscopia de resonancia magnética nuclear ( ${ }^{1} \mathrm{H}-\mathrm{y}{ }^{13} \mathrm{C}-\mathrm{RMN}$ ) (Duarte M. et al., 2001; Van de Velde K. et al., 2004; Vårum K. et al., 1991; Raymond L. et al., 1993), la espectroscopia UV primera derivada (Muzzarelli R. et al., 1985; Wu T. et al., 2008), la potenciometría (Jiang X. et al., 2003) y la conductimetría (Raymond L. et al., 1993). Otras técnicas alternativas incluyen el análisis elemental (Roberts G., 1992), el análisis térmico (Guinesi L. et al., 2006; García l. et al., 1983), la cromatografía de permeación de gel (Aiba S., 1986) y el dicroísmo circular (Domard A., 1987).

\subsubsection{Espectroscopia Infrarroja.}

La espectroscopia infrarroja puede ser utilizada tanto para identificar estructuralmente quitina y quitosano como para evaluar su grado de acetilación (DA). Por su simplicidad es el método más empleado en la determinación del grado de acetilación.

El método consiste en correlacionar las intensidades de absorbancia de dos bandas determinadas, una tomada como testigo o referencia y otra la de prueba, con el porcentaje de acetilación (2.1): 
donde: $A_{M}$ es la intensidad de la banda característica o de prueba y $A_{R}$ es la intensidad de la banda de referencia.

$A_{M}$ es una medida del contenido de grupos $\mathrm{N}$-acetilo o aminos, y por lo tanto proporcional al DA y $A_{R}$ es la intensidad de la banda de referencia, que es independiente del DA, y sirve a modo de referencia interna para corregir las diferencias en espesor de las películas o de concentración en las pastillas de $\mathrm{KBr}$. Así, el grado de acetilación de una muestra problema se estima comparando el valor de la relación $A_{M} / A_{R}$ correspondiente a dicha muestra con el muestras de referencia con un valor conocido de DA (Kasaai M., 2008). Los valores DA para ambas muestras deben ser similares para obtener un mejor resultado.

Van de Velde y Kiekens (Van de Velde K. et al., 2004) comentan que la determinación de valores precisos absolutos del DA empleando espectroscopia IR dependen marcadamente de la forma y preparación de la muestra, de la elección de las líneas de base, de referencia y de las señales cuyas intensidades se miden así como de la calibración por el uso de técnicas directas como la espectroscopia ${ }^{13} \mathrm{C}$ RMN.

Brugnerotto y colaboradores (Brugnerotto J. et al., 2001a) realizaron una extensa investigación en la que analizaron veinticinco muestras de quitina y quitosano provenientes de diferentes fuentes y con grados de acetilación desde 0,5\% hasta 97,9\%, determinados por espectroscopia ${ }^{1} \mathrm{H}$ RMN y ${ }^{13} \mathrm{C}$ RMN. Tomaron como banda característica $\left(A_{M}\right)$ a aquella localizada a $1320 \mathrm{~cm}^{-1}$, correspondiente al estiramiento $\mathrm{C}-\mathrm{N}$ del grupo amida (amida III) con línea de base $=1402-1478 \mathrm{~cm}^{-1}$ y como referencia $\left(A_{R}\right)$ a la banda a $1420 \mathrm{~cm}^{-1}$ asignada a la deformación $\mathrm{C}-\mathrm{H}$ y con línea de base $=1276-1348 \mathrm{~cm}^{-1}$ (figura 2.2.). Con la información obtenida propusieron la correlación lineal que viene expresada por la relación (2.2):

$$
A_{1320} / A_{1420}=0,3822+0,03133 \cdot D A(\%) \quad R^{2}=0.990
$$

Así el grado de acetilación se obtiene de la siguiente ecuación (2.3):

$$
\operatorname{DA}(\%)=31,92\left(\mathrm{~A}_{1320} / \mathrm{A}_{1420}\right)-12,20
$$


Dichos autores proponen que esta calibración es válida para el rango entero de DA y para todo tipo de muestras, independientemente de la composición química, técnica, estado o estructura ya que sus valores están de acuerdo a los DA determinados por espectroscopia ${ }^{1} \mathrm{H}$ RMN y ${ }^{13} \mathrm{C}$ RMN. Además plantean que las intensidades y las posiciones de las bandas elegidas no cambian ni con la humedad de la muestras ni con el tipo de puentes de hidrógeno existentes (Brugnerotto J. et al., 2001b).

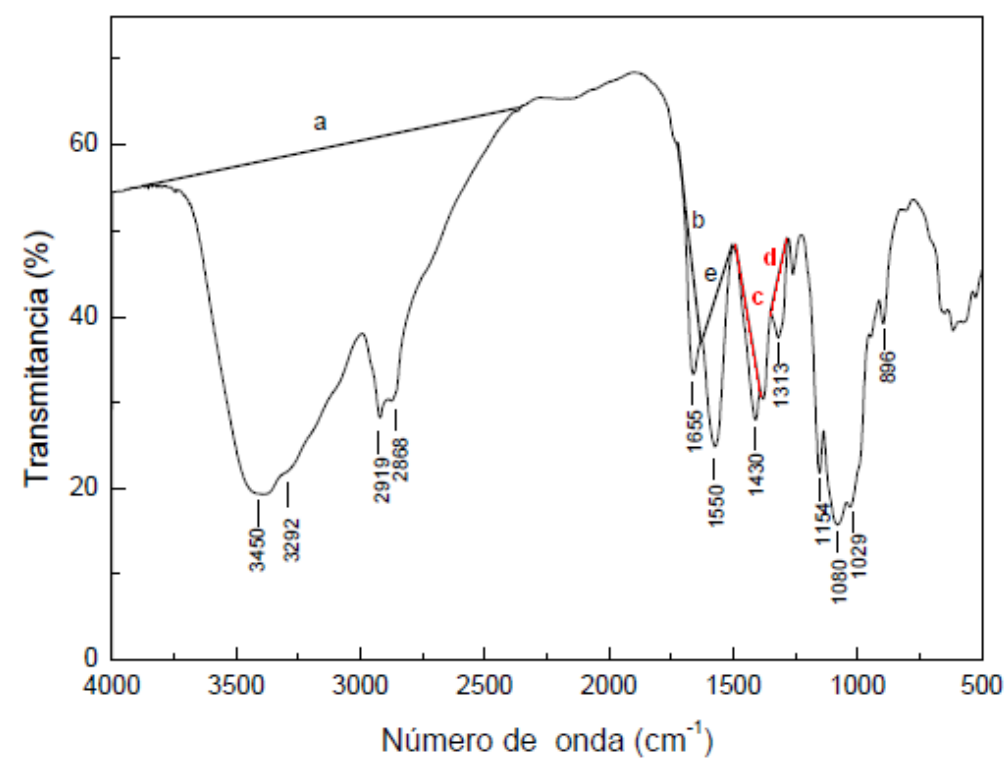

Figura 2.2. Espectro FTIR de una muestra de quitosano. Las líneas de base c y d (resaltadas en rojo) son las utilizadas por Brugnerotto. Tomado de Brugnerotto J. et al., 2001a.

\subsubsection{Espectroscopia ${ }^{13} \mathrm{C}$ RMN CP-MAS en estado sólido.}

La espectroscopia de resonancia magnética nuclear (RMN) de alta resolución es un método muy útil, simple, rápido y no invasivo para el estudio de las estructuras químicas y estéricas de los polisacáridos. La espectroscopia ${ }^{13} \mathrm{C}-\mathrm{RMN}$ CP-MAS de estado sólido es muy sensible a los cambios en el orden estructural ya que combina aditamentos especiales que mejoran la resolución y sensibilidad tales como un desacoplador de protón de alto poder para la polarización cruzada (CP) que mejora la señal, un desacoplador protón-dipolar (DD) que elimina las interacciones de los protones y un accesorio de rotación de muestra de alta velocidad de ángulo mágico (MAS) para alta resolución de los desplazamientos químicos. 
Heux y colaboradores (Heux L. et al., 2000) plantean que la determinación del DA por espectroscopia ${ }^{13} \mathrm{C}$ RMN puede ser evaluado a partir de las integrales relativas de los grupos metilo o carbonilo en comparación con las integrales de los carbonos del anillo del polisacárido. Además aclaran que si se considera el pico del carbonilo se puede tener un error de por lo menos el $4 \%$, por ello es que es más preciso considerar únicamente la integración de las señales del grupo metilo.

\section{CARACTERIZACIÓN DE LA MACROMOLÉCULA EN SOLUCIÓN}

Las propiedades físicas de los polímeros en solución son dependientes de la concentración. Los polisacáridos en solución presentan una dinámica sensible a los tamaños de cadena, su forma y número de cargas, las cuales dependen de la concentración del polímero. La hidrodinámica se refiere a las propiedades de soluciones diluidas mientras que la reología por lo general se encuentra asociada con soluciones concentradas (Harding S., 1995).

En el régimen diluido las cadenas macromoleculares de las soluciones poliméricas se encuentran aisladas estadísticamente unas de otras en el solvente, y los parámetros más importantes que determinan las propiedades físicas son el volumen hidrodinámico y la conformación de las moléculas. En el régimen concentrado, las macromoléculas se encuentran entrelazadas y las dimensiones de la cadena son independientes de la concentración del polímero (Dobrynin, A. et al., 1995; Cölfen H. et al., 2001).

Los regímenes diluido y concentrado se definen por parámetros de concentración denominados concentración de solapamiento $\left(\mathrm{C}^{*}\right)$ y concentración de enmarañamiento $o$ "entanglement" (Ce).

La transición entre un régimen diluido y uno semidiluido se define por $\mathrm{C}^{*}$, que es la concentración a la cual hay contacto físico del polímero ya que los dominios moleculares de las cadenas poliméricas comienzan a solaparse. $C^{*}$ es una medida del tamaño molecular y de la conformación del polímero: a mayor peso molecular y conformación más rígida más pequeño es el valor de C*(Hwang J. et al., 2000). En régimen diluido la concentración del polímero (C) es menor que $C^{*}$ (Cho J. et al., 2006).

En la transición del régimen semidiluido a un régimen concentrado se halla $\mathrm{Ce}$, que representa la concentración por encima de la cual predominan los "entanglements" 
en las cadenas del polímero y las dimensiones de las cadenas son independientes de la concentración del polímero. La concentración Ce corresponde al régimen semidiluido. En régimen concentrado C es mayor que Ce (Cho J. et al., 2006; Desbrières J., 2002).

Para caracterizar el comportamiento de una macromolécula en solución y especialmente su reología, uno de los parámetros fundamentales a determinar es su peso molecular promedio o masa molecular relativa, por ser de importancia en el entendimiento de sus aplicaciones biotecnológicas. Las propiedades en solución de quitina y quitosano no solo dependen del peso molecular y DA sino también de la distribución de los grupos acetilos.

Los métodos más comúnmente utilizados para determinar el peso molecular de la quitina y quitosano son viscosimetría (Rinaudo M. et al., 1993), dispersión de luz (Terbojevich M. et al., 1997) y cromatografía en permeación de gel (Baxter A. et al., 1992). En esta tesis se utilizó la metodología viscosimétrica por viscosimetría capilar y viscosimetría rotacional.

La viscosidad es una propiedad hidrodinámica de las soluciones poliméricas que depende del tamaño molecular y de la forma o grado de expansión de la macromolécula. La viscosidad de un polímero en solución depende de la naturaleza del polímero y del solvente, de la distribución de pesos moleculares, de la concentración y de la temperatura.

En soluciones diluidas la viscosidad está influenciada por las propiedades de las cadenas aisladas rodeadas por solvente, o por varias cadenas interaccionando entre sí. En cambio, en soluciones no diluidas o concentradas, el comportamiento del flujo está dominado por las interacciones colectivas entre las cadenas y los "entanglements" frecuentemente juegan un rol dominante.

Los polímeros en solución incrementan la viscosidad de ésta desde un valor de $\eta_{0}$ a $\eta$, donde $\eta$ y $\eta_{0}$ son, respectivamente, las viscosidades de la solución y la del solvente puro. Así en régimen diluido es de importancia este incremento. Por otro lado, en soluciones no diluidas y concentradas el objeto de estudio es la viscosidad del sistema y el solvente únicamente actúa como diluyente. 


\subsection{Estudios en régimen diluido. Evaluación del peso molecular promedio por viscosimetría capilar.}

En régimen diluido, las propiedades físicas de las soluciones se caracterizan por la viscosidad intrínseca [ $\eta$ ]. La viscosidad intrínseca tiene unidades de volumen/masa y está directamente relacionada con el peso molecular promedio del polímero en solución. Depende no sólo del tamaño de la macromolécula sino también de su conformación y de la naturaleza del solvente.

Experimentalmente las medidas de la viscosidad de un polímero en régimen diluido se llevan a cabo por medio de la técnica de viscosimetría capilar (Billmeyer F., 1984; Harding S. et al., 1991; Harding S. 1997), un método sencillo y muy utilizado para obtener el peso molecular de la quitina y quitosano. El método tiene la desventaja de no ser una técnica absoluta, por lo que requiere la determinación de las constantes mediante la correlación de valores de viscosidad intrínseca con valores de pesos moleculares medidos por un método absoluto.

En viscosimetría se emplean viscosímetros capilares del tipo Ostwald, Ubbelhode, o Cannon-Fenske en los que, basándose en la ley de Poiseuille, se mide el tiempo de caída del solvente puro $\left(t_{o}\right)$ y la solución $(t)$ en un tubo capilar entre dos marcas fijadas, a una temperatura determinada. Debido a que en viscosimetría capilar las concentraciones utilizadas son muy pequeñas, se considera que la densidad de la solución es similar a la densidad del solvente y por ello se sustituyen las viscosidades por el tiempo de caída.

Los valores obtenidos se relacionan con la viscosidad por medio de coeficientes de viscosidad relativa $\left(\eta_{\text {rel }}\right)$ y viscosidad específica $\left(\eta_{\mathrm{sp}}\right)$, de acuerdo a las expresiones (2.4) y (2.5) respectivamente. Cuando se tiene en cuenta el efecto de la concentración del polímero $(C)$ en la viscosidad se utilizan la viscosidad reducida $\left(\eta_{\text {red }}\right)$ y viscosidad inherente $\left(\eta_{\text {inh }}\right)$, definidos por las expresiones $(2.6)$ y $(2.7)$ respectivamente.

$$
\begin{gathered}
\eta_{\text {rel }}=\frac{\eta}{\eta_{0}} \approx \frac{t}{t_{0}} \\
\eta_{\text {sp }}=\eta_{\text {rel }}-1=\frac{\eta-\eta_{0}}{\eta_{0}} \approx \frac{\mathrm{t}-\mathrm{t}_{0}}{\mathrm{t}_{0}}
\end{gathered}
$$




$$
\begin{aligned}
& \eta_{\text {red }}=\frac{\eta_{\text {sp }}}{c}=\frac{\left(t-t_{0}\right)}{t_{0}} \cdot \frac{1}{c} \\
& \eta_{\text {inh }}=\frac{\left(\ln \eta_{\text {red }}\right)}{c}
\end{aligned}
$$

Aún en soluciones muy diluidas las moléculas de polímero interaccionan con las moléculas de solvente. Para eliminar estas interacciones y hallar así el valor de viscosidad intrínseca o viscosidad límite ([n]) es necesario extrapolar a concentración igual a cero según la siguiente expresión (2.8):

$$
[\eta]=\lim _{c \rightarrow 0}\left(\eta-\eta_{0}\right) /\left(\eta_{0} c\right)=\left(\eta_{\text {red }}\right)_{c \rightarrow 0}=\left(\eta_{\text {inh }}\right)_{c \rightarrow 0}
$$

Se conocen diferentes ecuaciones empíricas para realizar la extrapolación indicada en la expresión (2.8), tales como las de Huggins, Kraemer, Martin, Schulz - Blaschke y Solomon - Ciuta (Solomon O. et al., 1962), siendo el procedimiento más comúnmente utilizado el empleo de las Ecuaciones de Huggins (2.9) y Kraemer (2.10) por doble extrapolación:

$$
\begin{gathered}
\frac{\eta_{\mathrm{sp}}}{\mathrm{c}}=[\eta]_{H}+k_{H}[\eta]_{H}^{2} c \\
\frac{\left(\mathrm{ln} \eta_{\mathrm{red}}\right)}{\mathrm{c}}=[\eta]_{K}-k_{K}[\eta]_{K}^{2} c
\end{gathered}
$$

Donde $k_{\mathrm{H}}$ y $\mathrm{k}_{\mathrm{K}}$ son las constantes de Huggins y Kraemer, respectivamente. Estas constantes dependen de la forma de las moléculas y de la calidad del solvente. La sumatoria de ambas constantes debe ser de un valor cercano a 0,5 (Smidsrød O. et al., 1971).

Por lo tanto, para calcular la viscosidad intrínseca se mide el tiempo de caída de las soluciones diluidas de distinta concentración y el tiempo de caída del disolvente puro. Luego, a partir de estos valores se calcula la viscosidad relativa y la viscosidad específica, que permite obtener las viscosidades inherente y reducida. Finalmente, se representa gráfica y conjuntamente la viscosidad inherente y reducida frente a la concentración del polímero disuelto y se realizan las regresiones lineales correspondientes a los puntos 
obtenidos. La viscosidad intrínseca será el valor medio de las ordenadas en el origen de ambos ajustes.

Una vez calculada la viscosidad intrínseca, se puede determinar el peso molecular viscosimétrico $\left(M_{v}\right)$ de un polímero a partir de la Ecuación de Mark-Houwink-KuhnSakurada (MHKS) (2.11), que plantea la dependencia de la viscosidad intrínseca con el peso molecular promedio.

$$
[\eta]=K \cdot M_{v}^{a}
$$

Donde $K$ y $a$ son constantes empíricas válidas sólo para un sistema establecido de solvente-polímero, las cuales dependen de la naturaleza del polímero, del sistema de disolvente utilizado y temperatura. Generalmente el valor de $K$ varía entre $10^{-3}$ y $10^{-4}$. El exponente $a$ permite estimar la flexibilidad de una macromolécula y su conformación en solución haciendo uso del triángulo de Haug. Este triángulo describe los tres niveles de conformaciones macromoleculares representados en cada uno de los vértices, los cuales dependen del valor de $a$; un mayor valor de $a$ corresponde a una mayor extensión de la cadena. Así un valor de $a=0$ corresponde a esfera compacta, un tubo rígido corresponde a un valor de $a=1,8$ y un valor de $a$ entre 0,5 y 0,8 se presenta para el caso de polímeros de cadenas flexibles en buenos solventes (Solomon O. et al., 1962; Terbojevich M. et al., 1986).

Con la información proporcionada por las mediciones viscosimétricas se pueden determinar además las concentraciones que definen la transición entre los regímenes diluido y concentrado. Para ello se utilizan diferentes aproximaciones propuestas por distintos autores.

Desbrières (Desbrières J., 2002) tomando en cuenta que la viscosidad específica $\left(\eta_{\text {sp }}\right)$ puede expresarse por la Ecuación de Huggins (2.9) (Dobrynin A. et al., 1995) determinó C* como el valor de la pendiente de la curva en el cual la variación de la viscosidad específica $\left(\eta_{\text {sp }}\right)$ versus la concentración $\left\{C[\eta]+k_{H}(C[\eta])^{2}\right\}$ se desvía en uno en la Ecuación de Huggins.

Por su parte Hwang y colaboradores (Hwang J. et al., 2000) determinan en soluciones de quitosano la concentración $\mathrm{C}^{*}$ a partir de medidas de la viscosidad específica $\left(\eta_{s p}\right)$ como función de C $[\eta]$. Otros criterios utilizados para la estimación de la concentración $C^{*}$ consisten en hallar la relación del producto $C^{*}[\eta] \approx 1$ (Carreau $P$. et al., 
1997) o por medio de la obtención del valor al cual la viscosidad de una solución polimérica $(\eta)$ es el doble de la del solvente $\left(\eta_{0}\right)$ (Dobrynin A. et al., 1995).

La Ce también puede ser determinada de acuerdo a distintos enfoques. Desbrières (Desbrières J., 2002) la designa como aquella concentración en la cual se inicia el dominio terminal lineal en la gráfica log-log de viscosidad específica versus $C[\eta]+k_{H}(C[\eta])^{2}$.

\subsection{Evaluación de propiedades reológicas en régimen no diluido mediante viscosimetría rotacional.}

Por encima de la concentración $C^{*}$ las propiedades reológicas de las soluciones poliméricas semidiluidas y concentradas se caracterizan en términos de la deformación por medio de la viscosidad de corte o simplemente viscosidad (n) (Cho J. et al., 2006).

La reología es la ciencia que investiga la deformación definida como el cambio de forma o tamaño y el flujo de los materiales ante un esfuerzo. El esfuerzo $(\tau)$, se define como la fuerza aplicada (F) por unidad de área (A) de acuerdo a la ecuación (2.12).

$$
\tau=F / A
$$

La deformación puede ser reversible o irreversible, y de acuerdo a esto se habla de elasticidad, cuando el material retorna a su forma original una vez retirada la fuerza y plasticidad o flujo viscoso cuando los materiales se deforman irreversiblemente. Ciertos polímeros, como quitina y quitosano, pertenecen a esta última categoría.

Así cuando un esfuerzo $(\tau)$ externo y constante en el tiempo es aplicado a un polímero ocurre una deformación irreversible que causa que las capas de fluido se muevan a una cierta velocidad hasta alcanzar una velocidad de deformación constante en el estado estacionario. Las distintas capas del fluido, separadas a una distancia $\Delta y$, difieren una de la otra en una velocidad $\Delta v$. La tasa de cambio de la velocidad con la distancia se denomina gradiente de velocidad $(\dot{\gamma})$ (Ecuación 2.13).

$$
\dot{\gamma}=\Delta y / \Delta v
$$


La relación de proporcionalidad entre el esfuerzo y el gradiente de velocidad es la Ley de Newton de viscosidad (2.14):

$$
\tau=\eta \cdot \dot{\gamma}
$$

Aquellos sistemas para los cuales la viscosidad permanece constante independientemente del gradiente de velocidad se denominan newtonianos. En un gráfico de esfuerzo $(\tau)$ versus gradiente de velocidad $(\dot{\gamma})$ describen una línea recta que intercepta en cero con un único valor de la viscosidad como pendiente denominado viscosidad a gradiente cero $\left(\eta_{0}\right)$ (figura 2.3 a). Si la viscosidad es dependiente del gradiente de viscosidad el sistema se denomina no newtoniano. Existen dos tipos de desviaciones del régimen newtoniano: sistemas pseudoplásticos y dilatantes. En el primero (figura 2.3.b) la viscosidad disminuye con el aumento del gradiente de velocidad (o dicho de otra manera, a medida que aumenta el esfuerzo la viscosidad disminuye) y en aquellos dilatantes (figura 2.3.c) la viscosidad aumenta con el gradiente de velocidad. En dichos casos la viscosidad se define por un gradiente de velocidad y un esfuerzo dados. Así esas sustancias no se caracterizan por un único valor de viscosidad, sino por una viscosidad aparente $\left(\eta_{a p}\right)$ a un gradiente de velocidad particular. En un gráfico esfuerzo versus gradiente de velocidad describen una curva. La curvatura es una medida de la desviación del comportamiento newtoniano.

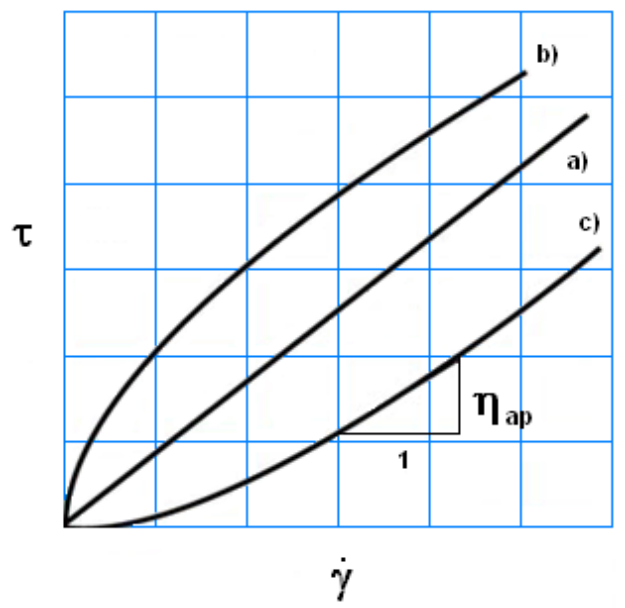

Figura 2.3. Curvas de esfuerzo $(\tau)$ versus gradiente de velocidad $(\dot{\gamma})$ para sistemas newtonianos (a) y no newtonianos: (b) pseudoplástico y (c) dilatante. 
La región de flujo pseudoplástica tiende a un régimen dado por la Ley de potencia o Ecuación de Ostwald de Waele (Hiemenz P., 1984) (2.15) que plantea que esfuerzo es proporcional a la potencia $\mathrm{n}$ del gradiente de velocidad.

$$
\tau=K(\dot{\gamma})^{n}
$$

De esta manera la viscosidad aparente queda definida por la expresión: (2.16)

$$
\eta_{a p}=\tau / \dot{\gamma}=K(\dot{\gamma})^{n-1}
$$

K y $\mathrm{n}$ son parámetros reológicos derivados de la curva del logaritmo del esfuerzo versus el logaritmo del gradiente de velocidad (Mucha M., 1997). K es el índice de consistencia y $\mathrm{n}$ es el índice de comportamiento de flujo. Este último adquiere el valor unitario en fluidos newtonianos y es menor a 1 para fluidos pseudoplásticos.

Cuando la viscosidad de las soluciones poliméricas se mide en función del gradiente de velocidad, la variación de la viscosidad en función del gradiente de velocidad presenta, en general, dos regiones distintivas (Cho J. et al., 2006):

1) a bajo gradiente de velocidad se observa una región en meseta denominada zona newtoniana en la cual la viscosidad a gradiente cero $\left(\eta_{0}\right)$ es constante $e$ independiente de la velocidad de deformación.

2) a elevado gradiente de velocidad, con valores superiores a un gradiente de velocidad crítica $\left(\dot{\gamma}_{c}\right)$ la viscosidad es aparente $\left(\eta_{\mathrm{ap}}\right)$, disminuye y es dependiente del gradiente de velocidad (Hwang J. et al., 2000). La $\left(\dot{\gamma_{c}}\right)$ marca el inicio del comportamiento pseudoplástico que depende del peso molecular del polímero y de la concentración de la solución.

\subsection{Propiedades de quitina en solución.}

Los estudios de las propiedades en solución de la quitina son limitados debido a la escasa solubilidad del polímero en la mayoría de los solventes conocidos, incluso aquellos sistemas de solventes típicos para la celulosa, sin que se produzca una degradación apreciable. La solubilización de la quitina presenta un importante problema 
principalmente debido a la existencia de fuertes interacciones por puentes de hidrógeno (Vincendon M. ,1985). La $\alpha$-quitina no es soluble en solventes clásicos y solo es soluble en solventes especiales fluorados como hexafluoroacetona que normalmente degradan la quitina o su uso no es ambientalmente conveniente.

Un sistema efectivo es aquel reportado por Austin, compuesto por $\mathrm{N}, \mathrm{N}$ dimetilacetamida (DMAc) conteniendo cloruro de litio (ClLi) 5-8\% (Austin P. 1975a;1975b). En dicho sistema el acetilo de la quitina forma un complejo de coordinación con el ClLi, el cual es soluble en DMAc. Vincendon (Vincendon M. ,1985) demostró que la disolución de la quitina en DMAC-5\%CILi procede por un mecanismo de interacción fuerte entre una molécula de ClLi con protones comprometidos en enlaces puentes de hidrógeno intermoleculares de los grupos $\mathrm{OH}$ o $\mathrm{NH}$ de los residuos de Nacetilglucosamina. Esta interacción destruye los puentes de hidrógeno intercatenarios permitiendo que la quitina se hinche y finalmente se solubilice.

Terbojevich y colaboradores (Terbojevich M. et al., 1988; Terbojevich M. et al., 1996) y Poirier y colaboradores (Poirier M. et al., 2002) llevaron a cabo estudios en soluciones diluidas y moderadamente concentradas de quitina en DMAC/ CILi 5-8\% con el fin de evaluar el peso molecular promedio. Determinaron mediante viscosimetría, cromatografía de exclusión molecular (SEC-MALS) y por dispersión de luz las constantes a y K de la ecuación MHKS (ecuación 2.11), así como el índice de persistencia. Por otro lado, Mucha (Mucha M., 1997) y Chen y colaboradores (Chen B. et al., 2004) realizaron estudios reológicos de quitina en el mismo solvente.

Si bien actualmente se han encontrado otros sistemas para solubilizar el polímero (mezclas de ácidos clorhídrico, fosfórico, sulfúrico o nítrico en 2-cloroetanol), la solubilidad de la quitina depende en gran medida de la fuente de extracción del biopolímero. Por lo que el complejo DMAc/ CILi $5 \%$ es el más utilizado para la determinación de propiedades en solución no sólo de la quitina y celulosa sino también de una gran variedad de polisacáridos de alto peso molecular.

\subsection{Propiedades del quitosano en solución.}

El conocimiento del comportamiento polielectrolito del quitosano en solución y su reología son muy importantes, ya que para la mayoría de sus aplicaciones (preparación de 
películas, membranas, fibras e hidrogeles) son necesarias soluciones de este polisacárido (Brugnerotto J. et al., 2001b; Berth G. et al., 2002).

El quitosano en su forma cristalina es normalmente insoluble en soluciones acuosas, pero, en contraste con la quitina, el quitosano puede ser disuelto en soluciones de ácidos orgánicos diluidos tales como ácidos acético y fórmico, entre otros. La solubilización se alcanza debido a grupos amino libres protonables presentes en su estructura molecular (Park J. et al., 1983), según el siguiente equilibrio:

$$
\text { Quito }-\mathrm{NH}_{2}+\mathrm{H}_{3} \mathrm{O}^{+} \rightleftharpoons \text { Quito }-\mathrm{NH}_{3}^{+}+\mathrm{H}_{2} \mathrm{O}
$$

Así, el quitosano se comporta como polielectrolito con grupos potencialmente ionizables, con un valor de $\mathrm{pK}_{\mathrm{a}}=6,3$ (Rinaudo M. et al., 1999). Su comportamiento en solución se encuentra en gran medida dominado por esta capacidad. El valor del $\mathrm{pK}_{\mathrm{a}}$ está relacionado con el grado de acetilación, por lo que la solubilidad del quitosano es dependiente del DA y del método de desacetilación (Hwang J. et al., 2000). El carácter polielectrolítico influye, entre otras cosas en sus propiedades hidrodinámicas, ácido-base, conductimétricas y reológicas (Argüelles W. et al., 2004).

Las propiedades en solución son afectadas por varios parámetros incluyendo el DA (Matsumoto T. et al., 1991), pH (Chen R. et al., 1994), fuerza iónica (Tsaih M. et al., 1999), la concentración (Guo H. et al., 2002), la temperatura (Chen R. et al., 1998), la concentración (Rinaudo M. et al., 1999) y naturaleza (Kurita K., 2001) del ácido utilizado para la protonación, así como la distribución de los grupos acetilo a lo largo de la cadena polimérica (Kubota N. et al., 1997).

Asimismo es importante considerar las uniones por puentes de hidrógeno inter- e intracatenarias y el carácter hidrofóbico de los grupos acetilo, como también de las condiciones de aislamiento y secado del polímero.

Una dificultad importante respecto a la solubilidad del quitosano es la de encontrar un solvente que permita su caracterización y evite la formación de agregados, ya que estos perturban la determinación del peso molecular no solo por viscosimetría sino también por dispersión de luz (Rinaudo M., 2006). Es por ello que Rinaudo y colaboradores (Rinaudo M. et al., 1993) proponen la mezcla de ácido acético 0,3 M y acetato de sodio $0,2 \mathrm{M}$ para estudios en solución del quitosano. 
III.

Hipótesis de Trabajo y Objetivos. 


\section{HIPÓTESIS DE TRABAJO Y OBJETIVOS}

\section{HIPÓTESIS DE TRABAJO}

El quitosano obtenido a partir de quitina extraída de pluma del calamar de Illex argentinus puede constituir una materia prima potencialmente útil para aplicaciones biomédicas.

Sobre la base de esta hipótesis se trazó el siguiente objetivo general.

\section{OBJETIVOS}

\section{Objetivo general:}

Investigar las propiedades en estado sólido y en solución del quitosano derivado del calamar argentino Illex argentinus, como fuente novedosa de esta macromolécula.

Para dar cumplimiento a este objetivo general se plantearon los siguientes objetivos específicos:

\section{Objetivos específicos:}

1) Aislamiento y posterior caracterización fisicoquímica de la quitina de pluma de calamar Illex argentinus mediante análisis de la estructura cristalina, grado de acetilación y evaluación del peso molecular promedio.

2) Obtención de quitosano por desacetilación de la quitina de pluma de calamar previamente aislada. 
3) Caracterización fisicoquímica del quitosano preparado mediante la determinación de parámetros estructurales, estimación del peso molecular promedio y evaluación de las propiedades reológicas.

Dichos objetivos se plantean para responder las siguientes preguntas más relevantes:

1) ¿Cuál es el peso molecular de los quitosanos obtenidos a partir de la $\beta$-quitina de la pluma de calamar Illex argentinus?

2) ¿Es posible obtener muestras de quitosano de alto peso molecular?

3) ¿Cuáles son los parámetros estructurales de quitina y quitosano? ¿Pueden ser descriptos como cadenas flexibles o semiflexibles en solución?

4) ¿Cómo varían las propiedades de dichas macromoléculas en solución?

La variedad de quitosanos comerciales de otras fuentes en existencia en el mercado es enorme. El interés de la presente tesis en los derivados de la pluma de calamar Illex argentinus obedece a razones científicas básicas, tales como obtención, caracterización y estudio teórico-experimental de muestras de alto peso molecular, ya que de esta especie sólo se ha estudiado la composición porcentual en quitina y proteínas, pero no se dispone de información respecto a las características macromoleculares de quitina y quitosano. De modo de poder evaluar el comportamiento y las propiedades relevantes para aplicaciones biomédicas es necesario realizar una caracterización estructural completa de la macromolécula.

La importancia de este estudio se basa en dos aspectos fundamentales. Por un lado, en nuestro país se dispone de materia prima derivada de un desecho proveniente de una de las principales industrias pesqueras del Mar Argentino, el cual puede constituir una fuente alternativa para la obtención de quitina y quitosano. Por otro lado, debe considerarse que en la actualidad la única fuente disponible de estos biopolímeros es a partir de productos de importación. Este aspecto no es menos importante, considerando la relevancia de las aplicaciones biomédicas propuestas y la proyección en el costo del producto final. De lo dicho se deduce el interés aplicado (estudio de la respuesta de películas preparadas con quitosano como sistemas de liberación controlada de drogas de uso farmacológico), que será desarrollado en la siguiente sección. 
IV.

Parte Experimental. 


\section{PARTE EXPERIMENTAL}

\section{OBTENCIÓN DE QUITINA}

El procedimiento incluye la extracción, aislamiento y purificación de la $\beta$-quitina a partir de la pluma del calamar Illex argentinus. Las muestras fueron obtenidas a partir de ejemplares frescos de origen comercial procedentes de la Plataforma Continental Este del Océano Atlántico Sur entre las latitudes $35-40^{\circ} \mathrm{S}$, durante la época de pesca comprendida entre Marzo y Agosto.

\subsection{Acondicionamiento de la materia prima.}

En esta primer etapa se extrajeron cuidadosamente las plumas del calamar Illex argentinus y se procedió a su limpieza. La misma consistió en un primer lavado con agua corriente para así separar la masa corporal y otros contaminantes que pudieron quedar adheridos a la pluma. Posteriormente se secaron a temperatura ambiente, hasta obtener plumas con estructura dura y quebradiza y por último se procedió al lavado con agua destilada. Previo al aislamiento y purificación de la quitina las plumas se secaron hasta peso constante a temperatura ambiente en tambor de vacío para así poder determinar su contenido en agua.

Una vez secas las plumas fueron cortadas en piezas de tamaño aproximadamente entre $2-5 \mathrm{~cm}$ y se sometieron a molienda en acetona a $0^{\circ} \mathrm{C}$ durante 30 segundos en un homogeneizador Ultra Turrax T25 (velocidad de $70 \mathrm{rpm}$ ) hasta tamaño de partículas de varios milímetros. Posteriormente se separaron por centrifugación (20 minutos a una velocidad de $5000 \mathrm{rpm}$ ) las piezas de la acetona y se secaron a temperatura ambiente en tambor de vacío hasta peso constante. Por último las muestras fueron separadas por tamizado, en tres grupos de tamaños de entre 0,45 y $0,85 \mathrm{~mm}$ con tamiz número 40 y número 20 respectivamente (Weast, $R$. et al., 1986). De esta manera se seleccionaron para su posterior análisis aquellas muestras con tamaño de partícula (t) $0,45 \mathrm{~mm} \leq \mathrm{t} \leq 0,8$ $\mathrm{mm}$. Las muestras fueron almacenadas en freezer hasta su posterior análisis. 


\subsection{Aislamiento y purificación de la quitina.}

El protocolo de aislamiento y purificación aplicado en este trabajo de tesis se confeccionó en base al trabajo realizado por Chaussard y Domard (Chaussard G. et al., 2004) debido a que las condiciones elegidas por esos autores evitan la posible degradación del polisacárido preservando así en mayor medida su estructura original.

\subsubsection{Extracción de lípidos y lipoproteínas.}

Percot y colaboradores (Percot A. et al., 2003) demostraron que tanto los lípidos como las lipoproteínas pueden ser los responsables de limitar la desproteinización, en relación a parámetros cinéticos desfavorables; se hace evidente entonces la importancia de su extracción. Trabajos previos basados en métodos convencionales no consideran el rol de estas moléculas en la etapa de desproteinización. Estos autores, basándose en Folch y colaboradores (Folch J. et al., 1957) realizan la extracción de lípidos y lipoproteínas con la mezcla cloroformo/metanol 2:1 v/v. Siguiendo este procedimiento se llevaron a cabo tres extracciones sucesivas, de una hora de duración cada una, reflujando la muestra en una relación de 1 gramo de pluma: $100 \mathrm{ml}$ de mezcla, manteniendo la temperatura a $40 \stackrel{\circ}{ } \mathrm{C}$.

\subsubsection{Desproteinización.}

La desproteinización se realizó siguiendo los lineamientos de Percot y colaboradores (Percot A. et al., 2003) con $\mathrm{NaOH} 1 \mathrm{M}$ en una relación 1 gramo de pluma: $15 \mathrm{ml}$ de $\mathrm{NaOH} 1 \mathrm{M}$, manteniendo agitación mecánica, durante 24 horas a temperatura ambiente.

Luego de este tiempo, el extracto se filtró empleando un embudo Buchner y la quitina aislada se lavó hasta neutralidad para remover el exceso de $\mathrm{NaOH}$. Por último la quitina fue liofilizada y secada hasta peso constante y almacenada en freezer hasta su posterior utilización. 
La ausencia de color en la muestra al final del tratamiento es indicativa de que se han removido las proteínas (Falini G. et al., 2001).

\section{OBTENCIÓN DE QUITOSANO}

El enfoque utilizado en la obtención de quitosano fue aquel propuesto por Kurita (Kurita K. et al., 1993) con modificaciones basadas en estudios de Lamarque y colaboradores (Lamarque G. et al., 2004) y Chandumpai y colaboradores (Chandumpai A. et al., 2004).

El procedimiento consistió en la desacetilación con $\mathrm{NaOH} 50$ \% (p/v), a 40 으. La reacción se llevó a cabo empleando una relación 1 gramo de quitina: $20 \mathrm{ml}$ de $\mathrm{NaOH}$. La suspensión de quitina en la solución de $\mathrm{NaOH}$ se mantuvo con agitación mecánica, en atmósfera inerte de nitrógeno y con recirculación de vapores por medio de una columna de reflujo, durante 48 horas. La mezcla reaccionante se sumergió en un baño de hielo molido-agua para detener la reacción y se neutralizó con $\mathrm{HCl}$ 0,1 M a 0ㅇ hasta $\mathrm{pH}$ 8,5. Posteriormente se centrifugó y se separó el producto sólido aislado. El quitosano obtenido fue liofilizado a peso constante y almacenado en freezer hasta su posterior caracterización.

En la tabla 3.1. se resumen las condiciones utilizadas en la obtención de quitina y quitosano a partir de la pluma de calamar Illex argentinus.

\begin{tabular}{|c|c|c|c|c|c|}
\hline Etapa & $\begin{array}{l}\text { Reactivos y } \\
\text { solventes }\end{array}$ & $\begin{array}{c}\text { Concentración } \\
\text { de reactivos y } \\
\text { solventes }\end{array}$ & $\begin{array}{l}\text { Sólido: líquido } \\
(p / v)\end{array}$ & Temperatura & $\begin{array}{l}\text { Tiempo de } \\
\text { reacción }\end{array}$ \\
\hline Acondicionamiento & Agua, acetona & - & - & 25 y $0^{\circ} \mathrm{C}$ & - \\
\hline $\begin{array}{l}\text { Extracción de lípidos } \\
\text { y lipoproteínas }\end{array}$ & $\begin{array}{c}\text { Cloroformo/ } \\
\text { metanol }\end{array}$ & $2: 1 \mathrm{v} / \mathrm{v}$ & $1: 100$ & $40^{\circ} \mathrm{C}$ & 3 horas \\
\hline Desproteinización & $\begin{array}{c}\text { Solución acuosa } \\
\text { de } \mathrm{NaOH}\end{array}$ & $4 \% p / v$ & 1:15 & $25^{\circ} \mathrm{C}$ & 24 horas \\
\hline Desacetilación & $\begin{array}{c}\text { Solución acuosa } \\
\text { de } \mathrm{NaOH}\end{array}$ & $50 \% p / v$ & $1: 20$ & $40^{\circ} \mathrm{C}$ & 48 horas \\
\hline
\end{tabular}

Tabla 3.1. Resumen de las condiciones utilizadas en la obtención de quitina y quitosano. 


\section{CARACTERIZACIÓN FISICOQUÍMICA DE QUITINA Y QUITOSANO}

\subsection{Caracterización de la pluma de calamar.}

Se llevó a cabo un análisis de la composición de la pluma de calamar. Se determinó el contenido porcentual en humedad, minerales y de los lípidos, lipoproteínas y proteínas extraídos. Asimismo se realizó la caracterización de los productos extraídos.

La determinación del porcentaje de humedad se realizó por análisis gravimétrico de la pluma previa y posteriormente a su acondicionamiento.

El contenido porcentual de minerales sobre la pluma inicialmente molida se determinó por incineración de la muestra a 700 C y posterior cuantificación gravimétrica. Se llevó a cabo un estudio mediante microscopía electrónica de barrido (Modelo Philips, SEM 505) utilizando energía de dispersión por rayos X (EDX) con un detector SUTWSapphire (EDAX). El análisis EDAX aportó información respecto de los principales elementos presentes en las cenizas.

El contenido porcentual de lípidos y lipoproteínas fue determinado por análisis gravimétrico de la muestra previo y posteriormente de realizada la extracción con cloroformo/ metanol 2:1 v/v. Un método sencillo para confirmar que los lípidos y lipoproteínas fueron eficazmente extraídos consiste en la eliminación del solvente del extracto orgánico, que contiene solubilizados una mezcla de lípidos diferentes y lipoproteínas, por rotaevaporación a $40^{\circ} \mathrm{C}$ y posterior caracterización cualitativa del residuo sólido obtenido mediante espectroscopia infrarroja (Shimadzu IR435).

El contenido de proteínas se cuantificó en el sobrenadante mediante espectrofotometría UV utilizando el Método de Bradford (Bradford M., 1976) y por análisis gravimétrico en la quitina obtenida.

\subsection{Caracterización de la $\beta$-quitina purificada.}

Como se comentó anteriormente, las diferencias estructurales que presentan las diferentes fuentes de quitina (caparazón de crustáceos con $\alpha$-quitina y pluma de calamar 
con $\beta$-quitina) son determinantes de características tales como grado de cristalinidad, peso molecular promedio y grado de acetilación. Dichas características tienen importancia sobre las propiedades finales y aplicaciones de la macromolécula. Se emplearon técnicas de ${ }^{13} \mathrm{C}-\mathrm{RMN}$ CP/MAS en estado sólido, espectroscopia IR y difracción de rayos X. Éstas técnicas se complementaron con los datos obtenidos mediante viscosimetría capilar y rotacional.

\subsubsection{Caracterización estructural.}

\subsubsection{Espectroscopia Infrarroja.}

El análisis estructural de la quitina se realizó por espectroscopia infrarroja empleando un equipo marca Shimadzu IR435. Los espectros se midieron en estado sólido en forma de pastilla. La muestra se mezcló con bromuro de potasio $(\mathrm{KBr})$ formando una pastilla por compresión en prensa hidráulica. El espectro infrarrojo fue obtenido en un intervalo de frecuencias de 4000 a $500 \mathrm{~cm}^{-1}$.

El espectro resultante fue comparado con datos bibliográficos y por concordancia de las bandas características de modo de corroborar la presencia del alomorfo $\beta$ - de la quitina.

\subsubsection{Determinación del grado de acetilación por espectroscopia ${ }^{13} \mathrm{C}$ - RMN CP-MAS en estado sólido.}

El espectro ${ }^{13} \mathrm{C}$ RMN CP-MAS de la $\beta$-quitina en estado sólido se registró con un instrumento Bruker-Avance II a 75,47 MHz. El tiempo de contacto fue de 1 milisegundo, el tiempo de repetición de 4 segundos y se acumularon 4096 escaneos. Las condiciones de transferencia de magnetización entre protón y carbón fueron optimizadas empleando una muestra de adamantano.

Siguiendo a Brugnerotto y colaboradores (Brugnerotto J. et al., 2001a; Brugnerotto J. et al., 2001b) el grado de acetilación (DA) fue determinado de acuerdo a la relación entre la intensidad de la resonancia del carbono del grupo metilo $\left(\mathrm{I}_{\mathrm{CH}}\right)$ y el promedio de 
todas las intensidades de resonancia de todos los carbonos del anillo glucosídico $\left(I_{c 1}, I_{C 2}\right.$, $\left.I_{C 3}, I_{C 4}, I_{C 5}, I_{C 6}\right)[122]$ según la siguiente expresión (4.1):

$$
D A(\%)=\frac{\mathrm{I}_{\mathrm{CH} 3} \times 100}{\left[\mathrm{I}_{\mathrm{C} 1}+\mathrm{I}_{\mathrm{C} 2}+\mathrm{I}_{\mathrm{C} 3}+\mathrm{I}_{\mathrm{C} 4}+\mathrm{I}_{\mathrm{C} 5}+\mathrm{I}_{\mathrm{C} 6}\right] / 6}
$$

\subsubsection{Difracción por Rayos $X$.}

El difractogramas de rayos $\mathrm{X}$ en polvo de la quitina purificada se obtuvo empleando un difractómetro de rayos $\mathrm{X}$ de amplio ángulo Philips PW1710 provisto de un

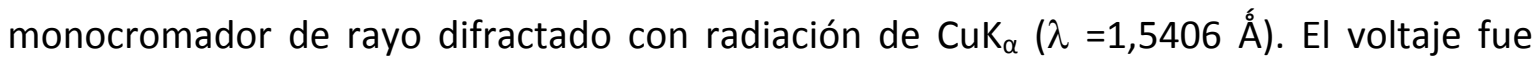
seleccionado en $40 \mathrm{kV}$ y la intensidad en $30 \mathrm{~mA}$. El intervalo angular (20) fue escaneado entre los $4^{\circ}$ y $40^{\circ}$ con incrementos de $0,02^{\circ}$ y el tiempo de medición de 2 segundos/incremento. La distancia entre planos en cada dirección fue calculada utilizando la Ecuación de Bragg.

Se calculó el Índice de cristalinidad (IC) de la quitina según el método de la intensidad de los picos propuesto por Focher y colaboradores (Focher B. et al., 1990). El método consiste en medir la máxima intensidad de los picos de difracción de la fase cristalina $\left(I_{110}\right)$ y la máxima intensidad de los picos en la fase amorfa $\left(I_{a m}\right)$ de acuerdo a la ecuación (5.2):

$$
\text { IC }(\%)=\left[\left(I_{110}-I_{a m}\right) / I_{110}\right] .100
$$

Donde $I_{110}$ es la máxima intensidad del pico de refracción (110) a $2 \theta=19,4$ y $\mathrm{I}_{\mathrm{am}}$ corresponde a la intensidad de difracción amorfa a $2 \theta=12,6$ (ambos expresados en unidades arbitrarias) (Cárdenas G. et al., 2004).

Asimismo se determinó el tamaño de los cristalitos (D) por la Ecuación de Scherrer, que relaciona la máxima intensidad del pico $(2 \theta)$ con el tamaño de los cristalitos, la longitud de onda de la radiación $\operatorname{CuK}_{\alpha}(\lambda=1,5406$ Á) y el ángulo del pico según la ecuación (4.3): 


$$
\Delta(2 \theta)=0,9 \lambda /(D \cos \theta)
$$

Donde $\Delta(2 \theta)$ es el ancho a la mitad de la altura máxima del pico a $2 \theta=19,4^{\circ}$ y $\theta$ es $1 / 2$ del ángulo de Bragg (expresado en radianes) correspondiente al pico cristalino.

\subsubsection{Caracterización de la macromolécula en solución.}

\subsubsection{Evaluación del peso molecular viscosimétrico de la quitina.}

La determinación de la viscosidad intrínseca de la $\beta$ - quitina obtenida se llevó a cabo mediante la técnica de viscosimetría capilar en solución de N,N-dimetilacetamida (DMAC) conteniendo $5 \%$ de ClLi a 25으. La quitina ( $C$ 0,2 mg/ml) fue disuelta en solución de $\mathrm{DMAc} / \mathrm{LiCl} 5 \%$ bajo agitación mecánica durante 48 horas a temperatura ambiente. Fueron preparadas diluciones a partir de una solución stock de manera tal que la viscosidad específica $\left(\eta_{\mathrm{sp}}\right)$ cumpla la condición $0,3<\eta_{\mathrm{sp}}<0,8$. Las viscosidades capilares se obtuvieron midiendo la viscosidad de cada dilución del stock con un viscosímetro Ostwald de $0,3 \mathrm{~mm}$ de diámetro, a una temperatura de $25( \pm 0,05) \mathrm{C}^{\circ}$ con un tiempo de caída para el solvente de $t_{0}>120$ segundos y un gradiente promedio de $240 \mathrm{seg}^{-1}$.

Los parámetros $K$ y a de la ecuación de MHKS (4.4) utilizados para calcular el peso molecular promedio viscosimétrico fueron aquellos obtenidos por Terbojevich y colaboradores (Terbojevich M. et al., 1988) mediante el empleo de técnicas de viscosimetría y dispersión de luz a $25^{\circ} \mathrm{C}$.

$$
[\eta]\left(\mathrm{cm}^{3} / \mathrm{g}\right)=0,24 \mathrm{M}_{\mathrm{v}}^{0,69}
$$

Con el objetivo de evaluar la dependencia de la viscosidad de la solución de $\beta$ quitina en función del gradiente de velocidad, se utilizó un reómetro rotacional Haake Rotovisco RV2 utilizando sensores cilíndricos coaxiales NV y un cabezal de medición MK 50. Las medidas fueron llevadas a cabo en una concentración de $0,1 \mathrm{mg} / \mathrm{ml}$ de $\beta$-quitina en $\mathrm{DMAc} / \mathrm{LiCl} 5 \%$ a $25( \pm 0,05) \mathrm{C}^{\circ}$, en función del gradiente de velocidad en un rango de 200-950 $\mathrm{s}^{-1}$. 


\subsubsection{Modelización de la quitina como macromolécula flexible.}

La conformación en solución de muchos polisacáridos puede describirse en términos de parámetros estadísticos tales como el radio de giro ( $\langle\mathrm{Rg}\rangle)$, la longitud estadística de Kuhn (b) y la longitud de persistencia (q). Estos parámetros hidrodinámicos permiten predecir la rigidez de la macromolécula en solución y pueden ser calculados a partir de medidas de viscosidad intrínseca [n].

El radio de giro ( $(R g\rangle)$ está definido como el cuadrado medio de la distancia de extremo a extremo de una cadena y su cálculo puede derivarse de medidas de [ $\eta$ ] y pesos moleculares. La relación existente entre la [n] y el radio de giro se da por la siguiente ecuación (4.5) (Carreau P. et al., 1997):

$$
[\eta]=\Phi \frac{\langle R g\rangle^{3}}{M_{n}}
$$

Donde $\Phi$ es una constante universal $\left(2,1.10^{23} \mathrm{~mol}^{-1}\right)$ y $\mathrm{Mn}$ es el peso molecular promedio en número.

La longitud estadística de Kuhn (b) puede ser determinada por la relación existente entre el radio de giro ( $\mathrm{Rg}$ ), la longitud virtual del enlace por unidad monomérica ( $/$ ) y el grado de polimerización (DP) (Anthonsen M. et al., 1993) de acuerdo a la ecuación (4.6). En general el valor de $b$ aumenta con el aumento de la rigidez de la cadena.

$$
b=\frac{6\langle R g\rangle^{2}}{l D P}
$$

La longitud de persistencia (q) indica la distancia en la cual la cadena puede ser considerada como rígida. Para el caso de polímeros semiflexibles se considera igual a $1 / 2 b$ (Mazeau K. et al., 2000).

Una característica general de los polisacáridos es su limitada flexibilidad debido a los impedimentos estéricos que imponen los enlaces glicosídicos. Además la aparición de puentes de hidrógeno restringe los movimientos segmentales y origina un ovillo aleatorio más expandido e inflexible. 
Mazeau y colaboradores (Mazeau K. et al., 2000; Mazeau K. et al., 2004) llevaron a cabo un análisis conformacional de quitinas con diferentes grados de acetilación (DA) y concluyeron que tanto quitina como quitosano son polímeros semiflexibles caracterizados por una longitud de persistencia (q) que depende moderadamente del DA. Además plantean que la rigidez de dichas macromoléculas se relaciona con la conformación de la molécula y especialmente con los puentes de hidrógeno intramoleculares. Así la presencia de unidades acetiladas incrementa la rigidez de la cadena por razones estéricas $\mathrm{y} / \mathrm{o}$ por puentes de hidrógeno entre dos residuos adyacentes.

El modelo de cadena vermiforme ha sido probado satisfactoriamente para el estudio de las características conformacionales de los polisacáridos. La Teoría de Yamakawa y Fujii (YF) (Yamakawa H. et al., 1974), desarrollada para un modelo de cadena vermiforme, interpreta la viscosidad intrínseca [ $\eta]$ de cilindros semiflexibles de longitud $L$ y diámetro $d$ en términos de diámetro reducido $d^{\prime}$ y longitud de contorno reducido $L^{\prime}$. Ambos valores se expresan en unidades de longitud de persistencia $q$. Así dicha teoría queda definida por la siguiente ecuación (4.7):

$$
[\eta]=\Phi L^{\prime 3 / 2} / \tau^{3} M
$$

Siendo (Terbojevich M. et al., 1988):

$\Phi$ una función de la longitud contorno reducido $L^{\prime}$ y diámetro reducido d';

$\mathrm{M}$ el peso molecular real de la cadena macromolecular;

$L^{\prime}$ representa la relación existente entre el peso molecular real (M) y el factor de corrimiento $\left(\mathrm{M}_{\mathrm{L}}\right)$ de acuerdo a la relación (4.8):

$$
L^{\prime}=M / M_{L}
$$

Donde $M_{L}$ corresponde a la masa molar por unidad de longitud de acuerdo a la siguiente ecuación (4.9):

$$
M_{L}=M_{0} / L_{0}=39,50 \mathrm{Da} / \AA
$$


Siendo $\mathrm{M}_{0}$ el peso molecular de la unidad repetitiva, que equivale a $203 \mathrm{Da}$ y $L_{0}$ la proyección de la unidad repetitiva sobre el eje de la cadena, que posee un valor de 5,14 $\AA$.

El diámetro reducido $d^{\prime}$, tabulado por la teoría YF, se define de acuerdo a relación entre el diámetro de cilindro equivalente $(d)$, determinado por difracción de rayos $\mathrm{X}$, y el índice de persistencia (q) (5.10):

$$
d^{\prime}=d \cdot q^{-1}=6,63 \AA \cdot q^{-1}
$$

Donde

$$
d=\left(M_{0} / \delta N L_{0}\right)^{1 / 2}
$$

Siendo $\delta$ la densidad del polímero y equivalente a $1,49 \mathrm{~g} / \mathrm{cm}$.

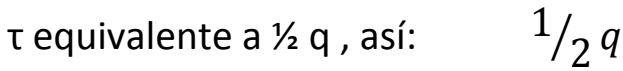

Y por lo tanto: $\quad \tau^{-1}=2 q=b$

En esta tesis la rigidez de la cadena macromolecular de la quitina fue analizada en términos de la teoría de Yamakawa y Fujii (YF) (Yamakawa H. et al., 1974), con los valores de viscosidad intrínseca hallados en DMAC/CILi 5\% a 25 oc calculados a partir de parámetros de Mark-Houwink reportados en la literatura (Terbojevich M. et al., 1988; Terbojevich M. et al., 1996; Poirier M. et al., 2002).

\subsection{Caracterización de quitosano.}

\subsubsection{Caracterización estructural. Determinación del grado de acetilación.}

Se realizaron mediciones por espectroscopia infrarroja con el fin de corroborar la identidad química del quitosano obtenido por desacetilación, así como para determinar su grado de acetilación. 
Las medidas se realizaron mediante la formación de una película por evaporación de una solución del quitosano en ácido acético $1 \% \mathrm{v} / \mathrm{v}$; el espectro fue obtenido en el infrarrojo medio, en un intervalo de frecuencia de $4000-500 \mathrm{~cm}^{-1}$.

La caracterización funcional del quitosano fue corroborada a partir de datos bibliográficos de bandas características en muestras similares.

El grado de acetilación del quitosano fue calculado a partir de la integración de bandas características a $1320 \mathrm{~cm}^{-1}$ y $1420 \mathrm{~cm}^{-1}$ de acuerdo a la ecuación (2.3) expuesta por Brugnerotto y colaboradores (Brugnerotto J. et al., 2001a):

Grado de N-acetilación $(\%)=31,92\left(\mathrm{~A}_{1320} / \mathrm{A}_{1420}\right)-12,20$

\subsubsection{Propiedades del quitosano en solución.}

\subsubsection{Evaluación del peso molecular promedio viscosimétrico.}

Se llevó a cabo la determinación de la viscosidad intrínseca del quitosano mediante la técnica de viscosimetría capilar en buffer ácido acético 0,3 $\mathrm{M}$ /acetato de sodio $0,2 \mathrm{M}$ a 25 으. Así el quitosano fue disuelto en solución de ácido acético ( $\mathrm{AcH}$ ) 0,3 M bajo agitación mecánica durante 72 horas a temperatura ambiente. Posteriormente se añadió acetato de sodio ( $\mathrm{AcNa}$ ) 0,2M y disolvió bajo agitación mecánica durante 24 horas. Una vez disuelta la solución fue filtrada con filtro acuoso 0,45 $\mu \mathrm{m}$.

Se prepararon diluciones a partir de una solución stock de manera tal que la viscosidad específica $\left(\eta_{s p}\right)$ estuvo comprendida entre $0,3<\eta_{\text {sp }}<0,8$. Las viscosidades capilares se obtuvieron midiendo la viscosidad de cada dilución con un viscosímetro Ostwald de $0,4 \mathrm{~mm}$ de diámetro, a $25( \pm 0,05) \mathrm{C}^{\circ}$ con un tiempo de caída para el solvente de $t_{0}<120$ segundos y un gradiente promedio de $643 \mathrm{~s}^{-1}$.

El peso molecular viscosimétrico fue calculado a partir de los parámetros MKHS hallados por Rinaudo y colaboradores (Rinaudo M. et al., 1993) y posteriormente corroborados por Brugnerotto y colaboradores (Brugnerotto J. et al., 2001b) (4.14):

$$
[\eta]\left(\mathrm{cm}^{3} / \mathrm{g}\right)=0,082 \mathrm{M}_{\mathrm{v}}^{0,76}
$$


A partir de los datos viscosimétricos y con el fin de constatar que las medidas se hallaban en régimen diluido, se halló $C^{*}$ como el valor de la pendiente en la gráfica de viscosidad específica en función del producto $\mathrm{C}[\eta]$ de acuerdo a la aproximación utilizada por Desbrières (Desbrières J., 2002) a partir de la Ecuación de Huggins (2.9) (Dobrynin A. et al., 1995):

$$
\eta_{s p}=C[\eta]+k_{H}(C[\eta])^{2}
$$

Como se comentó dicha ecuación presenta un comportamiento lineal en la zona diluida y se aleja de ésta en el régimen semidiluido. Por lo tanto se puede hallar a $C^{*}$ como el valor de la pendiente en la cual se desvía en uno de la expresión de Huggins.

\subsubsection{Reología de quitosano.}

Debido a los escasas publicaciones sobre quitosanos en soluciones no diluidas se iniciaron estudios referentes a las propiedades reológicas de los mismos. Los ensayos se Ilevaron a cabo con soluciones de quitosanos de Illex argentinus y, a fines comparativos, con muestras comerciales de quitosanos de origen crustáceo (Aldrich) en $\mathrm{AcH}$ al 1\% v/v. Se utilizó un viscosimetro rotacional Haake RV2 con sensores cilíndricos coaxiales NV y un cabezal de medición MK 50. Las mediciones se realizaron con soluciones de polímero al $0,25-1 \% \mathrm{p} / \mathrm{v}$, a una temperatura de $25 \pm 0,1^{\circ} \mathrm{C}$. Debido a la sensibilidad del equipo las medidas abarcaron un rango de gradientes entre 1 y $10^{4} \mathrm{seg}^{-1}$.

Para el análisis de las curvas reológicas se utilizó el Modelo de Cross (Cross M., 1965) (4.15) que permite estimar el valor de la viscosidad a gradiente cero $\left(\eta_{0}\right)$, el tiempo característico $\left(t_{1}\right)$, que representa el tiempo en que tardan las moléculas en desenredarse en un régimen semidiluído y la pendiente (1-n) en la zona no newtoniana.

$$
\eta=\frac{\eta_{o}}{1+\left[t_{1} \dot{\gamma}\right]^{(1-n)}}
$$


V.

Resultados y Discusión. 


\section{RESULTADOS Y DISCUSIÓN}

\section{CARACTERIZACIÓN DE LA PLUMA DE CALAMAR.}

Las plumas del calamar Illex argentinus representan el 0,2 \% p/p del calamar. Por análisis gravimétrico se encontró que las plumas contienen, en base seca, un $1 \%$ de cenizas, 2,3\% de lípidos y lipoproteínas, un 64 \% de proteínas y un 31\% de quitina.

Resultados similares fueron obtenidos por otros autores con pluma de calamar de otras especies, tal como se observa en la tabla 5.1, donde Kurita y colaboradores (Kurita K. et al., 1993) con ejemplares de Ommastrephes bartrami obtienen 58 \% de proteína y 35-40 \% de quitina, Chaussard y colaboradores (Chaussard G. et al., 2004) con ejemplares de Loligo hallan valores de $42,5 \%$ de proteína y $32,5 \%$ de quitina, $2 \%$ de de lípidos y lipoproteínas y $2 \%$ de cenizas. Lavall y colaboradores (Lavall R. et al., 2007), Tolaimate y colaboradores (Tolaimate A. et al.,2003) y Chandumpai y colaboradores (Chandumpai A. et al., 2004) obtienen valores similares. Las diferencias pueden ser atribuidas al origen de la fuente así como al protocolo de extracción y en última instancia al modo en que fueron analizados los extractos.

\begin{tabular}{|c|c|c|c|c|c|c|}
\hline \multirow[b]{2}{*}{ Especie estudiada } & \multicolumn{5}{|c|}{ Composición Química (\%) } & \multirow[b]{2}{*}{ Referencia } \\
\hline & Humedad & Proteínas & Cenizas & $\begin{array}{c}\text { Lípidos y } \\
\text { lipoproteínas }\end{array}$ & Quitina & \\
\hline Ommastrephes bartrami & n.r. & 58 & $\ll<$ & n.r. & $35-40$ & $\begin{array}{c}\text { Kurita K. et al., } \\
1993\end{array}$ \\
\hline Loligo sp. & 13 & 42,5 & 2,4 & 2 & 32,5 & $\begin{array}{c}\text { Chaussard G. et } \\
\text { al., } 2004\end{array}$ \\
\hline $\begin{array}{l}\text { L. lessoniana y } L \text {. } \\
\text { formosana }\end{array}$ & n.r. & n.r. & $\begin{array}{l}0,025- \\
0,042\end{array}$ & n.r. & $35-38$ & $\begin{array}{l}\text { Chandumpai } \\
\text { A. et al., } 2004\end{array}$ \\
\hline L. sanpaulensis y L. plei & 9,4 & n.r. & 1,9 & n.r. & $40-42$ & $\begin{array}{c}\text { Lavall R. et al., } \\
2007\end{array}$ \\
\hline Illex argentinus & n.r. & 64 & 1 & 2,3 & 31 & esta tesis \\
\hline
\end{tabular}

Tabla 5.1. Comparación de la composición química (\%) de la pluma del calamar lllex argentinus respecto a los reportados por otros autores. n.r.: valor no registrado. 
A partir del análisis EDAX de las cenizas de la pluma de calamar (figura 6.1.) se hallaron los principales elementos, mayoritariamente constituidos por fósforo, sodio, potasio, calcio y en menor medida magnesio.

El bajo contenido porcentual en materia inorgánica obtenido respecto a los otros extraíbles (tabla 5.2.) se halla en concordancia con aquellos reportados por otros autores (Lavall R. et al., 2007; Chaussard G. et al., 2004; Kurita K. et al., 1993; Chandumpai A. et al., 2004) y sustenta el hecho de que no sea necesario el paso de desmineralización en el proceso de purificación, contrariamente a lo que sucede con las fuentes de $\alpha$-quitina.

En la figura 5.2. se observa el espectro infrarrojo del extracto de lípidos y lipoproteínas obtenido. Chaussard y colaboradores (Chaussard G. et al., 2004) demostraron que la extracción con la mezcla cloroformo/ metanol 2:1 v/v es un sistema eficiente para separar lípidos y lipoproteínas. La presencia de bandas de absorción características en el espectro IR del extracto, tales como $U_{\mathrm{OH}}=3400 \mathrm{~cm}^{-1}, v_{\mathrm{C}=0} 1730 \mathrm{~cm}^{-1}, U_{\mathrm{NH}}=1640 \mathrm{~cm}^{-1}$ (amida l) y $1600 \mathrm{~cm}^{-1}$ ( $\left.U_{\text {cis } \mathrm{RHC}=\mathrm{CHR}}\right)$, confirman la presencia de ambos compuestos.

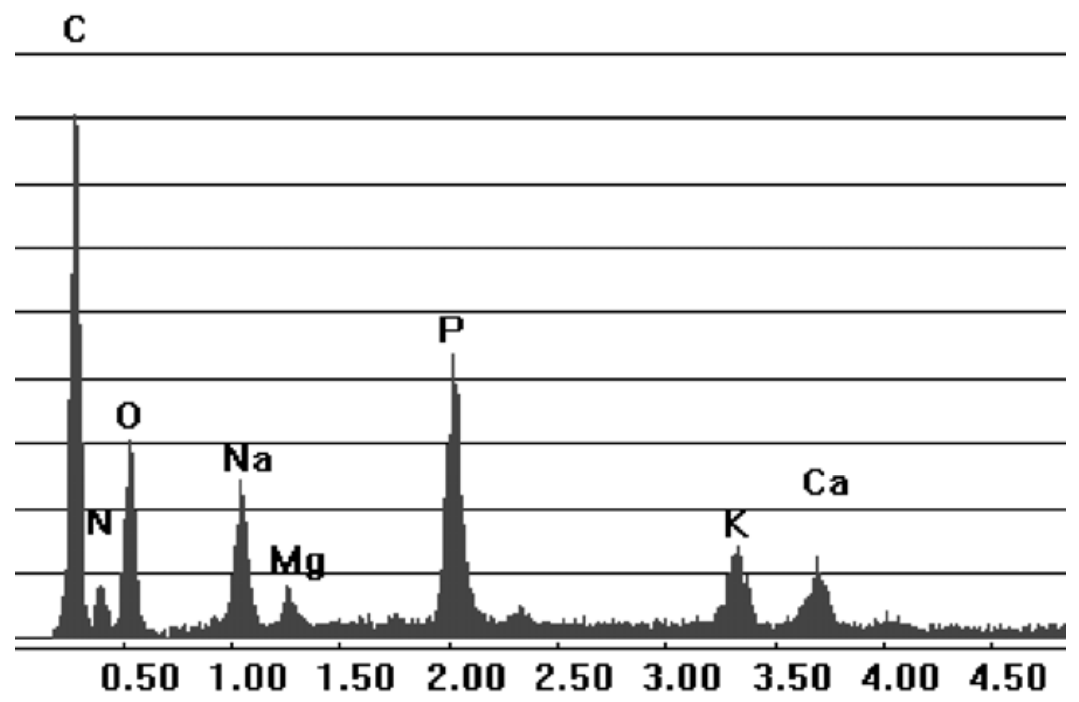

Figura 5.1. Composición EDAX de materia inorgánica de la pluma del calamar Illex argentinus. 
\begin{tabular}{l|l} 
Sección A:Quitina y quitosano & 3
\end{tabular}

V. Resultados y Discusión.

\begin{tabular}{|c|c|c|c|c|c|c|c|c|c|}
\hline \multicolumn{9}{|c|}{ Elementos químicos presentes en las cenizas (ppm) } & \multirow{2}{*}{ Referencias } \\
\hline $\mathrm{Na}$ & $M g$ & $P$ & $\kappa$ & $\mathrm{Ca}$ & $\mathrm{Fe}$ & $M n$ & $\mathrm{Cu}$ & $C d$ & \\
\hline 170 & 121 & 287 & 19 & 344 & 4 & n.r. & n.r. & n.r. & $\begin{array}{l}\text { Kurita K.et al., } \\
1993 .\end{array}$ \\
\hline 8540 & 1220 & n.r. & 255 & 1025 & 30 & 1 & 15 & 4 & $\begin{array}{l}\text { Chaussard G. } \\
\text { et al., } 2004 .\end{array}$ \\
\hline n.r. & $3,3 / 5,5$ & n.r. & n.r. & $17,7 / 24,2$ & $7,7 / 17,2$ & n.r. & $0,9 / 16,2$ & 8,1 & $\begin{array}{l}\text { Chandumpai } \\
\text { A. et al., } \\
2004 .\end{array}$ \\
\hline n.r. & $11,7+/-1$ & n.r. & n.r. & $94,5+/-5$ & $3,5+/-0,6$ & $3,5+/-0,6$ & n.r. & n.r. & $\begin{array}{l}\text { Lavall R. et } \\
\text { al., } 2007 .\end{array}$ \\
\hline 280 & 350 & 5700 & 150 & 10600 & n.r. & n.r. & n.r. & n.r. & $\begin{array}{l}\text { Tolaimate } A . \\
\text { et al., } 2003 .\end{array}$ \\
\hline 750 & 100 & 510 & 210 & 170 & n.r. & n.r. & n.r. & n.r. & esta tesis \\
\hline
\end{tabular}

Tabla 5.2. Comparación con datos bibliográficos acerca de los principales elementos hallados en las cenizas. Elementos expresados en ppm. n.r.: valor no registrado.

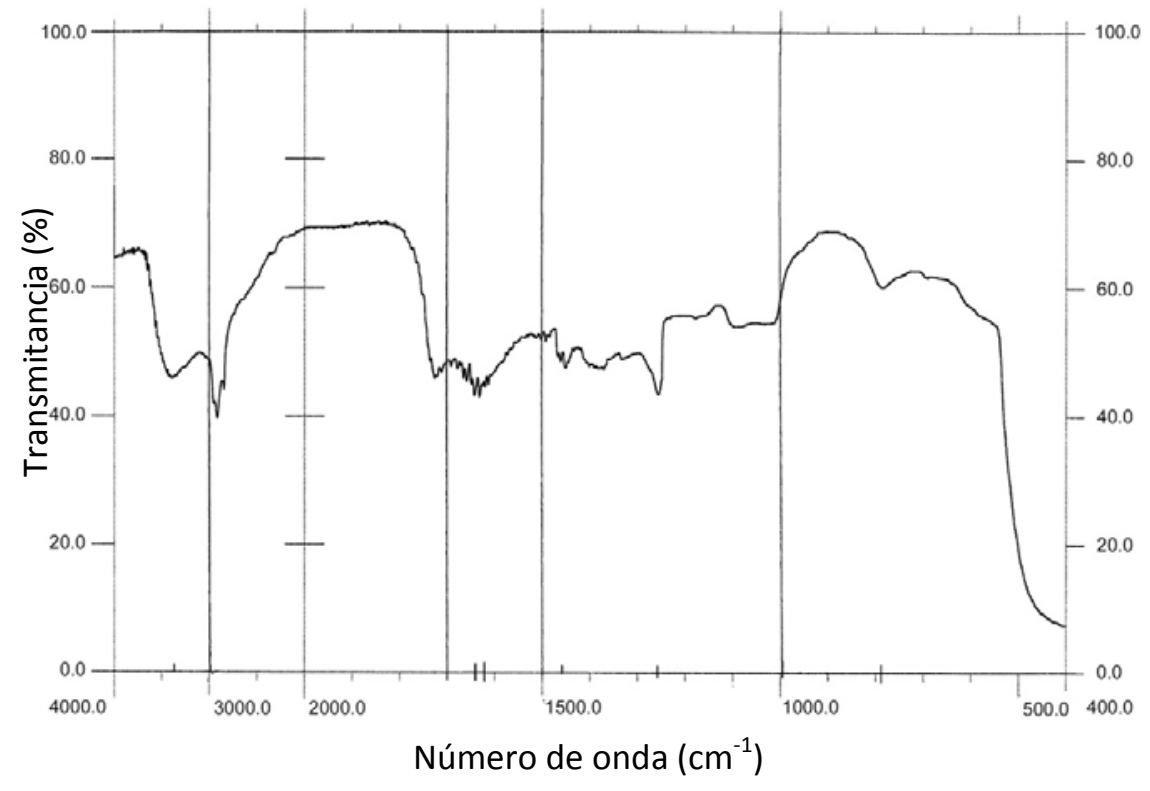

Figura 5.2. Espectro IR de los lípidos y lipoproteínas extraídos de la pluma de calamar Illex argentinus. 


\section{CARACTERIZACIÓN DE LA QUITINA PURIFICADA}

\subsection{Espectroscopía Infrarroja.}

El espectro infrarrojo de la $\beta$-quitina muestra bandas de absorbancias estrechas, típicas de los polisacáridos cristalinos (figura 5.3.).

La presencia del alomorfo $\beta$-quitina fue confirmada por la aparición de una única banda a $U_{\mathrm{C}=0} 1656 \mathrm{~cm}^{-1}$ (Amida I), asignada a la unión por puentes de hidrógeno $\mathrm{C}=\mathrm{O} \cdots \mathrm{H}-\mathrm{N}$ intracatenarios del grupo $\mathrm{C}=\mathrm{O}$ de la amida I con el grupo $\mathrm{N}-\mathrm{H}$ de la amida (Amidas II) (Kurita K. et al., 1993). La existencia de una única banda Amida I diferencia claramente al alomorfo $\beta$ - del $\alpha$-, en la cual aparecen una banda a $U_{\mathrm{c}=0} 1660 \mathrm{~cm}^{-1}$ y hombro asociado a $1627 \mathrm{~cm}^{-1}$, atribuido a puentes de hidrógeno intercatenarios $\mathrm{C}=0 \cdots \mathrm{HOCH}_{2}$ (Jang M. et al., 2004; Kurita K. et al., 1993; Focher B, et al., 1992).

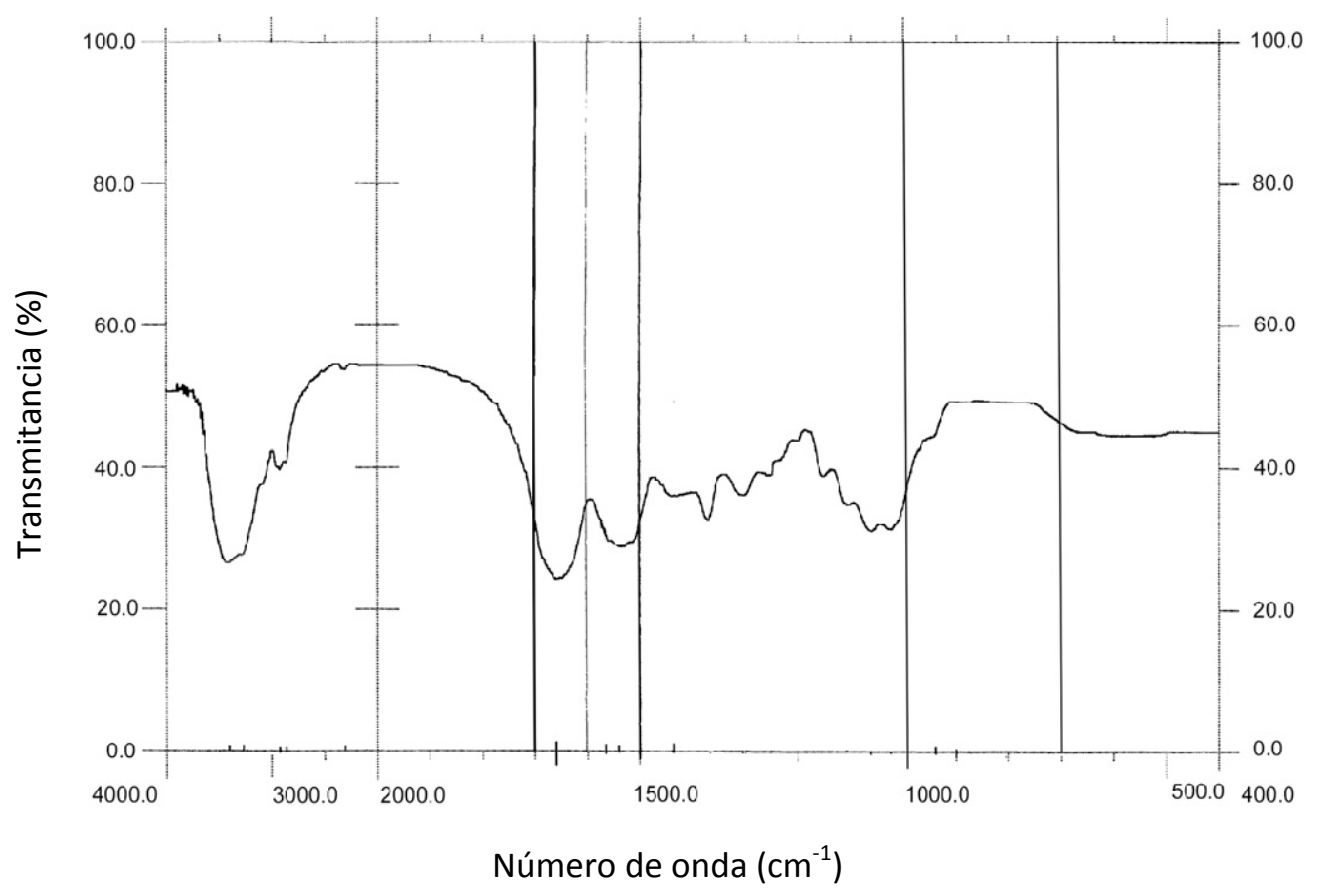

Figura 5.3. Espectro IR de transmitancia de la $\beta$-quitina extraída. 
Asimismo, las siguientes bandas permiten caracterizar el polisacárido (Lavall R. et al., 2007; Cárdenas G. et al., 2004): una amplia banda a $U_{\mathrm{OH}} 3420 \mathrm{~cm}^{-1}$ atribuida a puentes de hidrógeno intramoleculares $-\mathrm{O}(3) \mathrm{H} \cdots(5)$ del anillo, una banda a $U_{\mathrm{N}-\mathrm{H}} 3280 \mathrm{~cm}^{-1}$ debida a la deformación axial del grupo amino que participa en la formación de puentes de hidrógeno intermoleculares $\mathrm{C}=\mathrm{O} \cdots \mathrm{H}-\mathrm{N}$ (Focher B. et al., 1992), una banda Amida II a $U_{\mathrm{N}-\mathrm{H}}(\mathrm{C}-\mathrm{N}-\mathrm{H})+\delta_{\mathrm{N}-\mathrm{H}}$ $1560 \mathrm{~cm}^{-1}$ (Kurita K. et al., 1993), una banda $\delta_{\mathrm{C}-\mathrm{H}}+\delta_{\mathrm{C}-\mathrm{CH} 3} 1370 \mathrm{~cm}^{-1}, U_{\mathrm{C}-\mathrm{N}}+\delta_{\mathrm{N}-\mathrm{H}}=1315 \mathrm{~cm}^{-1}$ (amida III) y bandas a $U_{\mathrm{c}-\mathrm{o}} 1160 \mathrm{~cm}^{-1}, 1105 \mathrm{~cm}^{-1}, 1060 \mathrm{~cm}^{-1}$ y $1025 \mathrm{~cm}^{-1}$ asignadas a modos de vibración de estiramiento C-O-C y C-O.

\subsection{Espectroscopía ${ }^{13} \mathrm{C}$ RMN CP-MAS en estado sólido.}

En el espectro ${ }^{13} \mathrm{C}$ RMN CP-MAS en estado sólido de la quitina obtenida (figura 5.4.) se observan siete señales asignadas a los ocho átomos de carbono de la unidad repetitiva de la $\mathrm{N}$-acetilglucosamina. Dichas señales aparecen en los siguientes valores de desplazamientos químicos (ppm) (Tanner S. et al., 1990): $\delta=172,6$ (C=0), 104,4 (C1), 84,1 (C4), 75,0 (C3 y C5), $61,4(\mathrm{C} 6), 5,7(\mathrm{C} 2)$ y $22,8\left(\mathrm{CH}_{3}\right)$. La señal del carbonilo $(\mathrm{C}=\mathrm{O})$ aparece como un pico agudo y asimétrico, indicando la presencia de un único estado conformacional, típico de la estructura de la $\beta$-quitina. El espectro se caracteriza por la presencia de amplios picos asimétricos y hombros distintivos en $\mathrm{C} 6$ y $\mathrm{CH}_{3}$. Las señales de $\mathrm{C} 3$ y $\mathrm{C} 5$ se superponen en una resonancia centrada a 75,0 ppm, mientras que para el espectro de la $\alpha$-quitina estas señales son reportadas como dobletes (Focher B. et al., 1990; Cárdenas G. et al., 2004). Estas diferencias son atribuidas a diferentes configuraciones en C3 y C5 como resultado de los puentes de hidrógenos establecidos en los dos alomorfos. Así dichas características del espectro ${ }^{13} \mathrm{C}$ RMN CP-MAS confirman la identidad química de la quitina. 


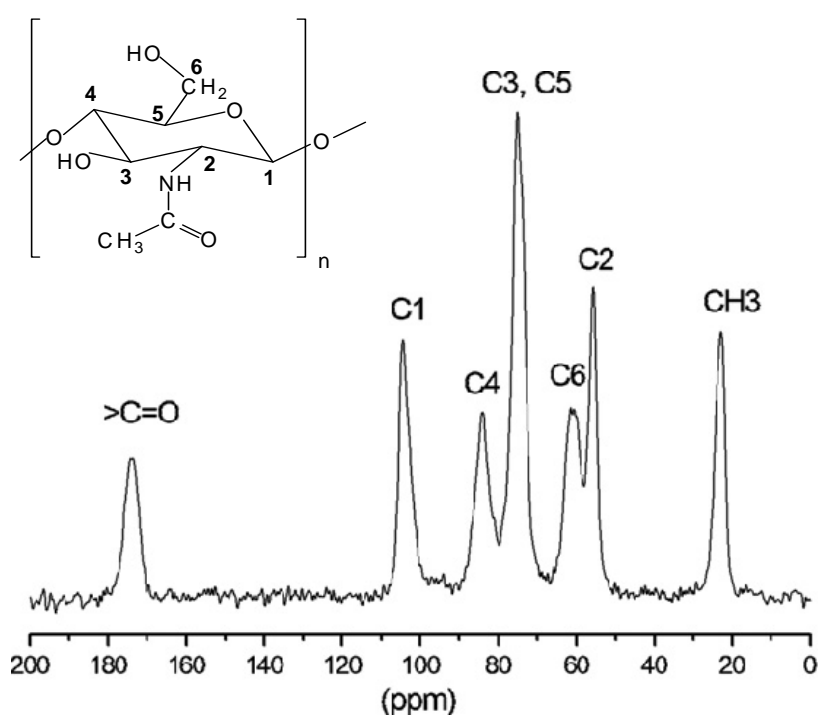

Figura 5.4. Espectro ${ }^{13} \mathrm{C}-\mathrm{RMN} C \mathrm{CP} / \mathrm{MAS}(75.47 \mathrm{MHz})$ de la $\beta$-quitina obtenida.

\subsubsection{Determinación del grado de acetilación.}

El grado de acetilación (DA) fue determinado en base a estudios por espectroscopia

${ }^{13} \mathrm{C}$ RMN CP-MAS realizados por Brugnerotto y colaboradores (Brugnerotto J. et al., 2001a; Brugnerotto, J. et al., 2001b) de acuerdo a la relación (5.1) (Ottøy M. et al., 1996). Se halló un valor de DA = 96\% para la $\beta$-quitina purificada aislada de pluma de calamar Illex argentinus. Distintos valores de DA han sido reportados a partir de $\beta$-quitinas de diferentes fuentes de calamares, entre ellos se pueden citar un 92\% para pluma del calamar Ommastrephes bartrami (Kurita K. et al., 1993), 100\% para pluma del calamar Loligo vulgaris (Tolaimate A. et al., 2003; Rhazi M. et al., 2000) y 79\% para pluma del calamar Loligo formosana (Methacanon P. et al., 2003).

Las discrepancias entre los valores reportados pueden ser atribuidas no sólo al método de determinación del grado de acetilación utilizado sino también a las diferencias de protocolo de aislamiento utilizados, que muchas veces incluyen el paso de desmineralización acídica e incluso desproteinización bajo diferentes condiciones alcalinas. Para el caso de esta tesis, debido al bajo contenido de minerales, la etapa de desmineralización no fue efectuada, 
y la etapa de desproteinización fue realizada bajo condiciones suaves (solución acuosa $\mathrm{NaOH}$ $1 \mathrm{M}$, temperatura ambiente y duración de la reacción 24 hs.) tal como lo sugerido por Chaussard y colaboradores (Chaussard G. et al., 2004) para así evitar la posible degradación de la macroestructura y desacetilación de la quitina nativa. Es de esperar que el valor obtenido sea reflejo de las condiciones de aislamiento utilizadas las cuales preservaron la estructura original del polisacárido.

Como se comentó previamente numerosos autores se inclinan por determinar el grado de acetilación mediante espectroscopía infrarroja. Baxter y colaboradores (Baxter A. et al., 1992) así como Chaussard y colaboradores (Chaussard G. et al., 2004) indican que para aquellas muestras con elevado grado de acetilación, como es el caso de la $\beta$-quitina de pluma de calamar estudiada en esta tesis, la determinación del grado de acetilación por espectroscopia de infrarrojo subestima los valores de DA debido a que la elevada higroscopicidad de la muestra aumenta la absorbancia de las bandas $\mathrm{OH}$ que se utilizan como referencia. Es por esto que consideran adecuado la obtención del DA por espectroscopia ${ }^{1} \mathrm{H}$ o ${ }^{13} \mathrm{C}$ RMN.

\subsection{Difracción por Rayos $X$.}

Tal como se aprecia en la figura 6.5., el difractograma de rayos $\mathrm{X}$ obtenido exhibe dos amplios máximos de difracción a $2 \theta=8,10^{\circ}$ (distancia intercatenaria: $10,91 \AA$ ) y $2 \theta=19,4^{\circ}$ $(4,57 \AA$ A). Este patrón de reflexión incluye valores coincidentes con los reportados para muestras de $\beta$-quitina de fuentes similares (Jang M. et al., 2004; Lavall R. et al., 2007; Kurita K. et al., 1993; Kim S. et al., 1996; Jaworska M. et al., 2003).

Roberts (Roberts G., 1992) aclara que el origen del material afecta fuertemente la estructura cristalina, dependiendo del tipo de arreglo de cadena y que la distancia intercatenaria depende del grado de hidratación de la muestra, la cual varía entre 9,3 y 11,1 Å. Cuanto más elevado es el valor de la distancia intercatenaria a lo largo del eje cristalográfico c, mayor es el grado de hidratación. En el alomorfo $\beta$ de la quitina los puentes de hidrógenos intercatenarios (a lo largo del eje cristalográfico c) están ausentes a diferencia de lo que 
ocurre en la $\alpha$-quitina. En el caso de esta tesis se halló un valor de 10,91 $\AA$, el cual se corresponde con la estructura $\beta$ de la quitina.

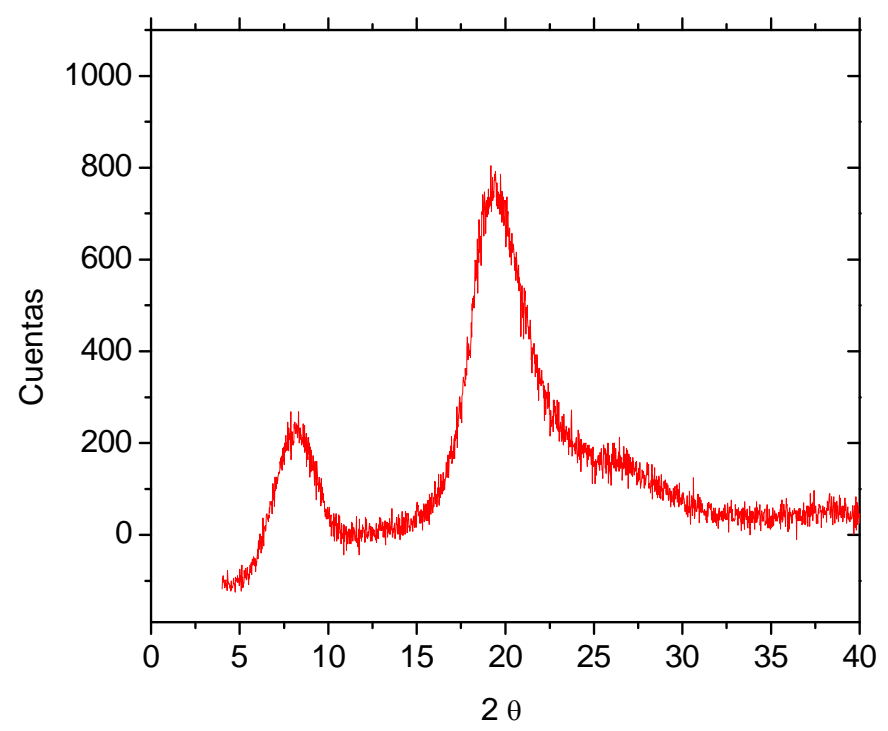

Figura 6.5. Difractograma de Rayos $X$ de la $\beta$-quitina aislada.

Así fue calculado el índice de cristalinidad (IC) de acuerdo a la ecuación (5.2) y el tamaño de cristalitas (D) mediante la ecuación (5.3). Los valores hallados fueron $74,9 \%$ y 2,32 $\mathrm{nm}$ respectivamente. Estos resultados están en concordancia con aquellos provenientes de muestras de $\beta$-quitina de pluma de calamar (Lavall R. et al., 2007; Chaussard G. et al., 2004; Cárdenas G. et al., 2004).

Lavall y colaboradores (Lavall R. et al., 2007) explican que la cristalinidad, el tamaño de los cristalitos y su grado de orientación ejercen una profunda influencia sobre la cantidad de agua adsorbida en la matriz polimérica así como en la solubilidad del polímero, de ahí la importancia de dicha información. Cárdenas y colaboradores (Cárdenas G. et al., 2004), Lavall y colaboradores (Lavall R. et al., 2007), así como Jaworska y colaboradores (Jaworska M. et al., 2003) obtienen valores de IC de entre $66,3 \%, 71,8-73,4 \%$ y $82,6 \%$ respectivamente. EI tamaño de los cristalitos hallados en esta tesis en similar al reportado por Jaworska y colaboradores (Jaworska M. et al., 2003), con un valor de 2,6 nm como también al de Lavall y colaboradores (Lavall R. et al., 2007), que encuentran valores de entre 3,17 nm y 3,24 nm. 


\subsection{Evaluación del peso molecular promedio viscosimétrico de la quitina.}

La viscosidad intrínseca de la $\beta$ - quitina en DMAC/CILi $5 \%$ a $25 \circ \mathrm{C}$ fue determinada gráficamente a partir de las curvas de viscosidad en función de la concentración de polímero por doble extrapolación de las relaciones de viscosidad de Huggins y Kramer (ecuaciones (2.9) y (2.10) respectivamente) y posterior cálculo del promedio de la intersección en ordenadas de ambas extrapolaciones.

Como se observa en la figura 6.6., la representación gráfica y conjunta de la viscosidad inherente y reducida en función de la concentración de polímero presentó el comportamiento lineal esperado dentro del rango de concentración utilizado para las medidas viscosimétricas $(0,02<\mathrm{c}<0,1 \mathrm{mg} / \mathrm{ml})$.

Por viscosimetría rotacional se analizaron en función del gradiente soluciones de $\beta$ quitina en $\mathrm{DMAc} / \mathrm{LiCl} 5 \%$ con una concentración de $0,1 \mathrm{mg} / \mathrm{ml}$ y no se observó variación de la viscosidad en función del gradiente, lo que indica que las medidas fueron realizadas en régimen Newtoniano.

La viscosidad intrínseca fue estimada en un valor de [n] $=7200 \pm 200 \mathrm{ml} / \mathrm{g}$. Los coeficientes de Huggins y Kramer fueron de $k_{H}=0,34$ y $k_{k}=-0,15$ respectivamente. La diferencia entre ambos coeficientes no fue mayor de 0,5 lo cual está de acuerdo con lo predicho por el modelo.

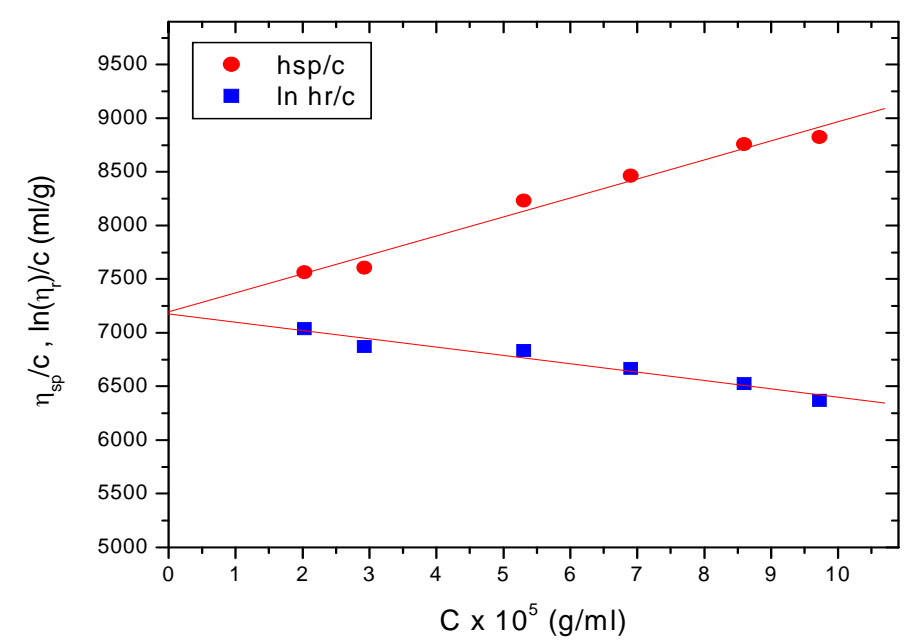

Figura 6.6. Viscosidad intrínseca de $\beta$-quitina en $\mathrm{LiCl}(5 \%) / D M A C$ a $25 \circ \mathrm{C}$ en función de la concentración. 
El peso molecular promedio viscosimétrico fue estimado en $M_{v}=3,07.10^{6} \mathrm{~g} / \mathrm{mol}$ de acuerdo a los parámetros $K$ y a de la ecuación de MHKS (5.4) propuesta por Terbojevich y colaboradores (Terbojevich M. et al., 1988).

Si bien los estudios de quitina en solución no son abundantes, el valor hallado en esta tesis es superior a aquellos reportados por otros autores a partir de ejemplares de Loligo sp. (Lamarque G. et al., 2004; Kim S. et al., 1996; Focher B. et al., 1990) bajo las mismas condiciones de análisis de las muestras (solvente utilizado, temperatura y set de constantes $K$ y a de la ecuación MKHS). Por ejemplo Lamarque y colaboradores (Lamarque G. et al., 2004) y Focher y colaboradores (Focher B. et al., 1990) que encuentran valores de $M_{v}=$ $1,34.10^{6} \mathrm{~g} / \mathrm{mol}$ y $1,8.10^{6} \mathrm{~g} / \mathrm{mol}$ respectivamente así como Kim y colaboradores (Kim S. et al., 1996) hallan valores de $M_{v}=3,0.10^{5} \mathrm{~g} / \mathrm{mol}$.

Es de esperar que el valor de peso molecular promedio viscosimétrico estimado en esta tesis sea reflejo no sólo del origen biológico de la $\beta$ - quitina sino de la preservación de la estructura original del polisacárido debida a las condiciones de aislamiento utilizadas. Por otra parte dicho valor puede deberse a una presumible polidispersidad de la muestra. Lamarque y colaboradores (Lamarque G. et al., 2004) justifican el uso de las constantes de Terbojevich y colaboradores (Terbojevich M. et al., 1988) argumentando que las constantes $K$ y a de la ecuación MKHS dependen fuertemente de la polidispersidad de las muestras, especialmente el valor de la constante $K$, comentando que cuando la polidispersidad es elevada el valor de $K$ es subestimado y como resultado se sobreestima el peso molecular. Una manera de sustentar la correcta estimación del peso molecular viscosimétrico sería la obtención del peso molecular promedio e índice de polidispersidad mediante cromatografía GPC o por dispersión de luz.

\subsection{Modelización de la quitina como una macromolécula flexible.}

La rigidez de cadena de la quitina fue analizada en términos de la Teoría de Yamakawa y Fujii (YF) (Yamakawa H. et al., 1974) (5.7), a partir de valores de viscosidad intrínseca calculados con los parámetros de MHKS en DMAC/CILi $5 \%$ a $25 \stackrel{\circ}{\circ}$ reportados en la literatura 
(Terbojevich M. et al., 1988; Terbojevich M. et al., 1996; Poirier M. et al., 2002) tal como se detallan en la tabla 6.3.

\begin{tabular}{ccccc}
\hline $\boldsymbol{K}(\mathbf{m l} / \mathbf{g})$ & $\boldsymbol{a}$ & $\mathbf{M}_{\mathrm{w}}(\mathbf{g} / \mathbf{m o l})$ & {$[\eta](\mathbf{m l} / \mathbf{g})$} & Referencia \\
\hline 0,24 & 0,69 & $0,51.10^{6}$ & 2100 & (Terbojevich M. et al., 1988) \\
0,021 & 0,88 & $1,2.10^{6}$ & 4700 & (Terbojevich M. et al., 1996) \\
0,0076 & 0,95 & $0,71.10^{6}$ & 2700 & (Poirier M. et al., 2002) \\
\hline
\end{tabular}

Tabla 6.3. Parámetros de MHKS reportados en la literatura, valores máximos de masa molar y viscosidad intrínseca para quitina en DMAC/CILi.

Primeramente fue calculada la masa molar a partir del valor de viscosidad intrínseca estimada por extrapolación en el rango de validez de Terbojevich y colaboradores (Terbojevich M. et al., 1988; Terbojevich M. et al., 1996) (T1988 y T1996 respectivamente) y Poirier y colaboradores (Poirier M. et al., 2002) (P2002) (figura 6.7). Se hallaron valores de $M_{v(T 1988)}=3,07 \cdot 10^{6} \mathrm{~g} \cdot \mathrm{mol}^{-1}$ y $M_{v(P 2002)}=1,96 \cdot 10^{6} \mathrm{~g} \cdot \mathrm{mol}^{-1}$ respectivamente. Además se encontró

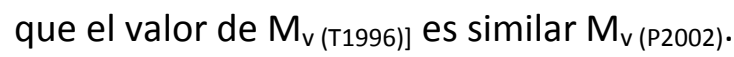

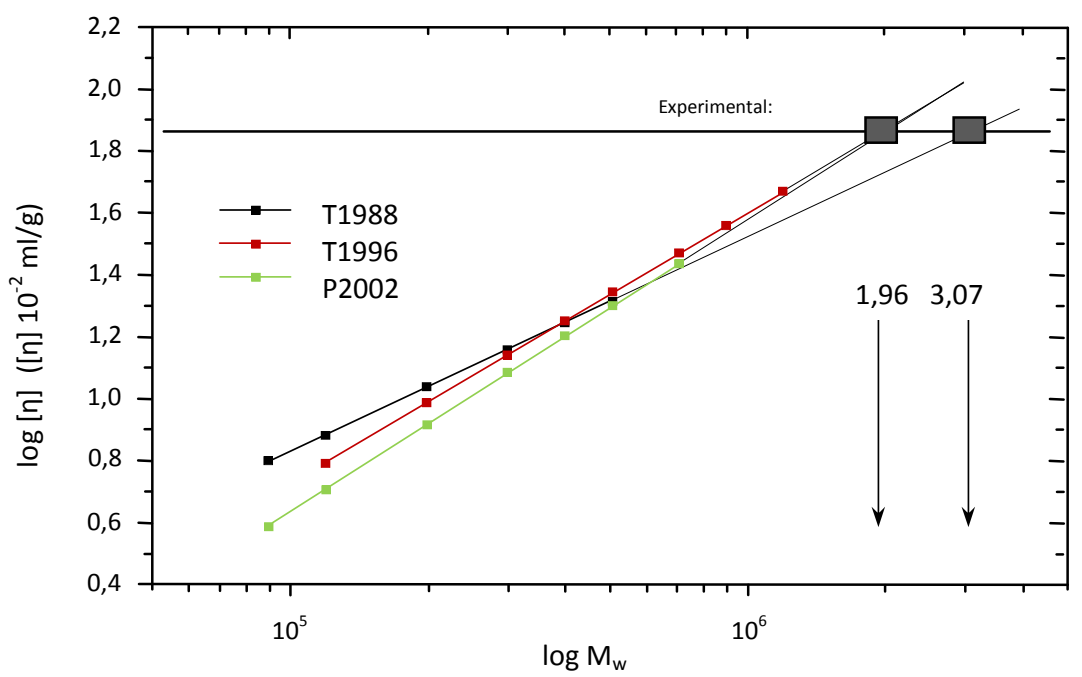

Figura 6.7. Masa molar de $\beta$-quitina de pluma de calamar calculada a partir de los set de parámetros MHKS citados en tabla 6.3. 
Utilizando los parámetros hallados por Terbojevich y colaboradores (Terbojevich M. et al., 1988) se realizaron cálculos de viscosidad intrínseca como función de la longitud de persistencia $(q)$ para pesos moleculares viscosimétricos $\left(M_{\mathrm{v}}\right)$ del orden de $3.10^{6} \mathrm{~g} / \mathrm{mol}$ (entre los límites $M_{\text {inf }}=3,0 \cdot 10^{6} \mathrm{~g} / \mathrm{mol}$ y $M_{\text {sup }}=3,2 \cdot 10^{6} \mathrm{~g} \cdot \mathrm{mol}$, obtenidos experimentalmente a partir de las incertezas en la viscosidad intrínseca). La gráfica de las mismas (figura 6.8.) son curvas crecientes debido a que la $[\eta]$ crece con $q$. Posteriormente se determinó un rango de valores de $q$ compatibles con la $[\eta]$ por intersección de dichas curvas con valores constantes

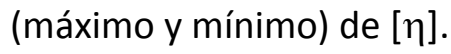

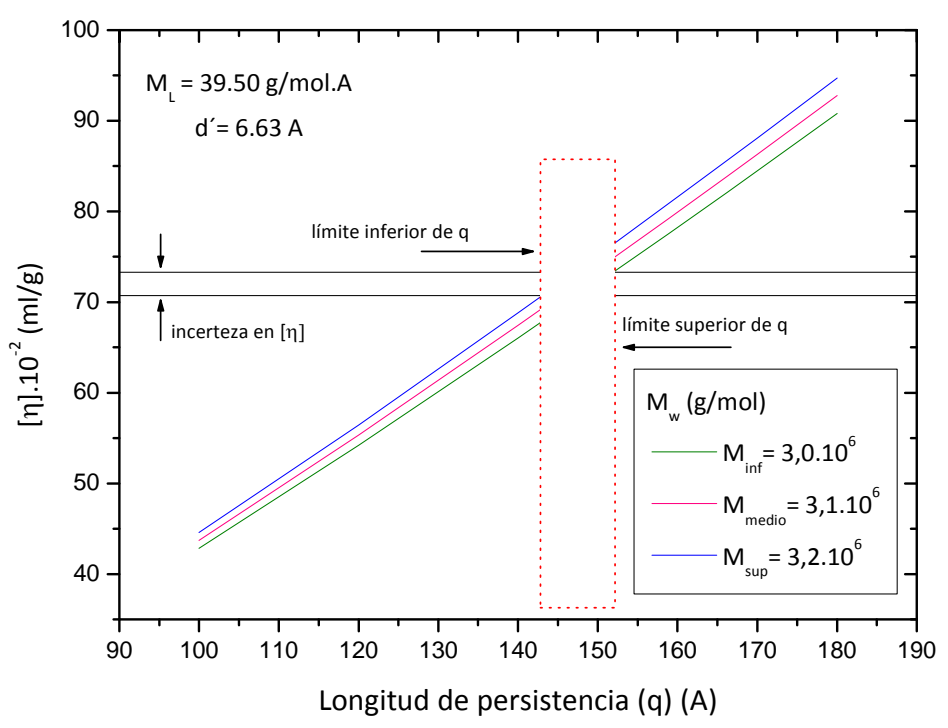

Figura 6.8. Longitud de persistencia (q) en función de la viscosidad intrínseca de acuerdo a los parámetros obtenidos por Terbojevich y colaboradores (Terbojevich M. et al., 1988).

De acuerdo a los valores de viscosidad intrínseca y eligiendo los parámetros estructurales de $\beta$-quitina de $M_{L}=39,5 \mathrm{~g} / \mathrm{mol} . \AA ̊$ (ecuación 5.9), $d^{\prime}=6,63 \AA$ (ecuación 5.10) se determinó una longitud de persistencia $q=145 \pm 5 \AA$ (figura 6.9.). Este valor es coincidente con el hallado por Terbojevich y colaboradores (Terbojevich M. et al., 1988) para masas molares menores que $0,51.10^{6} \mathrm{~g} / \mathrm{mol}$, lo que permitiría inferir la validez de la extrapolación de estos parámetros y descartar la existencia de agregados responsables de la elevada viscosidad intrínseca medida ( $7200 \mathrm{ml} / \mathrm{g}$ ). 


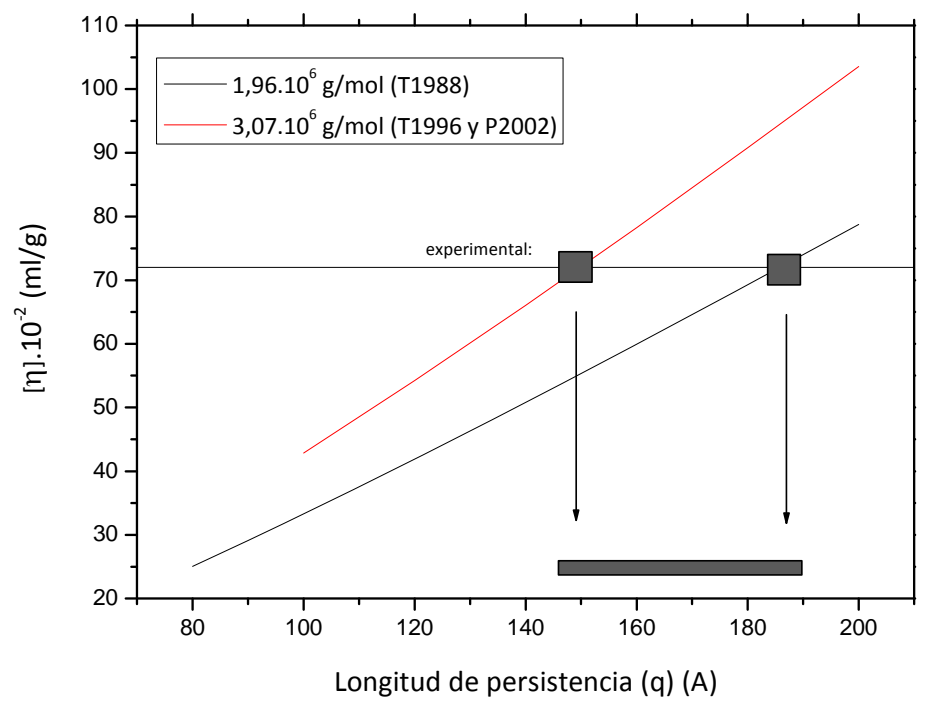

Figura 6.9. Longitud de persistencia (q) de la $\beta$-quitina de pluma de calamar en función de la viscosidad intrínseca a partir de los set de parámetros MHKS citados en tabla 6.3.

Poirier y Charlet (Poirier M. et al., 2002) obtuvieron fracciones de quitina con un índice de polidispersidad angosto $(1,3-1,4)$ y grado de acetilación $90-92 \%$ a partir de una extracción por coacervación en DMAC/CILi $5 \%$ a $30^{\circ} \mathrm{C}$. Dichos autores reportaron una set alternativo de parámetros MHKS válidos para masas molares de hasta $710.10^{3} \mathrm{~g} / \mathrm{mol}$ (correspondiente $a[\eta] \sim 2730 \mathrm{ml} / \mathrm{g}$ ). Utilizando estos parámetros el peso molecular de la $\beta$ quitina de pluma de calamar se reduce a $\mathrm{M}_{\mathrm{v}}=1,96.10^{6} \mathrm{~g} / \mathrm{mol}$ y la longitud de persistencia aumenta a $q=190 \pm 5 \AA$ (figura 6.9.). Valores casi similares tanto para $\mathrm{M}_{\mathrm{v}}$ como para $q$ fueron obtenidos mediante el uso de un segundo set de parámetros MHKS determinados por Terbojevich y colaboradores (Terbojevich M. et al., 1996) a partir de un mayor número de muestras y con diferentes técnicas de fraccionamiento que en (Terbojevich M. et al., 1988).

Lamarque y colaboradores (Lamarque G. et al., 2004) analizaron por viscosimetría muestras de $\beta$-quitina con $90 \% \mathrm{DA}$, reportando dos valores diferentes de pesos moleculares: $\mathrm{Mv}_{(\mathrm{T} 1988)}=1,34.10^{6} \mathrm{~g} / \mathrm{mol}$ y $\mathrm{Mv}_{(\mathrm{T} 1996)}=1,01.10^{6} \mathrm{~g} / \mathrm{mol}$ según el set de parámetros $\mathrm{MHKS}$ utilizados (T1988 o T1996 respectivamente). Aplicando la teoría YF a estos datos, encontramos una longitud de persistencia de $145 \AA$ o $170 \AA ̊$, respectivamente, demostrando una misma tendencia que para las muestras analizadas en esta tesis. 
Utilizando los parámetros MHKS de Poirier y colaboradores (Poirier M. et al., 2002) se obtiene un $\mathrm{Mv}=1,07.10^{6} \mathrm{~g} / \mathrm{mol}$ y $q=165 \AA$, valores cercanos a las predicciones realizadas para (Terbojevich M. et al., 1996), tal como se observa en la figura 6.10.

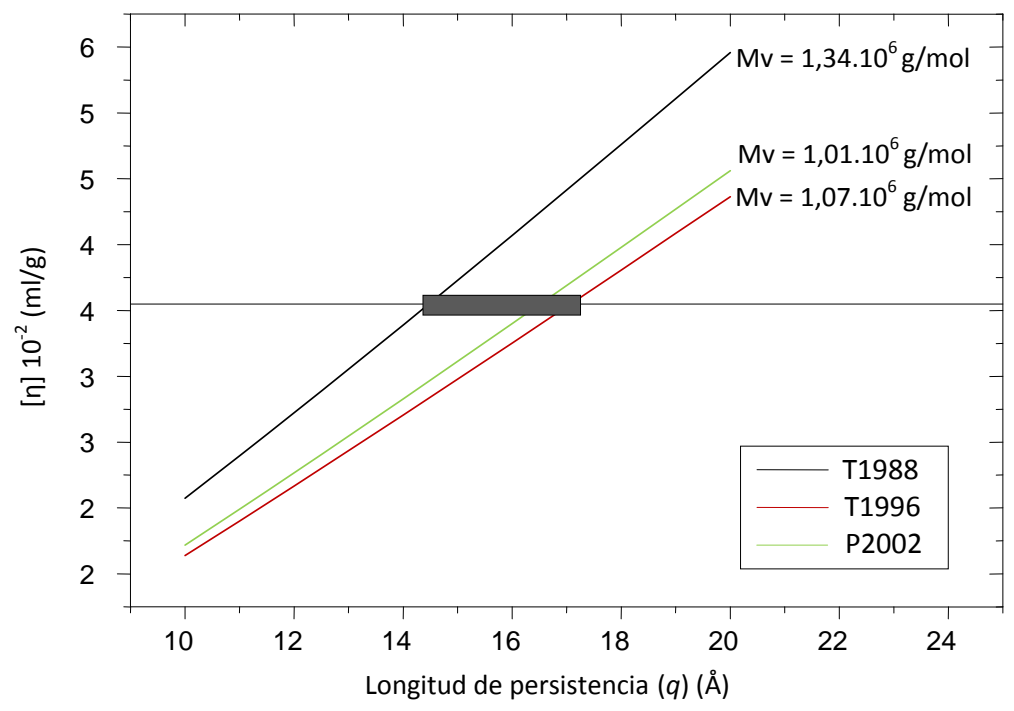

Figura 6.10. Longitud de persistencia (q) de muestras de $\beta$-quitina con $90 \%$ DA obtenidas por Lamarque y colaboradores (Lamarque G. et al., 2004) analizadas en función de la viscosidad intrínseca a partir de los set de parámetros MHKS citados en tabla 6.3.

Por otra parte Mazeau y Rinaudo (Mazeau K. et al., 2004) estimaron la longitud de persistencia a partir de cálculos por modelado conformacional de polisacáridos en solución y en estado sólido. Dichos autores reportan un valor límite de longitud de persistencia de 125 Å para quitina $100 \%$ acetilada. Esta cota está por debajo de las predicciones de la teoría YF para la viscosidad intrínseca usando los parámetros MHKS actuales en experimentos independientes de viscometría capilar.

Una apropiada caracterización de $\beta$-quitina requerirá discernir entre los conjuntos de parámetros MHS, a partir de medidas independientes de la longitud de persistencia con experimentos de dispersión de luz o rayos $X$. 


\section{CARACTERIZACIÓN DEL QUITOSANO OBTENIDO}

\subsection{Caracterización estructural del quitosano y determinación del grado de acetilación.}

En la figura 6.11. se muestra el espectro infrarrojo del quitosano obtenido. Las porciones más significativas del espectro corresponden a bandas características en $U_{\mathrm{OH}}$ y $U_{\mathrm{NH}}$ $3373 \mathrm{~cm}^{-1}, U_{\mathrm{C}-\mathrm{H}} 2924$ y $2841 \mathrm{~cm}^{-1}$. También se observan bandas características de las amidas a $U_{\mathrm{C}=\mathrm{O}} 1153 \mathrm{~cm}^{-1}$ (tensión antisimétrica del puente C-O-C) y $U_{\mathrm{C}-\mathrm{H}}(\mathrm{C}-\mathrm{N}-\mathrm{H})+\delta_{\mathrm{N}-\mathrm{H}} 1556 \mathrm{~cm}^{-1}$ (Amida II) a $v_{\mathrm{C}=\mathrm{O}} 1640 \mathrm{~cm}^{-1}$ (Amida I) y $v_{\mathrm{C}-\mathrm{N}}+\delta_{\mathrm{N}-\mathrm{H}} 1316 \mathrm{~cm}^{-1}$ (Amida III), así como bandas a $\delta_{\mathrm{C}-\mathrm{H}} 1466-$ $1377 \mathrm{~cm}^{-1}$ (del grupo CH2) y bandas a $U_{\mathrm{C}-\mathrm{O}} 1078 \mathrm{~cm}^{-1}, 1032 \mathrm{~cm}^{-1}, 1105 \mathrm{~cm}^{-1}$ (asignadas a modos de vibración de estiramiento C-O-C y C-O propias del esqueleto piranósico). Todas las bandas nombradas permiten corroborar la funcionalidad típica del quitosano.

En comparación con el espectro de la $\beta$-quitina (figura 6.3.) se observa como la banda a $1656 \mathrm{~cm}^{-1}$ disminuye a menores longitudes de onda mientras que aquella ubicada a 1560 $\mathrm{cm}^{-1}$ incrementa su valor, indicación de la prevalencia de grupos $\mathrm{NH}_{2}$.

La evaluación del grado de acetilación fue realizada mediante la integración de las bandas localizadas a $1316 \mathrm{~cm}^{-1}$ (banda característica correspondiente a la amida III) y 1456 $\mathrm{cm}^{-1}$ como banda de referencia, de acuerdo a la correlación (2.2) expuesta por Brugnerotto y colaboradores (Brugnerotto J.et al., 2001a):

$$
\operatorname{DA}(\%)=31,92\left(\mathrm{~A}_{1316} / \mathrm{A}_{1456}\right)-12,20
$$

El grado de acetilación porcentual (DA\%) resultante es de 7,4 \%. El valor hallado es consistente con aquellos obtenidos por Chandumpai y colaboradores (Chandumpai A. et al., 2004) bajo similares condiciones de reacción. Dichos autores determinan el DA en valores cercanos a $\operatorname{los} 7,5$ y $20 \%$. 


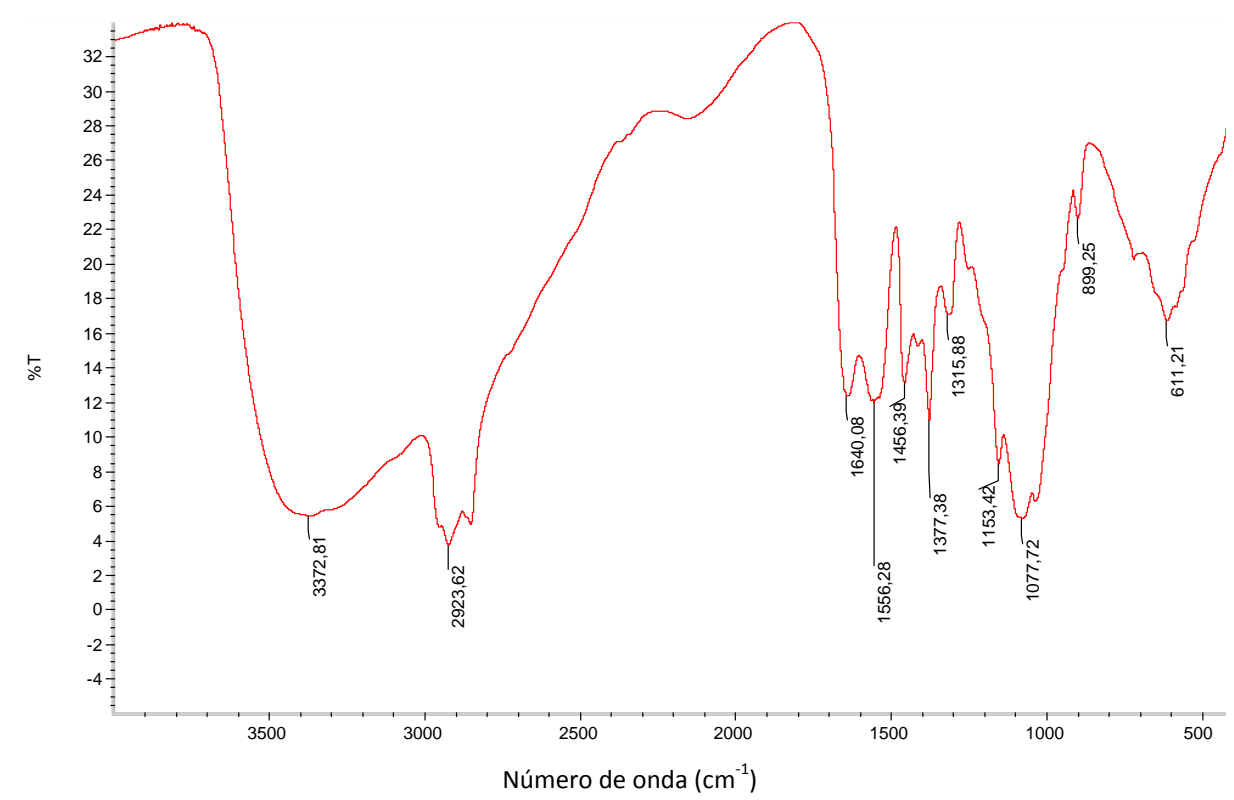

Figura 6.11. Espectro FTIR del quitosano obtenido.

Las similitudes o diferencias entre los valores reportados con los hallados en esta tesis pueden ser atribuidas no sólo a las diferentes condiciones de desacetilación utilizadas sino también debido a las diferencias en materia prima (fuentes de quitina), composición y dimensiones de la cadena.

Puede considerarse que las condiciones de desacetilación utilizadas durante la obtención de quitosano ( $\mathrm{NaOH} 50 \%$ p/v a 40 으, durante 48 hs. en una relación 1 gramo de quitina: $20 \mathrm{ml}$ de $\mathrm{NaOH}$ con agitación mecánica, en atmósfera de nitrógeno y con recirculación de vapores por medio de una columna de reflujo) son el principal factor que determina el valor hallado en esta tesis permitiendo la gran extensión de la desacetilación y evitando la degradación del polisacárido.

En relación a la materia prima utilizada, distintos valores de DA han sido reportados a partir de quitosanos obtenidos de $\beta$-quitina de pluma de diferentes fuentes de calamares, como ejemplo se puede citar a Tolaimate y colaboradores (Tolaimate A. et al., 2000; Tolaimate A. et al., 2003) y Methacanon y colaboradores (Methacanon P. et al., 2003). Dichos autores hallan un valor de DA\% de entre 1 - $4 \%$ para muestras desacetiladas de quitina de calamar Loligo vulgaris y 5 - 16\% para muestras de Loligo formosana respectivamente. 
Por último las discrepancias pueden deberse al método utilizado para determinar el grado de acetilación. Brugnerotto y colaboradores (Brugnerotto J. et al., 2001a) comentan que la titulación así como la espectroscopia $\mathrm{RMN}$ en estado líquido son válidas para materiales perfectamente solubles mientras que el análisis elemental, si bien es conveniente es menos preciso. Un claro ejemplo se puede observar en los valores hallados por Rhazi y colaboradores (Rhazi M. et al., 2000) mediante técnicas potenciométricas y por espectroscopia ${ }^{1} \mathrm{H}$ RMN así como también Abdou y colaboradores (Abdou E. et al., 2008) mediante potenciometría, análisis elemental, espectroscopia ${ }^{1} \mathrm{H}-\mathrm{RMN}$ y por espectroscopia IR. Además en caso de que la metodología utilizada fuera, espectroscopia IR, se conoce que el valor de DA se halla en estrecha relación con las líneas de base utilizadas para realizar dicho cálculo. En el caso de esta tesis se realizó la determinación del DA mediante espectroscopia IR de acuerdo a la correlación de bandas expuesta por Brugnerotto y colaboradores (Brugnerotto J. et al., 2001a) por considerarla acertada independientemente de la fuente, el grado de acetilación y pureza y solubilidad del polímero.

\subsection{Propiedades del quitosano en solución.}

\subsubsection{Evaluación del peso molecular promedio viscosimétrico del quitosano.}

La viscosidad intrínseca del quitosano en buffer ácido acético 0,3 M /acetato de sodio $0,2 \mathrm{M}$ a $25 \pm 0,1$ 으 fue determinada gráficamente (figura 6.12.) de manera similar a la indicada para la quitina, de acuerdo con las relaciones de viscosidad de Huggins y Kramer (ecuaciones (2.9) y (2.10) respectivamente) y posterior cálculo del promedio de la intersección en ordenadas de las dos extrapolaciones.

La representación gráfica y conjunta de la viscosidad inherente y reducida en función de la concentración de polímero presentó el comportamiento lineal esperado dentro del rango de concentración utilizado para las medidas viscosimétricas $(0,1<c<0,3 \mathrm{mg} / \mathrm{ml})$. 


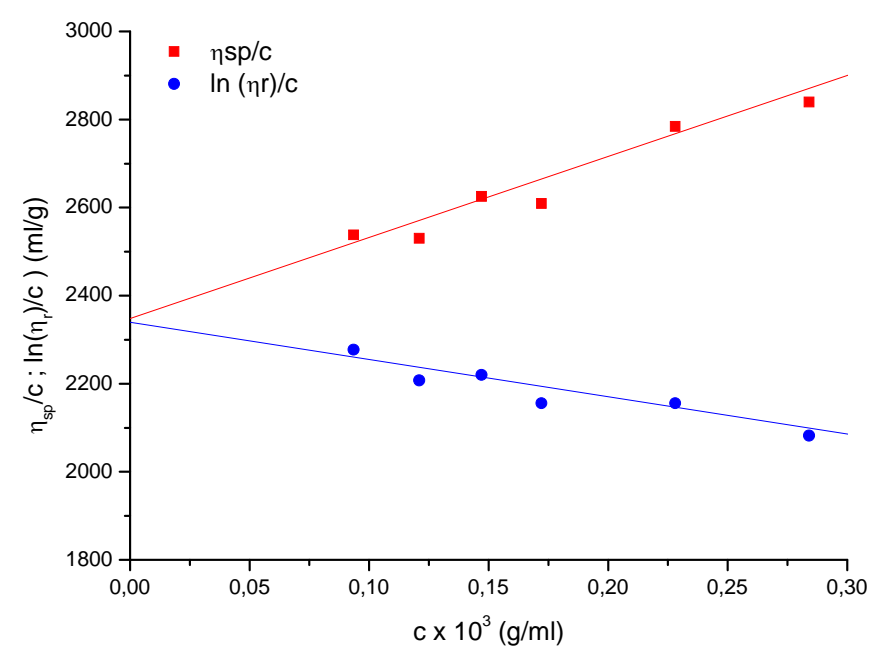

Figura 6.12. Viscosidad intrínseca del quitosano obtenido en buffer $\mathrm{AcH} 0,3 \mathrm{M} / \mathrm{AcNa} 0,2 \mathrm{M}$ a 25ㅇ $\mathrm{C}$ en función de la concentración.

La viscosidad intrínseca fue estimada en un valor de $[\eta]=2343 \mathrm{ml} / \mathrm{g}$. Los coeficientes de Huggins y Kramer fueron de $k_{H}=0,32 k_{K}=-0,16$ respectivamente. La diferencia entre ambos coeficientes fue de 0,48 . Dicho valor es consistente con los esperados para esta relación.

El valor calculado de la constante de Huggins $\left(\mathrm{k}_{\mathrm{H}}\right)$, que aporta información de la forma de las moléculas y de la calidad del solvente, fue de 0,32. Dicho valor se halla en coincidencia con lo dicho por Park y colaboradores (Park J. et al., 1983), que plantean que $\mathrm{k}_{H}$ posee un valor de 0,35 en un buen solvente. Así el buffer $\mathrm{AcH}$ 0,3 M/AcNa 0,2M utilizado es un buen solvente para el quitosano.

El peso molecular promedio viscosimétrico calculado fue de $M_{v}=779500 \mathrm{~g} \cdot \mathrm{mol}^{-1}$ de acuerdo a los parámetros $K$ y $a$ de la ecuación de MHKS (5.14) propuestos por Rinaudo y colaboradores (Rinaudo M. et al., 1993). Todas las muestras estudiadas evidenciaron un comportamiento similar. Si bien no puede realizarse una comparación precisa con la información de la literatura debido a la diversidad de la distribución de grupos acetilo y pesos moleculares, el valor hallado es elevado y muestra que tanto las condiciones de aislamiento y purificación de quitina como las de obtención de quitosano preservaron la estructura original del polisacárido, evitando la degradación. 
Con el fin de constatar que las concentraciones utilizadas medidas por viscosimetría capilar fueron realizadas en régimen diluido se efectuó una comparación con muestras de alto peso molecular, de origen comercial (Sigma Aldrich, DA 21\% determinado por FTIR y Mv $511000 \mathrm{~g} / \mathrm{mol})$. Se realizó la representación gráfica de la viscosidad específica $\left(\eta_{\text {sp }}\right)$ en función de la concentración C[n] (figura 6.13.) a partir de la Ecuación de Huggins (2.9) (Carreau P.et al., 1997):

$$
\frac{\eta_{\mathrm{sp}}}{\mathrm{c}}=[\eta]_{H}+k_{H}[\eta]_{H}^{2} c
$$

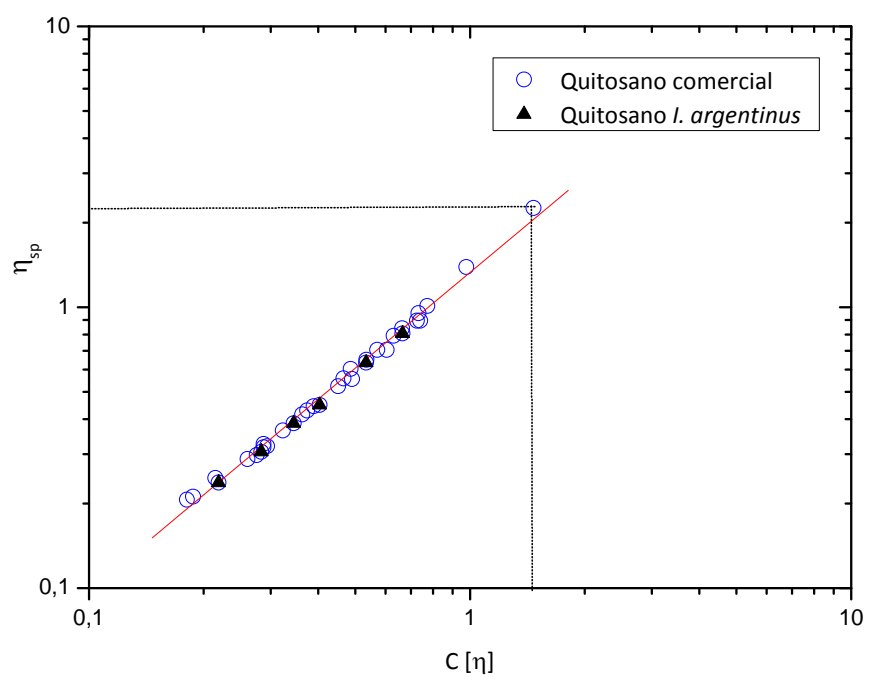

Figura 6.13. Gráfica log-log de la dependencia de la viscosidad especifica como función del parámetro de solapamiento $C[\eta]$ para el quitosano obtenido en esta tesis y quitosano comercial.

Como se comentó previamente dicha ecuación presenta un comportamiento lineal en la zona diluida y se aleja de ésta en el régimen semidiluido. De este modo fue hallada $C^{*}$ para las muestras de Illex argentinus en un valor de $6,2 \cdot 10^{-4} \mathrm{~g} / \mathrm{ml}$ y en $2,25.10^{-3} \mathrm{~g} / \mathrm{ml}$ para el caso del quitosano de origen comercial, como el valor de la pendiente en la cual se desvía en uno de la expresión de Huggins de acuerdo a la aproximación utilizada por Desbrières (Desbrières J., 2002).

La diferencia entre los valores obtenidos de $C^{*}$ respecto a los datos bibliográficos reportados puede explicarse como debida no sólo a los diferentes métodos de obtención de los datos viscosimétricos (viscosimetría capilar o rotacional) y a las diferentes aproximaciones 
utilizadas por los distintos autores sino también a las diferencias en materia prima de quitosano y fuerza iónica de los solventes utilizados para dichas mediciones. Desbrières (Desbrières J., 2002) a partir de soluciones de quitosanos de origen comercial (Mv =193000 $\mathrm{g} / \mathrm{mol}$ y $0,12 \mathrm{DA}$ ) en $\mathrm{AcH} 0,3 \mathrm{M} / \mathrm{AcNa} 0,2 \mathrm{M}$ a 25 o $\mathrm{C}$ realizó un análisis por viscosimetría capilar y rotacional en régimen diluido. Dicho autor halló valores de $C^{*}$ en $1,5.10^{-3} \mathrm{~g} / \mathrm{ml}$, con $\mathrm{C}[\eta]$ cercano a 1,07 y $[\eta]=1013 \mathrm{ml} / \mathrm{g}$ (utilizando $\mathrm{k}_{\mathrm{H}}$ de 0,45 ). Por otro lado Gartner y colaboradores (Gartner, C. et al., 2010) realizaron medidas de viscosidad en función del gradiente de velocidad a por reometría rotacional a $25{ }^{\circ} \mathrm{C}$ con quitosanos de origen comercial Aldrich (Mw de 226 kD y 30 \% DA) en ácido acético 0,3M y diferentes fuerzas iónicas. Mediante la aproximación de Dobrynin obtuvieron valores de $\mathrm{C}^{*}=2,1.10^{-3} \mathrm{~g} / \mathrm{ml}$ y a partir de la aproximación de Carreau un valor de $\mathrm{C}^{*}=1,2 \cdot 10^{-3} \mathrm{~g} / \mathrm{ml}$.

\subsubsection{Medidas de quitosano por reometría rotacional.}

En la tabla 6.4. se reportan los parámetros del Modelo de Cross (Cross M., 1965) de la ecuación 5.15 , hallados a $25^{\circ} \mathrm{C}$ en un rango de concentración de 0,5 y 1 \% p/v para soluciones de quitosano comercial y 0,25 y $0,5 \%$ para soluciones del quitosano obtenido en esta tesis.

$$
\eta=\frac{\eta_{o}}{1+\left[t_{1} \dot{\gamma}\right]^{(1-n)}}
$$

\begin{tabular}{ccccc}
\hline Quitosano & $\mathrm{C}(\% \mathrm{p} / \mathrm{v})$ & $\eta_{\mathrm{o}}$ (Pa.s) & $\mathrm{t}_{1}$ (seg.) & $1-\mathrm{n}$ \\
\hline $\begin{array}{c}\text { IIlex argentinus } \\
(\mathrm{Mv}=779500 \mathrm{~g} / \mathrm{mol})\end{array}$ & 0,25 & 0,018 & 0,0002 & 0,483 \\
$\begin{array}{c}\text { Comercial } \\
(\mathrm{Mv}=511000 \mathrm{~g} / \mathrm{mol})\end{array}$ & 0,50 & 0,232 & 0,0090 & 0,654 \\
\hline
\end{tabular}

Tabla 6.4. Parámetros del Modelo de Cross para soluciones de quitosano en AcH 1\% v/v obtenido por desacetilación y de origen comercial. 
Se observó un comportamiento no newtoniano pseudoplástico para todas las soluciones en el rango de mediciones realizadas (figura 6.14.). Las mediciones ponen en evidencia el efecto del peso molecular y la concentración sobre el comportamiento reológico del sistema.Con respecto al valor de la viscosidad a gradiente cero $\left(\eta_{0}\right)$ se observa que a medida que el peso molecular aumenta también lo hace la viscosidad. El tiempo característico $\left(t_{1}\right)$ tiene una respuesta similar en el rango de concentraciones utilizadas. El valor de la pendiente (1-n) en la región lineal está de acuerdo a los generalmente obtenidos para soluciones de quitosanos.

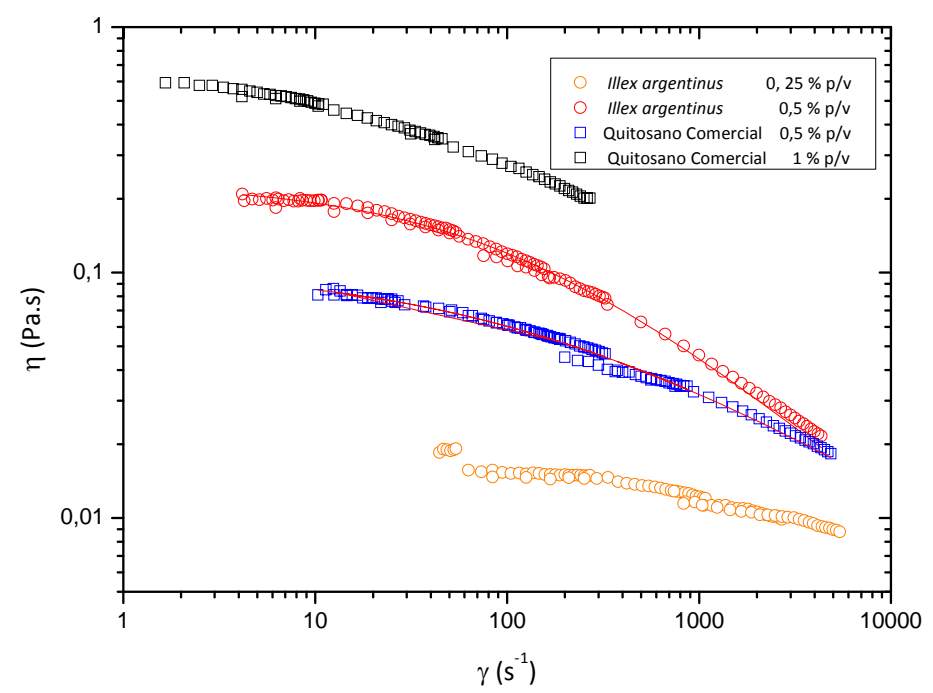

Figura 6.14. Efecto de la concentración sobre la viscosidad para soluciones de quitosano obtenido en esta tesis (Illex argentinus) y quitosano comercial (Aldrich).

La dependencia de la $\eta$ con la concentración del quitosano fue estudiada por Desbrières (Desbrières J., 2002) y Mucha (Mucha M., 1997) entre otros. Mucha (Mucha M., 1997) presenta resultados de la caracterización reológica de quitosanos de bajo peso molecular con distintos grados de acetilación en $\mathrm{AcH}$, en un rango de concentración de 0,5$5 \%$ y temperaturas entre 20 y $41^{\circ} \mathrm{C}$. Muestra que la pendiente de la relación $\eta$ versus $\dot{\gamma}$ (Ley de potencia) disminuye con el aumento del peso molecular y la concentración del quitosano, pero que aumenta con el aumento de la temperatura. Dicha autora reporta que la concentración es el efecto que más importancia ejerce sobre el gradiente y la viscosidad de las soluciones, ya que ambos se incrementan con el aumento de la concentración 
(aumentando más rápido la viscosidad que la concentración), lo que se corresponde al aumento progresivo de "entanglements" entre las cadenas macromoleculares.

Por su parte, Hwang y colaboradores (Hwang J. et al., 2000) a partir de quitosanos de $\alpha$-quitina con $\mathrm{Mw}=1,71 \cdot 10^{6} \mathrm{~g} / \mathrm{mol}([\eta]=1454 \mathrm{ml} / \mathrm{g}$ en $0,1 \mathrm{M} \mathrm{NaCl} / 0,1 \mathrm{M} \mathrm{AcH})$ evaluaron la dependencia de la viscosidad versus el gradiente en un rango de concentraciones de entre 0,25 a 2,5\%. Dichos autores observaron que el comportamiento pseudoplástico es más pronunciado para soluciones concentradas de quitosano debido al aumento en los "entanglements" a gradiente elevado.

Wang y colaboradores (Wang W. et al., 1994) agregan que el carácter no newtoniano aumenta con el aumento del grado de desacetilación (DD) debido a la estructura expandida de las cadenas y al aumento de "entanglements".

Martínez-Ruvalcaba y colaboradores (Martínez-Ruvalcaba A. et al., 2004) estudiaron la influencia de la concentración, temperatura, el tipo de ácido utilizado y la adición de sal sobre las propiedades reológicas de soluciones concentradas de quitosanos de origen comercial $\left(\mathrm{Mw}=1,08.10^{6} \mathrm{~g} / \mathrm{mol}\right.$ y $\mathrm{DD}$ de $25 \%$ ) para un rango de concentraciones entre $0,5 \mathrm{y}$ $2 \% \mathrm{p} / \mathrm{p}$. El análisis de dichas mediciones fue realizado mediante el Modelo de Cross. Dichos autores plantean que las soluciones de quitosano presentan un comportamiento pseudoplástico relacionado con las elevadas fuerzas intermoleculares por puentes de hidrógeno incluso a baja concentración, debido a la tendencia del quitosano a la formación de "entanglements". Hallaron que la viscosidad aumenta en función del aumento de la concentración, por la aparición de interacciones intermoleculares, y disminuye con el aumento de la temperatura. 
VI.

Conclusiones,

Recomendaciones

$y$

Perspectivas. 


\section{CONCLUSIONES, RECOMENDACIONES Y PERSPECTIVAS}

\section{CONCLUSIONES}

A lo largo de la literatura disponible el énfasis principal está en la calidad y propiedades físico-químicas de quitina y quitosano, que varían ampliamente con las diferentes fuentes de quitina y métodos de preparación.

Con el fin de ofrecer una alternativa para el procesamiento de la pluma de calamar generado en las zonas pesqueras del Mar Argentino, para obtener quitina y quitosano de alta calidad, se adecuaron las condiciones de aislamiento y purificación de la $\beta$-quitina a partir de la pluma del calamar Illex argentinus, el cual no ha sido reportado como materia prima para la obtención de los mencionados polímeros. Las condiciones se llevaron a cabo de modo de preservar la estructura original del polisacárido y evitando así su posible degradación.

Mediante la aplicación de las técnicas de ${ }^{13} \mathrm{C}-\mathrm{RMN} \mathrm{CP} / \mathrm{MAS}$ en estado sólido, espectroscopia IR y estudios de difracción de rayos $X$ se logró caracterizar estructuralmente la $\beta$-quitina aislada, la cual presentó tanto un alto grado de acetilación (96\%) como un elevado grado de cristalinidad (74,9\%) en acuerdo con $\beta$-quitina aisladas de otras especies de calamares. Estas determinaciones se complementaron medidas de viscosimetría capilar en DMAC/ClLi 5\%, lo que permitió estimar un alto peso molecular promedio viscosimétrico (superior a $2 \cdot 10^{6} \mathrm{~g} / \mathrm{mol}$ ).

Los requerimientos de cristalinidad, peso molecular promedio y grado de acetilación tienen importancia sobre las propiedades finales y aplicaciones de la macromolécula, y pueden variar en función de la aplicación deseada. Se considera que la $\beta$-quitina aislada tiene una calidad equiparable con la quitina comercial disponible.

La longitud de persistencia estimada para la $\beta$-quitina mediante la teoría de YF se halla en el rango 145 a $190 \AA$, dependiendo de los parámetros MKHS utilizados. Estas discrepancias también se encontraron en otros autores. Los resultados de este estudio contribuyen al entendimiento de la rigidez y la conformación de quitina en solución.

Se obtuvo quitosano partir de la $\beta$-quitina aislada por el método convencional de desacetilación. 
Las condiciones de desacetilación utilizadas son el principal factor que permiten la gran extensión de la desacetilación y evitan la degradación del polisacárido.

Empleando las metodologías que involucraron espectroscopia $I R$ y viscosimetría capilar en $\mathrm{AcH}$ 0,3 M/AcNa 0,2M se halla que el quitosano obtenido presenta una alta calidad debido a posee un elevado peso molecular promedio viscosimétrico $\left(\mathrm{M}_{\mathrm{v}}=779500\right.$ $\mathrm{g} / \mathrm{mol}$ ) y menor grado de acetilación (DA 7,4 \%) que el estándar de quitosano comercial obtenido a partir de crustáceos. El quitosano proveniente de calamar posee características valiosas para uso en aplicaciones biomédicas. Sin embargo es ambiguo concluir que el proceso utilizado es el óptimo para la producción de quitosano porque los intereses de las aplicaciones pueden variar de un estudio a otro e incluso de una aplicación a otra.

Mediante la realización de estudios reológicos se observó un comportamiento no newtoniano pseudoplástico y se puso en evidencia el efecto del peso molecular y la concentración sobre el comportamiento reológico del sistema.

\section{RECOMENDACIONES}

Para complementar este trabajo se sugiere realizar estudios más exhaustivos de propiedades en solución de quitina y quitosano mediante dispersión de luz así como por cromatografía GPC, ya que dichas medidas permitirían ampliar el conocimiento del comportamiento en solución de los biopolímeros.

Dado que el quitosano es un polielectrolito catiónico la evaluación de sus propiedades fisicoquímicas en solución no es sencilla, debido a que la mayoría de los métodos utilizados se ven afectados por fenómenos de asociación y adsorción como consecuencia de interacciones moleculares derivadas de este tipo de macromolécula. Esto trae como consecuencia un comportamiento hidrodinámico característico que lo diferencia de otros biopolímeros y polímeros sintéticos de naturaleza no iónica.

Teniendo en cuenta estas dificultades, es necesario disponer de muestras bien caracterizadas que puedan ser utilizadas como estándar. Esto significa obtener muestras de peso molecular bien definido, en un amplio rango de pesos moleculares, con distribución angosta y el mismo grado de acetilación. Esta última condición es sumamente importante a 
fin de garantizar el mismo comportamiento conformacional de las fracciones, ya que se ha demostrado que ciertos parámetros, relevantes a la calibración son fuertemente dependientes del grado de acetilación de las muestras. Una forma de obtener muestras que solo difieran en el peso molecular, sin modificar la estructura química de la macromolécula es mediante una degradación mecánica y por ultrasonido.

Asimismo se podría profundizar en el análisis reológico del quitosano acerca del efecto de la temperatura sobre las propiedades de soluciones más concentradas.

En vista de lo anterior, es recomendable que, a efectos de lograr la uniformidad y el control de la calidad del producto adecuado para el uso particular de quitosano, la relación entre los procesos de protocolo, las condiciones y las características específicas de los productos resultantes de quitosano sean monitoreados constantemente y correctamente.

\section{PERSPECTIVAS}

Argentina es un país con una riqueza de biomasa marina incalculable, pero lamentablemente este recurso se explota muchas veces irracionalmente, sin tomar en cuenta las implicaciones medio ambientales que esta genera. La industria pesquera en el procesamiento de recursos trae consigo un incremento en la cantidad de desechos que constituyen una fuente de contaminación ambiental. Sin embargo, existe la posibilidad de utilizar los desechos tales como exoesqueletos de crustáceos y pluma de calamar como fuentes de materia prima para producción de quitina. Teniendo en cuenta que la Argentina es el principal productor iberoamericano de calamar y a pesar de que la demanda de quitina y quitosano en el mercado argentino es aún pequeña, estamos en presencia de un mercado cautivo con perspectivas de crecimiento muy promisorias. Si bien en la actualidad la pluma de calamar no es la principal fuente de quitosano es un producto innovador y de calidad que puede ser fácilmente introducido al mercado argentino. 
VII.

Referencias Bibliográficas de la Sección A. 


\section{REFERENCIAS}

Abdou, E.S; Nagy, K.S.A.; Elsabee, M.Z. "Extraction and characterization of chitin and chitosan from local sources". Bioresource Technology, 99(5): 1359-1367 (2008).

Aiba, S. "Studies on chitosan: 1. Determination of the degree of $\mathrm{N}$-acetylation of chitosan by ultraviolet spectrophotometry and gel permeation chromatography". International Journal of Biological Macromolecules, 8(3): 173-176 (1986).

Aiba, S. "Studies on chitosan: 3. Evidence for the presence of random and block copolymer structures in partially $\mathrm{N}$-acetylated chitosans". International Journal of Biological Macromolecules, 13(1): 40-44 (1991).

Anthonsen, M. W.; Vårum, K. M.; Smisdrød, O. "Solution properties of chitosans: conformation and chain stiffness of chitosans with different degrees of $\mathrm{N}$-acetylation". Carbohydrate Polymers, 22(3): 193-201 (1993).

Aranaz,I.; Mengíbar,M.; Harris,R.; Paños, I.; Miralles, B.; Acosta, N.; Galed G.; Heras A. "Functional Characterization of Chitin and Chitosan". Current Chemical Biology, 3(2): 203230 (2009).

Arguelles-Monal W.; Goycoolea F.M.; Peniche C.; Higuera-Ciapara I. "Rheological study of the chitosan/glutaraldehyde chemical gel system". Polymer Gels and Networks, 6(6): 429440 (1998).

Argüelles-Monal, W.; Heras Caballero, A.; Acosta, N.; Galed, G.; Gallardo, A.;Miralles, B. "Caracterización de quitina y quitosano". En: Quitina y Quitosano: Obtención, caracterización y aplicaciones. Resultado del Proyecto CYTED IV.14: Obtención de quitina y quitosano a partir de desechos de crustáceos. Ed. Ana Pastor de Abram. Pontifica Universidad Católica de Perú/ Fondo Editorial. 105-144 (2004).

Arkhipkin,A. ; Perez,J.A.A. "Life-History reconstruction". En: Squid recruitment dynamics. "The genus Illex as a model. The commercial Illex species. Influences on variability". Rodhouse, P.G.; Dawe, E.G.; O’Dor R.K. (Eds.). FAO Fisheries Technical Paper. No.376. Rome. 157-180 (1998).

ASTM. F2103-01 "Standard guide for characterization and testing of chitosan salts as starting materials intended for use in biomedical and tissue-engineered medical product applications". (2001).

Austin, P.R. "Purification of chitin". US Patent 3,879,377(1975a). 
Austin, P.R. "Solvents for and purification of chitin". US Patent 3,892,731 (1975b).

Baxter, A.; Dillon, M.; Taylor, K.D.A;Roberts, G.A.F. "Improved method for infrared determination of the degree of $\mathrm{N}$-acetylation of chitosan". International Journal of Biological Macromolecules, 14(3): 166-169 (1992).

Berth, G.; Dautzenberg H. "The degree of acetylation of chitosans and its effect on the chain conformation in aqueous solution". Carbohydrate Polymers, 47(1): 39-51 (2002).

Billmeyer, F. W. Jr. Textbook of Polymer Science, John Wiley \& Sons, Inc. Carpenter, D. K.; Westerman, L. Chapter 7: "Viscosimetric methods of studying molecular weights and molecular weight distribution" . p 379-500. New York (1984).In: Polymer Molecular Weights. Part II. Ed. Slade, P.E. Jr. In. Techniques \& Methods of Polymer Evaluation. Vol.4. Marcel Dekker, Inc. New York (1975).

Bizikov, V.A. "Squid gladius: it use for the study of growth, age and intraespecies structure and evolution (on the example of the family Ommastrephidae)". Tesis doctoral, Inst. Oceanología, Acad. Ciencias URSS, Moscú, 513 pp. (En ruso, resumen en inglés). (1991a).

Bizikov, V.A. "A new method of squid age determination using the gladius". En: Squid age determination using statoliths. Jereb, P.; Ragonese, S. and Boletzki, S. V. (Eds.). N.T.R. I.T.P.P., Special publication, n. 1. Mazzara del Vallo, Italy, 39-51(1991b).

Blackwell, J.; Parker, K.D.; Rudall, K.M. "Chitin fibres of the diatoms Thalassiosira fluviatilis and Cyclotella cryptic". Journal of Molecular Biology, 28(2): 383-385 (1967).

Blackwell, J.; Weih, M.A. "Structure of chitin-protein complexes: Ovipositor of the Ichneumon fly Megarhyssa". Journal of Molecular Biology, 137(1): 49-60 (1980).

Braconnot, H. "Sur la Nature des Champignons". Annals of Chemistry and Physics, 79: 265-304 (1811).

Bradford M. "A rapid and sensitive method for the quantitation of microgram quantities of protein utilizing the principle of protein dye binding". Annals of Biochemistry, 72: 24854 (1976).

Brine, C.; Austin, P.R. "Chitin isolates: species variation in residual amino acids". Compilation of Biochemistry and Physiology, 70: 173-178 (1981). 
Brugnerotto, J.; Lizardi, J.; Goycoolea, F.M.; Argüelles Monal, W.; Desbriéres, J.; Rinaudo, M. "An infrared investigation in relation with chitin and chitosan characterization". Polymer, 42(8): 3569-3580. (2001a).

Brugnerotto, J.; Desbriéres, J.; Heux, L.; Mazeau, K. y Rinaudo, M. “Overview on structural characterization of chitosan molecules in relation with their behavior in solution". Macromolecular Symposia, 168(1): 1-20 (2001b).

Brunetti, N.E; Ivanovic M.L.; Elena B. "Calamares Omastréfidos (Cephalopoda, Ommastrephidae)". El Mar Argentino y sus recursos pesqueros, Tomo 2. Los moluscos de interés pesquero. Cultivos y estrategias reproductivas de bivalvos y equinoideos. Boschi, E.E. (Ed.). Publicaciones Especiales INIDEP, Mar del Plata, 37-68 (1998).

Brunetti, N.E.; Ivanovic, M.L.; Sakai, M. "Calamares de importancia comercial en Argentina. Biología, distribución, pesquerías, muestreo biológico". Instituto Nacional de Investigación y Desarrollo Pesquero (INIDEP), Mar del Plata, Argentina. 45p (1999).

Brzeski, M.M. "Concept of chitin/chitosan isolation from Antartic Krill (Euphasia superba) shells on a technical scale". Proceedings of the Second International Conference on Chitin and Chitosan. Hirano, S.; Tokura S. (Eds.). The Japan Society of Chitin and Chitosan, Sapporo, Japan, 1-15 (1982).

Caddy, J.F. "Cephalopods and demersal finfish stocks: some statistical trends and biological interactions". En: Squid 94 Venice, the $3^{\text {rd }}$ International Cephalopod Trade Conference proceedings, Dawe, E.G.; Warren, W.G. (Eds.).Agra Europe, London. 148-174 (1995).

Cárdenas, G.; Cabrera, G.; Taboada E.;Miranda, S.P. "Chitin Characterization by SEM, FTIR, XRD and ${ }^{13} \mathrm{C}$ Cross Polarization/Mass Angle Spinning NMR" Journal in Applied Polymeric Sciences, 93(4):1876-1885 (2004).

Carreau, P. J.; De Kee, D. C. R. y Chabra, P. R. "Rheology of polymeric systems: Principles and applications". Munich, Germany: Hanser Publishers, 52p. (1997).

Chandumpai, A.; Singhpibulporn, N.; Faroongsarng, D. y Sornprasit, P. "Preparation and physicochemical characterization of chitin and chitosan from the pens of the squid species, Loligo lessoniana and Loligo formosana". Carbohydrate Polymers, 58(4): 467-474 (2004).

Chaussard, G.; Domard, A. "New aspects of the extraction of chitin from squid pens". Biomacromolecules, 5(2): 559-564 (2004). 
Chen, B.; Sun, K.; Zhang K. "Rheological properties of chitin/lithium chloride, $\mathrm{N}, \mathrm{N}$ dimethyl acetamide solutions" Carbohydrate Polymers, 58(1): 65-69 (2004).

Chen, R. H.; Lin J. H.; Yang, M.J. "Relationships between the chain flexibilities of chitosan molecules and the physical properties of their cast films" Carbohydrates Polymers., 24: 41-46. (1994).

Chen, R. H.; Tsaih, M. L. "Effect of temperature on the intrinsic viscosity and conformation of chitosans in dilute $\mathrm{HCl}$ solution" International Journal of Biological Macromolecules., 23(2): 135-141 (1998).

Chen, Ch-H.; Wang, F-Y.; Ou, Z-P. "Deacetylation of $\beta$-Chitin. I. Influence of the Deacetylation Conditions". Journal of Applied Polymer Science, 93(5): 2416-2422 (2004).

Cho, J.; Heuzey, M.C.; Bégin, A.; Carreau, P.J. "Viscoelastic Properties of Chitosan Solutions: Effect of Concentration and Ionic Strength" Journal of Food Engineering, 74 (4):500-515 (2006).

Cölfen, H. Berth, G.; Dautzenberg H. "Hydrodynamic studies on chitosans in aqueous solution". Carbohydrate Polymers, 45(4): 373-383 (2001).

Cross, M.M. "Rheology of non-Newtonian fluids: A new flow equation for pseudoplastic systems" Journal of Colloid Science, 20(5): 417-437 (1965).

Desbrières J. "Viscosity of semiflexible chitosan solution: Influence of concentration, temperature, and role of intermolecular interactions". Biomacromolecules, 3(2): 342-349 (2002).

Dobrynin, A. V.; Colby, R. H.; Rubinstein, M. "Scaling Theory of Polyelectrolyte Solutions". Macromolecules, 28(6): 1859-1871(1995).

Domard, A. "Determination of $\mathrm{N}$-acetyl content of chitosan samples by circular dichroism measurements". International Journal of Biological Macromolecules, 9(6): 333-336 (1987).

Domszy, J.G.; Roberts, G.A.F. "Evaluation if infrared spectroscopic techniques for analysing chitosan". Die Makromolekulare Chemie, 186(8): 1671-1677(1985).

Duarte, M.L.; Ferreira, M.C.; Marvao, M.R.; Rocha, J. "Determination of the degree of

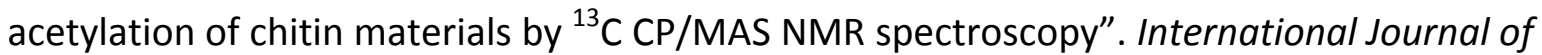
Biological Macromolecules, 28(5): 359-363 (2001). 
Dutta, K.P.; Ravi-Kumar, M.N.V.; Dutta, J. "Chitin and Chitosan for versatile applications". Journal of Macromolecular Science, 42(3): 307-354 (2002).

FAO. Review of the state of world marine fishery resources. FAO Fisheries Technical Paper. No. 457. Rome, FAO .Marine Resources Service, Fishery Resources Division. 235 p (2005).

Falini, G.; Fermani, S.; Ripamonti A. "Oriented crystallization of octacalcium phosphate into beta-chitin scaffold". Journal of Inorganic Biochemistry, 84(3-4): 255-258 (2001).

Focher, B.; Beltrame, P.L.; Naggi, A.; Torri, G. "Alkaline N-deacetylation of chitin enhanced by flash treatments. Reaction kinetics and structure modifications". Carbohydrate Polymers, 12(4): 405-418 (1990).

Focher,B.; Naggi, A; Torri, G; Cosani, A. ;Terbojevich, M. "Structural differences between chitin polymorphs and their precipitates from solutions-evidence from CP-MAS 13CNMR, FT-IR and FT-Raman spectroscopy" Carbohydrate Polymers., 17(2):97-102 (1992).

Folch, J.; Lees,M.; Stanley,G.H.S. "A simple method for the isolation and purification of total lipids from animal tissues". Journal of Biological Chemistry, 226: 497-509 (1957).

Gaill, F.; Persson, J.; Sugiyama, J.; Vuong, R.; Chanzy, H. "The chitin system in the tubes of deep sea hydrothermal vent worms". Journal of Structural Biology ,109(2):116-128 (1992).

García, I.; Peniche, C.; Nieto, J.M. "Determination of the Degree of Acetylation of Chitin and Chitosan by Thermal Analysis". Journal of Thermal Analysis, 28(1): 189-193(1983).

Gartner, C.; López, B.L."Medidas de la rigidez del quitosano en solución a través de la viscosidad intrínseca". Revista de la Facultad de Ingeniería Universitaria. Antioquia, 53: 20-29 (2010).

Gardner, K.H.; Blackwell, J. "Refinement of the Structure of $\beta$-chitin". Biopolymers, 14(8): 1581-1595 (1975).

Goycoolea, F.M.; Agulló, E.; Mato, R. "Fuentes y Procesos de Obtención". En: Quitina y Quitosano: Obtención, caracterización y aplicaciones. Resultado del Proyecto CYTED IV.14: Obtención de quitina y quitosano a partir de desechos de crustáceos. Ed. Ana Pastor de Abram. Pontifica Universidad Católica de Perú/ Fondo Editorial. p. 105-144 (2004).

Goycoolea F.M.; W. Arguelles-Monal; C. Pencihe, I.; Higuera-Ciapara. "Chitin and chitosan". En: Novel Macromolecules and Food Systems Developments in Food Science 
Series. D. G. Doxistakis and V. Kiosseoglou (Editores). Elsevier Science. pp. 267-305. (2000).

Goycoolea, F.M.; Higuera-Ciapara, I.; Hernandez, J.L.; García,K.D. "Preparation of chitosan from squid (Loligo spp) pen by a microwave- accelerated thermochemical process". En: Advances in Chitin Science. Domard, A.; Roberts, G.A.F., Vårum,K.M. (Eds.).Lyon: Jacques André.p.78-83 (1998).

Guinesi, L. y Cavalheiro, E. "The use of DSC curves to determine the acetylation degree of chitin/chitosan samples". Termochimica Acta, 444(2):128-33 (2006).

Guo, H-F. Lin H-L.; Yu, T. L. "Dilute solution properties of chitosan in propionic acid aqueous solutions". Journal of Macromolecular Sciences Part A Pure Applicated Chemistry, 39 A: 837-852 (2002).

Hackman, R.H. "Studies on Chitin: I.Enzymatic degradation of chitin and chitin esters" Australian Journal of Biological Sciences,7: 168-178 (1954)

Harding. S.E. "On the hydrodynamic analysis of macromolecular conformation". Biophysical Chemistry, 55: 69-93 (1995).

Harding,S.E. "The intrinsic viscosity of biological macromolecules. Progress in measurement, interpretation and application to structure in dilute solution". Progress in Biophysics and Molecular Biology, 68: 207-262 (1997).

Harding, S.E.; Vårum, K.M.; Stokke, B.T.; Smidrød, O. “Molecular weight determination of polysaccharides". En: Advances in Carbohydrate Analysis, Vol I, White, C.A. (Ed.). JAI Press, Birmingham. 63-144 (1991).

Heux, L.; Brugnerotto, J.; Desbrières, J.; Versali, M.-F.; Rinaudo, M. "Solid-State NMR for Determination of Degree of Acetylation of Chitin and Chitosan".Biomacromolecules,1(4): 746-751 (2000).

Hiemenz, P.C. "Polymer Chemistry-The Basic Concepts", Marcel Dekker,Inc. New. York and Bassel pp. Capítulo 2 "The viscous state" 75-87 (1984).

Hirano, S. "Chitin and chitosan as novel biotechnological materials". Polymer International, 48: 732-734 (1999).

Horton, D.; Lineback, D.R. "N-deacetylation: chitosan from chitin". En: Methods in Carbohydrate Chemistry. Whistler R. L.; Wolfrom M.L. (Eds). Academic Press, Nueva York, 403 (1965). 
Hunt, S.; El Sherief, A.A. "Periodic structure in the "pen" chitin of the squid Loligo vulgaris". Tissue \& Cell, 22(2):191-197 (1990).

Hunt, S.; Nixon, M. "A comparative study of protein composition in the chitin-protein complexes of the beak, pen, sucker disc, radula and oesophageal cuticle of cephalopods" Comparative Biochemistry and Physiology Part B: Comparative Biochemistry, 8(4): 535546 (1981).

Hwang, J. K.; Shin, H. H."Rheological properties of chitosan solutions". Korea-Australian Rheology Journal, 12(3/4): 175-179 (2000).

Jang, M-K.; Kong, B-G; Jeong, Y-I; Lee, C.H.; Nah, J-W. "Physicochemical characterization of $\alpha$-chitin, $\beta$-chitin, and $\gamma$-chitin separated from natural resources". Journal of Polymer Science Part A: Polymer Chemistry ,42(14): 3423-3432 (2004).

Jaworska, M.; Sakurai, K.; Gaudon, P. ; Guibal, E. "Influence of chitosan characteristics on polymer properties. I: Crystallographic Properties". Polymer International, 52(2): 198-205 (2003).

Jiang, Ch.; Xu,M.Q. "Kinetics of Heterogeneous Deacetylation of $\beta$-Chitin". Chemistry Enginer Technology, 29(4): 511-516 (2006).

Jiang, X.; Chen, L.; Zhong, W. "A new linear potentiometric titration method for the determination of deacetylation degree of chitosan". Carbohydrate Polymers, 54(1): 457463 (2003).

Kasaai M., "A review of several reported procedures to determine the degree of $\mathrm{N}$ acetylation for chitin and chitosan using infrared spectroscopy". Carbohydrate Polymers, 71(4): 497-508 (2008).

Kim, S.S.; Kim, S.H.; Lee, Y.M. "Preparation, Characterization, and Properties of $\beta$-Chitin and N-acetylated $\beta$-Chitin". Journal of Polymer Science: Part B: Polymer Physics, 34(14): 2367-2374 (1996).

Koide, S.S. "Chitin-Chitosan: properties, benefits and risks". Nutrition Research, 18(6): 1091-1101 (1998).

Kubota, N.; Eguchi,Y. "Facile preparation of water-soluble $\mathrm{N}$-acetylated chitosan and molecular weight dependence of its water-solubility", Polymer Journal, 29: 123127(1997). 
Kulicke, W. M.; Kniewske, R. "The shear viscosity dependence on concentration". Rheological Acta, 23: 75-83 (1984).

Kurita, K. "Controlled functionalization of the polysaccharide chitin", Progress in Polymer Sciences, 26:1921-1971 (2001).

Kurita, K. "Chitin and Chitosan: Functional Biopolymers from Marine Crustaceans". Marine Biotechnology, 8(3):203-226 (2006).

Kurita, K.; Tomita, K.; Tada, T.; Ishii, S.; Nishimura, Sh-I.;Shimoda K. "Squid chitin as a potential alternative chitin source: Deacetylation behavior and characteristic properties" Journal of Polymer Science Part A: Polymer Chemistry, 31(2):485-491 (1993).

Lamarque, G.; Chaussard, G. ;Domard, A. "Thermodynamic Aspects of the Heterogeneous Deacetylation of $\beta$-Chitin: Reaction Mechanisms". Biomacromolecules, 8(6):1942-1950 (2007).

Lamarque, G.; Viton, C.; Domard, A. "Comparative Study of the First Heterogeneous Deacetylation of $\alpha$ - and $\beta$-Chitins in a Multistep Process". Biomacromolecules, 5(3):9921001 (2004).

Lárez Velásquez, C. "Quitina y quitosano: Materiales del pasado para el presente y el futuro". Avances en Química, 1(2):15-21 (2006).

Lavall,R.L.; Assis, O.B.G; Campana-Filho, S.P. " $\beta$-Chitin from the pens of Loligo sp.: Extraction and characterization" Bioresource Technology , 98(13): 2465-2472 (2007).

Martínez-Ruvalcaba, A.; Chornet E.; Rodriguei, D. "Dynamic rheological properties of concentrated chitosan solutions " Journal of Texture. Studies, 35: 53-74 (2004).

Matsumoto, T.; Kawai M.; Masuda, T. "Heterogeneous molecular aggregation and fractal structure in chitosan/acetic acid systems", Biopolymers, 31: 1721-1726 (1991).

Mazeau, K.; Pérez, S.; Rinaudo M. "Predicted influence of N-acetyl group content on the conformational extension of chitin and chitosan chains". Journal of Carbohydrate Chemistry,19: 1269- 1284 (2000).

Mazeau, K.; Rinaudo. M."The prediction of the characteristics of some polysaccharides from molecular modeling. Comparison with effective behavior". Food Hydrocolloids, 18(6): 885-898 (2004). 
Methacanon, P.; Prasitsilp, M.; Pothsree, T.; Pattaraarchachai, J. "Heterogeneous Ndeacetylation of squid chitin in alkaline solution". Carbohydrate Polymers, 52(2): 119123(2003).

Mucha,M. "Rheological characteristics of semidilute chitosan solutions" Macromolecular Chemistry and Physics, 198: 471-484 (1997)

Muzzarelli,R.A.A.; Rocchetti, R. "Determination of the degree of acetylation of chitosans by first derivative ultraviolet spectrophotometry". Carbohydrate Polymers, 5(6): 61-72 (1985).

No, H.K.; Meyers, P. "Preparation of chitin and chitosan". En: Chitin Handbook. Muzarelli, R.A.A.; Peter, M.G. (Eds.). European Chitin Society, Grottammare. 475- 489 (1997).

Odier, A. "Mémoire sur la Composition Chimique des Paties Cornées des Insectes". Mém. Soc. Historie Nat., 1: 29-42 (1823).

Okuyama, K.; Noguchi, K.; Miyazawa, T.; Yui, T.; Ogawa, K. “Molecular and Crystal Structure of Hydrated Chitosan" Macromolecules, 30(19): 5849-5855 (1997).

Onar, N.; Sariisik, M., "Using and Properties Biofibers based on Chitin and Chitosan on Medical Applications", 3rd Indo-Czech Textile Research Conference, (2004).

Ottøy,M.H.; Varum,K.M.; Smidrød, O. "Compositional heterogeneity of deacetylated chitosan". Carbohydrate Polymers, 29(1): 17-24 (1996).

Park, J.W.; Choi, K.H.; Park, K.K. "Acid-base equilibria and related properties of chitosan" Bulletin of Korean Chemistry Society, 4:68-72 (1983)

Pelletier, A.; Lemire, I.; Sygusch, J.; Chornet, E.; Overend, R.P. "Chitin/chitosan transformation by thermo-mechano-chemical treatment including characterization by enzymatic depolymerization". Biotechnology Bioengineering, 36(3): 310-315 (1990).

Peniche, Covas, C.A. "Influencia de Algunos Parámetros en la Obtención de Quitosano y sus Características". Bioorg. Khimia, 1(9): 1248-1252 (1984).

Peniche Covas, C.A. "Estudios Sobre Quitina y Quitosano". Tesis para el Grado de científico de Doctor en Ciencias, Facultad de Química, Universidad de La Habana, La Habana, Cuba, (2006).

Percot, A.; Viton, C.; Domard, A. "Characterization of Shrimp Shell Deproteinization". Biomacromolecules, 4(5): 1380-1385 (2003). 
Perez,J.A.A.; O’Dor,R.K.; Beck, P.; Dawe, E.G. "Evaluation of gladius dorsal surface structure for age and growth studies of the short-finned squid, Illex illecebrosus (Teuthoidea: Ommastrephidae)" Canadian Journal of Fish Aquatic Sciences, 53(12): 28372846 (1996).

Peters, W. "Ocurrence of Chitin in Mollusca". Comparative Biochemistry and Physiology Part B: Comparative Biochemistry, 41(3):541-544 (1972).

Poirier,M.; Charlet, G. "Chitin fractionation and characterization in N,Ndimethylacetamide/lithium chloride solvent system". Carbohydrate Polymers, 50(4) : 363370 (2002).

Ravi-Kumar, M.N.V. "A review of chitin and chitosan applications". Reactive and Functional Polymers, 46(1): 1-27 (2000).

Raymond, L.; Morin, F.G.; Marchessault, R.H. "Degree of deacetylation of chitosan using conductometric titration and solid-state NMR". Carbohydrate Research, 246(1): 331-336 (1993).

Rhazi, M.; Desbrières, J; Tolaimate, A.; Alagui, A.; Vottero, P. "Investigation of different natural sources of chitin: influence of the source and deacetylation process on the physicochemical characteristics of chitosan". Polymer International, 49(4): 337-344 (2000).

Rinaudo,M. "Chitin and chitosan: Properties and applications". Progress in Polymer Science, 31(7): 603-632 (2006).

Rinaudo, M.; Milas, M.; Le Dung, P. "Characterization of chitosan. Influence of ionic strength and degree of acetylation on chain expansion". International Journal of Biological Macromolecules, 15(5): 281-285 (1993).

Rinaudo, M.; Pavlov G.; Desbrières,J." Influence of acetic acid concentration on the solubilization of chitosan" Polymer, 40: 7029-7032 (1999)

Roberts, G.A.F. “Chitin Chemistry”, $1^{\text {st }}$ Ed. MacMillan Press Ltd., London, UK, (1992).

Roberts, G.A.F. "Chitosan production routes and their role in determining the structure and properties of the product". En: Advances in Chitin Science, Domard, A.; Roberts, G.A.F.y Vårum, K.M. (Eds.).Jacques André Publisher: Lyon. 22-31. (1998). 
Roberts, G.A.F. "Thirty years of progress in chitin and chitosan". Progress on chemistry and application of chitin and its derivatives. Polish Chitin Society, Lódz, Poland. Volume XIII, (2008).

Roberts, G.A.F. "The Road is long..." Advances in Chitin Sciences, 10:3-10 (2007).

Roper, C.; Sweeney, M. y Nauen, C. FAO Species Catalogue. Vol 3: Cephalopods of the World. FAO Fisheries Synopsis, 125 p. (1984).

Rudall, K.M.; Kenchington, W. “The Chitin System”. Biological Review, 49: 597-636 (1973).

Sandford, P.A. "Chitosan: commercial uses and potential applications". En: Chitin and Chitosan Chitin and Chitosan: Sources, Chemistry, Biochemistry, Physical Properties and Applications. Skjak-Braek, G.; Anthonsen T.; Sandford, P. (Eds.). Kluwer Academic Publishers Group. (1989).

Sannan, T.; Kurita, K.;Iwakura, Y. "Studies on Chitin, 2: Effect of deacetylation on solubility". Die Makromolekulare Chemie, 177(12): 3589-3600 (1976).

Sannan, T., Kurita, K.; Ogura, K.; Iwakura,Y. "Studies on Chitin: 7. I.R. spectroscopic determination of the degree of deacetylation". Polymer, 19(4): 458-459 (1978).

Shahidi, F.; Abuzaytoun, R. "Chitin, chitosan, and co-products: chemistry, production, applications, and health effects" Advances in Food Nutrition Research ,49 : 93-135 (2005).

Smidsrød, O.; Haug. A. "Estimation of the Relative Stiffness of the Molecular Chain in Polyelectrolytes from Measurements of Viscosity at Different Ionic Strengths". Biopolymers, 10: 1213- 1227 (1971).

Solomon, O.; Ciutâ, I. "Détermination de la viscosité intrinsèque de solutions de polymères par une simple détermination de la viscosité". Journal of Applied Polymer Sciences, 6(24):683-686 (1962).

Streitwieser, A.; Heathcock, C.H. En “Química Orgánica” Mc Graw Hill 3ed. p 544 (1989).

Tanner, S.F.; Chanzy, H.; Vincendon, M.; Roux J.-C. ; Gaill, F. "High-resolution solid-state carbon-13 nuclear magnetic resonance study of chitin". Macromolecules, 23(15): 35763583 (1990).

Terbojevich, M.; Carraro, C.; Cosani, A.; Marsano, E.; "Solution studies of the chitinlithium chloride-N,N-dimethylacetamide system" Carbohydrate Research, 180(1):73-86 (1988). 
Terbojevich, M.; Cosani, A. "Molecular weight determination of chitin and chitosan" En: Chitin Handbook. Muzarelli, R.A.A.; Peter, M. eds. Grotammare. European Chitin Society. 87-101 (1997)

Terbojevich, M.; Cosani, A.; Bianchi, E.; Marsano, E. "Solution behaviour of chitin in dimethylacetamide / LiCl". En: Advances in chitin science Vol. 1. Domard, A.; Jeuniaux, C.; Muzzarelli, R.; Roberts, R. (Eds.). Lyon : Jacques André. 333-339 (1996).

Terbojevich, M.; Cosani, A; Palumbo, M.; Pregnolato, F. "Structural properties of hyaluronic acid in moderately concentrated solutions" Carbohydrates Research ,149:363377 (1986).

Tolaimate, A.; Desbrières, J.; Rhazi M.; Alagui, A. "Contribution to the preparation of chitin and chitosan with controlled physicochemical properties" Polymer, 44(26):79397952 (2003).

Tolaimate, A.; Desbrières, J; Rhazi, M.; Alagui, A.; Vincendon, M.; Vottero, P. "On the influence of deacetylation process on the physicochemical characteristics of chitosan from squid chitin". Polymer 41(7): 2463-2469 (2000).

Tsaih, M. L.;Chen, R. H."Effect of ionic strength and pH on the diffusion coefficients and conformation of chitosans molecule in solution" Journal in Applied Polymer Sciences., 73: 2041-2050 (1999).

Van de Velde, K.; Kiekens, P. "Structure analysis and degree of substitution of chitin, chitosan and dibutyrylchitin by FT-IR spectroscopy and solid state ${ }^{13} \mathrm{C} N \mathrm{NMR}^{\prime}$. Carbohydrate Polymers, 58(4):409- 416 (2004).

Vårum, K.M.; Anthonsen, M.W.; Grasdalen, H. Smidrød, O. "Determination of the degree of $\mathrm{N}$-acetylation and the distribution of $\mathrm{N}$-acetyl groups in partially $\mathrm{N}$-deacetylated chitins (chitosans) by high-field n.m.r. spectroscopy". Carbohydrate Research, 211(1):17-23 (1991).

Vincendon, M. "11H-NMR Study of the Chitin Dissolution Mechanism". Die Makromolekulare Chemie, 186(9):1787-1795 (1985).

Wang, W.; Xu, D. "Viscosity and flow properties of concentrated solutions of chitosan with different degrees of deacetylation" International Journal of Biological Macromolecules,16(3): 149-152 (1994). 
Weast, R.C.; Lide, D.R. CRC Handbook of Chemistry and Physics, $67^{\text {th }}$ edition. CRC Press, pág. F110 (1986).

Wu, T. Zivanovic, S. "Determination of the degree of acetylation (DA) of chitin and chitosan by an improved first derivative UV method". Carbohydrate Polymers, 73(2): 248253 (2008).

Wu, S.D.; Wu, C.S. y Chen, H.C. "Cuticle structure of squid Illex argentinus pen". Fisheries Science, 69(4): 849-855 (2003).

Yamakawa, H. ;Fujii, M. "Intrinsic Viscosity of Wormlike Chains. Determination of Shift Factor". Macromolecules, 7(1):128-135 (1974).

Yui,T.; Imada, K.; Okuyama, K.;Obata, Y.;Suzuki, K. ;Ogawa, K. "Molecular and crystal structure of the anhydrous form of chitosan". Macromolecules, 27(26): 7601-7605 (1994). 
Sección B.

Biomateriales para ingeniería de tejido óseo. 
I.

Ingeniería de Tejidos.

Generalidades,

Definiciones

$y$

Aplicaciones. 


\section{INGENIERÍA DE TEJIDOS EN SISTEMA ÓSEO: GENERALIDADES, DEFINICIONES Y APLICACIONES.}

\section{INGENIERÍA DE TEJIDOS EN SISTEMA ÓSEO.}

\subsection{Ingeniería de tejidos. Generalidades.}

El daño tisular o pérdida de órganos son las principales causas de enfermedad y muerte en el mundo. Las lesiones en cartílago y hueso, principalmente como resultado de una población cada vez más envejecida/senil, enfermedades degenerativas, fallas terminales o accidentes traumáticos, comprometen de manera significativa la calidad de vida resultando en un creciente problema socio-económico.

Los tratamientos convencionales para la reparación se basan en el empleo de dispositivos mecánicos o el injerto/trasplante de tejidos y órganos. En esto último el tejido u órgano puede provenir del mismo paciente (autoinjerto) de otro individuo (aloinjerto) e incluso de otras especies animales (xenoinjerto). Si bien estos métodos mejoran significativamente la supervivencia del paciente, conllevan una serie de limitaciones. En el caso de los dispositivos su éxito se ve seriamente limitado por la durabilidad de los mismos, infecciones asociadas y tromboembolización (Fuchs J. et al., 2001).

Por otra parte, el trasplante de órganos es una cirugía compleja, cara y limitada por la escasez de donantes y el tiempo en que los órganos se pueden conservar fuera del cuerpo. En el caso de los autoinjertos las principales limitaciones consisten en la morbilidad del sitio donante, la inflamación crónica así como el riesgo asociado de infección (Godbey W. et al., 2002). Los aloinjertos y xenoinjertos no sólo deben superar la escasez o disponibilidad de donantes de órganos, sino también el rechazo de los mismos. Esto plantea serias restricciones debido a immunoincompatibilidad, obligando a los pacientes a someterse a un tratamiento inmunosupresor de por vida. Además suponen 
numerosos efectos secundarios asociados como un mayor riesgo de infección, la transmisión de enfermedades virales, el desarrollo de tumores, entre otros.

En este contexto de carencia de terapias médicas efectivas para el tratamiento de heridas y enfermedades se desarrolla la ingeniería de tejidos como un estrategia terapéutica innovadora alternativa al reemplazo tisular o de un implante permanente.

La ingeniería tisular es una ciencia multidisciplinaria que aplica principios y métodos de la ingeniería de materiales y la biología molecular para el diseño y desarrollo de materiales funcionales en los que se pueda sembrar células y posteriormente crear sustitutos biológicos que restauren/reparen, mantengan o mejoren la función biológica de un tejido u órgano dañado (Shalak R. et al., 1988).

El enfoque que plantea la ingeniería de tejidos evita muchos de los inconvenientes de las técnicas de injerto, como lo son la escasez de tejidos y órganos, la morbilidad del sitio donante, el rechazo inmunológico y la transferencia de patógenos.

Los tejidos son estructuras tridimensionales compuestas por agregados de células rodeadas de una sustancia intercelular o matriz extracelular (MEC). La MEC es un ensamblaje dinámico de moléculas que actúa como marco estructural de las células y desempeña un papel importante en la regulación del mantenimiento de la función, el comportamiento celular y en las interacciones célula-célula y célula-MEC (Nair L. et al., 2006). La visión de la ingeniería de tejidos utiliza sobre todo la construcción célula-matriz para desarrollar tejidos funcionales.

\subsection{Matrices poliméricas tridimensionales o scaffolds.}

Langer y Vacanti (Langer R. et al., 1993) reportaron que el enfoque más común hacia el desarrollo de sustitutos biológicos está basado principalmente en tres componentes: las células, las moléculas bioactivas y las matrices poliméricas tridimensionales o "scaffolds".

Las células son las encargadas de sintetizar la matriz extracelular del tejido nuevo y restaurar la función de los tejidos dañados, mientras que el scaffold proporciona un 
ambiente favorable para la adhesión, proliferación y diferenciación celular. Esto puede ser mediante la expansión in vitro de células autólogas sobre el scaffold o la implantación in vivo de un scaffold acelular, que guíe a las células del paciente para la regeneración y reparación de tejido. Las moléculas bioactivas por otra parte facilitan y promueven la regeneración del celular del nuevo tejido. Durante el proceso de regeneración, el scaffold no sólo proporciona una estructura tridimensional temporal en donde se organizan las células y los estímulos que dirigen la formación del nuevo tejido sino que también puede ser utilizado como vehículo para la liberación de las moléculas bioactivas. Por último el scaffold sufre degradación al mismo tiempo en que ocurre la regeneración del tejido, por lo que una vez que el tejido se desarrolla completamente, el scaffold deja de existir como tal y el tejido recién creado puede realizar la función del tejido perdido (Ross J., 1998), eliminando así la presencia de un cuerpo extraño en el lugar de implantación y su consecuente inflamación crónica.

Los scaffolds cumplen diferentes funciones en el campo de la ingeniería de tejidos. Para llevar a cabo esa variedad de funciones deben ser morfológica y estructuralmente similar al tejido nativo y ser capaz de realizar funciones biológicas similares. Además deben cumplir una serie de requerimientos tales como tener apropiada biodegradabilidad, no ser tóxico y ni inmunogénico, es decir, no inducir ninguna respuesta adversa en el organismo y, lo más importante, poseer buena biocompatibilidad con los tejidos.

Como función principal el scaffold debe proporcionar apoyo estructural al crecimiento de las células y crear un entorno tridimensional que guíe la formación de tejido nuevo. Para ello la morfología, la arquitectura tridimensional y sus propiedades mecánicas deben ser apropiadas para la aplicación deseada y para el período previsto.

La arquitectura tridimensional del scaffold debe poseer una morfología y una porosidad (morfología, tamaño de poro e interconectividad) tal que las células puedan organizarse en tejidos in vitro y para la angiogenesis in vivo. La angiogenesis y la organización del tejido son procesos que se ven afectados tanto por la porosidad del material como por la morfología del poro (Madihaly S. et al., 1999).La formación de una estructura porosa con poros interconectados es de suma importancia ya que permite transporte y la migración de las células, lo que favorece no sólo el contacto y la 
proliferación celular sino también el transporte de nutrientes gases, metabolitos, moléculas bioactivas y desechos desde y hacia el medio circundante.

Además de las propiedades mecánicas y la arquitectura tridimensional, importan las propiedades superficiales del scaffold. Las propiedades físicas y químicas de la superficie de los materiales constituyentes determinan las interacciones entre las células y los materiales y en consecuencia afectan la adherencia de la célula. La adhesión celular desempeña un papel crucial en la determinación de la organización celular. Asimismo, el scaffold debe modular a las células adheridas para que puedan diferenciarse y mantener la expresión fenotípica (Nair L. et al., 2006).

En relación a la biodegradabilidad del scaffold, debe ocurrir a una tasa controlada tal que se corresponda a la tasa de regeneración del tejido en formación con el fin de que el tejido sustituya paulatinamente al scaffold. La degradación de los constructos célulamaterial juega un papel crucial en las aplicaciones a largo plazo debido a que afecta a varios procesos celulares entre los que se incluyen la proliferación celular, la regeneración del tejido y la respuesta a cuerpo extraño. Por ejemplo, en la ingeniería de tejidos del sistema esquelético, la degradación del scaffold debe ser lenta y además debe mantener sus propiedades mecánicas hasta que el tejido se regenere completamente.

\subsection{El tejido óseo.}

La función del tejido óseo es tanto biomecánica como metabólica. Biomecánicamente, el hueso representa el marco estructural principal para mantener la forma del esqueleto y funciona como apoyo y protección de los órganos vitales de la cavidad craneal, torácica y pélvica. Además posibilita la acción mecánica de los músculos al servir como palanca para los músculos que se insertan en ellos y transmitir las fuerzas de la contracción muscular durante el movimiento. Por último alberga la médula ósea hematopoyética. Metabólicamente sirve como un reservorio de iones, mayormente de iones de calcio y fósforo, y contribuye a la regulación de la composición de la matriz extracelular. 


\subsubsection{Estructura arquitectónica del hueso.}

Macroscópicamente, el tejido óseo en el esqueleto adulto se organiza bajo dos formas arquitectónicas: el hueso cortical o compacto, que constituye cerca del $80 \%$ del total del esqueleto y el hueso trabecular o esponjoso, también llamado hueso cancelloso, que corresponde al $20 \%$ restante (Baron R., 2003). El hueso cortical es casi sólido y posee un $10 \%$ de porosidad (Sikavitsas V. et al., 2001). En el otro extremo, el hueso trabecular posee una porosidad superior, que varía entre el 50 y el $90 \%$, y presenta una estructura esponjosa en panal de abejas con ramificaciones en barras, placas y varillas de diferentes tamaños llamados trabéculas (figura 1.1.).

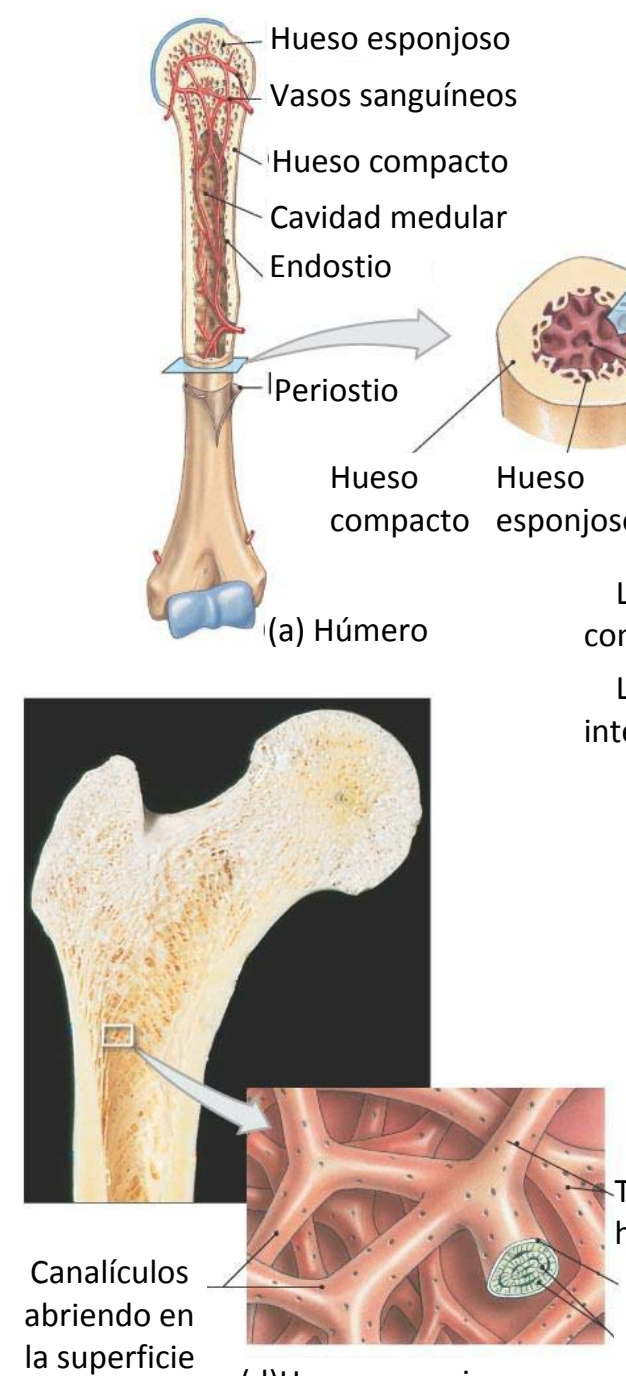

(d)Hueso esponjoso la superficie
Trabéculas de hueso esponjoso Endostio Lamelas $\sqrt{2}$

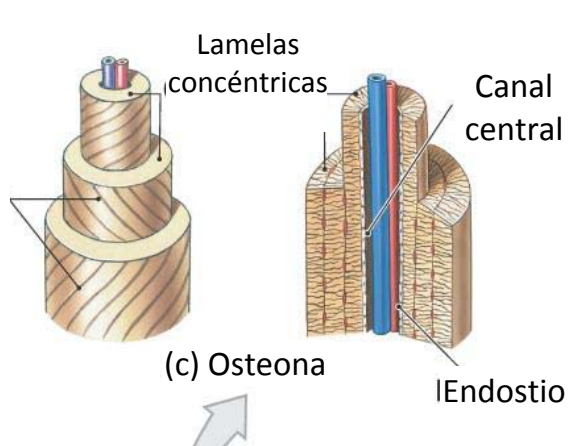

(c) Osteona

Lamelas circunferenciales Osteonas Periostio comelas $\sqrt{(6)}$
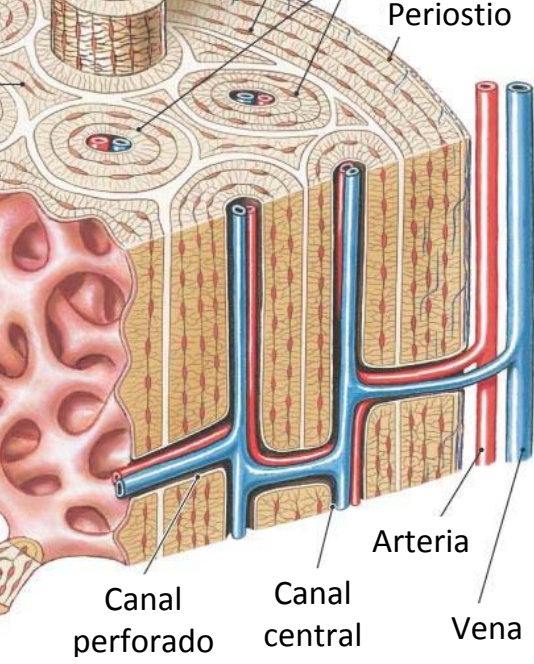
perforado

(b)Hueso compacto y esponjoso

Figura 1.1. Organización interna del hueso cortical y esponjoso. Tomado de Martini F. et al., 2009. 
Las proporciones de las dos formas arquitectónicas difieren en los distintos lugares del esqueleto. Mientras que el hueso cortical es el constituyente de los hueso largos (fémur y tibia), cortos (muñeca y tobillo) y planos (bóveda craneana y huesos irregulares), el hueso trabecular se halla comúnmente en metáfisis de los huesos largos (cubiertos por hueso cortical) y en los cuerpos vertebrales (Sikavitsas V. et al., 2001; Baron R., 2003).

\subsubsection{Estructura microscópica del hueso.}

El tejido óseo es una variedad de tejido conectivo cuya matriz extracelular está mineralizada y contiene a las células que lo secretan. Las células incluyen células osteoprogenitoras, osteoblastos, osteocitos y osteoclastos. Los osteoblastos secretan la matriz ósea mineralizada y posteriormente, al quedar rodeados por la matriz, se convierten en osteocitos alojados en espacios lagunares. Los osteoclastos son células derivadas de precursores de la línea monocito/macrófago y tienen como función la resorción y remodelación del hueso. La comunicación intercelular, particularmente entre osteoblastos y osteoclastos, es importante para la determinación de los efectos netos de la formación y resorción ósea.

\subsubsection{La matriz ósea.}

La matriz ósea está integrada por una fase mineral y una fase orgánica. Debido a esto, y desde una perspectiva de ciencia de los materiales, el hueso puede ser considerado como un material compuesto o "composite" (Salgado A. et al., 2004).

La fase mineral es el principal componente de la matriz ósea y está constituida mayoritariamente por calcio y fósforo en forma de cristales de hidroxiapatita $\left[\mathrm{Ca}_{10}\left(\mathrm{PO}_{4}\right)_{6}(\mathrm{OH})_{2}\right]$. Además contiene otros elementos como carbonatos, citratos, magnesio, sodio y potasio (Gartner L. 2002).

Por otra parte, la fase orgánica constituye cerca del 35\% del peso de la matriz ósea y está formada por proteínas colagenosas y no colagenosas. El colágeno es el componente predominante y está casi exclusivamente conformado por fibras de colágeno tipo I. El colágeno tipo I forma parte del osteoide o componente orgánico no 
mineralizado del hueso y se organiza en un patrón dentro de la microestructura del hueso. Su función principal es la de servir como un scaffold, modulando los sitios de calcificación del hueso (Golub, 2009). Las proteínas no colagenosas asisten al colágeno y modulan la calcificación y por tanto desempeñan un papel importante en la osteogénesis y la remodelación ósea (Golub, 2009). Incluyen citoquinas, glicosaminoglicanos (principalmente condroitinsulfato, queratansulfato y ácido hialurónico), proteoglicanos, glicoproteínas como osteonectina y trombospondina, proteínas gla como la osteocalcina, fosfoproteínas entre las cuales se incluyen las proteínas SILBING's como osteopontina y sialoproteína ósea, fosfolípidos y factores de crecimiento (Wiesmann H. et al.,2005). Los componentes no colagenosos de la fase orgánica del hueso se resumen en la tabla 1.1.

\begin{tabular}{|c|c|}
\hline Proteína & Función y propiedades \\
\hline Osteonectina & $\begin{array}{l}\text { Glicoproteína que media en la depositación de hidroxiapatita. Une } \mathrm{Ca}^{+2} \text {, colágeno y } \\
\text { factores de crecimiento. Puede influenciar proteínas antiadhesivas del ciclo celular. }\end{array}$ \\
\hline Trombospondina & $\begin{array}{l}\text { Glicoproteína que media la adhesión celular y depositación de hidroxiapatita. Une } \\
\mathrm{Ca}^{+2} \text {, colágeno I y C, osteonectina, heparina, trombina, fibrinógeno, laminina, } \\
\text { plasminógeno, entre otras. }\end{array}$ \\
\hline Fibronectina & $\begin{array}{l}\text { Glicoproteína. Unión osteoblástica al sustrato. Organiza el citoesqueleto y colabora } \\
\text { en la formación de la red entrecruzada de la MEC por medio de unión con fibrina, } \\
\text { heparina, colágeno. }\end{array}$ \\
\hline Osteopontina & $\begin{array}{l}\text { Proteína SIBLING constituyente de la línea de cemento. Involucrada en el } \\
\text { remodelamiento óseo. Inhibe la mineralización y la sintasa de óxido nítrico y quizás } \\
\text { regule la proliferación, la reparación tisular e inicie la mineralización. }\end{array}$ \\
\hline Sialoproteína ósea & $\begin{array}{l}\text { Proteína SIBLING constituyente de la línea de cemento. Se une a las células y fija } \\
\mathrm{Ca}^{+2} \text {. Quizás inicie la mineralización. }\end{array}$ \\
\hline Osteocalcina & $\begin{array}{l}\text { Proteína gla esqueletaria; involucrada en el remodelamiento óseo y quizás también } \\
\text { en el control de la mineralización por inhibición. Regula la maduración del mineral y } \\
\text { quizás regule la actividad de osteoclastos y sus precursores. }\end{array}$ \\
\hline Vitronectina & $\begin{array}{l}\text { Glicoproteína. Adhesión celular proteica debido a que posee sitios de unión para } \\
\text { integrinas. Unión a colágeno, plasminógeno y heparina. }\end{array}$ \\
\hline Ácido hialurónico & Quizás capture los sitios/espacios a ser hueso. \\
\hline Albúmina & Transporte proteico; inhibe el crecimiento del cristal de hidroxiapatita. \\
\hline
\end{tabular}

Tabla 1.1. Principales proteínas óseas no colagenosas y sus funciones. Tomado de varias fuentes (Boskey A., 2006; Buttler W. et al., 1996; Marks Jr., S. et al., 1996; Robey P., 1996; Rossert J. et al., 1996; Triffit J., 1996 ; Weiner S. et al., 1998). 
Puede considerarse que la matriz ósea es la responsable de las propiedades biomecánicas del hueso. Las fibras de colágeno le proporcionan flexibilidad y resistencia a la tracción mientras que la hidroxiapatita confiere dureza, rigidez y resistencia a la compresión.

\subsubsection{Osteoblastos.}

Los osteoblastos son las células encargadas de sintetizar y secretar la fase orgánica de la matriz ósea así como también de controlar el depósito de las sales minerales tanto en la formación inicial del hueso como en su posterior remodelamiento.

Son células poliédricas con citoplasma basófilo, Aparato de Golgi prominente y abundantes cisternas de retículo endoplasmático rugoso (RER) que forman una densa capa en la superficie del hueso, desde la cual se extienden mediante procesos celulares a través del hueso (Puzas J., 1993).

Los osteoblastos participan en la calcificación de la matriz ósea mediante la secreción de vesículas matriciales cargadas con fosfolípidos ácidos y ciertas proteínas, particularmente de la enzima fosfotransferasa fosfatasa alcalina (ALP) tejido no específica (Whyte M., 1994), la nucleótido pirofosfatasa fosfodiesterasa (NPP1/PC-1), anexinas, fosfatidilserina y metaloproteinasas de la matriz (Ali S., 1992). Dichos constituyentes tienen al menos dos funciones principales en la iniciación de la mineralización. Por un lado la actividad antagonista de las enzimas ALP y NPP1 junto con la ANK regula el inicio de la calcificación. La actividad enzimática de la NPP1 junto con la proteína celular asociada anquilosis (ANK) incrementan la concentración extracelular de pirofosfato (PPi), el inhibidor de la calcificación, mientras que la actividad hidrolítica del PPi por parte de la ALP, eleva la concentración extracelular del fosfato inorgánico (Pi), promotor de la mineralización y por tanto crea centros de nucleación para el depósito de sales minerales (Hessle L. et al., 2002; Addison W. et al., 2007). Por otro lado las proteínas, los lípidos y fosfolípidos sirven como sitios de nucleación para la depositación de hidroxiapatita (Anderson H., 2003).

Además de los productos anteriormente mencionados, los osteoblastos generan varios productos celulares, entre los que incluyen la enzima colagenasa, hormonas como 
la osteocalcina, proteínas extracelulares estructurales como osteonectina, fibronectina, vitronectina, osteopontina y sialoproteína ósea, así como también factores de crecimiento, proteoglicanos, proteínas implicadas en la adhesión celular y colágeno, mayormente colágeno tipo I. La secreción proteica varía en tiempo y espacio.

En cultivos celulares in vitro, Liam y Stein (Liam J. et al., 1992 y Stein G. et al., 1993) observaron el hueso es formado por los osteoblastos en una serie de etapas consisten en (1) la proliferación celular y la síntesis de los componente orgánicos de la matriz ósea; (2) el desarrollo y la maduración de la matriz ósea, mediante cambios en la composición y organización de la matriz de modo de que pueda ser mineralizada y (3) la mineralización de la matriz por deposición de hidroxiapatita. Dichos autores observaron en estudios in vitro la coincidencia de dichas etapas con la activación sucesiva de una serie de genes específicos que transcriben proteínas asociadas con la matriz, como el colágeno tipo I, la fibronectina, osteonectina y factores de crecimiento en la etapa de proliferación y síntesis de la matriz ósea. Posteriormente, durante la maduración de la matriz y es posible detectar la fosfatasa alcalina. Esta enzima se expresa en elevados niveles durante la diferenciación osteoblástica. Por último, durante la mineralización se produce la activación de glicoproteínas tales como la sialoproteína ósea, la osteocalcina y la osteopontina.

\subsubsection{Células osteoprogenitoras.}

Las células osteoprogenitoras (figuras 1.2.a y b) pertenecen al grupo de las células madre mesenquimales (MSC) no hematopoyéticas del tejido adulto. Las MSC son células pluripotenciales y con plasticidad celular que poseen un gran potencial de diferenciación en osteoblastos y otros fenotipos mesenquimales dependiendo del entorno tales como fibroblastos medulares o células reticulares del estroma, condrocitos del cartílago y adipocitos del tejido graso (Bielby R. et al., 2007; Flores-Figueroa E. et al., 2006).

Las células osteoprogenitoras residen en la capa celular interna del periostio (tejido que recubre la superficie ósea), recubriendo los canales haversianos, en hueso trabecular, médula ósea, membrana sinovial y en el líquido sinovial (Bielby R. et al., 2007). 
Morfológicamente, se caracterizan por presentar una morfología espigada, en forma de huso, con la presencia de un núcleo alargado, central, que contiene de dos a tres nucléolos y citoplasma con abundantes ribosomas libres pero con escaso RER y Aparato de Golgi pobremente desarrollado (Flores-Figueroa E. et al., 2006). Estas células son más activas durante el periodo de crecimiento óseo intenso y no expresan fosfatasa alcalina, hasta que han adquirido el compromiso de diferenciación hacia el linaje osteoblástico (Pittenger M. et al., 1999).

Las células osteoprogenitoras no solo actúan como fuente de progenitores de los osteoblastos sino que tienen una función indirecta en la homeostasis normal del esqueleto, regulando la osteoclastogénesis a través de la expresión de RANKL y OPG (Gori F. et al., 2000). Asimismo desempeñan también un papel importante en la reparación de fracturas o daño óseo. Se ha demostrado que las moléculas de señalización que coordinan la cascada de reparación pueden regular la actividad celular de las MSC y otros linajes progenitores, induciendo la proliferación celular y la diferenciación in vitro, lo que conduce a la cura de fracturas y el restablecimiento de la integridad del esqueleto (Bielby R. et al., 2007).

\subsubsection{Osteocitos.}

Los osteocitos (figuras 1.2.a y c) son células óseas maduras derivadas de los osteoblastos. Se encuentran insertos en cavidades de la matriz osificada llamadas lagunas osteocitarias y su rasgo morfológico más llamativo son las prolongaciones citoplasmáticas, albergadas en calcóforos o canalículos de la matriz, que los conectan con osteocitos vecinos y otras células de la superficie ósea mediante uniones gap (Baron R., 2003). Tanto en las lagunas osteocitarias como en calcóforos se encuentra líquido intersticial que posibilita el intercambio de iones y metabolitos y la comunicación química y eléctrica entre las células.

Los osteocitos no segregan materiales de la matriz ósea y poseen una escasa actividad metabólica. Su función es la de mantener el intercambio de nutrientes y productos de desecho del tejido óseo y parece ser que su preservación es necesaria para que el tejido óseo mantenga sus propiedades biomecánicas. Los osteocitos suelen 
relacionarse con la mecanotransducción, ya que teóricamente pueden detectar estrés mecánico y microlesiones del tejido óseo y responder a estímulos liberando de adenosin monofosfato cíclico (AMPc), osteocalcina y factor de crecimiento similar a insulina (IGFI) (Bozal C., 2006). La liberación de estos factores facilita la incorporación, el crecimiento y desarrollo de preosteoblastos y también contribuyen a la redistribución de fuerzas a largo plazo que actúan en el esqueleto.

a)

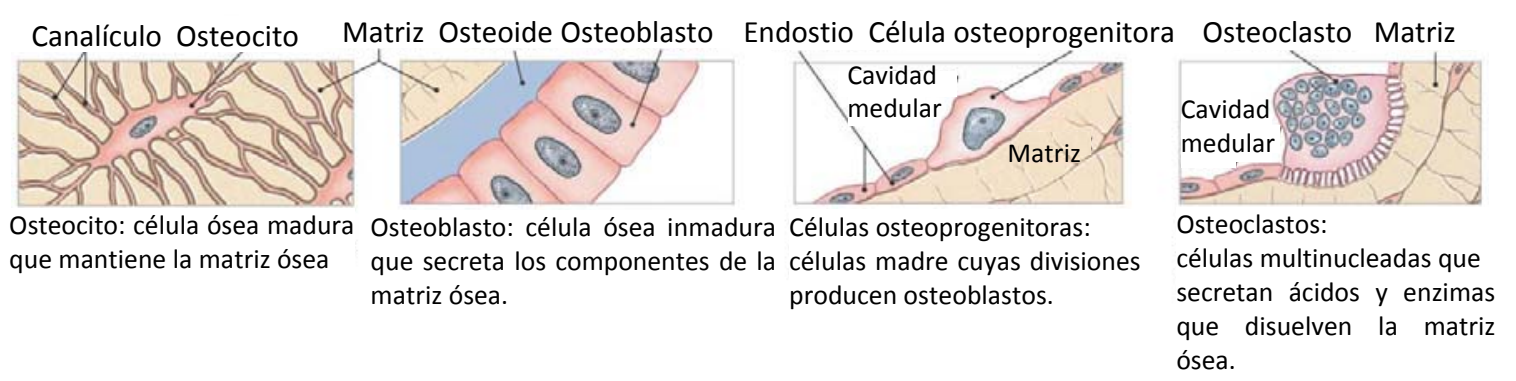

b)

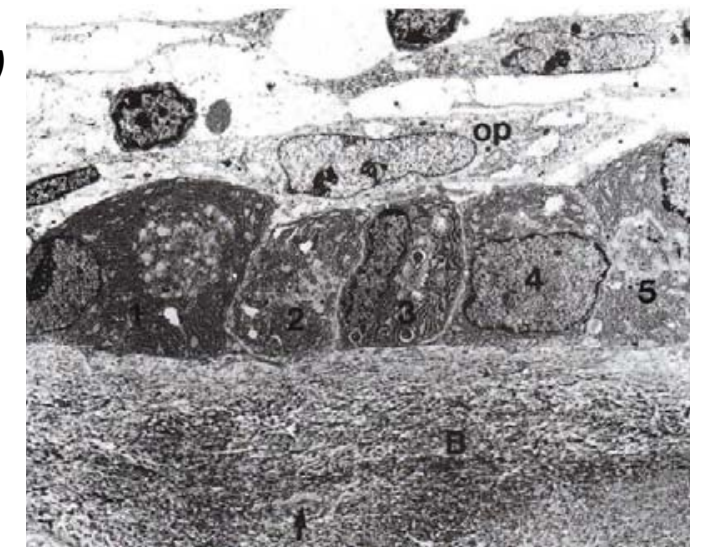

c)

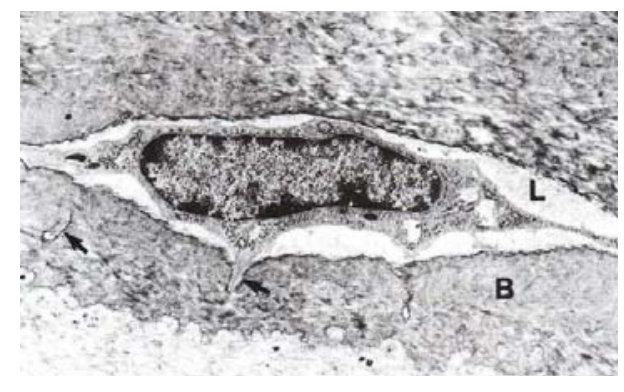

d)

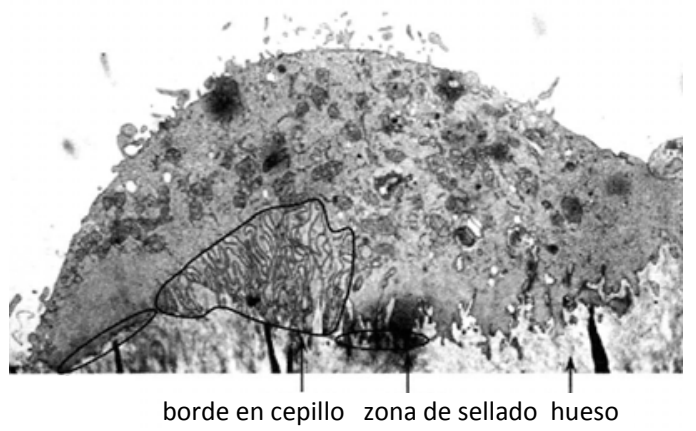

Figura 1.2. Tipos celulares óseos. Imagen esquemática (a) y microfotografías $(b, c$ y $d$ ). b) microfotografía (2500x) mostrando los osteoblastos alineados (numerados del 1 al 5) sobre la superficie del hueso (B) y una célula osteoprogenitora (op); la flecha indica un osteocito con prolongaciones en canalículos. c) microfotografía (1000x) mostrando un osteocito en su laguna (L) con sus prolongaciones (flechas) extendiéndose hacia los canalículos. d) osteoclasto. Imagen a) tomada de Martini F. et al., 2009; microfotografías b) y c) tomadas de Marks S. et al., 1988 y d) tomado de Baron R., 2003. 


\subsubsection{Osteoclastos.}

Los osteoclastos (figuras 1.2.a y d) son células gigantes multinucleadas originadas por fusión de células mononucleares (derivadas del linaje hematopoyético) que se encargan de la resorción de la matriz ósea.

Los osteoclastos se localizan en la superficie del hueso en un área discreta llamada laguna de reabsorción y se caracterizan por la presencia de un borde en cepillo (Mundy G., 1993; Parfitt A., 1994). El borde en cepillo se une mediante integrinas a la laguna de reabsorción y se encuentra completamente rodeado por una zona clara, rica en filamentos de actina y que carece de organelas (Holtrop M. et al., 1977). Están ricamente dotados con enzimas lisosomales, específicamente la fosfatasa ácida tartrato-resistente (TRAP) y además poseen anhidrasa carbónica, la cual es utilizada en la producción de iones $\mathrm{H}^{+}$secretados al borde en cepillo.

Los osteoclastos reabsorben el hueso mediante la disolución de la fase mineral y por acción enzimática de la fase orgánica. La fase mineral ósea es reabsorbida por la secreción de iones $\mathrm{H}^{+}$que disminuyen el $\mathrm{pH}$, conduciendo a la liberación de iones $\mathrm{Ca}^{2+}$, $\mathrm{HPO}_{4}{ }^{2-}$ y $\mathrm{H}_{2} \mathrm{PO}^{4-}$ de la hidroxiapatita. La fase orgánica del hueso es degradada por medio de una serie de proteasas y glicosidasas tales como metaloproteinasas de la matriz y varias proteasas lisosomales de cisteína (Baron R., 2003).

\subsubsection{Fisiología del hueso.}

\subsubsection{Osteogénesis y remodelamiento óseo.}

La osteogénesis o crecimiento óseo es un proceso que ocurre durante toda la vida, e involucra la remodelación ósea en los adultos (Duplomb L. et al. 2007). En dicho proceso participan todos los tipos celulares óseos.

El desarrollo normal del esqueleto durante la embriogénesis en la etapa fetal comienza con el reclutamiento y la agregación de células madre mesenquimales (MSC) para formar condensaciones. Dentro del núcleo de condensación mesenquimal las células 
se diferencian en condrocitos en la osificación endocondral o directamente en osteoblastos en la vía de la formación ósea intramembranosa (Ferguson C. et al. 1999).

La remodelación ósea es un proceso complejo que involucra una serie de funciones celulares dirigidas hacia la resorción ósea seguidos de una fase de formación de hueso nuevo. Esto ocurre de manera continua durante la vida adulta normal ya que necesario para el mantenimiento de una matriz ósea mineralizada y por tanto de la estructura ósea normal.

En la remodelación ósea se sustituye el hueso en pequeñas superficies óseas mediante grupos de células que actúan coordinadamente y que se conocen como unidades multicelulares de remodelamiento óseo o unidades multicelulares básicas (BMUs) (Frost H., 1991). El nuevo segmento de tejido resultante de la acción de esta unidad se denomina unidad estructural ósea (BSU). Durante este proceso no hay cambio en la forma del hueso porque tanto la formación y resorción ósea se producen en el mismo sitio anatómico (Hill P. et al., 1998). El mantenimiento de la masa ósea requiere que la formación de hueso por los osteoblastos y la reabsorción por los osteoclastos estén equilibrados (Dunstan C. et al., 2007).

La remodelación ósea depende de la cooperación entre los distintos tipos celulares del linaje osteoclástico y osteoblástico, ciertos moduladores sistémicos y mediante la regulación de factores locales. A saber: (i) determinados tipos celulares, tales como MSC y osteoclastos, (ii) hidroxiapatita y moléculas de la matriz extracelular, (iii) la expresión de hormonas (como lo es la calcitonina, la hormona paratiroidea (PTH), 1,25dihidroxivitamina $D$, hormonas sexuales y otras hormonas esteroides), de factores locales sintetizados por las células óseas (tales citoquinas, factores de crecimiento y prostaglandinas), iones, y vitaminas (Kwan Tat S. et al. 2004); y (iv) estímulos mecánicos (Papachroni K. et al., 2009).

Brevemente, el ciclo de remodelado consiste en una serie de fases que se inician con la en la que activación de los precursores osteoclásticos, los cuales migran y diferencian en osteoclastos (fase de activación). Una vez diferenciados, los osteoclastos multinucleados inician la fase resorción ósea en la laguna resortiva mineralizada. Luego de que una cierta cantidad de hueso fue removido, el osteoclasto entra en apoptosis y se 
lleva a cabo una fase de reposo o inversión en la que se deposita una línea de cementación rica en glicoproteínas y que servirá de asiento a los osteoblastos.

Los productos de la resorción ósea activan precursores osteoblásticos los cuales migran hacia las lagunas resortivas. Así en la fase de reversión dichos precursores se expanden y proliferan diferenciándose a osteoblastos maduros. Además el osteoblasto produce osteoprotegerina, que inhibe la osteoclastogénesis y por tanto la actividad resortiva del osteoclasto. Posteriormente comienza la fase de formación en la que los osteoblastos maduros ocupan la laguna de resorción depositando el osteoide no mineralizado que posteriormente se mineraliza. La fase finaliza cuando la nueva unidad estructural ósea está completamente formada.

En la fase de reposo, una vez integrados en el osteoide, los osteoblastos se convierten en osteocitos diferenciados. La superficie del hueso neoformado se cubre de osteoblastos que persisten en reposo como células de revestimiento aplanadas hasta que un nuevo ciclo de remodelación comienza (Hill P. et al., 1998).

La remodelación es un proceso importante en tres aspectos: en primer lugar el hueso, por su función de soporte estructural, está sometido a la fatiga, por tanto el remodelado óseo reemplaza al hueso que contiene grietas para evitar así fallas estructurales. En segundo lugar, la remodelación ósea es necesaria para adaptar las propiedades materiales del hueso a las exigencias mecánicas que se colocan en el esqueleto. Por último, debido a que el hueso es un importante reservorio de calcio, la remodelación del hueso desempeña un papel crítico en la regulación de la homeostasis del calcio cuando es insuficiente, ya que es liberado del hueso por los osteoblastos para satisfacer la demanda (Dunstan C. et al.,2007).

\subsubsection{Mecanismos biológicos de reparación y regeneración ósea.}

El restablecimiento del hueso como consecuencia de una lesión o fractura si bien se asemeja mucho al proceso de osteogénesis normal del esqueleto, difiere en algunos aspectos tales como la inflamación y el aumento de fuerzas mecánicas en los adultos (Hutchinson C. et al., 2007). Brevemente, el proceso de reparación ósea consiste en la formación de un hematoma, seguido por una rápida cascada inflamatoria, angiogenesis 
localizada, vascularización y la formación de un callo. Posteriormente se lleva a cabo la producción de matriz extracelular y la remodelación ósea (Braddock M. et al., 2001; Deschaseaux F. et al., 2009).

En el proceso de consolidación de una fractura participan coordinadamente una compleja red de diferentes tipos celulares (MCS, fibroblastos, macrófagos, condroblastos, osteoblastos, osteoclastos) y vías moleculares de señalización (efectores de la inflamación, factores de crecimiento (TGF- $\beta$ e IGF), proteínas morfogenéticas óseas, angiopoyetinas, y factores angiogénicos, entre otros). Las moléculas de señalización evalúan el daño en los tejidos y regulan la actividad celular, induciendo la muerte celular, el reclutamiento la proliferación y diferenciación de linajes celulares progenitores como las MSC perivasculares en condrocitos u osteoblastos (Bielby R. et al., 2007; Braddock M. et al., 2001; Deschaseaux F. et al., 2009). Todo esto conduce al restablecimiento de la integridad del esqueleto.

La mayoría de las fracturas son secundarias (indirectas) y se reparan por la formación de callos a través de una combinación de osificación intramembranosa y endocondral, siendo el periostio la principal fuente de células reparadoras. En la formación ósea intramembranosa las MSC periósticas se diferencian en osteoblastos para formar hueso sin una etapa anterior del cartílago y hay poco reclutamiento de las células de otros tejidos (Bielby R. et al., 2007). Sin embargo en la cura de una fractura cortical primaria o directa hay poca contribución perióstica, por lo que MSC procedentes de sitios perivasculares (que quedan atrapadas en el hematoma) proporcionan la fuente de osteoprogenitores. Por último ocurre producción de matriz ósea y la remodelación ósea en la que se reemplaza el hueso primario de la formación intramembranosa de hueso con hueso secundario, que refuerza adicionalmente la zona de fractura. Al mismo tiempo, se resorbe el callo y reconstituye la continuidad del hueso (Braddock M. et al., 2001).

La comprensión de los mecanismos de reparación ósea es relevante en el entendimiento de enfermedades con anomalías en el remodelado óseo, tanto en aquellas donde el hueso sufre regresión (osteoporosis y osteogénesis imperfecta), así como en la artritis, osteolisis inducida por tumor y osteopetrosis (donde el hueso crece en exceso). 


\subsection{Ingeniería de tejidos para reparación y regeneración ósea.}

Las lesiones óseas comprometen principalmente el rol biomecánico del hueso afectado, ya que si bien los otros huesos en el cuerpo pueden compensar la función metabólica del hueso lesionado no pueden soportar la carga. El trasplante de hueso es tratamiento más comúnmente utilizado con el objetivo de inducir la osteogénesis, la osteoinducción y así sustituir el defecto del esqueleto (Leong, J. 1993). En situaciones donde se requiere la inducción de la osteogénesis se prefiere el hueso esponjoso por poseer un efecto osteinductivo mucho más pronunciado que en el hueso cortical. La elevada porosidad del hueso trabecular permite que el tejido que rodea al injerto se vascularise en cuestión de semanas y el hueso nuevo crezca en cuestión de meses. Aunque el trasplante de hueso autólogo es el método de elección, a menudo existe el problema de que el suministro sea inadecuado, la falta de la forma y la geometría deseada, y esencialmente el aloinjerto óseo se utiliza a menudo como alternativa.

Ante este escenario, los sustitutos biodegradables generados vía ingeniería tisular pueden actuar como un esqueleto temporal que se inserta en los sitios defectuosos del esqueleto con el fin de soportar y estimular la regeneración de tejido óseo mientras se degradan gradualmente y son reemplazadas por tejido óseo nuevo.

Unos de los principales requerimientos que debería cumplir un scaffold ideal debería es el parecerse arquitectónica y bioquímicamente al hueso trabecular y poseer propiedades mecánicas similares (Yaszemski M, et al., 1996).

\section{POLÍMEROS BIODEGRADABLES COMO BIOMATERIALES PARA REGENERACIÓN ÓSEA.}

Boretos y colaboradores (Boretos J. et al., 1984) y Doherty y colaboradores (Doherty P. et al., 1992) definen biomaterial como "cualquier sustancia diferente a una droga o combinación de sustancias, de origen sintético o natural, destinada a la interfaz de los sistemas biológicos, que puede ser utilizada en cualquier momento con el fin de valorar, tratar, incrementar o reemplazar cualquier tejido, órgano o función del cuerpo humano". 
Entre los biomateriales desarrollados para su utilización en aplicaciones de ingeniería de tejido óseo se encuentran las cerámicas bioactivas y los polímeros. Las cerámicas bioactivas son interesantes por su similitud química con el hueso lo que permite que se adhieran espontáneamente al hueso y la osteogénesis (Hench et al., 1984). Sin embargo, la elevada fragilidad, la poca flexibilidad respecto al hueso natural y su baja biodegradabilidad restringe las aplicaciones clínicas.

Los polímeros biodegradables son ampliamente utilizados en ingeniería de tejidos óseo debido a las ventajas que presentan en relación a su degradabilidad en condiciones fisiológicas y eliminación por vías metabólicas, así como por su facilidad de procesamiento respecto a biomateriales cerámicos o metálicos. Un gran número de polímeros biodegradables tanto de origen natural como sintético han sido estudiados para el desarrollo de scaffolds como sustitutivos óseos (Watanabe J. et al, 2003).

La especial atención que han recibido los polímeros naturales se debe a su semejanza estructural con sustancias macromoleculares que el medio ambiente biológico está preparado para reconocer y metabolizar a residuos no tóxicos (Coutinho D. et al., 2008). La gran mayoría de los biomateriales naturales utilizados hoy en día están constituidos por polímeros presentes en la matriz extracelular de tejido óseo, tejido cartilaginoso, la piel, los tendones y los ligamentos, entre otros (Herrero J.,1997). Las proteínas, los polihidroxialcanoatos y los polisacáridos son las clases más investigadas. Como ejemplos puede citarse la gelatina ( $L i$ X. et al., 2006), el colágeno (Ignatius A.et al., 2005), el almidón (Gomes M. et al., 2002), el alginato (Li Z. et al., 2005) y el quitosano (Adekogbe I. et al, 2005; Huang Y. et al., 2005a); cada uno con diferencias importantes en cuanto a degradabilidad, capacidad de mantener células viables y variaciones en cuanto a su desempeño mecánico (Sachlos et al., 2003).

Los polímeros sintéticos, en contraste, ofrecen no sólo la biodegradabilidad control de las propiedades mecánicas, sino también su alta reproducibilidad y la posibilidad de producción a gran escala. Entre los polímeros sintéticos los poliésteres han sido ampliamente estudiados en ingeniería de tejido. Los más utilizados son el ácido poliláctico y el acido poliglicólico (Agrawal C. et al., 1995; Athanasiou K. et al., 1996), sus copolímeros (Wu Y. et al., 2006) y la poli-e-caprolactona (Sarasam A. et al., 2005; Wiliams J. et al., 2005). Las ventajas de estos polímeros son su biocompatibilidad y su variación en 
la velocidad de degradación en función de su peso molecular, su grado de cristalinidad y la composición de sus co-monómeros y/o aditivos (Martínez Palau M., 2008).

Debido a que no existe ningún material que por sí solo cumpla con todos los criterios para que el injerto óseo sea exitoso, gran parte del éxito de los scaffolds consiste en seleccionar un material y diseño adecuado que pueda hacer frente a las variables físicas y biológicas inherentes a cada aplicación.

\subsection{Métodos de biofabricación y procesamiento de scaffolds.}

Se han desarrollado numerosos métodos de fabricación para cumplir los distintos requisitos de los scaffolds, los cuales se encuentran bien descritos en las referencias señaladas, además de estar revisadas en numerosos libros. Dichos métodos utilizan diferentes técnicas basadas en la evaporación de solvente (solvent-casting) y lixiviación de partículas (particulate leaching), liofilización, separación de fases, el espumado con gas o procesamientos mediante derretimiento y fusión así como por electrospinning y prototipado tridimensional. Con excepción del espumado con gas o por procesamiento mediante derretimiento estas técnicas utilizan solventes orgánicos. Cada método de elaboración posee ventajas y desventajas y por tanto confiere al scaffold características estructurales diferentes.

Entre las técnicas más sencillas y convencionalmente utilizadas se encuentran la técnica de evaporación de solvente (solvent casting) y la liofilización. La técnica de evaporación de solvente consiste en el vertido de la solución de polímero sobre una superficie y dejarla secar al aire o al vacío hasta evaporación completa del solvente. Debido a la cohesión adecuada entre las moléculas, la suficiente difusión y completa evaporación del disolvente, las cadenas de polímeros se unen para formar películas. Si bien el procedimiento no requiere de aparatos sofisticados y es método simple y reproducible, presenta limitaciones de espesor y en las propiedades mecánicas, y algunos autores cuestionan la homogeneidad y la interconexión de los poros, así como la presencia de solvente residual (Mano J. et al., 2007).

La técnica de liofilización se diferencia de la anterior en que la solución de polímero se congela de modo de formar cristales de hielo, los cuales son posteriormente 
removidos por liofilización. Mediante esta técnica se obtienen matrices porosas con un tamaño de poro puede ser controlado por la velocidad de congelación y el pH (Mano J. et al., 2007 Sachlos E. et al., 2003).

Otros procedimientos mediante los cuales pueden obtenerse matrices porosas son la lixiviación de partículas (particulate leaching) y el proceso de espumado por gas. Mientras que la lixiviación de partículas requiere de la dispersión de partículas de porógeno (como sal, azúcar u otros) en una mezcla polimérica y que posteriormente son retiradas por inmersión en un solvente específico, en el proceso de espumado por gas se fabrican esponjas de de alta porosidad mediante saturación del polímero con gas (generalmente dióxido de carbono) a alta presión y a temperatura controlada. Ambas técnicas permiten el control del tamaño de poro (ya sea por el tamaño y proporción de porógeno y polímero o variando la temperatura, la presión, y las tasas reducción de la presión), pero no así orientación y el grado interconexión de los mismos (Buckley C. et al., 2004; Ma P., 2004a; Ma P., 2004b; Mano J. et al., 2007; Sachlos E. et al., 2003).

Por otra parte pueden utilizarse la técnica de separación de fases y procesado por derretimiento y fusión, las cuales pueden procesarse en combinación con lixiviación de partículas, extrusión y moldeo por inyección con agentes de soplado. (Mano J. et al., 2007; Sachlos E. et al., 2003).

Además los polímeros pueden ser procesados mediante extrusión a modo de fibras textiles y posteriormente unidas en tejidos de malla. La principal ventaja que poseen es una elevada proporción de área superficial/ volumen, sin embargo por lo general poseen una baja integridad mecánica (Sachlos E. et al., 2003; Ma P., 2004a; Ma P., 2004b).

Entre las técnicas más recientes y complejas se halla el proceso de electrospinning que utiliza un campo eléctrico de alta intensidad para la formación y el depósito de fibras de polímeros sobre un sustrato y el prototipado tridimensional. Este último implica estrategias de fabricación por capas a partir de modelos generados por un ordenador, utilizando software de diseño asistido y una computadora de manufactura (Mano J. et al., 2007; Ma P., 2004a; Ma P., 2004b; Sachlos E. et al., 2003).

Por lo dicho anteriormente que se deduce la importancia de seleccionar la técnica correcta según la aplicación final deseada. 


\subsection{Quitosano como biomaterial.}

La utilización del quitosano como biomaterial en ingeniería de tejidos genera interés debido gran versatilidad. Se ha estimulado su empleo en diversas aplicaciones en el área biomédica y farmacéutica no sólo por su bajo costo y fácil accesibilidad sino por poseer interesantes propiedades de biocompatibilidad (Muzzarelli R., 1993) y biodegradabilidad (Shigemasa Y. et al., 1994), por su naturaleza catiónica e hidrofilidad, además de ser no tóxico (Hirano S. et al., 1990) y poseer efectos antimicrobianos (Khor E. et al., 2003). Como se comentó anteriormente la biocompatibilidad y la biodegradabilidad son una de las características biológicas más importantes de ahí que en la actualidad sea un biopolímero ampliamente utilizado en la ingeniería de tejido y medicina regenerativa. Otras propiedades tales como sus efectos analgésico, antitumoral, hemostático, hipocolesterolémico y antioxidante también han sido reportadas (Ravi Kumar M. et al., 2004).

La biocompatibilidad del quitosano y por tanto gran parte del interés como biomaterial se debe principalmente a la similitud estructural y bioquímica de las unidades de $\mathrm{N}$-acetilglucosamina y glucosamina con la mayoría de las biomoléculas que conforman los tejidos del cuerpo humano, en particular con los glicosaminoglicanos de la matriz extracelular de vertebrados que se sabe están implicados en una amplia variedad de procesos biológicos que incluyen la migración, diferenciación y proliferación celular, la respuesta inmune y la organización citoesquelética (Khan T. et al., 2000).

La capacidad del quitosano de soportar y modular el crecimiento y proliferación celular ha sido probada con éxito en células vasculares del miocardio y endoteliales, células neuronales, fibroblastos, hepatocitos, y células epiteliales o queratinocitos (Chatelet C. et al., 2001; Wang J. et al., 2003).

La naturaleza catiónica y gran densidad de carga en solución del quitosano es una de las propiedades innatas de gran importancia. Los glicosaminoglicanos son una clase de macromoléculas de naturaleza aniónica que interaccionan con factores de crecimiento, receptores y proteínas de adhesión, por lo que el quitosano puede no sólo interaccionar con dichos compuestos sino también con proteoglicanos, los cuales tienen la función de organizar y dar funcionamiento adecuado a la matriz extracelular, y otras especies 
cargadas negativamente distribuidas ampliamente en el organismo. En diversas aplicaciones de ingeniería de tejidos esta propiedad es esencial debido a que un gran número de citoquinas y factores de crecimiento son modulados por glicosaminoglicanos tales como la heparina, hialuronato, dermatán sulfato, el sulfato de condroitina y sulfato de queratina.

La biodegradabilidad del quitosano ocurre gracias a la hidrólisis de los enlaces glicosídicos por medio de hidrolasas tales como quitosanasa, quitinasa, lipasa, glicosidasa, lisozima, y fosfatasa. En varios fluidos y tejidos de mamíferos la biodegradación del quitosano es catalizada por la lisozima, una enzima no específica (Shigemasa Y. et al., 1994) y se ha reportado que la escisión del enlace glucosídico del quitosano por la lisozima podría deberse a la unión de los residuos de $\mathrm{N}$-acetilglucosamina al sitio activo de la enzima (Aiba S., 1992). Su acción produce oligoquitosacáridos no tóxicos de longitud variable, que estimulan a las diferentes células, mientras que los monómeros liberados se fosforilan y se incorporan por vías metabólicas a glicosaminoglicanos (ácido hialurónico, sulfato de queratán y condroitín sulfato) y glicoproteínas, componentes del tejido conectivo y matriz extracelular (Muzzarelli R., 1997). Además dichos productos pueden ser excretados (Pangburn S. et al., 1982).

Además es importante destacar que la tasa de degradación, la cual se halla relacionada con que el grado de acetilación (DA) (Hirano S. et al., 1989) también afecta a la biocompatibilidad. Tasas degradativas elevadas en muestras de quitosano con alto DA producen acumulación de amino azúcares y por lo tanto una respuesta inflamatoria aguda mientras que quitosanos con bajo DA inducen una respuesta mínima debido a la baja tasa de degradación (Kurita K. et al., 2000).

Respecto de la actividad antimicrobiana del quitosano y sus derivados, se ha sugerido, por su naturaleza policatiónica, la interacción con grupos aniónicos de la superficie celular de bacterias, levaduras y hongos, lo que generaría una barrera impermeable al transporte de solutos esenciales (Helander I. et al., 2001).

El quitosano es uno de los materiales con mayor potencial debido no sólo por sus propiedades biológicas sino también a sus propiedades físicas y químicas las cuales pueden ser controladas bajo condiciones suaves y mediante técnicas de procesamiento relativamente sencillas. El alto contenido en aminas primarias es una característica 
estructural única del quitosano que confiere propiedades funcionales para la biofabricación. Tal como se muestra en la figura 1.3, el pH altera sustancialmente el estado de carga y las propiedades del quitosano. En condiciones acuosas ligeramente ácidas, el grupo amino se encuentra protonado y el quitosano se comporta como un polielectrolito catiónico soluble. A pH elevado, las aminas se desprotonan, las repulsiones electrostáticas del quitosano se reducen, y el polímero se insolubiliza (Sorlier P. et al., 2001; Vårum, K. et al., 1994). Siendo el pKa quitosano cercano a la neutralidad (Rinaudo M. et al., 1999), la transición soluble-insoluble se produce a $\mathrm{pH}$ entre 6 y 6,5 un rango ideal para las aplicaciones biológicas (Yi H. et al., 2005). Esto permite la formación de asociaciones interpoliméricas que pueden ser utilizadas para producir diferentes soportes dependiendo de las condiciones para iniciar la transición soluble-insoluble (Madihaly S. et al., 1999; Montembault A. et al., 2005).

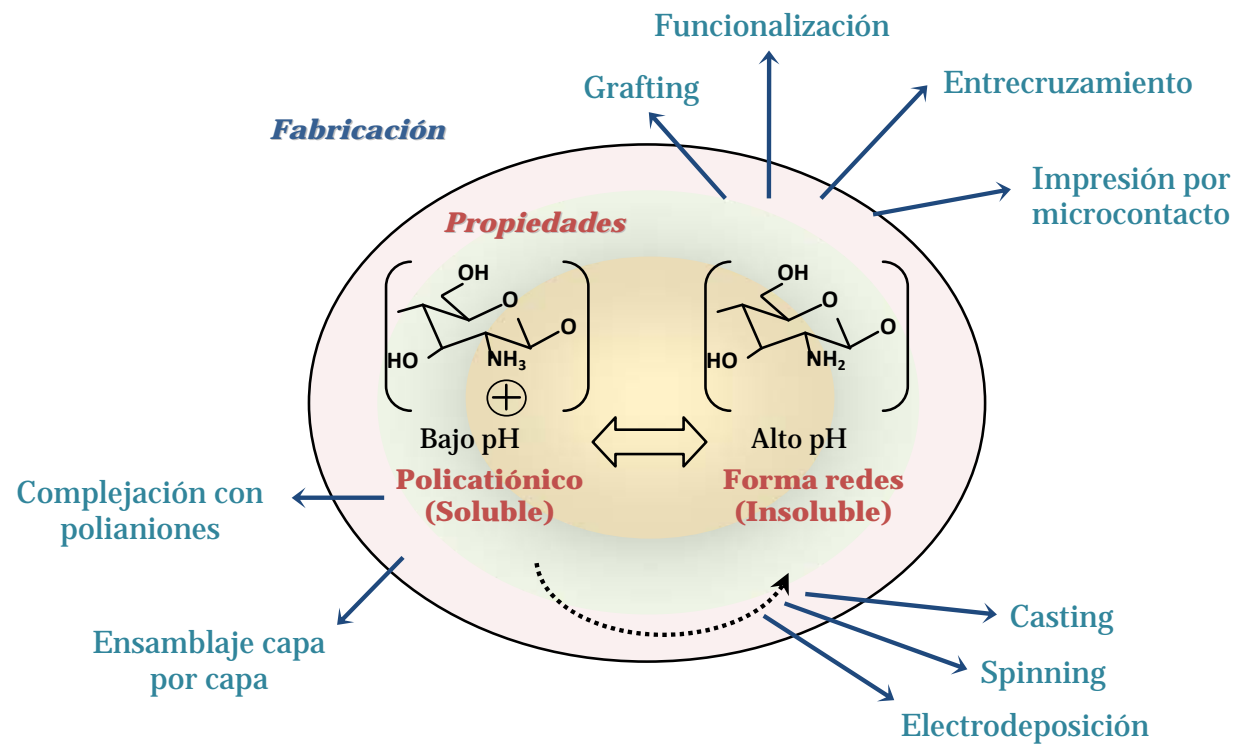

Figura 1.3. Representación esquemática de versatilidad del quitosano en la biofabricación. Tomado de Yi H. et al., 2005.

En este sentido ha sido evaluados scaffolds basados en quitosano procesados como films, hidrogeles, (Ashton R. et al., 2007), esponjas (Izquierdo R. et al., 2008), fibras (Chew S. et al., 2008), membranas (Costa Martinez E. et al., 2007) así como scaffolds inyectables basados tanto en la combinación de macropartículas y células (Garkhal K. et al., 2007), como de microesferas y nanopartículas. 
Existen numerosos reportes respecto a las características de los films de quitosano, las cuales varían en relación a las diferentes fuentes de quitina para producir quitosano, las propiedades y peso molecular del quitosano, los solventes utilizados, los métodos de preparación de la película, y los tipos y cantidad de plastificantes utilizados, entre otras (No H. et al., 1999; Nunthanid J. et al., 2001).

El quitosano tiene la habilidad de formar estructuras porosas mediante técnicas de procesamiento entre las que podemos mencionar la liofilización, en la cual una solución de quitosano en ácido acético es congelada y seguidamente liofilizada, obteniéndose una estructura porosa con un tamaño de poro que depende principalmente de la temperatura de congelación (Madihally S. et al., 1999). También es posible obtener estructuras porosas a través del proceso de formación interna de burbujas en el cual la solución de quitosano se mezcla con un porógeno como el carbonato cálcico (Chow K. et al., 2001). Además se han producido fibras de quitosano y mallas 3D por la técnica de electrospinning (Tuzlakoglu K. et al., 2004).

La preparación de micropartículas y su aplicación como scaffold en la ingeniería de tejido constituye una alternativa frente a los demás tipos de estructuras tridimensionales utilizadas con este fin. Existen diversos métodos para la obtención de micropartículas de quitosano entre las que podemos mencionar el método de emulsificación y gelificación ionotrópica (Acikgoz M. et al., 1996), coacervación (Chellat F. et al., 2000), la precipitación y entrecruzamiento químico (Aggarwal A. et al., 2001), la emulsión y entrecruzamiento químico (Denkbas E. et al., 1999), el método de evaporación de solvente (Lim S. et al., 2000), y el método de spray-drying (Filipovic-Grcic J. et al., 2003).

Las propiedades hasta ahora descritas y muchas otras hacen del quitosano un material de gran interés en el campo de la ingeniería tisular. La capacidad del quitosano de formar soportes ha encontrado muchas aplicaciones dentro de los campos de ingeniería de tejidos y liberación de drogas, para mantener, reforzar y en algunos casos organizar la regeneración tisular así como para liberar materiales bioactivos o influenciar directamente el crecimiento celular.

Los scaffolds de quitosano han sido utilizados en varios tipos de tejidos en los que se pueden incluir: el tejido óseo (Seol Y. et al., 2004; Malafaya P. et al., 2005), el cartílago (Suh J. et al., 2000; Oliveira S. et al., 2009), el hígado (Li J. et al., 2003), los vasos 
sanguíneos, la regeneración de nervios (Huang Y. et al., 2005b) y en la regeneración de la piel entre otros.

\subsubsection{Quitosano en aplicaciones de ingeniería en tejido óseo.}

Dentro de la gran variedad de polímeros naturales propuestos para el desarrollo de scaffolds ingeniería de tejido óseo, el quitosano es ampliamente estudiado. Diversos reportes de biocompatibilidad in vitro demuestran la notable citocompatibilidad y capacidad osteogénica del quitosano al promover la adhesión y proliferación celular de células osteoblásticas, células madre mesenquimales, células osteoprogenitoras, así como por la deposición de sales minerales en cultivos de osteoblastos (Muzzarelli R. et al., 1993; Kim I. et al., 2008; Tuzlakoglu K. et al., 2004; Fakhry A. et al., 2004). Además el quitosano puede moldearse en estructuras porosas que permiten la osteoconducción (Kawakami T. et al, 1992; Martino A. et al., 2005).

Fakhry y colaboradores (Fakhry et al., 2004) realizaron un análisis de la adhesión celular y de los perfiles fenotípicos de osteoblastos y fibroblastos de ratón cultivados en quitosano y demostraron una significativa adhesión temprana de osteoblastos, así como una mejor extensión y mejor desarrollo del citoesqueleto en comparación con los fibroblastos.

Por su parte Seol y colaboradores (Seol Y. et al., 2004) estudiaron el crecimiento y proliferación celular de osteoblastos de calvaria de rata sobre esponjas porosas de quitosano fabricadas por liofilización. Dichos autores evaluaron la actividad de la fosfatasa alcalina, la deposición de calcio, así como por estudios histológicos realizados luego de 56 días y corroboraron la formación ósea dentro de las esponjas.

\subsection{Mezclas de quitosano con otras sustancias.}

El quitosano como biopolímero natural, es un material que posee propiedades biológicas adecuadas, y por ello, dentro de la gran variedad de polímeros propuestos para el desarrollo de scaffolds, ha sido ampliamente utilizado en solitario (García Cruz D. et al., 2008a; Tuzlakoglu K. et al., 2004). Sin embargo en ocasiones sus aplicaciones en la 
regeneración del tejido óseo se ven restringidas no sólo por su hidrofilicidad, las pobres propiedades mecánicas de los scaffolds propias de su alta temperatura de transición vítrea y su cristalinidad (Madihally S. et al., 1999) sino también por su elevada tasa de degradación (Hirano S. et al., 1989) y limitaciones en el soporte de la adhesión, proliferación celular (Lopez-Perez P. et al., 2007).

Con el objetivo de modificar las propiedades mecánicas del quitosano y mejorar la biocompatibilidad muchos autores han optado por la combinación con una gran variedad de materiales, entre los que se puede destacar la utilización de polímeros tanto de origen natural como sintético (Xiao Y. et al., 2008) y por la adición de agentes entrecruzantes que refuerzan las estructura (Berger J. et al., 2004).

\subsubsection{Mezclas poliméricas.}

La formación de mezclas entre polímeros naturales y sintéticos constituye una alternativa versátil y más eficiente que las modificaciones químicas para desarrollar nuevos materiales con propiedades combinadas que no se pueden alcanzar mediante el uso de polímeros individuales. En particular la amplia gama de propiedades fisicoquímicas y técnicas de procesamiento relativamente sencillas que provienen de los polímeros sintéticos pueden integrarse con la buena biocompatibilidad y biodegradabilidad dada por los polímeros naturales.

Existe gran variedad de mezclas poliméricas disponibles en la bibliografía. En el contexto de este trabajo de tesis importan aquellas mezclas de quitosanos con polímeros sintéticos como una manera más eficiente para mejorar la ductilidad de quitosano. En especial la mezcla de quitosano con un polímero sintético hidrofóbico constituye una manera sencilla de equilibrar su fuerte carácter hidrofílico y sus pobres propiedades mecánicas.

En los últimos tiempos se han estudiado mezclas de quitosanos con poliésteres alifáticos biodegradables como polihidroxibutirato y el copolímero polihidroxibutirato-covalerato, ácido poliláctico, poliglicólico, policaprolactona y sus copolímeros (Correlo V. et al., 2005; Castro C. et al., 2005), no sólo para su utilización en aplicaciones biomédicas 
sino también en la química ambiental con el fin de minimizar los residuos de envases plásticos y con ello reducir la contaminación ambiental.

Hsieh y colaboradores (Hsieh C. et al., 2005) modificaron matrices de quitosano con ácido $\gamma$-poli glutámico ( $\gamma$-PGA), un polímero hidrófilo y biodegradable. Dichos autores encontraron que la adición de $\mathrm{\gamma}$-PGA aumenta no solo la hidrofilicidad y adsorción de las proteínas séricas sino que además mejora las propiedades mecánicas, con un incremento de la fuerza máxima.

Costa-Pinto y colaboradores (Costa-Pinto A. et al., 2008) y Correlo y colaboradores (Correlo, V. et al., 2009) evaluaron scaffolds porosos 3D basados en quitosano y poliésteres creados mediante la técnica de moldeo por derretimiento y compresión seguido por lixiviación de sal. Mediante dicha técnica obtuvieron scaffolds con propiedades distintivas concernientes a la porosidad, interconectividad y propiedades mecánicas dependiendo de la cantidad y el tamaño de partícula del porógeno así como por la proporción y tipo de poliéster alifático utilizado en la mezcla. Dichos autores hallaron que son adecuados para el soporte en la adhesión, viabilidad/proliferación y diferenciación osteoblástica de una línea de células progenitoras de médula ósea de ratón.

\subsubsection{Poli- $\varepsilon$ - caprolactona.}

La poli- $\varepsilon$-caprolactona ( $P C L)$ es un poliéster semicristalino biodegradable que se obtiene a partir de la $\varepsilon$-caprolactona mediante polimerización por apertura del anillo (figura 1.4.). La estructura molecular de la PCL consta de un grupo éster y cinco grupos metilenos con características apolares que le confieren a la molécula propiedades similares a las olefinas. Entre sus características fisicoquímicas más relevantes se destacan un punto de fusión $(T \mathrm{~m})$ relativamente bajo, de alrededor de $60^{\circ} \mathrm{C}$ y una temperatura de transición vítrea (Tg) alrededor de los $-60^{\circ} \mathrm{C}$ (Brode G. et al., 1972).

Debido a su biodegradabilidad, biocompatibilidad, así como por poseer propiedades mecánicas adecuadas y condiciones de procesamiento bastante sencillas $(\mathrm{Ng}$ K. et al., 2000; Sarasam A. et al., 2005) ha sido ampliamente explorado por su uso potencial en medicina regenerativa. En la actualidad la $\mathrm{PCL}$ es de uso común como 
material de suturas (Amass W.et al., 1998), sistemas de liberación controlada de drogas (Coombes A. et al., 2004).

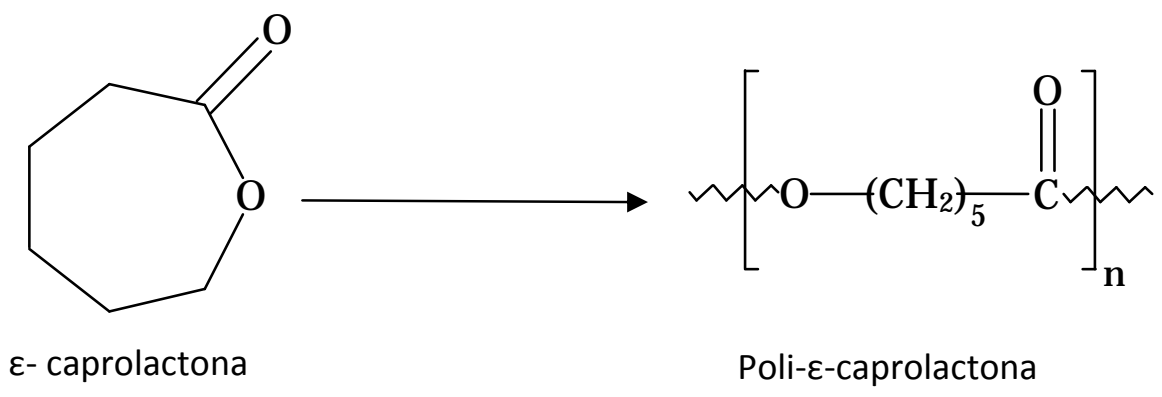

Figura 1.4. Reacción generalizada de obtención de poli-e-caprolactona por apertura de anillo.

Sin embargo, las aplicaciones de la PCL en solitario, especialmente aquellas relacionadas a la ingeniería de tejidos, se encuentran restringidas. Esto se debe a su naturaleza semicristalina, que retarda la entrada de fluidos a la matriz (Pitt C., 1990), y a sus propiedades hidrofóbicas, su carga neutral y la ausencia de grupos funcionales bioactivos, que genera una limitada actividad bioregulatoria y por ende una citocompatibilidad desfavorable en la adhesión y el crecimiento celular (Chen F. et al., 2007). Por su cristalinidad e hidrofobicidad, la cinética de degradación de la PCL es más bien lenta (Wu C., 2005). Por otra parte, su biodegradabilidad en medios biológicos in vitro e in vivo es consecuencia de la susceptibilidad de los enlaces éster a la hidrólisis no enzimática, seguida de la fragmentación en oligómeros (Chandy T. et al., 1990). Además presenta gran susceptibilidad a la degradación microbiana, haciendo de la PCL un material no favorable para el crecimiento celular.

Como alternativa en nuestro grupo de investigación de desarrollaron scaffolds a partir de mezclas de PCL con otros polímeros sintéticos (Cortizo M.S. et al, 2008; Fernandez J. et al., 2010; Fernandez J. et al., 2011). Dichos materiales fueron estudiados como scaffolds para el crecimiento de osteoblastos y se observó que poseen mayor capacidad osteogénica y osteoconducción respecto a aquellos compuestos únicamente por PCL. 
Por todo lo expuesto anteriormente resalta la importancia de generar, por mezcla de quitosano y $\mathrm{PCL}$, un biomaterial superior en donde las limitaciones del quitosano son complementadas por la PCL.

De hecho, Sarasam y Madihally (Sarasam A. et al., 2005) reportaron un mejoramiento en las propiedades mecánicas y en la adhesión celular en membranas de la mezcla de quitosano con poli- $\varepsilon$-caprolactona. Posteriormente Mei y colaboradores (Mei N. et al., 2005), García Cruz y colaboradores (García Cruz D. et al., 2008b) y Wu y colaboradores (Wu H. et al., 2010) prepararon y caracterizaron fisicoquímica, mecánica y biológicamente scaffolds similares.

El principal problema para la formación de mezclas entre la PCL y el quitosano radica en encontrar un solvente adecuado que sea común para los dos polímeros. La PCL es soluble en solventes orgánicos, mientras que el quitosano lo es en soluciones acuosas acidas diluidas. Sarasam y colaboradores (Sarasam A. et al., 2005; Sarasam A. et al., 2006) estudiaron las propiedades fisicoquímicas y antibacteriales de mezclas de PCL y quitosano y hallaron como solvente el acido acético glacial para la PCL y una solución acuosa de acido acético (0,5M) para disolver el quitosano. She y colaboradores (She H. et al., 2007) explican que cuando el quitosano se disuelve en ácido acético diluido, las cadenas macromoleculares tienden a alejarse unas de otras y se entremezclan con las cadenas de PCL.

\subsubsection{Refuerzo de la estructura del scaffold por entrecruzamiento.}

La incorporación de un agente entrecruzante en una matriz polimérica resulta importante en ingeniería de tejidos. Un agente entrecruzante es una molécula que posee al menos dos grupos funcionales reactivos que permiten la formación de puentes entre las cadenas poliméricas, y cuyo peso molecular es mucho menor que el de las cadenas entre dos entrecruzamientos consecutivos (Berger J. et al., 2004).

Los tratamientos de reticulación permiten modificar el comportamiento mecánico del material y por ende la integridad estructural del scaffold y también modificar la bioactividad y el patrón de degradación del scaffold. 
El entrecruzamiento de los scaffolds puede ocurrir por dos vías: la vía química donde la reticulación ocurre mediante la formación de enlaces covalentes entre el polímero y el agente reticulante y la vía física, donde la reticulación tiene lugar por interacciones electrostáticas.

De los varios agentes químicos estudiados capaces de reticular el quitosano pueden citarse a la epiclorhidrina y los dialdehídos como el glutaraldehido, y el glioxal (Berger J. et al., 2004). A pesar de elevada eficiencia reticulante y su bajo costo, dichas sustancias no son adecuados biológicamente debido a que los productos finales son por lo general tóxicos (Oliveira B. et al., 2005). Sin embargo en los últimos tiempos la genipina, un entrecruzante covalente natural ha despertado el interés de muchos científicos (Mi F. et al., 2003) debido a que no es tóxico.

El entrecruzamiento físico evita la posible toxicidad de reactivos y otros efectos indeseables del entrecruzamiento químico (Chen S. et al., 2008). Es un procedimiento simple que no requiere de moléculas auxiliares como catalizadores y por lo general utiliza contraiones multifuncionales de bajo peso molecular. Entre los más comúnmente se encuentran moléculas portadoras de grupos fosfatos; como el tripolifosfato, un polianión no tóxico (Mi F. et al., 1999; Shu X. et al., 2002a; Shu X. et al., 2002b). Además los scaffolds entrecruzados pueden generarse directamente sumergiendo los scaffolds en soluciones del entrecruzante o por solubilización o dispersión de los agentes entrecruzantes en la solución polimérica (Berger J. et al., 2004).

El tripolifosfato (TPP) es un anión multivalente que posee como máximo 5 cargas negativas puede interaccionar con el quitosano por vía electrostática para formar redes iónicas entrecruzadas (Shu X. et al., 2002a; Shu X. et al., 2002b). Debido a esto los scaffolds de quitosano entrecruzados con TPP son ampliamente utilizados en la industria farmacéutica, particularmente en sistemas de liberación controlada de drogas (Shu X. et al., 2002a; Mi F. et al., 2003).

Tal como se comentó previamente en medio ácido el quitosano se comporta como un policatión cuyos grupos amonios pueden reaccionar con compuestos cargados negativamente. Esto permite la formación de una estructura reticulada mediante puentes iónicos (Muzzarelli R. et al., 2009; Chen S. et al., 2008). El entrecruzamiento del quitosano depende de la disponibilidad de los sitios catiónicos y de las especies cargadas 
negativamente (Tiwary A. et al., 2010), y el pH juega un papel fundamental en el tipo de entrecruzamiento (Bhumkar D. et al., 2006). Por tanto las propiedades de los scaffolds de quitosano están fuertemente influenciados por las interacciones electrostáticas existentes entre los aniones y quitosano (Shu X. et al., 2002a; Shu X. et al., 2002b).

Para el quitosano, el incremento del pH (especialmente cercano a su pKa) resulta en una disminución drástica del grado de ionización de los grupos amino. A pH superiores a 7,5 menos del $10 \%$ de los grupos aminos se hallan ionizados (Shu X. et al., 2002a; Shu X. et al., 2002b). Por otro lado la disminución del pH hacia una condición neutral o acídica reduce el número de cargas del TPP (Shu X. et al., 2002a; Shu X. et al., 2002b). Esto debilita la densidad del entrecruzamiento (Srinatha A. et al., 2008).

El mecanismo de entrecruzamiento del quitosano con el TPP puede ocurrir por deprotonación y/o por interacciones iónicas según las condiciones de $\mathrm{pH}$ (figura 1.5) (Bhumkar D. et al., 2006). En solución acuosa el tripolifosfato se disocia formando iones hidroxilo e iones fosfóricos. $\mathrm{A} \mathrm{pH}$ ácido $(\mathrm{pH}=3)$ únicamente están presentes los iones fosfóricos del TPP, los cuales interaccionan con los grupos amonio del quitosano y la reticulación es predominantemente iónica. $\mathrm{A}$ pH básico $(\mathrm{pH}=9)$ sin embargo coexisten en el TPP los iones hidroxilo y los iones fosfóricos, que compiten entre sí por los amonios del quitosano. Los iones hidroxilo se unen a los grupos amino y tiene lugar la deprotonación del quitosano (Bhumkar, D. et al., 2006).

Por otra parte los hidroxilos a lo largo de la cadena del quitosano también puede reaccionar reticulantes iónicos (Berger J. et al., 2004). Incluso pueden ocurrir interacciones hidrofóbicas adicionales dentro de la red, favorecidas por un aumento del DA en el quitosano o enlaces de hidrógeno intercatenarios debidos a la repulsión electrostática reducida luego de la neutralización de quitosano por el reticulante (RuelGariépy E. et al., 2000). 

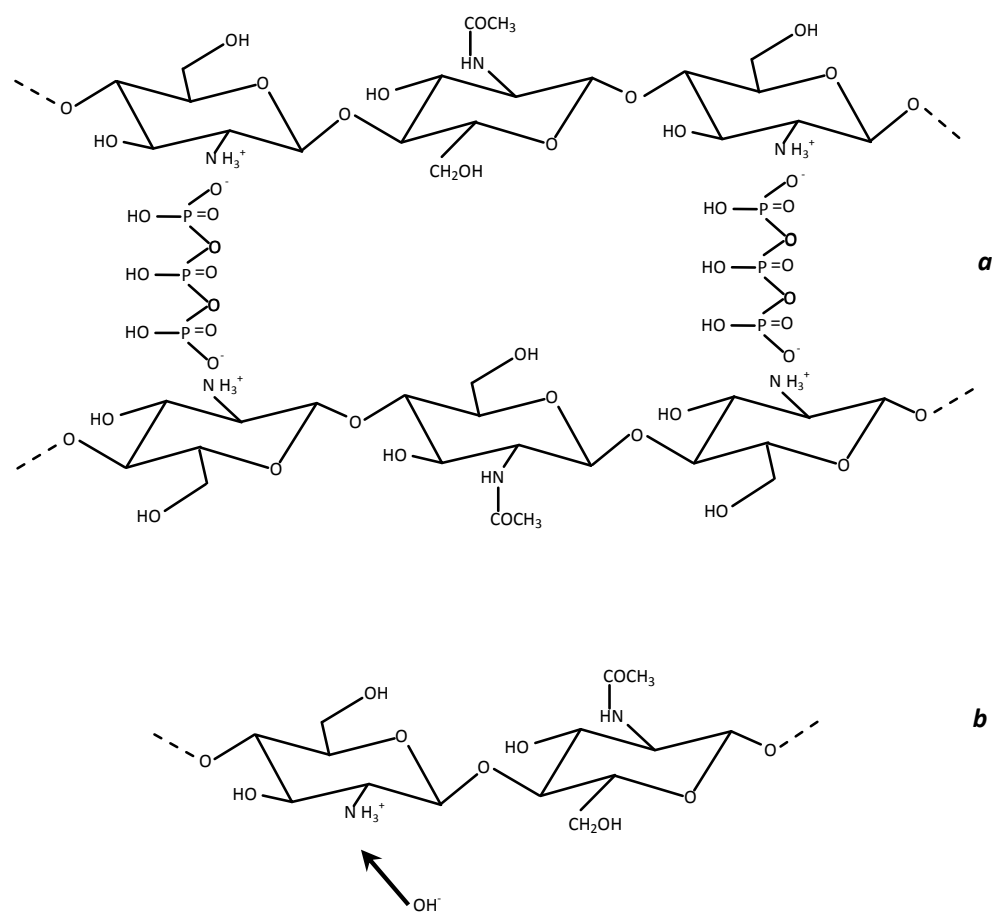

Figura 1.5. Interacción entre los grupos funcionales del quitosano y el tripolifosfato por entrecruzamiento iónico (a) y desprotonación del grupo amina (b). Basado en Bhumkar D. et al., 2006.

\section{SISTEMAS DE LIBERACIÓN CONTROLADA DE DROGAS EN INGENIERÍA DE TEJIDOS ÓSEO.}

\subsection{Sistemas de liberación controlada de drogas e ingeniería de tejidos.}

El problema de la administración convencional y repetitiva de un fármaco es que en cada administración la concentración terapéutica de la droga alcanza picos en el cuerpo y disminuye rápidamente, sobre todo cuando la velocidad de eliminación del mismo es muy elevada. Esto puede llevar a una situación desfavorable donde en algunos momentos la concentración de fármaco será demasiado bajo para proporcionar un beneficio terapéutico, y en otros momentos la concentración será demasiado alto resultando en efectos secundarios adversos (Nair L. et al., 2006). Además muchas desventajas asociadas al empleo de determinados fármacos consisten en que pueden 
alcanzar gran variedad de sitios en los cuales puede que se encuentren fuera de su intervalo terapéutico, que sean inactivos, o que su acción sea indeseada o nociva, y por tanto, con efectos secundarios negativos (Sáez V. et al., 2003).

La tecnología de liberación controlada de drogas mejora la eficacia terapéutica del fármaco y resuelve muchos de los problemas de la administración tradicional de drogas mediante el control de la localización espacial y la cinética de liberación del fármaco. Esto conlleva al aumento de la especificidad de los agentes terapéuticos para un determinado tejido celular, así como un incremento de la tasa terapéutica y biodisponibilidad del fármaco a un ritmo deseado y por un período específico de tiempo con el fin de mantener la concentración del fármaco dentro de la ventana terapéutica del mismo (Uhrich $K$. et al., 1999; Nair L. et al., 2006; Liechty W. et al., 2010; Mouriño V. et al., 2010). Además reduce el número de tratamientos necesarios y elimina la necesidad de la administración especializada de fármacos (por ejemplo las repetidas inyecciones) (Uhrich K. et al., 1999) ya que los sistemas de liberación controlada pueden ser localizados virtualmente en cualquier cavidad corporal del organismo en, o cerca de la zona enferma, y pueden ser implantados, o administrados sistémicamente a través de las membranas nasales (ruta nasal), de las membranas mucosas de la boca (ruta oral), del ojo (ruta oftálmica), de la piel (ruta transdermal), entre otras (Sáez V. et al., 2003).

Por otro lado las investigaciones demuestran que a menudo que los scaffolds por si solos no pueden proporcionar un modelo suficiente para guiar la reparación de heridas y regeneración de tejidos (Holland $T$. et al., 2006). Las aplicaciones biomédicas en ingeniería de tejidos han mejorado significativamente durante las dos últimas décadas, principalmente mediante la integración de los scaffolds con dispositivos de administración controlada de de fármacos. Esto permite que los scaffolds puedan realizar múltiples funciones como vehículos de liberación controlada de drogas capaces de controlar y guiar el proceso de regeneración de los tejidos (Peppas N. et al., 1994; Lee S. et al., 2007). Bajo este enfoque el agente terapéutico es atrapado en una matriz desde la cual se libera de manera controlada (figura 1.6.).

Entre los distintos sistemas considerados los polímeros biodegradables han ganado una considerable atención por su carácter no invasivo, el control sobre la las propiedades físico-químicas y la biodistribución, principalmente debidos a su estabilidad y 
una mayor capacidad de carga. Los polímeros incorporados con agentes terapéuticos pueden tanto ser bioactivos para proporcionar sus propios beneficios terapéuticos como biodegradarse y mejorar la cinética de liberación agente terapéutico y evitar su acumulación (Liechty W. et al., 2010).

La tasa y forma de liberación de fármacos a partir de los sistemas poliméricos están gobernadas por el control adecuado de una multitud de parámetros tales como la naturaleza y geometría de la matriz polimérica, el tipo y propiedades de la droga y la manera en la que se carga la droga, su tasa de depuración así como de la interacción entre la matriz polimérica y el fármaco (Nair L. et al., 2006; Mouriño V. et al., 2010). La configuración de la matriz, en forma de láminas, esponjas, hidrogeles, geles inyectables, micro y nanopartículas o sus composites, determina la estabilidad y la cinética de liberación del fármaco (Lee S. et al., 2007). El mecanismo y la velocidad de liberación de fármacos varía según el método de incorporación de la droga a la matriz, químico (covalente) o físico (no covalente, por atrapamiento, adsorción a la superficie o por complejación iónica) (Lee S. et al., 2007; Nair L. et al., 2006).

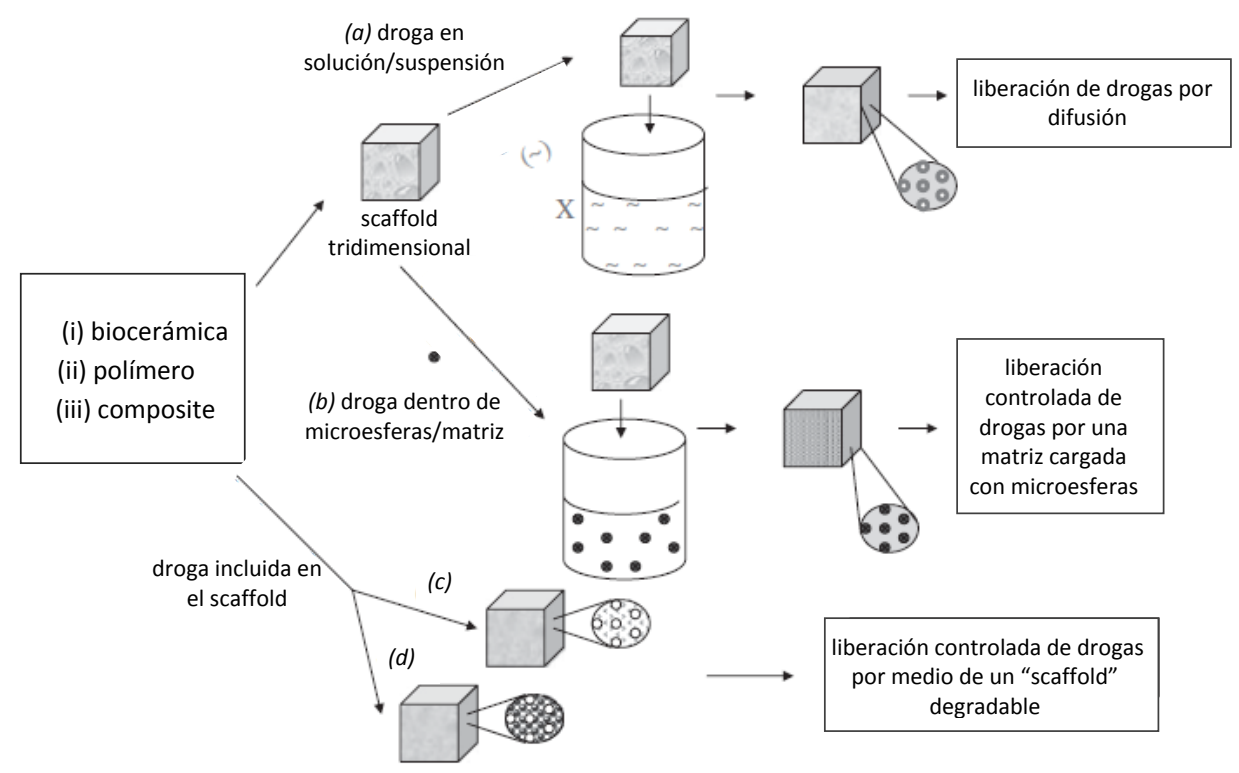

Figura 1.6. Representación esquemática de las estrategias más comunes de liberación de fármacos mediante scaffolds tridimensionales. Las drogas pueden ser adsorbidas a la superficie del "scaffold"(a) o atrapadas en la estructura del mismo (b), incluidas directamente (c) o dentro de microesferas (d). Tomado de Mouriño V. et al., 2010. 
Los hidrogeles, redes tridimensionales entrecruzadas capaces de absorber grandes cantidades de agua o fluidos biológicos (Berger J. et al., 2004), son ampliamente investigados como sistemas de liberación (Peppas N. et al., 2000). Una de las características más notorias de dichos sistemas es que el hinchamiento y por tanto de la tasa de liberación de fármaco puede ser controlados por los estímulos externos, tales como el pH, la fuerza iónica y la temperatura (Nair L. et al., 2006). En este contexto se han investigado hidrogeles poliméricos basados en colágeno, fibrina, quitosano (SokolskyPapkov M. et al., 2007; Malafaya P. et al., 2007) así como por polímeros sintéticos, entre los que se puede citar al polietilenglicol (Burdick J. et al., 2002). Los hidrogeles basados en quitosano muestran mayor hinchamiento cuando el pH del medio está por debajo pKa del polímero (Nair L. et al., 2006).

La liberación del fármaco desde las matrices se realiza por la degradación y la erosión del polímero, así los polímeros biodegradables y bioerosionables son los más relevantes en aplicaciones de administración de fármacos. La biodegradación es con frecuencia una característica deseable para las aplicaciones de liberación controlada ya que permite una eliminación completa mediante el metabolismo (Uhrich K. et al., 1999). La degradación se diferencia de la erosión en que ruptura del enlace covalente se produce por reacciones químicas (Liechty W. et al., 2010). Las rutas más comunes de la biodegradación in vivo son la hidrólisis y la ruptura enzimática que resulta en la escisión de la cadena del polímero. Es por ello que los polímeros que poseen en su estructura enlaces lábiles como por ejemplo, anhídrido, éster, amida son sensibles a la actividad enzimática. (Liechty W. et al., 2010). Sin embargo, para algunos polímeros, la escisión de las cadenas laterales resulta en un producto soluble que puede ser excretado.

Mientras que en los polímeros naturales como en el quitosano la degradación ocurre por ruptura del enlace glicosídico en los residuos de N-acetilglucosamina (Aiba S., 1992), en la mayoría de los polímeros sintéticos biodegradables como el ácido poliláctico/

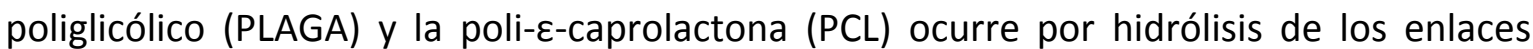
éster (Liechty W. et al., 2010). Debido a su baja tasa de degradación y su elevada permeabilidad a drogas en comparación con el PLAGA, la PCL es extensamente investigada como sistema de liberación controlada de droga a largo plazo (Blanco M. et al., 2003). 


\subsection{Sistemas de liberación controlada de drogas en ingeniería de tejido óseo.}

La mejora de la actividad biológica y el rendimiento de los scaffolds como sustitutos óseo es una de las principales preocupaciones en la regeneración ósea (Mouriño V. et al., 2010). Avances recientes en la biología, la medicina y la ingeniería han llevado al descubrimiento de nuevos agentes terapéuticos y nuevos materiales para la reparación de grandes defectos óseos causados por trauma, defectos congénitos o tumores óseos (Holland T. et al., 2006). La regeneración de defectos óseos puede acelerarse mediante la incorporación de agentes terapéuticos en scaffolds biodegradables que se liberen controladamente durante un tiempo y a un ritmo adecuados, de modo de permanecer en los sitios de lesión durante un tiempo suficiente para reclutar osteoprogenitores y estimular los procesos de cicatrización del tejido (Lee S. et al., 2007).

Existe una amplia gama de materiales poliméricos biodegradables que se pueden seleccionarse en ingeniería de tejido y liberación controlada de droga del sistema óseo, que muestran diferentes tasa de liberación del fármaco, tasas y mecanismos de degradación (Nair L. et al., 2006), así como la tasa de crecimiento de tejido (Holland T. et al., 2006). Dependiendo del tamaño, la forma y la estructura de defectos óseos, el sistema puede ser preformulado antes de la implantación, o inyectarse directamente en el sitio de la lesión (Lee S. et al., 2007).

Respecto a las numerosas estrategias de liberación de agentes terapéuticos citadas en la literatura con el fin de promover la regeneración ósea, éstas consisten en liberar factores de crecimiento específicos (por ejemplo, citoquinas y hormonas); morfógenos, proteínas, agentes antimicrobianos y antiinflamatorios (glucocorticoides, la dexametasona, ibuprofeno), así como fármacos para el tratamiento de trastornos óseos (Mouriño V. et al., 2010). De hecho se han formulado scaffolds porosos y nanofibras de quitosano en combinación con factores de crecimiento que promueven la formación ósea (Lee S. et al., 2007). 


\subsection{Bisfosfonatos.}

Los bisfosfonatos (BPs) son compuestos sintéticos de pequeño tamaño (menor a 300Da) que presentan en su estructura ácido fosfónico. Son análogos estables de los pirofosfatos inorgánicos (figura 1.7.) y se diferencian de éstos en que el átomo de oxígeno que une los grupos fosfato del pirofosfato se halla sustituido por un átomo de carbono. Esta particularidad les confiere mayor resistencia a la hidrólisis enzimática (Papapoulos S., 2008).<smiles>O=P(O)(O)OP(=O)(O)O</smiles>

$a$<smiles>[R]C([R2])(P(=O)(O)O)P(=O)(O)O</smiles>

b

Figura 1.7. Estructura química genérica del pirofosfato inorgánico (a) y bisfosfonatos (b).Tomado de Pappalopulos S., 2008.

En la actualidad los bisfosfonatos son ampliamente utilizados para el diagnóstico y tratamiento de una gran variedad de enfermedades con alto remodelamiento óseo tales como la enfermedad de Paget del hueso, el mieloma, la hipercalcemia del cáncer, la enfermedad metastásica ósea y diferentes tipos de osteoporosis (Russell R. et al., 1999; Panzavolta et al. 2009).

Estudios recientes implican a diversos posibles objetivos para la acción de estos fármacos. El principal efecto de los bifosfonatos es la inhibición de la resorción ósea y esto ocurre por mecanismos fisicoquímicos y mediante efectos celulares sobre osteoclastos. En el primer caso, la incorporación de los BPs a los cristales de hidroxiapatita en la superficie de la matriz ósea altera el proceso de mineralización, logrando como resultado que la sustancia ósea se vuelva menos soluble, y por tanto inhiben la precipitación de fosfato de calcio in vitro y calcificación in vivo (Rogers M. et al., 1997). En relación a los efectos sobre osteoclastos éstos se llevan a cabo por la disminución en el desarrollo y reclutamiento de precursores osteoclásticos y osteoclastos 
y por la promoción de la apoptosis de osteoclastos maduros (Hughes D. et al., 1995; Russell R. et al., 1999). Además los BPs ejercen efectos directos sobre osteoblastos, osteocitos, y macrófagos, regulando así la función de las diferentes células en el esqueleto.

\subsubsection{Relación estructura-actividad de los bisfosfonatos.}

La inhibición de la resorción ósea mediada por bisfosfonatos se halla estrechamente vinculada por la presencia de dos dominios funcionales de la molécula (Rogers M. et al., 1997) (figura 1.8.). Por un lado el dominio compuesto por los grupos fosfónicos es esencial en la afinidad por la hidroxiapatita y para el mecanismo bioquímico de acción. La unión con la hidroxiapatita ocurre como resultado de la quelación de iones de calcio mediante la coordinación bidentada con los átomos de oxígeno de los grupos fosfonato (Fleisch H. et al., 1969). Por otro lado, las variaciones en la estructura de las cadenas laterales, $R_{1}$ y $R_{\mathbf{2}}$ que parten del átomo de carbono (tabla 1.2.) generan diferencias en cuanto a su actividad y propiedades biológicas, su potencia como inhibidores de la resorción ósea, la farmacocinética y la toxicidad.

Generalmente $\mathrm{R}_{\mathbf{1}}$ es un grupo hidroxilo $(\mathrm{OH})$, lo cual maximiza la afinidad de unión al hueso y previene tanto el crecimiento del cristal como su disolución (Jung A. et al., 1973). La estructura de la cadena lateral $R_{2}$ es el determinante fundamental del potencial antirresortivo, incluyendo efectos en la unión con la hidroxiapatita (Geddes A. et al., 1994). La máxima potencialidad se debe a la presencia de átomos de nitrógeno en posiciones críticas de la cadena lateral y en una configuración específica. La metilación del grupo amino o la inclusión de éste dentro de un anillo heterocíclico incrementa más aun la potencia. Así aquellos BPs que contienen un grupo amino primario (como el alendronato y pamidronato) son hasta 100 veces más potente que los que no son aminados como etidronato o clodronato (Shinoda H. et al., 1983; Schenk R. et al., 1986) y el ibandronato, risedronato y zoledronato que poseen un grupo amino secundario o terciario son los BPs de mayor potencia antiresortiva (Sietsema W. et al., 1989).

Una vez localizados en el hueso, la estructura y conformación del grupo $\mathbf{R}_{\mathbf{2}}$ así como la de los grupos fosfonatos determinan la actividad biológica e influencian la 
habilidad de la droga a interactuar sobre blancos moleculares específicos (Russell R. et al., 1999).

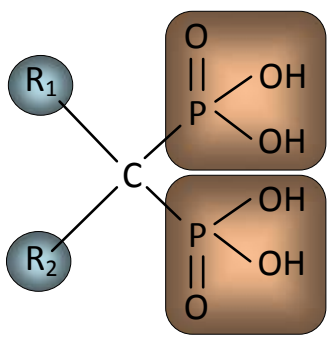

Figura 1.8. Dominios funcionales de los bisfosfonatos. Tomado de Russell R., 2007.

\begin{tabular}{|c|c|c|}
\hline Bisfosfonato & Cadena lateral R1 & Cadena lateral R2 \\
\hline Etidronato & $-\mathrm{OH}$ & $-\mathrm{CH}_{3}$ \\
\hline Clorodronato & $-\mathrm{Cl}$ & $-\mathrm{Cl}$ \\
\hline Tiluronato & $-H$ & \\
\hline Pamidronato & $-\mathrm{OH}$ & $-\mathrm{CH}_{2}-\mathrm{CH}_{2}-\mathrm{NH}_{2}$ \\
\hline Alendronato & $-\mathrm{OH}$ & $-\left(\mathrm{CH}_{2}\right)_{3}-\mathrm{NH}_{2}$ \\
\hline Neridronato & $-\mathrm{OH}$ & $-\left(\mathrm{CH}_{3}\right)_{5}-\mathrm{NH}_{2}$ \\
\hline Olpadronato & $-\mathrm{OH}$ & $-\left(\mathrm{CH}_{2}\right)_{2}-\mathrm{N}\left(\mathrm{CH}_{3}\right)_{2}$ \\
\hline Ibandronato & $-\mathrm{OH}$ & $-\mathrm{CH}_{2}-\mathrm{N} \backslash\left(\mathrm{CH}_{2}\right)_{4}-\mathrm{CH}_{3}$ \\
\hline Risedronato & $-\mathrm{OH}$ & \\
\hline Zoledronato & $-\mathrm{OH}$ & $-\mathrm{CH}_{2}-\mathrm{N}_{1}^{\prime}$ \\
\hline
\end{tabular}

Tabla 1.2. Estructura de los bifosfonatos utilizados en humanos. Tomado de Ezra A. et al., 2000. 
Anteriormente los distintos BPs se clasificaban sobre la base a su potencia para inhibir eficazmente la resorción ósea en BPs de primera generación (etidronato), segunda generación (tiludronato, clodronato, pamidronato) y tercera generación (neridronato, olpadronato, ibandronato, risedronato, alendronato) (Rosen C. et al., 1996). Actualmente se clasifican según sus mecanismos moleculares de acción.

\subsubsection{Mecanismos de acción y efectos celulares en sistema óseo.}

La acción antirresortiva directa de los BPs sobre los osteoclastos genera efectos celulares adversos en la función osteoclástica y supervivencia celular, reduciendo el número de osteoclastos maduros. Una vez que se adsorben al mineral óseo, especialmente en los sitios de resorción (donde el mineral está más expuesto), los BPs se internalizan en los osteoclastos por endocitosis y perturban el metabolismo celular por inhibición enzimática, desorganizando las fibras de actina citoesqueletarias con posterior pérdida del borde en cepillo (Murakami H. et al., 1995; Sato M. et al., 1991). Esto conlleva a la pérdida de la capacidad resortiva de los osteoclastos e induce en última instancia la apoptosis (Hughes D. et al., 1995), una forma de muerte celular programada.

Las diferencias en la estructura de la cadena lateral $R_{2}$ de los bifosfonatos ejercen influencias sobre el mecanismo molecular de acción para causar apoptosis. Los BPs no aminados como clodronato y etidronato, son metabolizados a análogos tóxicos no hidrolizables del ATP, que se acumulan intracelularmente e inhiben enzimas dependientes del ATP (Frith J. et al., 1996). Por otra parte BPs aminados y más potentes como alendronato y risedronato, interfieren en las reacciones enzimáticas de la vía del mevalonato, lo que previene la biosíntesis de compuestos isoprenoides e inhibe la prenilación de proteínas regulatorias clave en procesos celulares importantes de la función osteoclástica (Rogers M., 2004).

Además del efecto directo proapoptótico sobre osteoclastos maduros, los BPs generan efectos que están mediados indirectamente por prevención de fusión de precursores osteoclásticos de la médula o el bazo (Boonekamp P. et al., 1986) o por acciones sobre células del linaje osteoblástico. Esto último puede ocurrir por prevención de la secreción de factores estimulantes de los osteoclastos o por estimulación de la 
producción de factor inhibitorio de los osteoclastos (Sahni M. et al., 1993; Niskikawa M. et al., 1996). Por ello, las células osteoblásticas tratadas con bifosfonatos exhiben una capacidad reducida para promover la formación de osteoclastos, e inhiben la resorción ósea mediante los osteoclastos maduros (Vitte C. et al., 1996).

Los bisfosfonatos no sólo inhiben la resorción ósea sino que también tienen un efecto positivo sobre la formación de hueso al afectar directamente a las células del linaje osteoblástico, estimulando el desarrollo de progenitores (Giuliani N. et al., 1998; Im G. et al., 2004), así como la proliferación y diferenciación de osteoblastos en cultivo (Vaisman D. et al., 2004) mediante la regulación de diferentes vía enzimáticas (Mathov l. et al., 2001; Itoh F. et al., 2003). Además se ha demostrado in vitro e in vivo el efecto antiapoptótico de los BPs sobre osteocitos y osteoblastos (Plotkin L. et al., 1999; Bellido T. et al., 2006). Esto permite el mantenimiento de la función mecanorreceptora de osteocitos y el aumento del grosor del hueso trabecular al demorar la apoptosis de osteoblastos y por tanto contribuye a la eficacia antifractura de los bisfosfonatos (Balena R. et al., 1993; Storm T. et al., 1993).

Plotkin y colaboradores (Plotkin L. et al., 1999; Plotkin L. et al., 2006) estudiaron los efectos anti-apoptóticos de los BPs sobre las células del linaje osteoblástico y demostraron que estos ocurren por mecanismos diferentes e independientemente de la estructura del BPs y de su capacidad de inducir la apoptosis en osteoclastos. Además dichos autores demostraron que los efectos antiapoptóticos en osteoblastos y osteocitos ocurren de manera dosis dependiente a concentraciones observadas de entre $10^{-8}$ a $10^{-7}$ $M$, varios órdenes de magnitud menores que las requeridas para inducir apoptosis de osteoclastos, las cuales se hallan entre $10^{-5}$ a $10^{-4} \mathrm{M}$ (Plotkin L. et al., 1999; Hughes D.et al., 1995).

Vaisman y colaboradores (Vaisman D. et al., 2004; Vaisman D. et al., 2005) investigaron el posible efecto directo de tres BPs nitrogenados (alendronato, pamidronato y zoledronato) sobre la actividad específica de la exoenzima osteoblástica fosfatasa alcalina (ALP), implicada en la formación ósea y la mineralización, a partir de un extracto de células UMR-106 de osteosarcoma de rata. Dichos autores hallaron que los BPs inhiben la actividad de la ALP por medio de la quelación de cationes divalentes por 
parte de los grupos fosfónicos, en un modo dosis y tiempo dependiente y en un rango de concentración de entre $10^{-5} \mathrm{M}$ y $10^{-4} \mathrm{M}$.

\subsubsection{Bisfosfonatos en sistemas de liberación controlada de drogas.}

A pesar de su amplia utilización en enfermedades con alto remodelamiento óseo, la mayor desventaja de los BPs es su baja biodisponibilidad debido a su mínima absorción intestinal, la cual varía típicamente entre un $1 \%$ a $10 \%$, dependiendo de la estructura química, la dosis y la ruta de administración (Ezra A. et al., 2000). Además presenta importantes efectos secundarios como malestares estomacales, úlceras de garganta e inflamación del esófago. Como alternativa del tratamiento sistémico de administración y con el objetivo de mejorar la biodisponibilidad y la seguridad en el uso de la terapia con bifosfonatos, se ha estudiado sistemas de administración local nasales y subcutáneos, así como por la utilización de scaffolds de liberación de drogas (Ezra A. et al., 2000).

En este sentido Nieto y colaboradores (Nieto A. et al., 2008) evaluaron el control del dosaje del alendronato sódico en scaffolds mesoporosos basados en sílica y Fauchex y colaboradores (Fauchex C. et al., 2009) evaluaron los efectos celulares de la liberación in vitro de zoledronato en sistemas basados en apatita deficiente en calcio.

Patashnik y colaboradores (Patashnik S. et al., 1997) prepararon y evaluaron microesferas de quitosano cargadas con derivados bisfosfónicos. $\mathrm{Y}$ por otra parte Golomb y colaboradores (Golomb G. et al., 1992) evaluaron la eficacia prolongada in vivo de matrices entrecruzadas de quitosano conteniendo derivados bisfosfónicos. 
II.

Hipótesis de Trabajo

y Objetivos. 


\section{HIPÓTESIS DE TRABAJO Y OBJETIVOS}

\section{JUSTIFICACIÓN}

Enfermedades tales como osteoporosis, osteonecrosis, osteogénesis imperfecta y tumores óseos se caracterizan por pérdida de masa ósea con deterioro de la microarquitectura lo que se asocia con riesgo de fractura en la población general. Las terapias convencionales para la reparación de lesiones óseas incluyen la reconstrucción quirúrgica, el trasplante, y el reemplazo por prótesis artificiales. En la actualidad el tratamiento de dichas enfermedades es un área de gran interés, a tal punto que la ingeniería de tejidos se ha convertido en una terapia alternativa para tratar la pérdida de hueso por medio de la utilización de productos biomédicos obtenidos a partir de biomateriales con aplicaciones en reparación de tejidos dañados.

\section{HIPÓTESIS DE TRABAJO}

Es posible crear scaffolds biodegradables basados en quitosano obtenido a partir de la pluma de calamar. Las características de este biopolímero extraído de fuentes marinas encajan perfectamente con aquellas cualidades necesarias para el diseño de soportes poliméricos biocompatibles que pueden ser utilizados en ingeniería tisular regenerativa del tejido óseo.

Sobre la base de esta hipótesis se trazó el siguiente objetivo general: 


\section{OBJETIVOS}

\section{Objetivo general:}

Desarrollo y caracterización de scaffolds basados en mezclas de los polímeros biodegradables quitosano y el poliéster sintético poli- $\varepsilon$-caprolactona, con o sin drogas con actividad osteogénica, que favorezcan el crecimiento de células del tejido óseo para su utilización en aplicaciones de ingeniería tisular de reparación y regeneración del tejido óseo y su posterior aplicación en implantes óseos.

Para alcanzar este objetivo general se plantearon los siguientes objetivos específicos:

\section{Objetivos específicos:}

1) Preparación de scaffolds basados en mezclas de quitosano y poli-e-caprolactona, compatibilizados mediante el uso del entrecruzante no tóxico tripolifosfato de sodio, con o sin la inclusión de la droga bisfosfónica alendronato de sodio.

2) Caracterización fisicoquímica y estructural de los scaffolds preparados a partir de la mezcla de quitosano y poliéster utilizando técnicas de microscopía y espectroscópicas.

3) Evaluación de la respuesta biológica (biocompatibilidad y posible citotoxicidad) de los diferentes scaffolds con un modelo experimental in vitro de osteoblastos en cultivo.

La evaluación de las características fisicoquímicas y biológicas de los diferentes scaffolds permitirá seleccionar los más adecuados para su posterior aplicación como futuro material de aplicación en el tratamiento de lesiones óseas. 
III.

Parte Experimental.

Elaboración y Caracterización de

"Scaffolds" Biodegradables

Quitosano/

Poli-e-caprolactona

para

Regeneración Ósea. 


\section{EXPERIMENTAL: DESARROLLO Y CARACTERIZACIÓN DE SCAFFOLDS BIODEGRADABLES QUITOSANO/POLI-E-CAPROLACTONA PARA REGENERACIÓN ÓSEA.}

\section{ELABORACIÓN DE SCAFFOLDS BASADOS EN QUITOSANO/ POLI- $\varepsilon-C A P R O L A C T O N A$ POR LA TÉCNICA DE EVAPORACIÓN DE SOLVENTE.}

Para la elaboración de los scaffolds biodegradables de quitosano (Qo) y poli- $\varepsilon$ caprolactona $(\mathrm{PCL})$ se utilizó la técnica de evaporación de solvente o solvent casting, la cual se basa en la disolución del polímero en un solvente orgánico, y una vez disuelto, se vierte en un molde para luego dejar que ocurra la evaporación del solvente.

Respecto de los polímeros utilizados para la preparación de las mezclas de

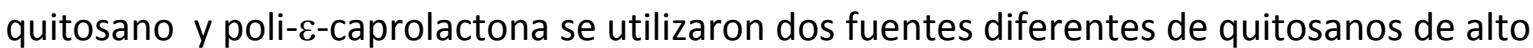
peso molecular: quitosano de origen comercial Sigma Aldrich (QoA) y aquel obtenido por desacetilación de quitina del calamar argentino Illex argentinus (Qol), previamente caracterizado en la sección A de esta tesis. Dichas muestras poseen grados de acetilación de $21 \%$ y $7,4 \%$, respectivamente (determinado mediante espectroscopia FTIR), y valores de peso molecular promedio viscosimétrico $(\mathrm{Mv})$ de 511000 y $779500 \mathrm{~g} / \mathrm{mol}$ respectivamente. Previo a su utilización el quitosano fue purificado por disolución y precipitación (Rinaudo M., 2006). Para ello fue disuelto en solución de ácido acético 1\% (p/v) y filtrado bajo sistema Buchner. Posteriormente se ajustó el pH de la solución en un valor de 7,5 por adición de $\mathrm{NaOH}$, lo que causó la insolubilización del polímero. Por último el polímero fue neutralizado con agua destilada, freezado y liofilizado.

La poli- $\varepsilon$-caprolactona $(\mathrm{PCL})$ (Aldrich) utilizada posee un peso molecular promedio en peso $(\mathrm{Mw}$ ) de $65000 \mathrm{~g} / \mathrm{mol}$ e índice de polidispersidad de 1.4 (según lo indicado por el fabricante).

Se prepararon soluciones de quitosano y PCL en acido acético, por ser un solvente común a ambos polímeros (Sarasam A. et al., 2005). La PCL fue disuelta en ácido acético 
glacial $(\mathrm{AcH})$ y las muestras de quitosano (QoA y Qol) fueron disueltas en soluciones acuosas de ácido acético al 0,5 M (3\% v/v), según lo reportado por Sarasam y colaboradores (Sarasam A. et al., 2005). Las concentraciones de ambos polímeros fueron de $0,5 \% \mathrm{p} / \mathrm{v}$. Todas las soluciones fueron preparadas con agua bidestilada (MilliQ), a temperatura ambiente y agitadas en un agitador mecánico a temperatura ambiente hasta disolución completa.

Para la realización de los scaffolds, fueron mezcladas las soluciones de los polímeros previamente disueltas en $\mathrm{AcH}$, en una relación 1:3 v/v Qo:PECL, respectivamente (Sarasam A. et al., 2005). Se generaron diferentes scaffolds de acuerdo a la adición o no del bisfosfonato alendronato sódico y el entrecruzante iónico tripolifosfato de sodio (tabla 3.1.).

Con el objeto de generar sistemas de liberación controlada de droga se prepararon soluciones acuosas de alendronato sódico, ácido-1-hidroxi-3-aminobutiliden1,1-bisfosfónico $\left(\mathrm{C}_{4} \mathrm{P}_{2} \mathrm{NO}_{7} \mathrm{H}_{9} \mathrm{Na}_{4} .3 \mathrm{H}_{2} \mathrm{O}\right.$, con peso molecular 391, provisto por Laboratorio Elea, Argentina) en un rango de concentración entre $1,5.10^{-7} \mathrm{M}$ y $1,5.10^{-5} \mathrm{M}$, a partir de una solución stock estable de $10^{-2} \mathrm{M}$. El rango de concentración fue seleccionado en base a lo reportado por Vaisman y colaboradores (Vaisman D. et al., 2005), Plotkin y colaboradores (Plotkin L. et al., 2006) y Gangoiti y colaboradores (Gangoiti M. et al., 2008).Las diluciones fueron preparadas, de manera tal que se utilizaron concentraciones equivalentes a 0,$1 ; 0,5 ; 1 ; 2 ; 5 ; 10 \% \mathrm{p} / \mathrm{p}$ respecto a la masa total de polímero.

El refuerzo de la matriz polimérica se realizó por entrecruzamiento iónico con tripolifosfato de sodio $\left(\mathrm{Na}_{5} \mathrm{P}_{3} \mathrm{O}_{7}\right.$, con peso molecular 367,8$)$ calidad alimenticia, provisto por Sudamfos S.A. Para ello se prepararon soluciones acuosas del entrecruzante en una concentración de $1 \% \mathrm{p} / \mathrm{p}$ respecto a la masa de polímero, así como una sal equimolar de alendronato-tripolifosfato de sodio $1 \% \mathrm{p} / \mathrm{p}$ y $0,1 \% \mathrm{p} / \mathrm{p}$. Dicha sal fue preparada en solución acuosa, posteriormente rotavaporeada y preservada en desecador hasta su utilización.

Se utilizaron diferentes protocolos para la generación de las mezclas, así como el modo de secado de los scaffolds. Por un lado se basó en lo realizado por Sarasam y colaboradores (Sarasam A. et al., 2005), denominado protocolo A y que consiste en la mezcla de polímeros, posterior desgasificación por sonicación durante un breve período y 
por último el secado de los scaffolds se realizó a temperatura ambiente. Además se realizó una variación del protocolo citado posteriormente por Sarasam y colaboradores (Sarasam A. et al., 2006) y García Cruz y colaboradores (García Cruz D. et al., 2008), denominado $B$, que consistió en calentar las soluciones poliméricas a $40^{\circ} \mathrm{C}$ bajo ligera agitación magnética y posteriormente de modo de formar mezclas homogéneas, la solución de quitosano fue adicionada en agitación con temperatura, suave y lentamente a la solución de PCL. El secado de dichos scaffolds fue realizado en estufa a $40^{\circ} \mathrm{C}$.

En relación a los scaffolds con alendronato, en el caso del protocolo $A$, el bisfosfonato fue disuelto en la solución de quitosano bajo agitación mecánica y posteriormente se adicionó lentamente dicha mezcla a la solución de PCL. Por último la mezcla fue degasificada por una breve sonicación. En el caso del protocolo B (figura 3.1.) se adicionó lentamente la solución de quitosano a la de $\mathrm{PCL}$ y una vez disuelto ambos polímeros, se procedió lentamente a la incorporación de la solución acuosa del bisfosfonato, la cual fue dispersada en la solución polimérica mediante agitación magnética hasta obtener una mezcla completamente homogénea .

En aquellos scaffolds conformados por la adición de la sal equimolar alendronatotripolifosfato de sodio, se realizó del mismo modo que lo anteriormente expuesto para el alendronato según protocolo A. En relación a la sal equimolar, fue adicionada como solución acuosa a la solución de quitosano, agitada mecánicamente y agregada suavemente a la solución de $\mathrm{PCL}$ en ácido acético. Al igual que en el caso anterior la solución fue degasificada por sonicación.

Las muestras se colocaron en moldes de polipropileno copolímero random (Aquasystem), para evitar que la mezcla se adheriera. Posteriormente se dejó evaporar el solvente de las muestras a temperatura ambiente durante 5 días para el caso de protocolo A o en estufa a $40{ }^{\circ} \mathrm{C}$ por aproximadamente 72 horas (protocolo B). Con el objetivo de retirar posibles restos de solvente, las muestras fueron secadas hasta peso constante en tambor de vacío.

El refuerzo de los scaffolds por entrecruzamiento iónico se realizó sumergiendo los scaffolds previamente formados en soluciones acuosas de tripolifosfato sódico en un rango de concentración del 0,1 al 1 \% p/p por el lapso de una hora (Bhumkar D. et al., 
2006; Shu X. et al., 2002a). Luego de ese tiempo las muestras fueron lavadas con agua bidestilada hasta neutralidad y secadas en tambor de vacío a peso constante.

Los scaffolds fueron preservados hasta su posterior utilización en desecadores con humedad relativa controlada en $33 \%$ mediante cloruro de magnesio.

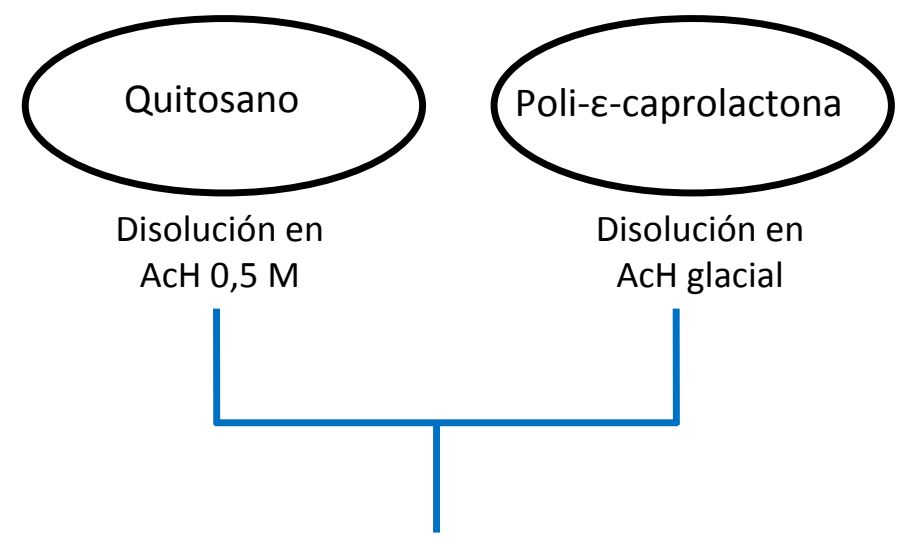

Mezcla uniforme de ambos polímeros bajo agitación magnética a $40^{\circ} \mathrm{C}$<smiles>CCCC</smiles>
Incorporación de la solución acuosa de Alendronato

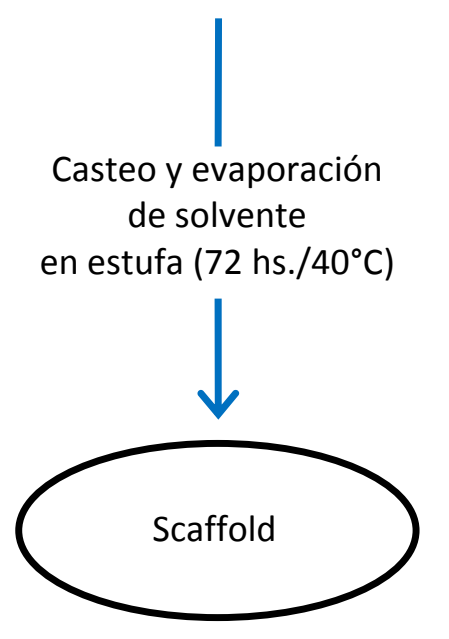

Figura 3.1. Esquema del procedimiento seguido para la elaboración de "scaffold" de quitosano y

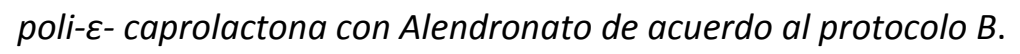


III. Experimental: Desarrollo y Caracterización de "Scaffolds" Biodegradables Quitosano/ poli-ع-caprolactona para Regeneración Ósea.

\begin{tabular}{|c|c|c|c|}
\hline \multirow{2}{*}{ Muestra } & \multicolumn{3}{|c|}{ Composición (\% p/p) } \\
\cline { 2 - 4 } & alendronato & tripolifosfato & $\begin{array}{c}\text { Sal } \\
\text { equimolar }\end{array}$ \\
\hline Qo-PECL & - & - & - \\
\hline Qo-PECL-Ale 10 \% & 10 & - & - \\
\hline Qo-PECL-Ale 5 \% & 5 & - & - \\
\hline Qo-PECL-Ale 2 \% & 2 & - & - \\
\hline Qo-PECL-Ale 1 \% & 1 & - & - \\
\hline Qo-PECL-Ale 0,5 \% & 0,5 & - & - \\
\hline Qo-PECL-Ale 0,1 \% & 0,1 & - & - \\
\hline Qo-PECL-TPP & - & 1 & - \\
\hline Qo-PECL-Ale 1 \%-TPP & 1 & 1 & - \\
\hline Qo-PECL-Ale 0,1 \%-TPP & 0,1 & 0,1 & - \\
\hline Qo-PECL-Sal 1\%- TPP & - & 1 & 1 \\
\hline Qo-PECL-Sal 0,1\%- TPP & - & 0,1 & 0,1 \\
\hline
\end{tabular}

Tabla 3.1. Resumen de la composición porcentual en los diferentes scaffolds.

\section{CARACTERIZACIÓN FISICOQUÍMICA DE LOS SCAFFOLDS}

Existen numerosos parámetros que influyen en la interacción célula-material y por tanto en la respuesta biológica. En especial la composición química de los materiales tiene un gran peso en la respuesta celular ya que afecta tanto las características superficiales del material como su comportamiento durante la degradación. Además, las propiedades superficiales y la porosidad del scaffold son determinantes en el soporte de la adhesión celular, en el crecimiento y la diferenciación celular en el tejido adecuado. Así dichos aspectos son claves y deben ser caracterizadas con detalle.

\subsection{Análisis de la micromorfología superficial.}

Se llevo a cabo una estudio cuantitativo acerca de las características morfológicas de los diferentes scaffolds obtenidos. Dicho estudio fue realizado mediante técnicas de microscopía electrónica de barrido (SEM) y microscopía óptica (MO).

Para el estudio micromorfológico de los scaffolds mediante microscopía SEM se utilizó un microscopio electrónico de barrido Phillips 505 (Holland). Las superficie exterior 
de los materiales fue previamente cubierta con una capa conductora de oro. Las micrografías fueron tomadas con un voltaje de $25 \mathrm{kV}$ para así obtener imágenes de alta resolución. Las imágenes fueron analizadas con el software Soft Imaging System ADDAll.

Debido al carácter fluorescente del quitosano (García Cruz M. et al., 2008b) y con el objetivo de analizar la distribución de quitosano en el scaffold, las distintas muestras fueron observadas mediante microscopía óptica de fluorescencia (Olympus BX51, Olympus Corp., Tokio, Japón), equipado con filtros apropiados (Olympus U-MWG2). Las fotografías de la superficie de los scaffolds se obtuvieron con una cámara color digital (Olympus DP71) conectada al microscopio. Las imágenes fueron analizadas con su correspondiente software.

\subsection{Análisis de las interacciones moleculares.}

El cambio en la estructura química y las interacciones fisicoquímicas existentes entre los distintos constituyentes de los scaffolds fueron evaluados mediante espectroscopia infrarroja (FT-IR Thermo Nicolet 380, Thermo Electron Corporation, Madison, WI). Las muestras montadas fueron escaneadas a temperatura ambiente en un rango de 4000-400 $\mathrm{cm}^{-1}$, con una acumulación de 32 barridos y con una resolución de 4 $\mathrm{cm}^{-1}$. Los espectros obtenidos fueron analizados con el software EZ-OMNIC.

\section{ESTUDIOS DE BIOCOMPATIBILIDAD IN VITRO}

El comportamiento biológico de los scaffolds es, en definitiva, su propiedad más importante. El éxito de un implante, más allá de cuestiones como disponibilidad de materiales, facilidad de fabricación o costos, depende de provocar una apropiada reacción biológica in vivo. Previo a los estudios in vivo en animales y finalmente en seres humanos, es indispensable la realización de estudios in vitro, ya que estos aportan información sobre el tipo de respuesta que se podría esperar al utilizar el biomaterial in vivo. Los cultivos celulares in vitro son ideales para la observación y el análisis de las 
interacciones substrato-célula y la influencia de los materiales en el comportamiento celular respecto a su biocompatibilidad y citotoxicidad.

\subsection{Cultivos celulares e incubación.}

Debido a que los materiales desarrollados en la presente tesis doctoral tienen como finalidad ser utilizados en aplicaciones de reparación y regeneración ósea, el análisis de la biocompatibilidad de los scaffolds basados en quitosano-PCL fue realizado con dos líneas de células óseas: (1) células tipo osteoblasto provenientes de la línea celular UMR-106, derivada de osteosarcoma de rata y (2) células preosteoblásticas provenientes de la línea celular MC3T3-E1, derivada de calvaria del ratón. Dichas líneas celulares han sido previamente utilizadas en nuestro grupo de trabajo (Cortizo M.C. et al., 2004; Molinuevo M. et al., 2007; Gangoiti M. et al., 2008; Fernandez J. et al., 2010).

La línea celular UMR-106 derivada de osteosarcoma de rata fue elegida para llevar a cabo los experimentos de biocompatibilidad debido a que se ha demostrado que conservan una serie de características fenotípicas de osteoblasto diferenciado (Partridge $N$. et al., 1983). Estas características incluyen la capacidad de respuesta a los agentes calciotrópicos como la hormona paratiroidea y $1 \alpha, 25$-dihidroxivitamina $D_{3}\left(1,25-(O H)_{2} D_{3}\right)$, la expresión de un nivel relativamente alto de actividad de la fosfatasa alcalina y síntesis de colágeno tipo I (Partridge N. et al., 1989). Sin embargo no expresan osteocalcina, osteonectina ni mineralizan en cultivo (Partridge N. et al., 1983).

La línea celular preosteoblástica MC3T3-E1 derivada de calvaria del ratón es adecuada para estudios del desarrollo osteogénico in vitro, debido a que expresan marcadores osteoblásticos y llevan a cabo la mineralización de la matriz extracelular (Quarles L. et al., 1992). Durante la primera semana de cultivo proliferan activamente, pero mantienen su apariencia fusiforme de osteoblasto inmaduro y expresan bajos niveles de fosfatasa alcalina. Sin embargo cuando se la incuba en presencia de un medio osteogénico de $\beta$-glicerol fosfato y ácido ascórbico, se induce la diferenciación al fenotipo osteoblástico (Quarles L. et al., 1992). Bajo estas condiciones los niveles de fosfatasa alcalina aumentan alcanzado un pico máximo a los 14 días, mientras que la mineralización en cultivo se alcanza a la final de la tercer semana. 
Las líneas celulares fueron cultivadas según protocolos ya establecidos. Las células fueron sembradas en frascos de cultivo de $75 \mathrm{~cm}^{2}$ (Corning, Princeton, NJ, USA) y cultivadas en medio de Eagle modificado por Dulbecco (DMEM, Gibco, Gaithersburg, MD, USA) con $10 \%$ de suero fetal bovino (FBS, Gen, Buenos Aires, Argentina), $100 \mathrm{U} / \mathrm{ml}$ de penicilina y $100 \mu \mathrm{g} / \mathrm{ml}$ de estreptomicina (McCarthy $A$. et al., 1997). Las células fueron mantenidas en incubadoras a $37^{\circ} \mathrm{C}$, en una atmósfera equilibrada con $5 \%$ de $\mathrm{CO}_{2}$.

Luego del crecimiento en monocapa hasta un $70-80 \%$ de confluencia fueron subcultivadas cada 7 días. La confluencia celular fue confirmada visualmente por observación del frasco de cultivo bajo microscopia de contraste de fase. El medio de cultivo fue aspirado, el frasco lavado con $1 \mathrm{ml}$ de solución salina tamponada estéril de buffer fosfato PBS-EDTA y las células desprendidas del frasco mediante tripsinización con $1 \mathrm{ml}$ de $0,1 \%$ tripsina-1 mM EDTA en solución buffer PBS libre de $\mathrm{Ca}^{+2}-\mathrm{Mg}^{+2}$ (Gibco, Gaithersburg, MD, USA) durante 5 minutos a $37^{\circ} \mathrm{C}$. Una vez tripsinizadas, se procedió a añadir medio de cultivo para neutralizar la reacción de tripsinización. Así las células fueron resuspendidas por adición de medio de cultivo.

A partir de la suspensión celular se tomaron alícuotas de modo de mantener la línea celular y para llevar a cabo los diferentes experimentos.

Previo al sembrado celular sobre los scaffolds con las distintas composiciones (tabla 3.1.) éstos fueron cortados en discos de 14 o $30 \mathrm{~mm}$ de diámetro con la ayuda de un sacabocados, colocados en placas de cultivo tisular de poliestireno (Corning, Princeton, NJ, USA) y esterilizados con radiación ultravioleta (UV) por un lapso de 1 hora. Luego la suspensión celular fue sembrada sobre la superficie de cada "scaffold" utilizando una dilución adecuada y seguidamente incubadas en medio de cultivo con $10 \%$ FBS en atmósfera humidificada con un $5 \%$ de $\mathrm{CO}_{2}$ a 37 ㅇ. .

Respecto a la línea celular UMR-106, en los estudios destinados a la observación de la morfología celular se utilizó una mayor concentración celular y los cultivos se extendieron durante 24 horas, mientras que para los estudios de diferenciación donde se evaluó la actividad de fosfatasa alcalina, los cultivos se realizaron por un lapso de 48 horas.

En el caso de la línea pre-osteoblástica MC3T3-E1, una vez que fue plaqueada sobre los diferentes scaffolds, se incubó en medio de cultivo por el lapso de una semana y 
posteriormente inducida a diferenciarse en un medio osteogénico que contenía $5 \mathrm{mM} \beta$ glicerol-fosfato y $25 \mu \mathrm{g} / \mathrm{ml}$ acido ascórbico. Bajo estas condiciones los cultivos se extendieron por dos semanas (Cortizo A. et al., 2006).

Cada experimento fue realizado por triplicado y se utilizó como control negativo un pocillo sin el scaffold polimérico o con un scaffold de Qo-PCL sin alendronato ni entrecruzante. Los valores obtenidos en cada experiencia fueron normalizados respecto a los controles.

\subsection{Estudios de biocompatibilidad.}

Aunque la biocompatibilidad de scaffolds basados en quitosano-PECL ya ha sido estudiada por otros autores (Mei N. et al., 2005; García Cruz D. et al., 2008; Wu H. et al., 2010), es de esperar que la incorporación del alendronato y tripolifosfato en la matriz polimérica modifique su comportamiento biológico. Así las experiencias realizadas tienen como propósito determinar que tan bien los scaffolds con las diferentes composiciones pueden soportar el crecimiento, proliferación y diferenciación in vitro de las células osteoblásticas UMR-106 y MC3T3-E1.

\subsubsection{Ensayos de morfología y crecimiento celular.}

La morfología y el crecimiento celular sobre los distintos scaffolds fueron evaluados transcurridas 24 horas de incubación.

Para ello las células fueron fijadas 5 minutos con metanol 100\% y luego teñidas con Giemsa o Hematoxilina- Eosina. Posteriormente se llevó a cabo la observación con un microscopio óptico (Nikon Eclipse E400 Nikon Tokio, Japón) y la toma de fotografías con una cámara digital (Nikon Coolpix 4500, Nikon Tokio, Japón) adicionada al microscopio. A partir de las imágenes fotográficas se realizó el conteo de las células teñidas con el software Image J. Se efectuaron conteos del número de células por campo, con un objetivo de 40x, en diez campos. Cada campo consistió en una única porción del scaffold con su correspondiente área de crecimiento. 


\subsubsection{Ensayos de diferenciación celular.}

La diferenciación celular en los distintos scaffolds fue evaluada por medio de la expresión del marcador óseo fosfatasa alcalina. Para ello las células fueron cultivadas sobre los distintos scaffolds por un lapso de 48 horas en el caso de la línea celular UMR106 o durante dos semanas para la línea celular MC3T3-E1.

\subsubsection{Actividad enzimática específica.}

Al final del periodo de incubación y previo retirado del medio de cultivo, las células crecidas sobre los diferentes scaffolds fueron lavadas con solución salina de buffer fosfato (PBS) y posteriormente lisadas en Tritón X-100 al 0,1\% (Sigma-Aldrich, Buenos Aires, Argentina). Por último los extractos fueron centrifugados 2 minutos a $7000 \mathrm{rpm}$, el pellet fue descartado y se separó el sobrenadante. Se utilizaron alícuotas del extracto total de células para la determinación de la actividad enzimática y determinación del contenido de proteínas por el Método de Bradford (Bradford M., 1976).

La evaluación de la actividad de la ALP se llevó a cabo por un método cinético cuantitativo basado en la determinación espectrofotométrica de la tasa de hidrólisis inicial de paranitrofenilfosfato (50 mM p-NPP) por medio de la ALP y la formación del cromógeno amarillo paranitrofenol ( $\mathrm{p}-\mathrm{NP})$ en buffer glicina-Mg $(\mathrm{pH} 10,5)$ a una temperatura de $37^{\circ} \mathrm{C}$. La producción de p-NP se determina por absorbancia a $405 \mathrm{~nm}$. El incremento en la absorbancia debido a la formación del p-NP es proporcional a la actividad de la ALP (Tietz N., 1983; Cortizo A. et al., 1995). El ensayo de actividad específica de la ALP se realizó de acuerdo a la descripción de Cortizo y colaboradores (Cortizo A. et al., 1995).

La determinación de contenido de proteínas se realizó por el Método de Bradford (Bradford M., 1976). Dicho método es un ensayo colorimétrico que consiste en un análisis espectroscópico que depende de la composición de aminoácidos de la proteína medida y se basa en el cambio de absorbancia del colorante Brilliant Blue G-250, en medio ácido, cuando el colorante se une a proteínas. La unión de la proteína estabiliza la forma aniónica azul del colorante, por lo que la cantidad del complejo en disolución es una 
medida de la concentración de proteínas presente en la muestra, que puede ser estimada mediante una lectura del espectro de absorbancia (Noble J. et al., 2009). El cambio espectral se registra a $595 \mathrm{~nm}$ a $37^{\circ} \mathrm{C}$.

La determinación de la concentración total de proteína se llevó a cabo por correlación de las concentraciones proteicas obtenidas con una curva de calibración estándar de albúmina sérica bovina con concentraciones conocidos de 5-50 $\mu \mathrm{g}$.

A partir de la información obtenida por ambas técnicas fue calculada la actividad enzimática específica de la ALP respecto al normalizaron respecto al valor de proteína total. Los resultados se expresaron como nmoles de sustrato convertido/min.mg de proteína y se refieren como porcentaje basal respecto del control.

\subsubsection{Análisis estadístico de los datos.}

Todos los experimentos se repitieron al menos una vez y se realizaron por triplicado. Los valores obtenidos fueron expresados como el valor promedio de las réplicas y su desviación estándar (media \pm SEM). La significancia estadística de las diferencias de los valores medios de los resultados para todos los parámetros estudiados de las distintas muestras fue evaluada utilizando la prueba de One-way-ANOVA y ANOVA factorial con un intervalo de confianza del $95 \%$ y se consideró un nivel de significancia estadística $\mathrm{p}<0,05$. Las medias fueron evaluadas por la prueba post-hoc de Tukey y por medio de la prueba de Fisher de las mínimas diferencias significativas para comparación de pares, con un nivel de significación $\alpha=0.05$. El análisis estadístico se realizó con el programa Statistica 7.0 (Statsoft, Inc., Tulsa, OK). 
IV.

Resultados y Discusión. 


\section{RESULTADOS Y DISCUSIÓN}

\section{ELABORACIÓN DE SCAFFOLDS BIODEGRADABLES BASADOS EN QUITOSANO/ POLI- $\varepsilon-C A P R O L A C T O N A$.}

Tal como se comentó en el parte experimental los scaffolds fueron preparados mediante la técnica de evaporación de solvente siguiendo dos protocolos diferentes. Se utilizó esta técnica por varias razones: en primer lugar, es una técnica sencilla que puede ser llevada a cabo en el laboratorio sin la necesidad de poseer equipamientos complejos. En segundo lugar, esta técnica requiere de una pequeña cantidad de polímero, lo cual es de gran interés ya que los polímeros son relativamente costosos.

La apariencia general de los scaffolds preparados de acuerdo al protocolo A, que consistió en adicionar la droga al quitosano y luego dicha mezcla a la PCL con posterior sonicación y secado a temperatura ambiente, muestra que dichos scaffolds son opalescentes (figura 4.1).

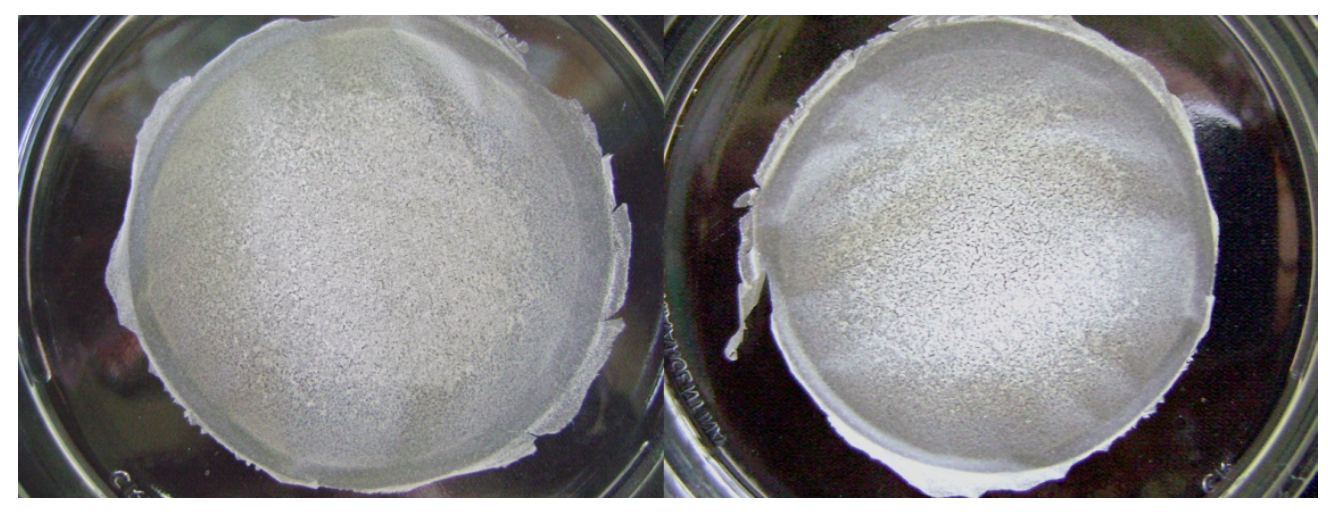

Figura 4.1. Apariencia general de los scaffold basados en quitosano y poli-e-caprolactona con alendronato al 1\%, elaborado según el protocolo $A$. a) realizados con quitosano de calamar 1 llex argentinus; b) realizados con quitosano de origen comercial (Aldrich). 
Los scaffolds realizados según el protocolo B, que consistió en la adición de la droga bisfosfónica posterior a la mezcla de ambos polímeros bajo agitación mecánica con temperatura a $37^{\circ} \mathrm{C}$ y posterior secado en estufa a $37^{\circ} \mathrm{C}$, poseen una apariencia general homogénea y son traslúcidos, tal como se observa en la figura 4.2.

En ninguno de los casos se observaron diferencias en el aspecto general de las diferentes muestras en relación a la fuente de quitosano, salvo una leve opacidad en aquellos compuestos por el quitosano obtenido en esta tesis. Además tampoco se observaron diferencias macroscópicas en relación a la cantidad de droga bisfosfónica adicionada, si bien se observó para el caso de aquellas muestras realizadas según el protocolo A posteriormente entrecruzadas que se tornaron más opalescentes.

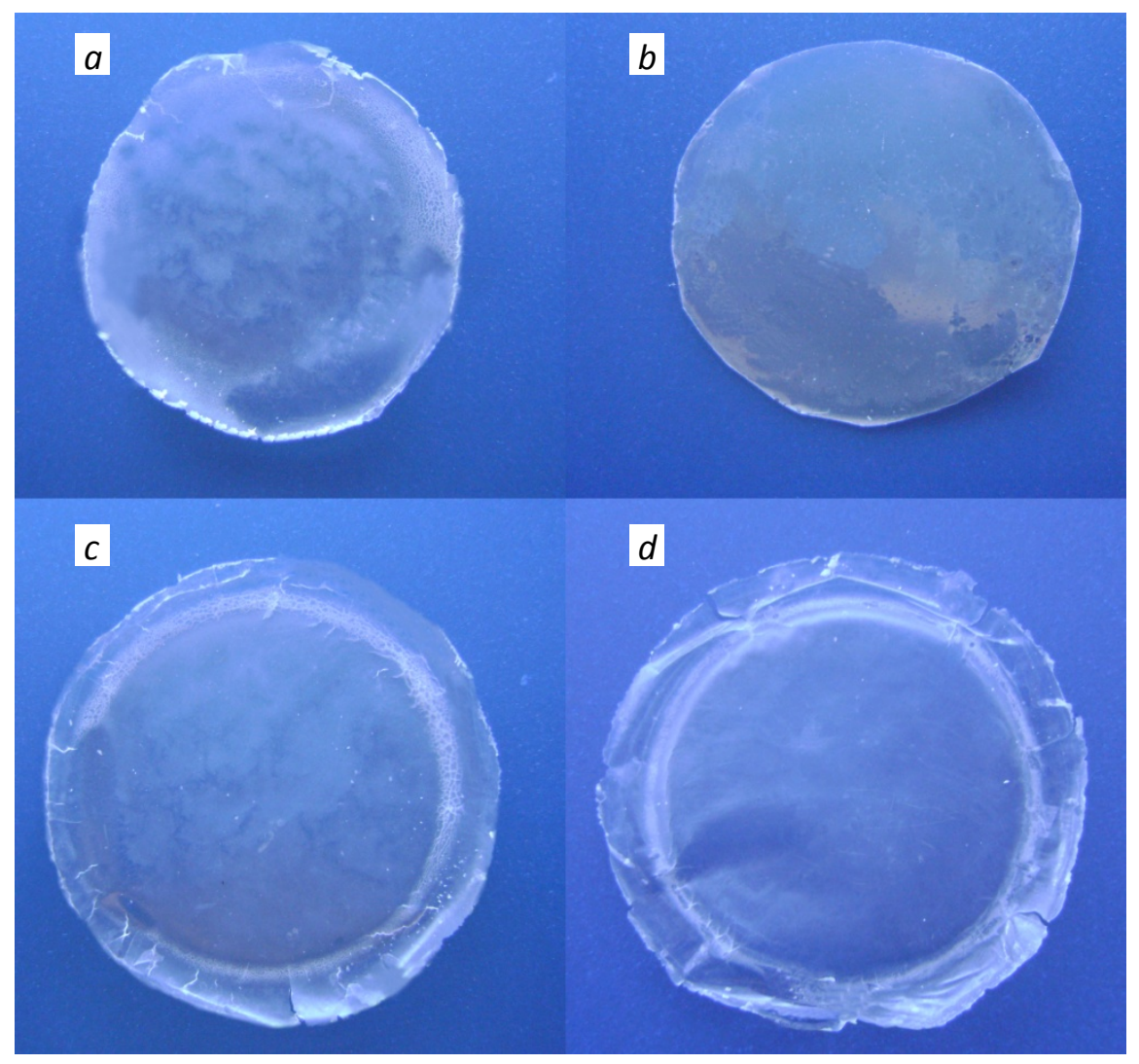

Figura 4.2. Apariencia de los diferentes scaffolds basados en quitosano de origen comercial Aldrich ( $a$ y b) y quitosano de Illex argentinus ( $c$ y d) elaborados según el protocolo B. a) Quitosano-PCL; b) Quitosano-PCL-Alendronato $1 \% p / p ; c)$ Quitosano-PCL ; d) Quitosano-PCL-Alendronato $1 \% p / p$. 


\section{CARACTERIZACIÓN FISICOQUÍMICA DE LOS SCAFFOLDS.}

\subsection{Análisis de la micromorfología superficial.}

La micromorfología superficial de los diferentes scaffolds basados en las mezclas de quitosano y poli-ع-caprolactona fue examinada mediante microscopía electrónica de barrido (SEM). Se tomaron imágenes de los scaffolds según los diferentes protocolos realizados.

En relación a las imágenes obtenidas de aquellos scaffolds realizados mediante el protocolo A (figura 4.3) se observa en todos los casos que los scaffolds son levemente porosos con poros de contorno irregular e interconectados y además los componentes muestran una distribución homogénea lo largo de su superficie.

La caracterización superficial de los scaffolds evidencia un cambio en la micromorfología a medida que se adiciona alendronato (Ale) o tripolifosfato (TPP) a la mezcla. Los scaffolds compuestos únicamente por la mezcla polimérica (figura 4.3.a) presentan una superficie más irregular, en cambio aquellos con alendronato (figura 4.3.b) presentan una estructura compuesta por pequeñas plaquetas. Los scaffolds con alendronato y entrecruzados con tripolifosfato (figura 4.3.c) poseen una estructura con agrupamientos globulares y poros regularmente distribuidos.

En aquellos scaffolds realizados según el protocolo $B$, se observa un cambio en la microestructura general de los scaffolds (figura 4.4) respecto a aquellas obtenidas de acuerdo al protocolo A. Los scaffolds poseen una superficie ligeramente lisa con distribución homogénea de los componentes, que puede considerarse menos irregular respecto a aquellos scaffolds obtenidos según el protocolo A. Además se hallan poros circulares-elípticos de un tamaño de área promedio de 17,4 $\mu \mathrm{m}$ (medidos con el software Image J), distribuidos regularmente a lo largo de la superficie. Debido a que no se realizó un análisis interno de dichos scaffolds no puede determinarse si dichos poros se hallan interconectados. Al igual que en el caso del protocolo A se evidencia un cambio en la micromorfología superficial a medida que se adiciona alendronato en la mezcla. Aquellos scaffolds compuestos únicamente por la mezcla polimérica (figura 4.4 a) presentan una 
IV. Resultados y Discusión.

superficie lisa y homogénea, mientras que la adición de alendronato (figura 4.4 b y $c$ ) genera una estructura más irregular con pequeñas prominencias.
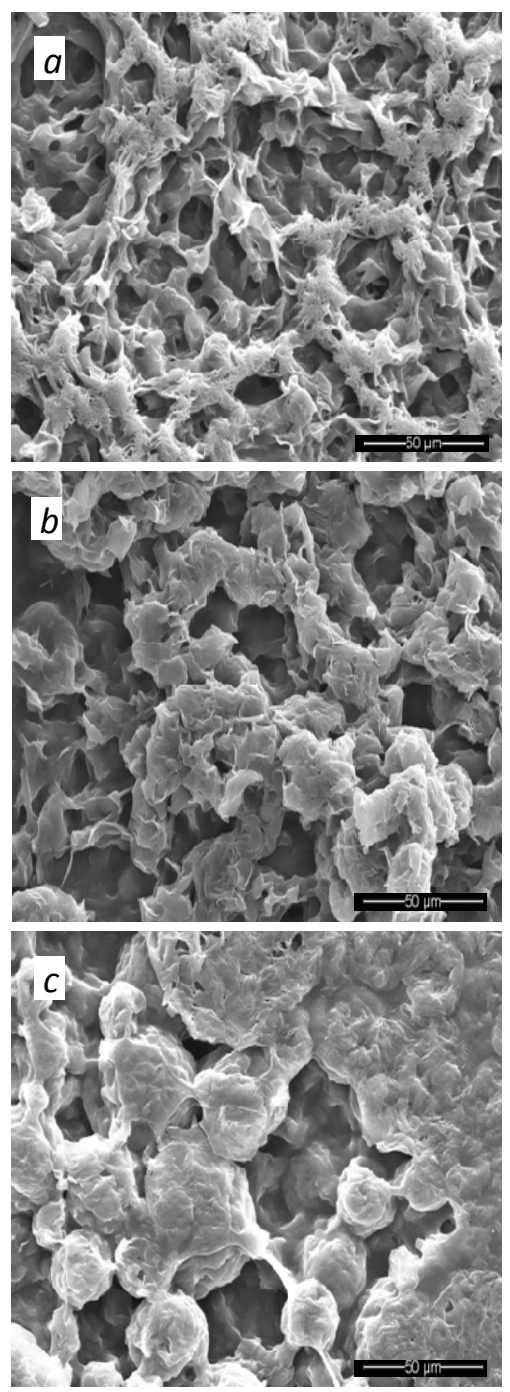

Figura 4.3. Microfotografías SEM de la superficie de los diferentes scaffolds realizados de acuerdo al protocolo A con quitosano de origen comercial (Aldrich). Arriba: scaffolds de Qo-PCL (a), centro: Qo-PCL-Ale 2 \% (b); abajo: Qo-PECL-Ale-TPP (c). Magnificación 600x. 
IV. Resultados y Discusión.
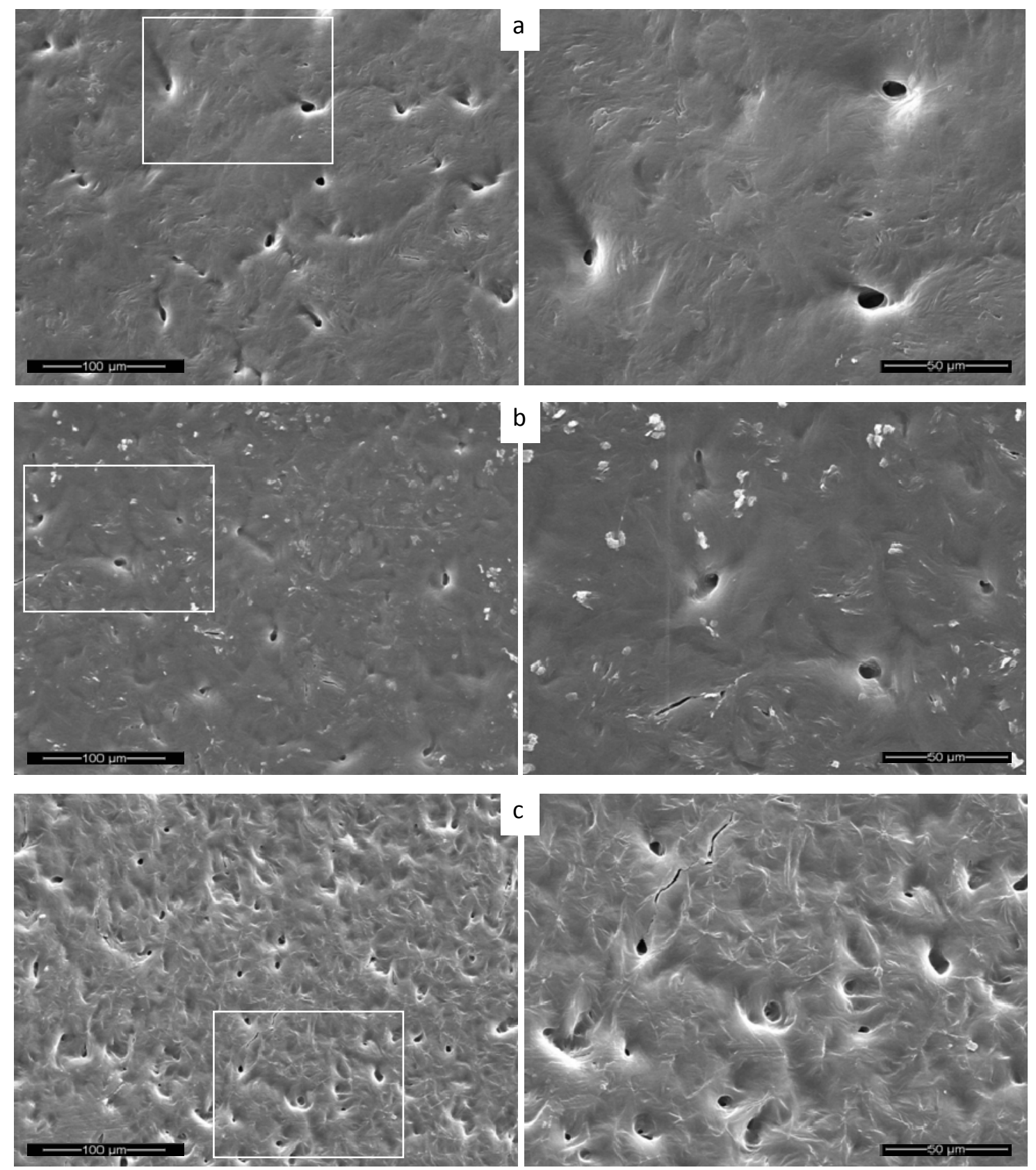

Figura 4.4. Microfotografías SEM de la superficie de los diferentes scaffolds realizados de acuerdo al protocolo B, con quitosano de calamar Illex argentinus. (a) Scaffolds de Qo-PCL; (b) Qo-PCL-Ale 0,5\%; (c) Qo-PECL-Ale 1\%. Izquierda: imágenes con magnificación 300x; derecha: detalle de la imagen con magnificación 600x. 
Como técnica complementaria y aprovechando las características fluorescentes del quitosano que absorbe radiación con un pico de absorción a $488 \mathrm{~nm}$ del UV visible y que es emitida como fluorescencia de color verde (García Cruz D. et al., 2008), se observaron las distintas muestras mediante microscopía óptica de fluorescencia con el objetivo de visualizar la distribución de los componentes poliméricos en el scaffold. En las figuras 4.5. y 4.6. se presentan las imágenes obtenidas para las distintas composiciones y de acuerdo a los protocolos A y B respectivamente.

En la figura 4.4.a, que se muestra como control y que corresponde a scaffolds compuestos únicamente por quitosano se observa una fluorescencia homogénea en toda la superficie, mientras que en aquellos scaffolds compuestos por ambos polímeros la

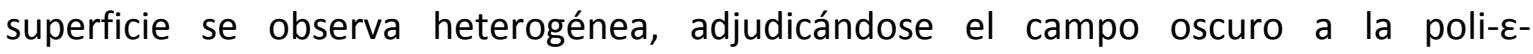
caprolactona (figura 4.5.b). Esto se halla en concordancia con lo hallado por García Cruz y colaboradores (García Cruz D. et al., 2008) en muestras de quitosano-PCL analizadas bajo microscopía confocal. Además se observa que a medida que se adiciona alendronato y tripolifosfato se forman agrupamientos de mayor intensidad fluorescente (figura 4.4. $c$ y d).
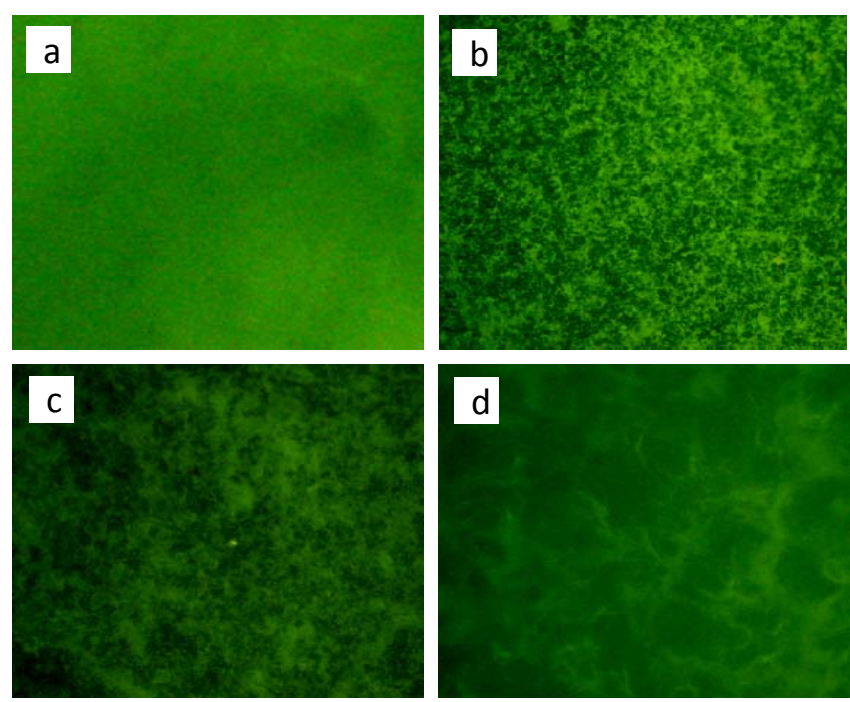

Figura 4.5. Distribución del quitosano Illex argentinus en los scaffolds realizados de acuerdo al protocolo A visualizados mediante microscopía óptica de fluorescencia. Qo (a); Qo-PCL (b); QoPECL-Ale 0,1\% (c) y Qo-PCL-Ale 0,1\%-TPP (d). Magnificación 10x. 
Del mismo modo que en el caso anterior, se observa que en los scaffolds obtenidos de acuerdo al protocolo B (figura 4.6.) la intensidad de la señal fluorescente se interrumpe en los sitios donde se encuentra la poli-ع-caprolactona (figura 4.6.a). No se observan cambios en la intensidad de la señal fluorescente a medida que se adiciona alendronato (figuras 4.6. $b$ y $c$ ), sin embargo puede notarse una leve diferencia en intensidad de señal respecto a aquel sin Alendronato.
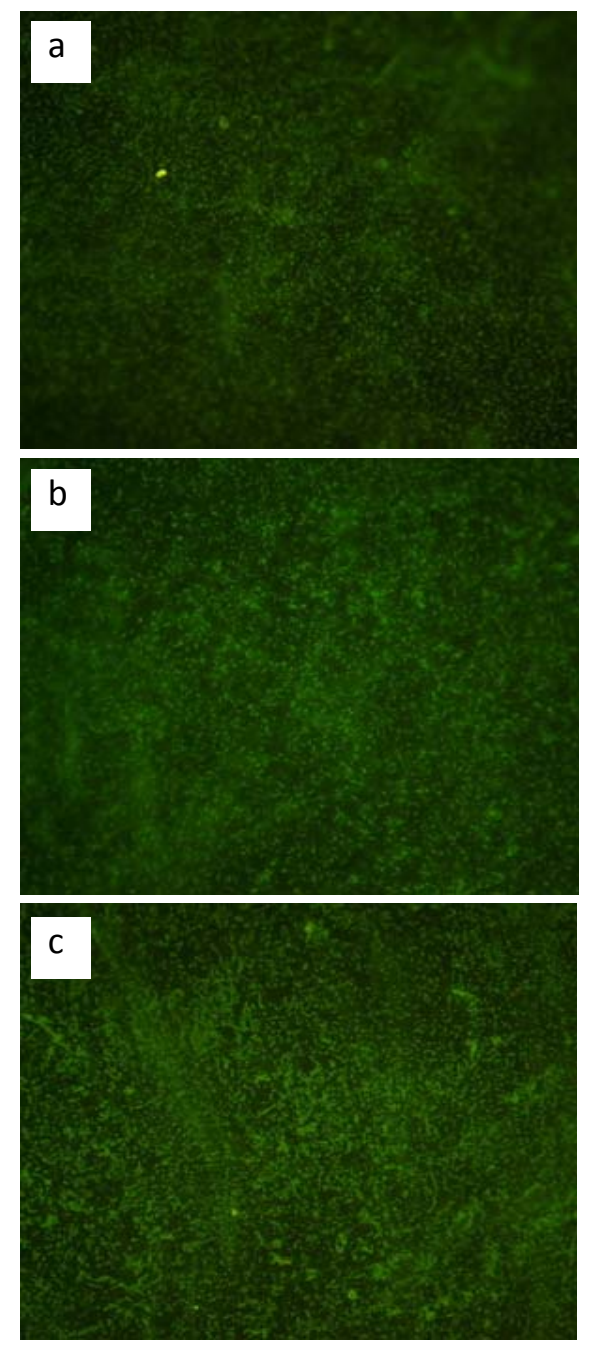

Figura 4.6. Distribución del quitosano Illex argentinus en los scaffolds realizados de acuerdo al protocolo B visualizados por con microscopía óptica de fluorescencia. Qo-PCL (a), Qo-PCL-Ale 0,1\% (b) y Qo-PCL-Ale 1 \% (c). Magnificación 10x. 


\subsection{Análisis de las interacciones moleculares.}

El cambio en la composición química en relación a los diferentes scaffolds fue analizado mediante espectroscopia FTIR. Las figuras 4.7. y 4.9. muestran los espectros obtenidos.

Se detectaron varias bandas de absorción específicas para distintos componentes. Como rasgo más distintivo en el espectro infrarrojo son evidentes las bandas características de los grupos funcionales presentes en la estructura de los polímeros

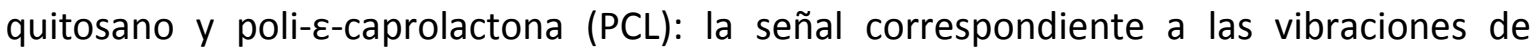
estiramiento del grupo carbonilo de la PCL que aparece en $1722 \mathrm{~cm}^{-1}$ y en el quitosano las bandas características del grupo amida localizadas a $1640 \mathrm{~cm}^{-1}$ (amida I), $1556 \mathrm{~cm}^{-1}$ (amida II) y $1316 \mathrm{~cm}^{-1}$ (amida III). Dichas bandas han sido reportadas por otros autores (Bhumkar D. et al, 2006; Sarasam A. et al., 2006; García Cruz D. et al., 2009; Wang Y. et al., 2009) en espectros de diferentes mezclas, aunque su intensidad varía dependiendo de la composición de las mezclas.

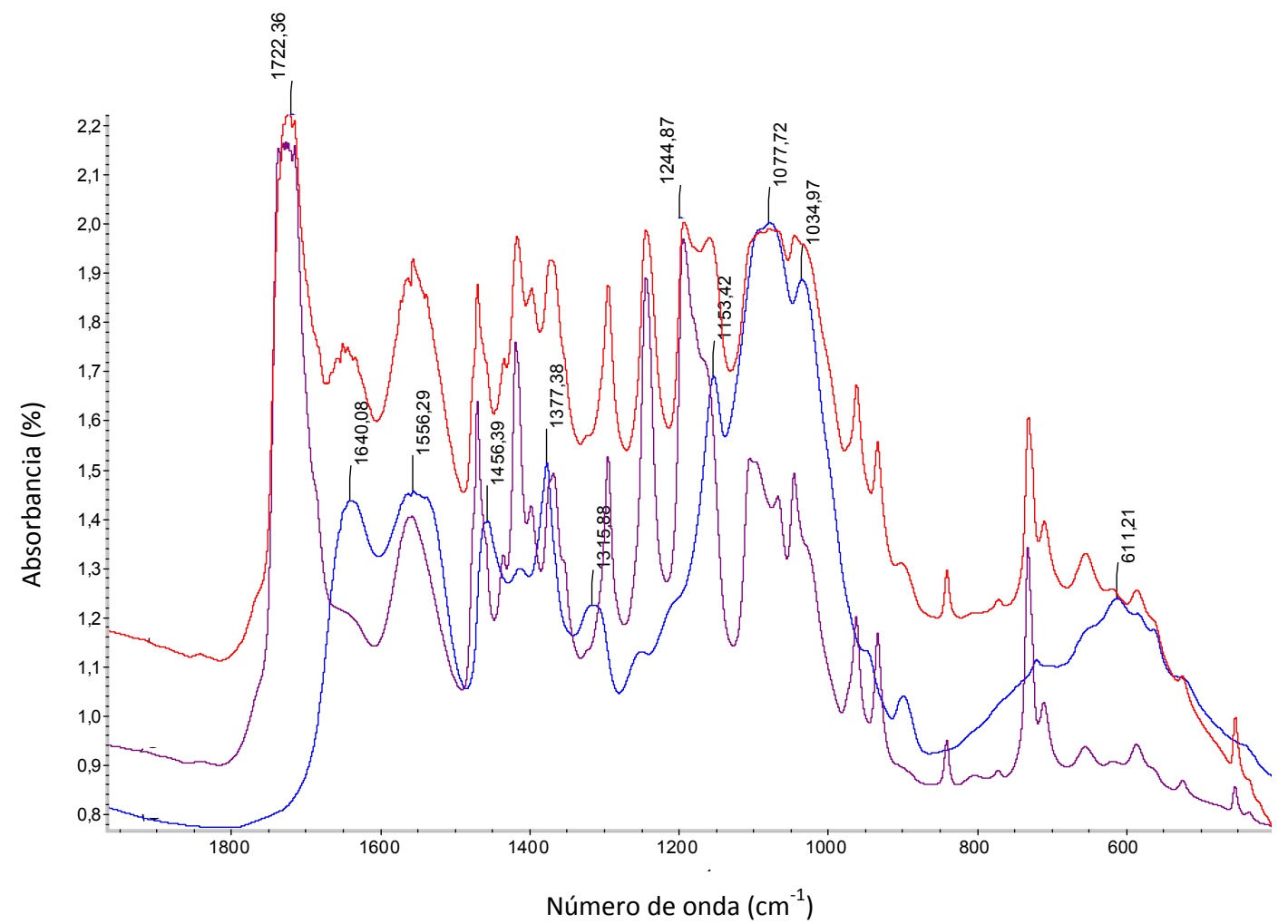

Figura 4.7. Espectro FTIR de absorbancia de quitosano (azul), scaffolds de quitosano y poli-ecaprolactona (violeta) y scaffolds de quitosano, poli-e-caprolactona y alendronato (rojo). 
En el espectro de las mezclas no se observa ningún desplazamiento de la frecuencia en las bandas de los grupos funcionales característicos respecto a los correspondientes componentes puros (datos obtenidos de la bibliografía (Sarasam A. et al., 2006; García Cruz D. et al., 2009; Wang Y. et al., 2009) y de los espectros IR obtenidos previamente en la sección A de este trabajo de tesis), lo cual es indicativo de que no existe una interacción mutua con formación de enlaces covalentes entre las cadenas de quitosano y $\mathrm{PCL}$ y es consistente con lo reportado en la literatura para mezclas de $\mathrm{PCL}$ con otros polisacáridos (Cascone M. et al. 2001).

Otras interacciones posibles entre los componentes poliméricos incluyen enlaces de hidrógeno intermoleculares entre el átomo de oxígeno del grupo carbonilo de la PCL y el hidrógeno del grupo hidroxilo o ion amonio del quitosano (figura 4.8.).

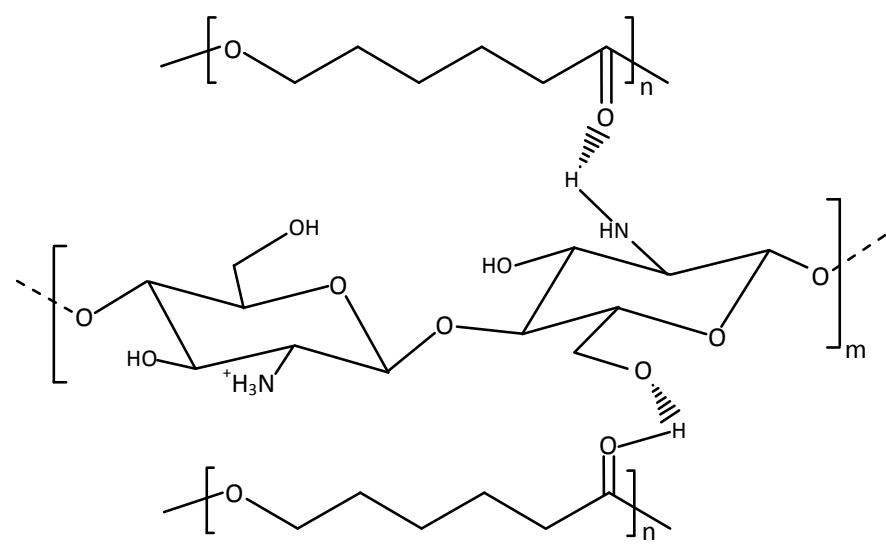

Figura 4.8. Interacción por puentes de hidrógeno entre los grupos funcionales del quitosano y la

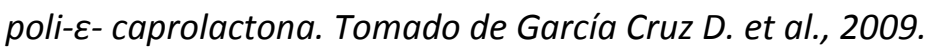

El espectro FTIR de los scaffolds de las mezclas quitosano-PCL, tanto en presencia como en ausencia de alendronato, exhibe la banda característica del grupo carbonilo de la PCL a $1722 \mathrm{~cm}^{-1}$ pero aparece un hombro cercano a $1690 \mathrm{~cm}^{-1}$, atribuible a puentes de hidrógeno de los grupos carbonilo con grupos dadores $-\mathrm{OH}$ y $-\mathrm{NH} 2$ del quitosano. Además las bandas de las amidas se mueven a menor longitud de onda. Todo esto sugiere la presencia de interacciones por puentes de hidrógeno entre ambos componentes de la mezcla, lo que indica que los polímeros, con características inmiscibles, básicamente coexisten dentro de los scaffolds. Estos resultados se hallan en concordancia con los 
hallados por otros investigadores (Sarasam A. et al., 2006; She H. et al., 2007; García Cruz et al., 2009; Wan et al., 2009).

Respecto de aquellos scaffolds con alendronato (Ale), independientemente de la concentración de droga adicionada, el análisis de área de las bandas 1556 y $1640 \mathrm{~cm}^{-1}$ (figuras 4.7 y 4.9 ) evidenciaría una interacción iónica entre el quitosano y alendronato, lo que estaría en concordancia con lo hallado por Ochiuz y colaboradores (Ochiuz L. et al., 2009)

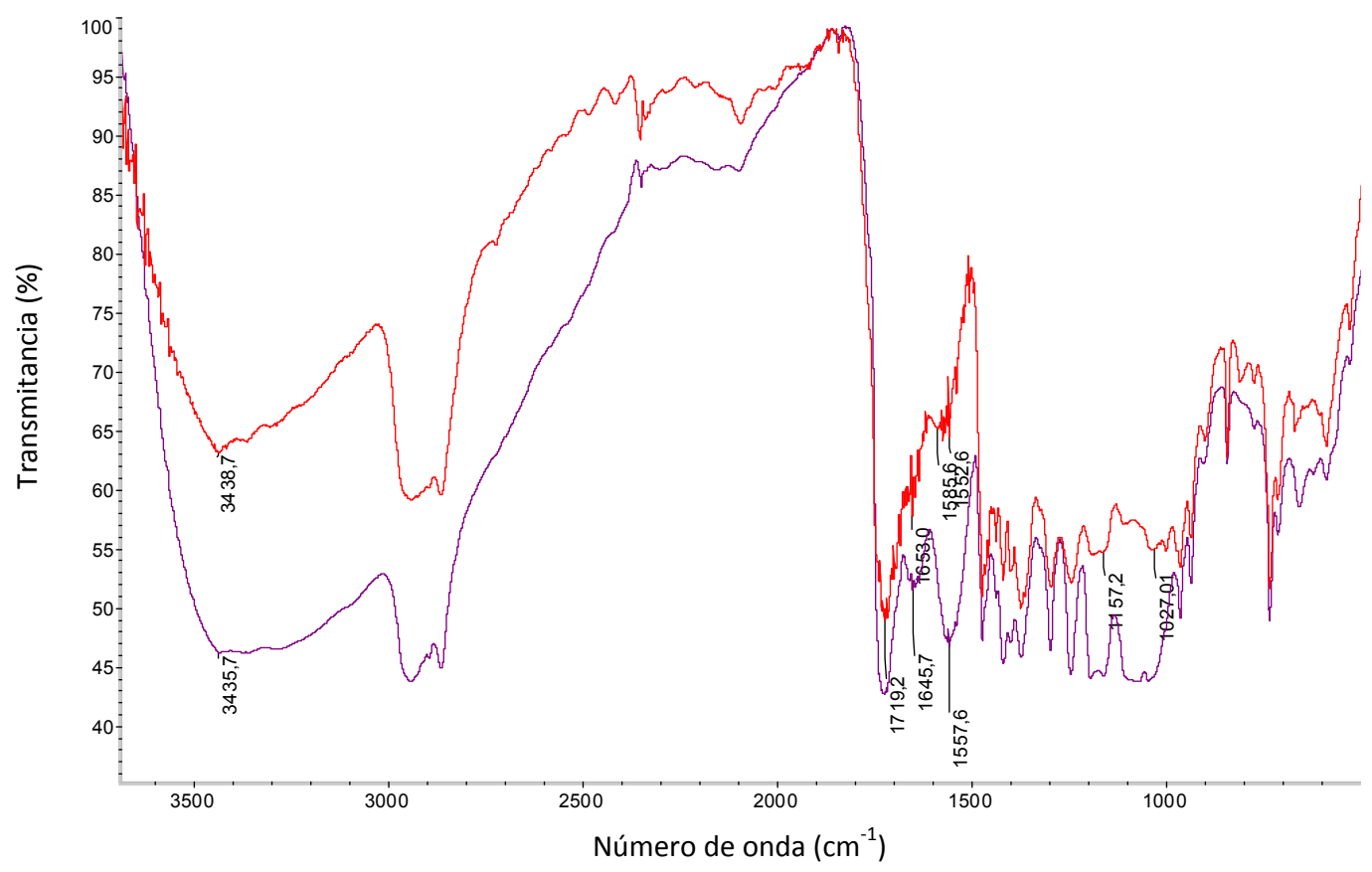

Figura 4.9. Espectro FTIR de transmitancia de los scaffolds de quitosano-PCL-alendronato (rojo) y quitosano-PCL-alendronato entrecruzados con tripolifosfato (violeta).

Tal como se comentó previamente, Bhumkar y colaboradores (Bhumkar D. et al., 2006) explican que el tripolifosfato (TPP) en solución acuosa se disocia para dar tanto grupos $\mathrm{OH}^{-}$como iones fosfóricos, los cuales compiten por interaccionar con los grupos amino protonado del quitosano, uniéndose los grupos $\mathrm{OH}^{-}$por desprotonación y los fosfóricos por interacción iónica para formar redes entrecruzadas. El espectro del quitosano muestra una banda típica a $1646 \mathrm{~cm}^{-1}$ atribuible a la Amida I; esta banda desaparece en aquellos scaffolds entrecruzados con TPP y aparecen dos nuevas bandas a 1653 y 1586 $\mathrm{cm}^{-1}$ (figura 4.9.). La desaparición de esta banda puede ser atribuida a la unión entre los 
iones fosfóricos y amonios, lo cual se halla en concordancia con lo hallado por Bhumkar y colaboradores (Bhumkar D. et al., 2006), Mi y colaboradores (Mi F. et al., 1999) en scaffolds basados en Qo y por García Cruz y colaboradores (García Cruz D. et al., 2009) en mezclas de quitosano y PCL.

Por todo lo expuesto anteriormente puede considerarse que los cambios en la estructura micromorfológica detectados mediante microscopía SEM y microscopía óptica de fluorescencia en los diferentes scaffolds adicionados con alendronato y entrecruzados con TPP, se deban a las interacciones existentes entre el quitosano con el alendronato y TPP. Esto estaría de acuerdo con los resultados hallados mediante el análisis espectroscópico.

\section{ESTUDIOS DE BIOCOMPATIBILIDAD IN VITRO}

Es de esperar que la incorporación del alendronato y tripolifosfato de sodio en la matriz polimérica modifique su comportamiento biológico. Para ello se investigó el efecto del agregado de dichos componentes en los scaffolds, evaluando el crecimiento, la proliferación y diferenciación de las células osteoblásticas UMR-106 y MC3T3-E1.

\subsection{Estudios en la línea celular UMR-106 derivada de osteosarcoma de rata.}

En una primera instancia se evaluó el crecimiento y diferenciación de células UMR106 sobre los scaffolds obtenidos con quitosano de origen comercial (Aldrich), así como el efecto la inclusión de diferentes concentraciones de alendronato (Ale). La figura 4.10. muestra el aspecto y cantidad de células crecidas luego de 24 horas de cultivo. Cualitativamente puede observarse un menor crecimiento celular sobre los scaffolds de Qo-PCL (figura 4.10 b) en comparación con el cultivo control realizado sobre los discos de plástico comercial (figura 4.10. a). Además, se observó que el agregado de $1 \%$ p/p y $10 \%$ $\mathrm{p} / \mathrm{p}$ de alendronato a los scaffolds de Qo-PCL (figuras 4.10. $c$ y $d$ ) inhibieron el crecimiento 
celular, indicando un efecto citotóxico con el agregado de $10 \%$ de alendronato en el scaffold.

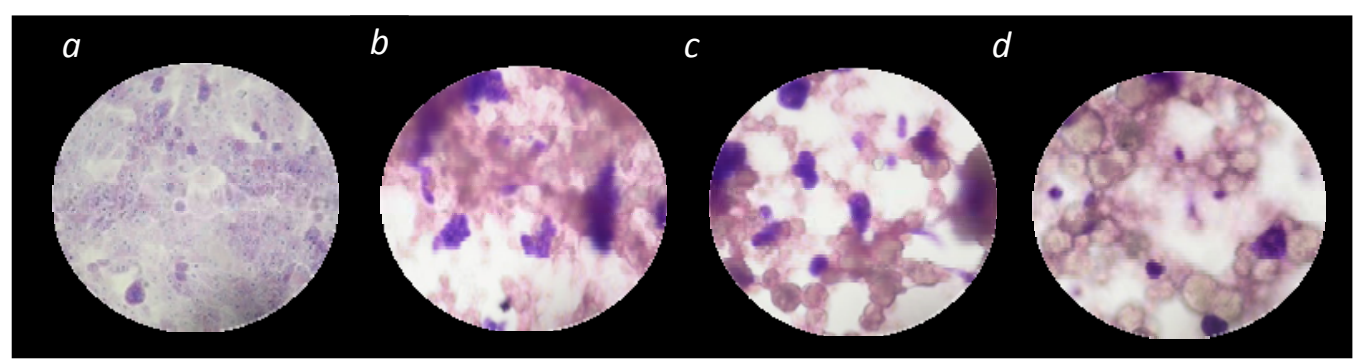

Figura 4.10. Crecimiento de células UMR-106 sobre discos de plástico (control) (a), scaffolds de Qo-PCL (b), scaffold de Qo-PCL-1\% Alendronato (c) y scaffold de Qo-PCL-10\% Alendronato (d). Las células fueron cultivadas sobre diferentes sustratos durante 24 horas, posteriormente fijadas, teñidas con Giemsa y observadas al microscopio óptico bajo un objetivo 40x.

En base a los resultados obtenidos se decidió disminuir la concentración de alendronato para evitar el efecto citotóxico del agregado de $10 \% \mathrm{p} / \mathrm{p}$ de bisfosfonato en el scaffold. Así en los siguientes experimentos se estudió el efecto de la adición en el scaffold de alendronato al 1,2 y $5 \%$ p/p sobre el crecimiento, a través del conteo de células teñidas con Giemsa y estimado a partir del contenido proteico, y sobre la diferenciación osteoblástica, evaluada a través del marcador fosfatasa alcalina (ALP).

De acuerdo al conteo celular por tinciones con Giemsa sobre las mezclas de Qo$\mathrm{PCL}$ y en las adicionadas con alendronato al 1,2 y $5 \%$ p/p (figura 4.11.) se observa una disminución en la proliferación celular $(p<0,01)$ respecto a aquellos scaffolds sin droga (Qo-PCL (control): 100 +/- 4 \%, Qo-PCL-Ale 1\%: 38 +/- 2; Qo-PCL-Ale 1\%: 32,5 +/- 3; QoPCL-Ale 5\%: $21+/-1,5)$.

Por otra parte, tal como se observa en la figura 4.12., la adición de alendronato induce una inhibición significativa dosis dependiente, tanto en el contenido proteico como en la actividad de la ALP $(p<0,01)$.

Estos estudios sugieren que el alendronato liberado al medio de cultivo en el transcurso de las 48 horas de cultivo estaría ejerciendo un efecto citotóxico sobre el crecimiento y desarrollo de los osteoblastos UMR-106 cuando son crecidos con concentraciones de alendronato entre 1 y $5 \% \mathrm{p} / \mathrm{p}$. 


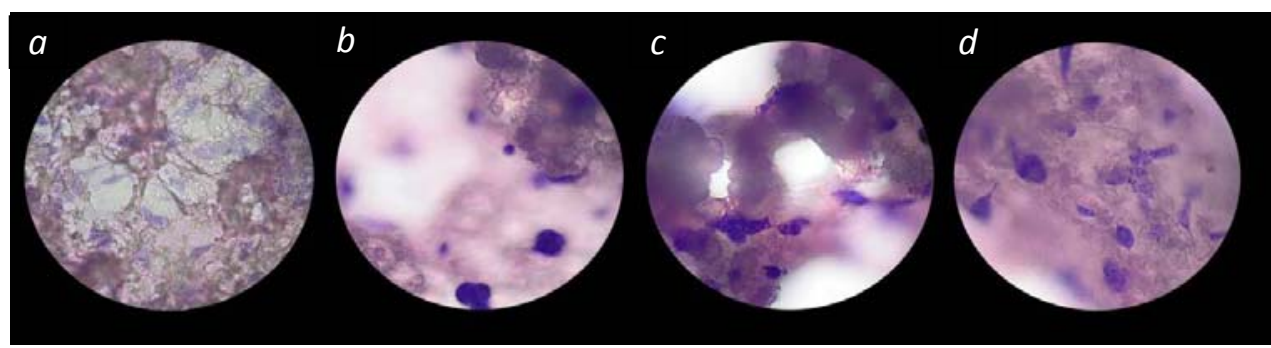

Figura 4.11. Efecto de la adición de Alendronato 1,2 y $5 \%$ p/p en el crecimiento de células UMR106. a) scaffold de Qo-PCL sin alendronato; b) scaffold de Qo-PCL con alendronato $5 \% \mathrm{p} / \mathrm{p}$; c) scaffold de Qo-PCL con alendronato $2 \% \mathrm{p} / \mathrm{p}$; d) scaffold de Qo-PCL con alendronato $1 \% \mathrm{p} / \mathrm{p}$. Las células fueron cultivadas sobre los distintos sustratos durante 48 horas, posteriormente fijadas, teñidas con Giemsa y observadas al microscopio óptico bajo un objetivo 40x.

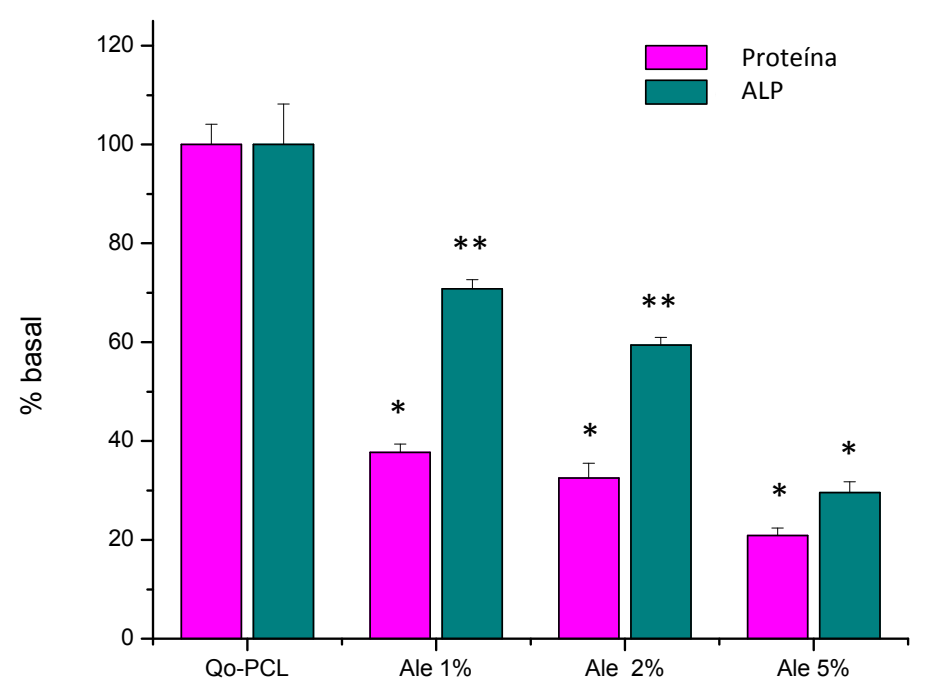

Figura 4.12. Efecto de la adición de diferentes concentraciones de alendronato sobre el crecimiento y diferenciación de células UMR-106. Los osteoblastos UMR-106 fueron cultivados 48 horas sobre scaffolds $\sin$ o con el agregado de 1, 2 y $5 \% \mathrm{p} / \mathrm{p}$ alendronato. Al final de dicho período, los scaffolds fueron lavados y la células extraídas con 0,1\% de Tritón X100. El contenido de proteínas y la actividad de fosfatasa alcalina fueron determinadas en el extracto. Los resultados se hallan expresados como porcentaje respecto del basal (scaffold de Qo-PCL sin droga), en promedio $\pm S E M, n=6$. Diferencias significativas respecto del basal: ${ }^{* *} p<0,01 * p<0,05$. 
En otra serie de experimentos se evaluó el efecto de la fuente de quitosano de los scaffolds de Qo-PCL (Qo de origen comercial Aldrich y Qo de Illex argentinus) en la diferenciación celular. En base a los resultados obtenidos previamente, las concentraciones de alendronato utilizadas fueron aún menores $(0,1,0,5$ y $1 \% \mathrm{p} / \mathrm{p})$. Los resultados fueron analizados con el test de ANOVA factorial y se muestran en la figura 4.13.

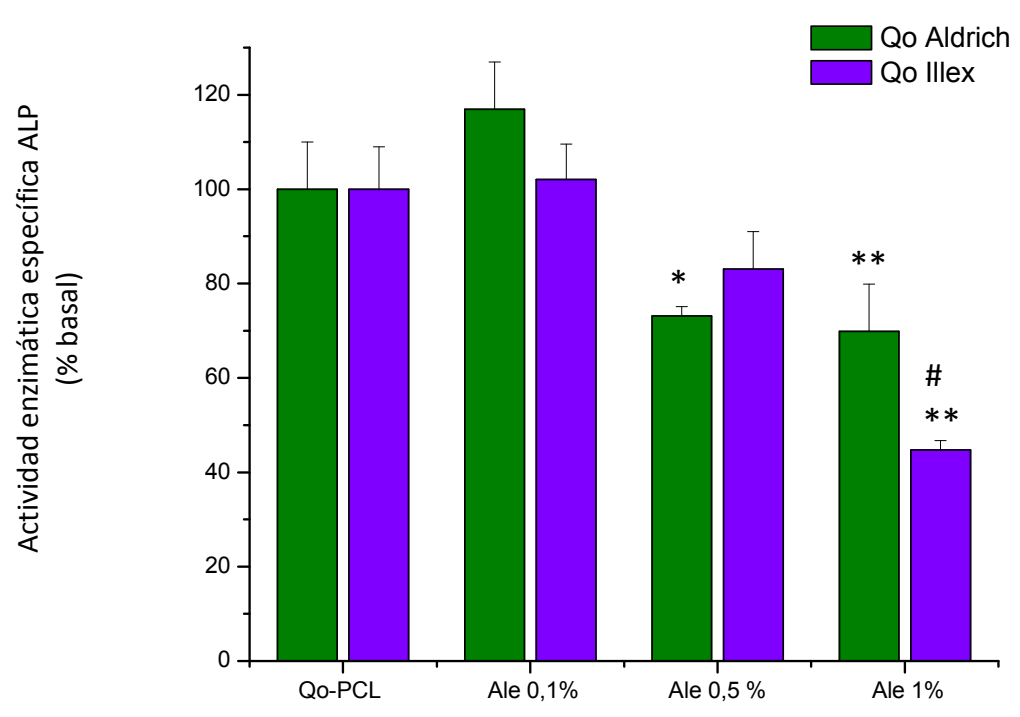

Figura 4.13. Efecto de las diferentes fuentes de quitosano con varias concentraciones de alendronato en diferenciación de células UMR-106. Los osteoblastos UMR-106 fueron cultivados durante 48 horas sobre scaffolds basados en quitosano comercial Aldrich (Qo Aldrich) y quitosano de calamar Illex argentinus (Qo Illex) con o sin el agregado de 0,1, 0,5 y 1\% de alendronato. Los resultados se hallan expresados como porcentaje respecto del basal (scaffold de Qo-PCL sin droga), en promedio $\pm S E M, n=6$. Diferencias significativas respecto del basal (Qo-PCL): ${ }^{* *} p<0,01$ * $p<0,05$; Diferencias significativas respecto de la fuente de quitosano: \# $p<0,05$.

El análisis de los valores absolutos de fosfatasa alcalina no muestra diferencias significativas entre los scaffolds preparados con las distintas fuentes de quitosano (1435 \pm 168 y $1450 \pm 135$ ug/min. mg proteína, para Qo comercial Aldrich y Qo de Illex argentinus, respectivamente). El agregado de alendronato en concentraciones de entre 0,1 y $1 \% \mathrm{p} / \mathrm{p}$ en los scaffolds indujo un efecto inhibitorio dosis-dependiente. La observación de este 
efecto utilizando diferentes tipos de quitosano muestra sólo diferencias significativas cuando los scaffolds contenían la dosis más alta de alendronato, es decir, de $1 \% \mathrm{p} / \mathrm{p}$ ( $\mathrm{p}<$ $0,05)$. Esta observación podría sugerir que mayores cantidades de alendronato se estarían liberando al medio de cultivo durante el periodo de incubación y así ejerciendo un efecto inhibitorio mayor sobre la diferenciación osteoblástica.

Finalmente se evaluó el efecto del entrecruzamiento iónico de los scaffolds con tripolifosfato de sodio sobre la diferenciación celular.

El efecto del entrecruzamiento fue analizado en scaffolds basados en quitosano de Illex argentinus adicionados con $1 \%$ alendronato, de modo de observar si el entrecruzamiento afecta el efecto citotóxico del alendronato. Los resultados obtenidos de los ensayos de crecimiento y diferenciación se muestran en las figuras 4.14.y 4.15.

Claramente puede observarse que la cantidad de células teñidas con Hematoxilina-Eosina (figura 4.14.) sobre los scaffolds entrecruzados con TPP (figura 4.14.c) fue mucho menor que las células crecidas sobre los scaffolds de Qo-PCL solo (figura 4.14.a) o sobre el de Qo-PCL-1\% Ale (figura 4.14.b).

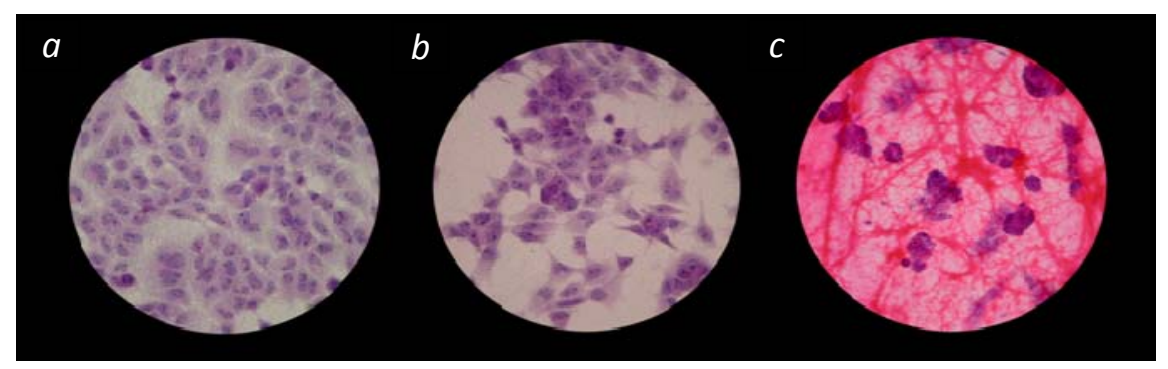

Figura 4.14. Efecto del entrecruzamiento con tripolifosfato (TPP) sobre el crecimiento de células UMR-106. Los osteoblastos UMR-106 fueron cultivados 24 horas sobre scaffolds de quitosano de calamar Illex argentinus (a), con el agregado de $1 \% \mathrm{p} / \mathrm{p}$ alendronato (b) o con alendronato $1 \% \mathrm{p} / \mathrm{p}$ y entrecruzados con $1 \%$ p/p de TPP(c).Las células fueron fijadas, teñidas con hematoxilina-eosina y observadas al microscopio óptico bajo un objetivo 40x.

En la figura 4.15. puede observarse el efecto del entrecruzante sobre el crecimiento, estimado a partir del contenido de proteína y sobre la diferenciación osteoblástica, evaluada a través de la ALP. Se observa que tanto el crecimiento celular 
como la actividad de la ALP fueron dramáticamente inhibidos cuando las células fueron cultivadas sobre aquellos scaffolds entrecruzados en comparación con aquellos no entrecruzados y adicionados únicamente con $1 \% \mathrm{p} / \mathrm{p}$ de alendronato $(\mathrm{p}<0,05)$.

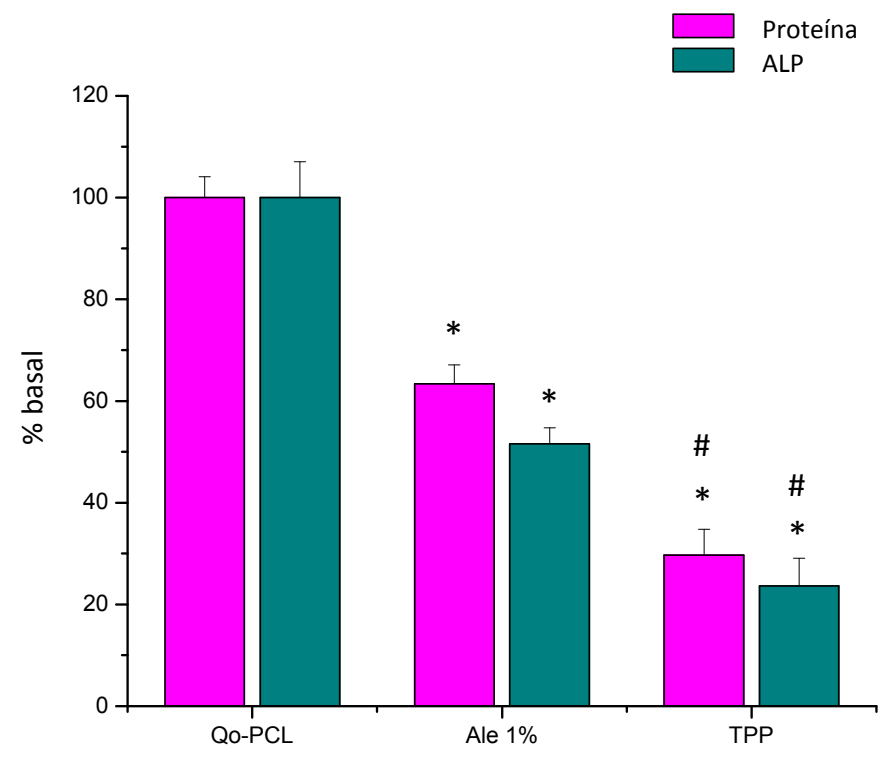

Figura 4.15. Efecto de la adición del entrecruzante Tripolifosfato de sodio sobre el crecimiento y la diferenciación de osteoblastos UMR-106. Los osteoblastos UMR-106 fueron cultivados durante 48 horas sobre scaffolds basados en quitosano de calamar Illex argentinus adicionados con alendronato $1 \% \mathrm{p} / \mathrm{p}$ con o $\sin 1 \% \mathrm{p} / \mathrm{p}$ TPP. Los resultados se hallan expresados como porcentaje respecto del basal (scaffold de Qo-PCL), en promedio $\pm S E M, n=6$. Diferencias significativas respecto del basal (Qo-PCL): * $p<0,01$. Diferencias significativas respecto de Qo-PCL-1\% alendronato: $\#<<0,05$.

Por otro lado se analizó el efecto del modo de adición del entrecruzante, es decir, sumergiendo el scaffold en la solución del entrecruzante o adicionando una sal equimolar de alendronato y tripolifosfato al tiempo que se procesa el scaffold; este último en una concentración de $0,1 \% \mathrm{p} / \mathrm{p}$. Para estos estudios se utilizó el quitosano de origen comercial Aldrich y los scaffolds fueron adicionados con $0,1 \% \mathrm{p} / \mathrm{p}$ de alendronato (figura 4.16.).

Los resultados muestran el entrecruzante iónico, independientemente de la forma en la que se adiciona disminuye la expresión del marcador osteoblástico ALP y de la proteína. Este efecto se debe exclusivamente al entrecruzante y es independiente de la 
adición de la droga $(p<0,01)$. Dicho efecto puede visualizarse teniendo en cuenta que no existen diferencias significativas entre el control sin droga ni entrecruzante y aquellos scaffolds no entrecruzados adicionados con $0,1 \%$ alendronato, lo que se encuentra de acuerdo a lo observado anteriormente (figura 4.13.).

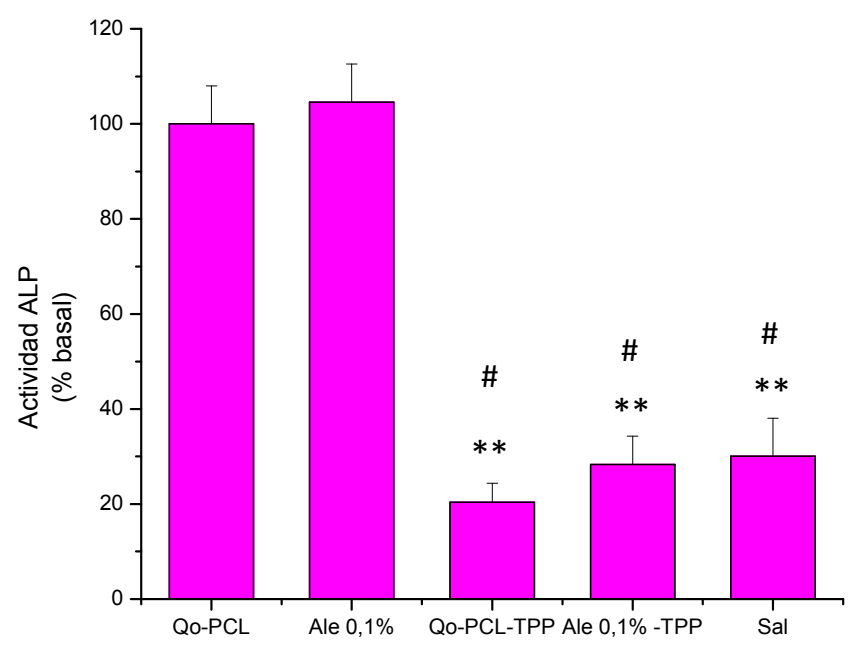

Figura 4.16. Efecto del modo de adición de Tripolifosfato de sodio sobre el crecimiento y la diferenciación de células UMR-106. Los osteoblastos UMR-106 fueron cultivados durante 48 horas sobre scaffolds basados en quitosano de origen comercial (Aldrich) adicionados con alendronato $0,1 \% \mathrm{p} / \mathrm{p}$, con o sin el agregado de 0,1\% p/p TPP en solución o forma de sal equimolar. Los resultados se hallan expresados como porcentaje respecto del basal (scaffold de Qo-PCL sin droga ni entrecruzante), en promedio $\pm S E M, n=6$. Diferencias significativas respecto del basal (Qo-PCL): ${ }^{* *} p<0,01$. Diferencias significativas respecto de Qo-PCL-0,1\% alendronato: \# $p<0,01$.

\subsection{Estudios en la línea celular MC3T3-E1 derivada de calvaria de ratón.}

En base a los resultados obtenidos con la línea celular UMR-106 se realizaron estudios similares utilizando la línea celular preosteoblástica MC3T3-E1. Se evaluó el efecto de la fuente de quitosano de los scaffolds de Qo-PCL (Qo de origen comercial Aldrich y Qo de Illex argentinus) y de la concentración de alendronato adicionada a los 
IV. Resultados y Discusión.

mismos $(0,1,0,5$ y $1 \% \mathrm{p} / \mathrm{p})$. Los resultados fueron analizados con el test de ANOVA factorial y se muestran en las figuras 4.17 y 4.18.

Los resultados muestran diferencias estadísticamente significativas entre las fuentes de quitosano de origen comercial y de Illex argentinus. Los valores de proteína obtenidos para los scaffolds sin alendronato fueron de $26 \pm 2,7$ y $35 \pm 0,5$ ug proteína/well. Se observó también un efecto inhibitorio del alendronato sobre el crecimiento celular. Este efecto no fue dependiente de la fuente de quitosano, sino de la concentración del alendronato agregado al scaffold.

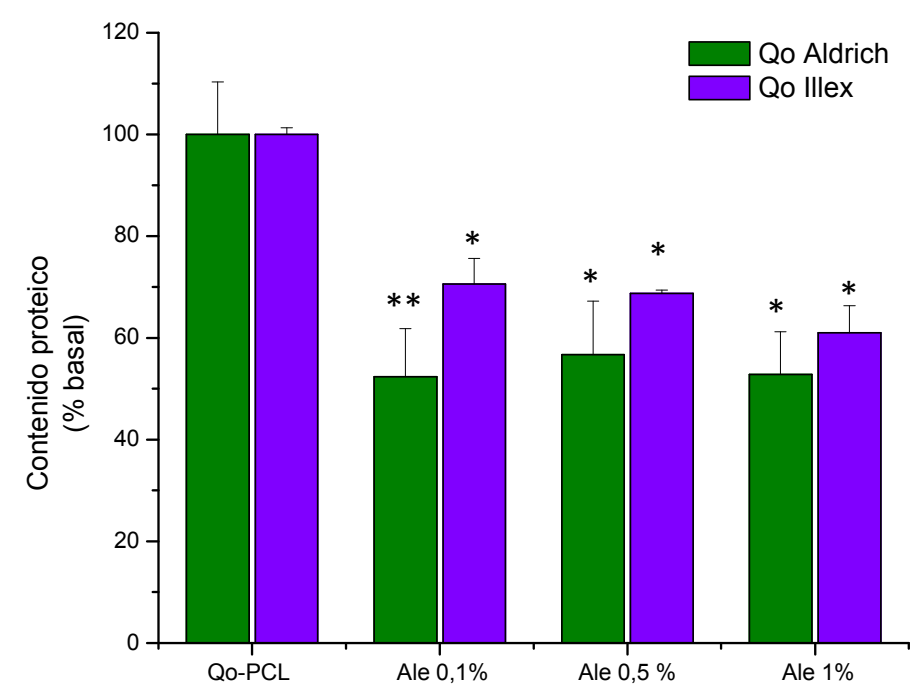

Figura 4.17. Efecto de las diferentes fuentes de quitosano y de la adición de diferentes concentraciones de Alendronato sobre el crecimiento de células MC3T3E1. Los osteoblastos MC3T3E1 fueron cultivados durante 2 semanas en un medio osteogénico sobre scaffolds de Qo$P C L$ sin o con el agregado de 0,1, 0,5 o 1 \% p/p de Alendronato. Al final del período de cultivo, los scaffolds fueron lavados y las células extraídas con 0,1\% de Tritón X100. En el extracto se determino el contenido de proteínas. Los resultados se expresan como porcentaje respecto del basal (scaffold de Q0-PCL), en promedio $\pm S E M, n=6$. Diferencias respecto al basal: * $p<0,05$, $p<0,01$.

La figura 4.18. muestra la actividad de ALP de las células MC3T3-E1 diferenciadas durante dos semanas en un medio osteogénico sobre scaffolds preparados con ambas fuentes de quitosano. En este caso no se observaron diferencias significativas respecto de la fuente de quitosano (Qo Aldrich o Qo de Illex argentinus) en los scaffolds sin 
alendronato $(9,4 \pm 0,7$ y $8,0 \pm 0,8 \mathrm{ug} / \mathrm{min}$. mg proteína respectivamente). Esta observación concuerda con lo encontrado en la actividad de ALP de los osteoblastos UMR-106 (figura 4.14.). El agregado de alendronato indujo un efecto inhibitorio únicamente en las mayores concentraciones estudiadas ( $1 \% \mathrm{p} / \mathrm{p})$, efecto que fue similar para los scaffolds preparados con ambas fuentes de quitosano.

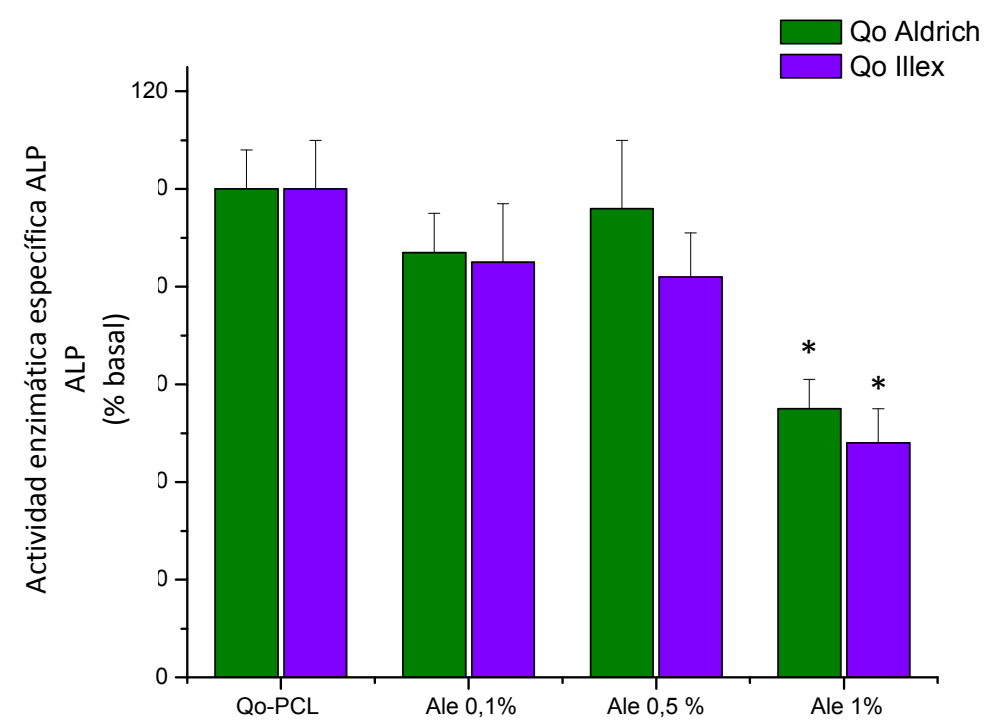

Figura 4.18. Efecto de la fuente de quitosano y de la adición de diferentes concentraciones de alendronato sobre la diferenciación de las células MC3T3-E1. Los osteoblastos MC3T3-E1 fueron cultivados sobre scaffolds de Qo-PCL basados en quitosano comercial Aldrich (Qo Aldrich) y quitosano de calamar Illex argentinus (Qo Illex), sin o con el agregado 0,1, 0,5 y 1\% p/p de alendronato durante dos semanas en un medio osteogénico. Al final de este período de cultivo, los scaffolds fueron lavados y las células extraídas con 0,1\% de Tritón X100. La actividad de ALP fue determinada en el extracto. Los resultados se expresan como porcentaje respecto del basal (scaffold de Qo-PCL), en promedio $\pm S E M, n=6$. Diferencias significativas respecto del basal: * $p<$ 0,05 .

\subsection{Discusión.}

La adhesión y proliferación celular son comportamientos celulares indicadores de la funcionalidad celular y además dichos eventos condicionan la diferenciación. Es por ello 
que los estudios de crecimiento y diferenciación celular permiten obtener una idea general acerca de cómo se desarrollan las células sobre el material, de modo de observar si el material afecta de alguna manera el comportamiento celular. Los ensayos de biocompatibilidad in vitro que utilizan cultivos celulares sobre quitosano (o conjugados) han demostrado que las células proliferan adecuadamente y por tanto su excelente biocompatibilidad.

La evaluación de la proliferación y diferenciación celular de células UMR-106 realizada en este trabajo de tesis, muestra que tanto en los scaffolds compuestos únicamente por la mezcla polimérica de Qo-PCL como en aquellos adicionados con bajas concentraciones de alendronato, las células presentan una morfología poliédrica normal y son capaces de crecer adecuadamente. Respecto a esto puede decirse que el tipo y proporción de ambos polímeros utilizada así como las bajas concentraciones de alendronato ensayadas $(<0,5 \% \mathrm{p} / \mathrm{p})$, no causan citotoxicidad alguna y son biocompatibles. Por tanto dichos scaffolds crean un ambiente adecuado para el crecimiento celular. Esto se halla en concordancia con lo reportado en mezclas de quitosano y poli-ع-caprolactona por Mei y colaboradores (Mei N. et al., 2005) en estudios de biocompatibilidad in vitro con fibroblastos, García Cruz y colaboradores (García Cruz D. et al., 2009) y Schagemann y colaboradores (Schagemann et al., 2009) en estudios in vitro con condrocitos, así como por Wu y colaboradores (Wu H. et al., 2010) en estudios de biocompatibilidad in vitro realizados con osteoblastos de calvaria de rata. Sin embargo en este trabajo de tesis se reporta por primera vez como la adición de dosis de alendronato entre $1 \%$ y $10 \%$ p/p en los scaffolds generan efectos citotóxicos, observándose una notoria disminución en el número de células crecidas bajo las condiciones experimentales estudiadas.

Por otra parte se llevaron a cabo ensayos de diferenciación, que permiten evaluar la funcionalidad y progresión hacia un fenotipo osteoblástico específico. Así, en este trabajo de tesis la diferenciación fue evaluada mediante la expresión del marcador de diferenciación fosfatasa alcalina.

De acuerdo a los resultados obtenidos en las experiencias realizadas, puede decirse que para el caso de la línea celular UMR-106 se observa una reducción en los valores de actividad enzimática específica en aquellos scaffolds adicionados con dosis de alendronato entre el $1 \%$ y el $10 \%$ p/p. Este efecto desaparece en concentraciones de 0,5 
$\% \mathrm{p} / \mathrm{p}$ de alendronato. Para el caso de la línea celular MC3T3-E1 se observa un escenario similar de acuerdo a la evaluación del crecimiento y diferenciación sobre scaffolds conteniendo concentraciones menores a $0.5 \%$ de alendronato. En síntesis, para ambos tipos celulares se encontraron efectos similares del alendronato incorporado en los scaffolds.

En la bibliografía no se han encontrado reportes acerca de sistemas de liberación de drogas basados en scaffolds de quitosano-PCL. Es sabido que el tipo de droga, su peso molecular y solubilidad, el modo en el que se adiciona al scaffold así como las propiedades de disolución del/los polímeros presentes, las interacciones existentes entre la droga y polímero, y el/los pKa de la droga son factores importantes que gobiernan los patrones de liberación de la droga desde los scaffolds.

Bhattarai y colaboradores (Bhattarai N. et al., 2010) explican que los mecanismos de liberación de drogas in vitro a partir de un scaffold puede ocurrir por difusión, por hinchamiento del scaffold, disolución del polímero, así como por reacciones químicas dentro del scaffold que conllevan a la degradación de la cadena polimérica, eliminación de sus grupos pendientes o erosionando el scaffold. Dependiendo del sistema el mecanismo de liberación puede estar regulado principalmente por los cambios de $\mathrm{pH}$, por la disolución del polímero y por degradación (Bhattarai N. et al., 2010). En el caso de que el mecanismo predominante sea por difusión, la liberación de la droga ocurre rápidamente y no de manera sostenida, en los períodos iniciales. Lo contrario ocurre en los mecanismos degradativos (Biondi M. et al, 2008) cuya cinética es controlada por la naturaleza del polímetro utilizado.

Si bien no se evaluó directamente la liberación de alendronato en el medio de cultivo, se realizó un ensayo preliminar de liberación con un scaffold basado en quitosano comercial Aldrich adicionado con alendronato al 5\% p/p. Se observó que un 99, 6\% del alendronato contenido en el scaffold fue liberado al medio de disolución luego de 6 horas (figura 4.19.). Este resultado sugeriría que luego de $48 \mathrm{~h}$ de incubación, el alendronato incluido en los scaffolds usados para los estudios de biocompatibilidad celular, se habría liberado completamente al medio de cultivo. 


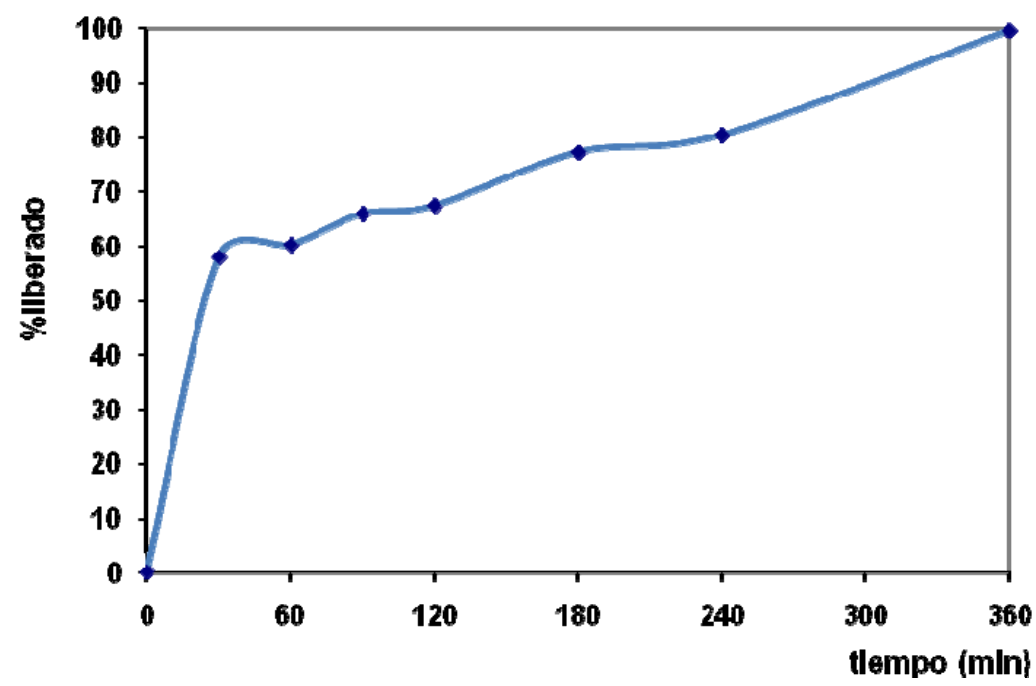

Figura 4.19. Perfil de liberación del alendronato a partir de un scaffold basado en quitosano de origen comercial Aldrich, adicionado con $5 \% \mathrm{p} / \mathrm{p}$ de alendronato. El scaffold fue colocado en una cuba de disolución con buffer fosfato $\mathrm{pH}=7,4, a 35^{\circ} \mathrm{C}$ y con paletas de agitación a $50 \mathrm{rpm}$. Se tomaron alícuotas a diferentes tiempos, las cuales fueron complejadas con $\mathrm{Fe}^{+++}$y analizadas por espectroscopía UV.

En nuestro grupo de investigación se ha demostrado un efecto inhibitorio cuando las células UMR-106 fueron cultivadas en presencia de alendronato en concentraciones entre $10^{-5}$ a $10^{-4} \mathrm{M}$ (Gangoiti M. et al., 2008). Por anteriormente comentado, en caso de liberarse el $100 \%$ de la dosis en aquellos scaffolds adicionados con una dosis de alendronato de $10 \% \mathrm{p} / \mathrm{p}$, la concentración de alendronato alcanzada sería del orden de $10^{-4} \mathrm{M}$, lo que explicaría la citotoxicidad observada. Por otro lado, una dosis de $0,1 \%$, que correspondería a una concentración del orden de $10^{-6} \mathrm{M}$, no ejercería, ninguna inhibición sobre el crecimiento celular, tal como se observa en las figuras 4.13 y 4.18 . Esto se hallaría en concordancia con lo reportado por Plotkin y colaboradores (Plotkin L. et al., 2006) y en nuestro grupo de investigación por Gangoiti y colaboradores (Gangoiti M. et al., 2008).

La droga puede ser adicionada al scaffold directamente mediante simple permeación, por atrapamiento o por inmovilización. En este trabajo de tesis la droga fue inmovilizada en la mezcla por interacciones iónicas (tal como se evidenció previamente mediante técnicas espectroscópicas-FTIR). Existe una tendencia en la bibliografía de explicar que en aquellos casos donde la droga se halla permeada ocurre una liberación a 
modo de ráfaga o burst que se desencadena rápidamente, y como resultado puede perderse hasta el $70 \%$ de la carga terapéutica.

La pregunta que surge es ¿porqué siendo que la droga no ha sido incorporada por simple permeación, puede liberarse tan rápidamente en un breve lapso de tiempo? Boonsongrit y colaboradores (Boonsongrit Y. et al., 2006) comentan que la eficiencia de atrapamiento se halla en función de la interacción iónica y que varía con los cambios de $\mathrm{pH}$, siendo máxima cuando el $\mathrm{pH}$ de la solución en la que se prepara el sistema es similar al pKa de la droga. Podría ser que la eficiencia de atrapamiento de la droga en el sistema basado en Qo-PCL no sea lo suficientemente buena y/o que además ocurra un cambio de $\mathrm{pH}$ cuando los scaffolds entran en contacto con el medio de cultivo, tal que disminuyan drásticamente las interacciones entre polímero y droga y por ende ocurra una liberación en burst. De hecho Ma y colaboradores (Ma Z. et al., 2002) en estudios de liberación de insulina en nanopartículas de quitosano, así como Boonsongrit y colaboradores (Boonsongrit Y. et al., 2006) en estudios de liberación de drogas modelo en micropartículas de quitosano plantean que el perfil de liberación de la droga con un fuerte efecto burst y una total liberación de la misma en un corto período es indicativo de pobres interacciones iónicas.

Numerosos reportes indican que la tasa de liberación de la droga puede reducirse a un $10-25 \%$ mediante el entrecruzamiento del polímero. Suponiendo el caso de que la eficiencia de atrapamiento haya sido adecuada y que la liberación de la droga podría reducirse por entrecruzamiento, se analizó el efecto del entrecruzamiento y posteriormente el modo de adición del mismo al scaffold.

Ha sido demostrado que el crecimiento y la proliferación celular en membranas de quitosano se ve afectada por la estructura química, hidrofilicidad e hidrofobicidad de la superficie, la carga eléctrica, la microtopografia y la flexibilidad entre otras características. Es conocido que la morfología de las células cambia de acuerdo a la superficie del material y en correlación con la energía superficial del sistema (Dalby M. et al., 2003). En las figuras 4.14.a se puede observar tanto en el scaffold control sin droga como en aquel adicionado con alendronato al $1 \% \mathrm{p} / \mathrm{p}$ (figura 4.14.b) que las células están bien extendidas, con una conformación típicamente poliédrica y presentan múltiples 
filopodias, favoreciendo el contacto intercelular y formando puentes intercelulares entre ellas, lo cual sugiere una interacción entre las células y el sustrato.

Para el caso de los scaffolds entrecruzados el panorama es completamente distinto, ya que el número de células viables es mucho menor en comparación con aquellos no entrecruzados (tanto con alendronato como sin la droga). A diferencia de lo anteriormente comentado para el caso de los scaffolds no entrecruzados, las células sobre los scaffolds entrecruzados adoptan una conformación más redondeada y no se observan filopodias (figura 4.14.c), indicativo de que las condiciones de entrecruzamiento estudiadas no son las adecuadas para una correcta proliferación celular e interacción con la matriz.

Shu y colaboradores (Shu X. et al., 2002 b) plantean que el grado de ionización del Qo y TPP se hallan principalmente controlados por el pH de la solución y que por tanto scaffolds de Qo entrecruzados con TPP muestran un comportamiento de hinchamiento dependiente del pH y de la fuerza iónica. Tal como comenta Berger y colaboradores (Berger J. et al., 2004) para obtener una elevada densidad de entrecruzamiento entre Qo y TPP, la densidad de cargas global del quitosano y del entrecruzante deben ser lo suficientemente altas para permitir interacciones entre ambos. Al mismo tiempo debe prestarse particular atención a los tiempos de entrecruzamiento y concentración del TPP, de modo de que la reacción sea incompleta para impedir que el quitosano precipite y que el scaffold pueda hincharse en el medio donde debe liberarse la droga. Es por ello que en este trabajo de tesis se utilizaron concentraciones de TPP de $1 \%$ y $0,1 \%$ (en ambos modos de entrecruzamiento) y tiempos de reacción de una hora (en el caso del entrecruzamiento por inmersión). Un aumento en la densidad de entrecruzamiento induce una disminución en el hinchamiento y en la sensibilidad del sistema por el pH (Berger J. et al., 2004). Sin embargo la densidad de entrecruzamiento puede modificarse por condiciones externas, principalmente por el pH del medio de aplicación del sistema.

De acuerdo a los resultados obtenidos en las experiencias de proliferación y diferenciación se observa claramente un efecto citotóxico por parte del TPP. Hsu y colaboradores (Hsu S. et al., 2004) proponen que el ambiente óptimo para el crecimiento celular ocurre cuando las células cargadas negativamente se encuentran con superficies con carga positiva. Los resultados obtenidos podrían explicarse por el cambio en la 
estructura química del quitosano, si se tiene en cuenta que la reacción de reticulación del biopolímero con el TPP ocurre a través de los grupos amino libres (no acetilados), lo que afecta el carácter catiónico. El carácter catiónico le permite mantener una carga positiva a $\mathrm{pH}$ ácido, por ello puede interaccionar con las superficies celulares y proteínas plasmáticas, combinando interacciones específicas tipo glicosaminoglicano con otras inespecíficas asociadas a su carga, favoreciendo la proliferación. De hecho Amaral y colaboradores (Amaral l. et al., 2007) comentan que un mayor número de grupos aminos libres favorecería la proliferación celular. En cambio, al realizar el entrecruzamiento el carácter catiónico del quitosano disminuye con lo que se reduce la capacidad de interaccionar con las superficies celulares, y por tanto disminuiría la capacidad del scaffold de presentar una mejor compatibilidad con los osteoblastos. Este efecto podría ser influenciado por la composición del medio de cultivo. Ello justificaría el efecto hallado tanto en scaffolds con alendronato como sin la adición del bisfosfonato, independientemente de la forma en la que se entrecruzó el scaffold.

Por último, debido a que el grado de acetilación (DA) resulta ser un parámetro importante que influye en las diferentes propiedades fisicoquímicas del quitosano, así como la biodegradabilidad (Tomihata K. et al., 1997), numerosos autores han realizado estudios sobre la influencia de los diferentes parámetros fisicoquímicos del quitosano (Qo) en el comportamiento biológico (Hamilton V. et al., 2007; Chatelet C. et al., 2001; Suphasiriroj W. et al., 2009) y mecánico (Santos C. et al., 2006) de los scaffolds basados en este biopolímero. Es por ello que fueron realizadas experiencias con el objetivo de analizar el posible efecto de la fuente de quitosano en el comportamiento biológico de los scaffolds adicionados con alendronato, tomando en cuenta que el quitosano purificado en la sección $A$ de este trabajo de tesis posee un grado de acetilación menor respecto a aquel de origen comercial ( $7,4 \%$ y $21 \%$ respectivamente).

Los reportes relacionados a las propiedades biológicas son ciertamente variables. Chatelet y colaboradores (Chatelet C. et al., 2001) investigaron in vitro el rol del grado de acetilación (DA) de los films de Qo y demostraron que el DA si bien no afecta la citocompatibilidad del Qo, un mayor DA genera una menor adhesión y proliferación de queratinocitos y fibroblastos. Similares resultados fueron obtenidos posteriormente por Hsu y colaboradores (Hsu S. et al 2004). Por su parte, Hamilton y colaboradores 
(Hamilton V. et al., 2007) realizaron una evaluación in vitro sobre la adhesion y proliferación de precursores osteoblásticos en films de quitosanos correctamente caracterizados fisicoquímicamente. Observaron que todos los films fueron osteocompatibles pero no hallaron correlación alguna entre las propiedades fisicoquímicas y el comportamiento biológico de los mismos. Dichos autores indican que la gran variabilidad entre los materiales basados en quitosano hace muy dificultoso el entendimiento y la comparación de la respuesta biológica. Por último, Suphasiriroj y colaboradores (Suphasiriroj W. et al., 2009) estudiaron el efecto del DA y el peso molecular sobre la proliferación y diferenciación en osteoblastos de la línea celular MC3T3-E1 en scaffolds basados en quitosano. Dichos autores observaron que independientemente del peso molecular, a mayor grado de acetilación se observa una mayor proliferación y un mayor porcentaje de expresión de actividad de la fosfatasa alcalina; por tanto plantean que el DA es un factor crucial a tener en cuenta para posibles aplicaciones del Qo en ingeniería de tejido óseo y no así el peso molecular del polímero. Estos resultados contradicen las observaciones previas respecto al grado de acetilación en relación al crecimiento celular.

Diferentes DA resultan en diferentes cantidades de grupos amino presentes en la superficie del scaffold. La proliferación celular en materiales basados en quitosano ha sido atribuida a interacciones electrostáticas no específicas entre los grupos amino protonado del quitosano y grupos carboxilato y sulfato cargados negativamente que se encuentran en los proteoglicanos de la superficie celular (Henriksen I. et al., 1996). Es por ello que podría pensarse que las diferencias en el comportamiento biológico respecto a la fuente de Qo, se hallen en relación con la cantidad y tipo de moléculas de superficie con carga negativa resultantes en afinidades específicas de tipo celular en quitosanos con diferentes grados de acetilación.

Los resultados de este trabajo de tesis muestran muy pocas diferencias respecto a la fuente de quitosano. Comparando scaffolds de Qo-PCL sin alendronato, únicamente se encontraron diferencias significativas en el crecimiento de las células MC3T3E1 (siendo estos un $34 \%$ más sobre scaffolds preparados con quitosano de calamar Illex argentinus respecto al quitosano de origen comercial Aldrich). Esto estaría en contradicción con las observaciones halladas por Suphasiriroj y colaboradores (Suphasiriroj W. et al., 2009) 
pero en acuerdo con lo encontrado por Chatelet y colaboradores (Chatelet C. et al., 2001) y por Hsu y colaboradores (Hsu S. et al 2004). Sin embargo, este efecto no fue observado para el caso de las células UMR-106 de osteosarcoma, sugiriendo un efecto dependiente de la naturaleza de la línea celular. Por otro lado, en las experiencias con scaffolds conteniendo $1 \% \mathrm{p} / \mathrm{p}$ de alendronato, las diferencias significativas en la expresión de ALP se observaron para el caso de los osteoblastos UMR-106 (figura 4.13.). Los scaffolds con quitosano de Illex argentinus ejercieron un efecto inhibitorio mayor sobre la diferenciación osteoblástica respecto de los scaffolds preparados con quitosano de origen comercial, este último con mayor grado de acetilación. 
V.

Conclusiones,

Recomendaciones

y Perspectivas. 


\section{CONCLUSIONES, RECOMENDACIONES Y PERSPECTIVAS}

\section{CONCLUSIONES}

El objetivo principal de esta sección fue la de desarrollar y caracterizar un scaffold totalmente biodegradable basado en biomateriales novedosos con propiedades biológicas superiores, dirigido a aplicaciones de liberación de fármacos en ingeniería de tejidos para el tratamiento de heridas o enfermedades óseas. El enfoque adoptado para lograr este objetivo fue el mezclar el biopolímero natural quitosano, con un poliéster sintético policaprolactona ( $\mathrm{PCL}$ ) mediante la técnica de evaporación de solvente con el agregado de la droga antiresortiva alendronato. La intención del uso del quitosano fue la de aportar una estructura altamente hidrofílica y biocompatible, debido a que sus características encajan perfectamente con aquellas cualidades necesarias para dichas aplicaciones, mientras que la de la PCL estuvo destinada a reforzar las propiedades fisicoquímicas y mecánicas de los scaffolds.

Respecto a las fuentes de quitosano utilizadas, éstas fueron quitosano de calamar Illex argentinus (purificado en la sección A de este trabajo de tesis) y quitosano de origen comercial Aldrich, ambas con diferentes grados de acetilación $(7,4$ \% y $21 \%$ respectivamente).

Las propiedades físico-químicas y biológicas de los scaffolds, fabricados con las diferentes fuentes de quitosanos, fueron analizadas y comparadas.

En base a los resultados obtenidos, las conclusiones con respecto a los objetivos específicos son las siguientes:

Se ha logrado preparar scaffolds de quitosano-PCL con diferentes contenidos del bisfosfonato alendronato $y$ en algunos casos entrecruzadas mediante el uso de tripolifosfato de sodio. 
La caracterización superficial de los scaffolds mediante técnicas de microscopía electrónica, óptica y por espectroscopía FTIR permitieron revelar diferencias de acuerdo a su composición en alendronato y tripolifosfato.

La morfología analizada mediante microscopía revela que los scaffolds basados en mezclas de quitosano y poli- $\varepsilon$-caprolactona presentan una estructura levemente porosa con interacción interpolimérica. El análisis de la microtopografía indica que la adición de alendronato y tripolifosfato influencia las propiedades superficiales de los scaffolds. A medida que aumenta el contenido de alendronato en las mezclas, la superficie de los scaffolds sufre modificaciones y se torna más irregular.

Mediante espectroscopía FTIR fueron evaluadas las interacciones fisicoquímicas de los diferentes constituyentes, infiriéndose interacciones por puentes de hidrógeno entre los componentes poliméricos e interacciones de tipo iónicas entre el alendronato y tripolifosfato con el quitosano, las cuales serían responsables de los cambios superficiales observados.

Se evaluó in vitro el crecimiento y la diferenciación osteoblástica de las células crecidas en los diferentes scaffolds basados en mezclas de quitosano y poli- $\varepsilon$ caprolactona, observándose que dichos materiales presentan una buena biocompatibilidad. Las células crecieron bien mostrando una morfología normal y fueron capaces de proliferar en todas las matrices poliméricas. En los cultivos in vitro de osteoblastos se obtienen mejores resultados en cuanto a proliferación celular y diferenciación con bajas dosis de alendronato. La inclusión de altas concentraciones de alendronato induce un efecto inhibitorio dosis-dependiente sobre la progresión celular. Esto estaría relacionado con la concentración efectiva de alendronato en el medio de cultivo.

Sin embargo, los scaffolds entrecruzados con tripolifosfato resultaron ser tóxicos para el crecimiento y diferenciación de los osteoblastos, induciendo una reducción de la actividad de la ALP y de la proteína celular en un $50 \%$ respecto de aquellas sin adición del entrecruzante.

Finalmente, los estudios caracterización fisicoquímica y biológica realizados con las distintas fuentes de quitosano muestran scaffolds que son similares en su morfología 
superficial y que ambos permiten una adecuada biocompatibilidad con los osteoblastos en cultivo. Es por ello que puede considerarse el uso del quitosano de Illex argentinus como una buena alternativa al uso de quitosanos comerciales importados para el desarrollo de scaffolds. Los estudios además sugieren que los scaffolds basados en quitosano-PCL adicionados con dosis de alendronato entre 0,1 y $0,5 \% \mathrm{p} / \mathrm{p}$ poseen un gran potencial y serían los candidatos más adecuados en aplicaciones de ingeniería de tejido óseo.

\section{RECOMENDACIONES}

Las conclusiones de esta tesis doctoral no están destinadas a ser definitivas, sino que son un resumen de los resultados significativos y las inferencias derivadas de la investigación llevada a cabo durante la duración del trabajo de tesis. Quedan, evidentemente, muchos otros estudios a realizar, así como la expansión y el desarrollo de lo que se ha llevado a cabo.

Los estudios de caracterización superficial realizados han sido un primer acercamiento, por lo que sería interesante analizar con mayor profundidad la interacción entre la droga y entrecruzante con el biopolímero, así como las diferencias superficiales ya que es un hecho conocido que éste es un punto determinante en la citocompatibilidad de un material.

Debido a que pueden existir alteraciones significativas en la hidrofilicidad de los scaffolds cuando se adiciona el bisfosfonato y el entrecruzante, y que tales alteraciones puedan afectar la viabilidad celular, sería adecuado realizar una completa caracterización de la energía superficial como por ejemplo mediante experiencias de ángulo de contacto de los scaffolds, siempre teniendo en cuenta las interacciones electrostáticas entre la superficie y el liquido así como las diferencias en topografía ya que éstas pueden influenciar la interacción energética de la interfase sólido-líquido. Dicho análisis podría revelar información respecto a las propiedades fisicoquímicas de los materiales y su interacción con las células.

En lo que concierne al sistema de liberación de fármacos es necesario realizar estudios del comportamiento degradativo del material simulando las condiciones 
fisiológicas. Estudios adicionales acerca de la naturaleza y forma de liberación de alendronato en el tiempo y en diferentes medios proporcionarían información fundamental sobre las características de la superficie del material. Además, debido a que el objetivo final de dichos materiales es, en forma general, actuar como substitutos temporales, siendo reemplazados de forma gradual por el tejido neoformado, es de gran relevancia el estudio de la evolución de las diferentes propiedades del material a lo largo de su degradación y su influencia en el crecimiento celular.

Es necesario estudiar en mayor profundidad las propiedades biológicas y biomecánicas de los scaffolds. Para ellos deben realizarse mayores cultivos celulares con el fin de validar los resultados descritos en esta tesis, prestando especial atención a la capacidad de los scaffolds por mantener el crecimiento y la diferenciación celular, la cinética de crecimiento, la absorción y el depósito de componentes de matriz extracelular. También podrían realizarse estudios detallados con respecto a la influencia del tamaño de poro, forma y porosidad en la colonización y el crecimiento celular (es decir, espesor máximo del scaffolds y la tasa de penetración celular entre otros.

Además podrían realizarse estudios más detallados acerca de la influencia la fuente de origen del quitosano (grado de desacetilación y peso molecular entre otras características) en la proliferación y diferenciación celular.

Por último deben realizarse estudios de citotoxicidad y evaluaciones in vivo de modo de caracterizar el sistema de liberación.

\section{PERSPECTIVAS}

En general, se beneficiará la población usuaria de los productos farmacéuticos novedosos, al poder disponer de formas farmacéuticas estudiadas cuyas características, potencial actividad terapéutica y funcionalidad permitirán el tratamiento de enfermedades óseas, entre otras.

Las consecuencias del proyecto pueden afectar el desarrollo del sector pesquero de calamar, surgiendo como una alternativa novedosa para el aprovechamiento de desechos y generación de nuevas alternativas de crecimiento a nivel industrial, así como 
el establecimiento de pequeñas industrias de producción o el desarrollo de nuevas líneas de investigación y producción dentro de las grandes empresas farmacéuticas del país.

Aunque no existe un scaffold ideal como sistema de suministro de fármacos, diversos materiales promisorios están presentes en la investigación moderna. La necesidad de una mejor prestación de los sitios de las heridas sigue siendo un desafío. 
VI.

Referencias Bibliográficas de la Sección $B$. 


\section{REFERENCIAS}

Aiba S. "Studies on chitosan: 4. Lysozymic hydrolysis of partially N-acetylated chitosan". International Journal of Biological Macromolecules, 14 (4):225-228 (1992).

Abdel-Fattah, W.I.; Jiang, T.; El-Bassyouni, G.E.T.; Laurencin, C.T. "Synthesis, characterization of chitosans and fabrication of sintered chitosan microsphere matrices for bone tissue engineering". Acta Biomaterialia, 3(4):503-514 (2007).

Acikgoz, M.; Kas, H.S.; Orman, M.; Hincal, A.A. "Chitosan microspheres of diclofenac sodium: I. application of factorial design and evaluation of release kinetics". Journal of Microencapsulation, 13(2):141-159 (1996).

Adekogbe, I.; Ghanem, A. "Fabrication and characterization of DTBP-crosslinked chitosan scaffolds for skin tissue engineering". Biomaterials, 26(35): 7241-7250 (2005).

Addison, W.N.; Azari, F.; Sorensen, E.S.; Kaartinen, M.T.; McKee, M.D. "Pyrophosphate Inhibits Mineralization of Osteoblast Cultures by Binding to Mineral, Up-regulating Osteopontin, and Inhibiting Alkaline Phosphatase Activity". Journal of Biological Chemistry, 282(21):15872-15883 (2007).

Aggarwal, A.; Kaur, S.; Tiwary, A.K.; Gupta, S. "Chitosan microspheres prepared by an aqueous process: release of indomethacin". Journal of Microencapsulation, 18(6):819-23, (2001).

Agrawal, C.M.; Niederauer, G.; Athanasiou, K.A. "Fabrication and Characterization of PLA-PGA orthopaedic implants". Tissue Engineering, 1(3):241-252 (1995).

Ali, S.Y. "Constitutive enzymes of matrix vesicles". Bone and Mineral, 17(2):168171(1992).

Amass, W.; Amass, A.; Tighe, B. "A review of biodegradable polymers: uses, current developments in the synthesis and characterization of biodegradable polyesters, blends of biodegradable polymers and recent advances in biodegradation studies". Polymer International, 47(2): 89-144(1998).

Amaral, I.F.; Cordeiro, A.L.; Sampaio, P.; Barbosa, M.A. "Attachment, spreading and short-term proliferation of human osteoblastic cells cultured on chitosan films with different degrees of acetylation" Journal of Biomaterials Science. Polymer Edition, 18 (4): 469-485 (2007). 
Anderson, H.C. "Matrix vesicles and calcification". Current Rheumatology Reports, 5(3):222-226(2003).

Ashton, R.S.; Banerjee, A.; Punyani, S.; Schaffen, D.V.; Kane R.S. "Scaffolds based on degradable alginate hydrogels and poly(lactide-co-glycolide) microspheres for stem cell culture". Biomaterials, 28(36): 5518-5525 (2007).

Athanasiou, K.A.; Niederauer, G.G.; Agrawal, C.M. "Sterilization, toxicity, biocompatibility and clinical applications of polylactic acid polyglycolic acid copolymers". Biomaterials, 17(2):93-102 (1996).

Balena, R.; Toolan, B.C.; Shea, M.; Markatos, A. Myers, E.R.; Lee, S.C.; Opas, E.E.; Seedor, J.G.; Klein, H.; Frankenfield, D. "The effects of 2-year treatment with the aminobisphosphonate alendronate on bone metabolism, bone histomorphometry, and bone strength in ovariectomized nonhuman primates". Journal of Clinical Investigation, 92(6): 2577-2586 (1993).

Baron R.E. "Anatomy and biology of bone matrix and cellular elements". Chapter 1. General principles of Bone Biology. Primer on the Metabolic Bone Diseases and Disorders of Mineral Metabolism $5^{\circ}$ Ed. Favus M.J, Ed. American Society for Bone and Mineral Research, Washington DC. 1-8 (2003).

Bellido, T.; Plotkin, L.I. "Prevención de la apoptosis de osteocitos y osteoblastos con bifosfonatos: vía de sobrevida mediada por hemicanales de cx43 y la activación de quinasas reguladas por señales extracelulares, independientemente de la transcripción génica". Actualizaciones en Osteología, 2(3):131-136 (2006).

Berger, J.; Reist, M.; Mayer, J.M.; Felt, O.; Peppas, N.A.; Gurny, R. "Structure and interactions in covalently and ionically crosslinked chitosan hydrogels for biomedical applications". European Journal of Pharmaceutics and Biopharmaceutics, 57(1):19-34 (2004).

Bhattarai, N.; Gunn, J.; Zhang, M. "Chitosan based hydrogels for controlled localized drug delivery". Advanced Drug Delivery Reviews, 62(1):83-89 (2010).

Bhumkar, D.R.; Pokharkar, V.B. "Studies on effect of pH on cross-linking of chitosan with sodium tripolyphosphate: A technical note". AAPS PharmSciTech, 7(2): 50 E1-E6 (2006). 
Bielby, R.; Jones, E.; McGonagle, D. "The role of mesenchymal stem cells in maintenance and repair of bone". Injury. International Journal of the Care of the Injured, 38(Suppl. 1): 26-32(2007).

Biondi, M.; Ungaro, F.; Quaglia, F.; Netti P.A. "Controlled drug delivery in tissue engineering". Advanced Drug Delivery Reviews, 60(2): 229-242 (2008).

Blanco, M.D.; Bernardo, M.V.; Sastre, R.L.; Olmo, R; Muniz, E.; Teijon, J.M. “Preparation of Preparation of bupivacaine-loaded polyepsilon-caprolactone microspheres by spray drying: drug release studies and biocompatibility". European Journal of Pharmaceutics and Biopharmaceutics, 55(2):229- 236 (2003).

Boonekamp, P.M.; Wee-Pals L.J.A.; Wijk-van Lennep M.L.L.; Wil Thesing C.; Bijvoet, O.L.M. "Two modes of action of Bisphosphonates on osteoclastic resorption of mineralized matrix". Bone and Mineral, 1(1):27-39 (1986).

Boonsongrit, Y.; Mitrevej, A.; Mueller, B.W. "Chitosan drug binding by ionic interaction". European Journal of Pharmaceutics and Biopharmaceutics, 62(3):267-74 (2006).

Boskey, A.L. "Mineralization, Structure and Function of Bone". Bone and Cartilage Metabolism, 1st Ed. Seibel MJ, Robins SP, Bilezikian JP (eds), Academic Press, San Diego. 345-360 (2006).

Boretos, J.W.; Eden, M. Contemporary Biomaterials: Material and Host Response, Clinical Applications, New Technology and Legal Aspects. Noyes Publications, Park Ridge, NJ. 232233 (1984).

Bozal C. "Biología del osteocito". Actualizaciones en Osteología, 2(1): 19-21 (2006).

Braddock, M.; Houston, P.; Campbell, C.; Ashcroft, P. "Born Again Bone: Tissue Engineering for Bone Repair". News in Physiological Sciences, 16: 208-213(2001).

Bradford, M.M. "A rapid and sensitive method for the quantitation of microgram quantities of protein utilizing the principle of protein- dye binding". Analytical Biochemistry, 72(1-2):248-254 (1976).

Brode G.L.; Koleske J.V. "Lactone polymerization and polymer properties". Journal of Macromolecular Science. Part A Pure and Applied Chemistry. 6(6): 1109-1144(1972).

Buckley, C.T.; O'Kelly K.U. “Regular scaffold fabrication techniques for investigations in tissue engineering" Cap. V. Topics in Bio-Mechanical Engineering. Proceedings of the 1st 
symposium on Biomechanical Engineering P.J. Prendergast and P.E. McHugh (Eds.), Trinity Centre for Bioengineering \& National Centre for Biomedical Engineering Science. 147-166 (2004).

Burdick, J.A.; Mason, M.N.; Hinman, A.D.; Thorne, K.; Anseth, K.S. "Delivery of osteoinductive growth factors from degradable PEG hydrogels influences osteoblast differentiation and mineralization". Journal of Controlled Release, 83(1):53-63 (2002).

Buttler, W.T.; Ridall, A.L.; McKee, M.D. "Osteopontin" Cap. 13 Principles of Bone Biology, 1st Ed, John P. Bilezikian, Lawrence G. Raisz and G.A. Rodan (Eds.) Academic Press, San Diego 176-182 (1996).

Cascone, M.G.; Barbani, N.; Cristallini, C.; Giusti, P.; Ciardelli G.; Lazzeri L. "Bioartificial polymeric materials based on polysaccharides". Journal of Biomaterials Science-Polymer Edition, 12(3): 267-281 (2001).

Castro, C.; Gargallo, L.; Leiva, A. Radic, D. "Interactions in blends containing chitosan with functionalized polymers". Journal of Applied Polymer Science, 97(5):1953-1960 (2005).

Chatelet, C.; Damour, O.; Domard, A. "Influence of the degree of acetylation on some biological properties of chitosan films". Biomaterials, 22(3): 261-268(2001).

Chandy, T.; Sharma C. P. "Chitosan as a biomaterial". Biomaterials, artificial cells, and artificial organs, 18 (1):1-24(1990).

Chellat, F.; Tabrizian, M.; Dumitriu, S.; Chorne, E.; Rivard, C.H.; Yahia, L.J. "Study of biodegradation behavior of chitosan-xanthan microspheres in simulated physiological media". Journal of Biomedical Materials Research. Part A, 53(5): 592-599 (2000).

Chen, F.; Lee, C. N.; Teoh, S. H. "Nanofibrous modification on ultra-thin poly (epsiloncaprolactone) membrane via Electrospinning". Materials Science and Engineering $C$. Materials for Biological Applications, 27(3): 325-332 (2007).

Chen, S.; Liu, M.; Jin, S.; Wang B. "Preparation of ionic-crosslinked chitosan-based gel beads and effect of reaction conditions on drug release behaviors". International Journal of Pharmaceutics, 349 (1-2): 180-187(2008).

Chew, S.Y.; Mi, R.; Hoke, A.; Leong, K.W. "The Effect of the Alignment of Electrospun Fibrous Scaffolds on Schwann Cell Maturation" Biomaterials, 29 (6): 653-661 (2008). 
Chow, K.S.; Khor, E. "Novel fabrication of open-pore chitin matrixes". Biomacromolecules, 1(1): 61-67 (2001).

Coombes, A. G.; Rizzi, S. C.; Williamson, M.; Barralet, J. E.; Downes, S.; Wallace, W. A. "Precipitation casting of polycaprolactone for applications in tissue engineering and drug delivery". Biomaterials, 25 (2): 315-25(2004).

Correlo, V.M.; Boesel, L.F.; Bhattacharya, M.; Mano, J.F.; Neves, N.M.; Reis, R.L. "Properties of melt processed chitosan and aliphatic polyester blends". Materials Science and Engineering. Part A. Structural Materials: Properties, Microstructure and Processing, 403(1-2): 57-68 (2005).

Correlo, V. M.; Boesel L. F.; Pinho E.; Costa-Pinto A. R.; Alves da Silva, M. L.; Bhattacharya, M.; Mano, J.F.; Neves, N.M.; Reis, R.L. "Melt-based compression-molded scaffolds from chitosan-polyester blends and composites: Morphology and mechanical properties". Journal of Biomedical Materials Research Part A. 91(2): 489-504 (2009).

Cortizo, A.M.; Etcheverry, S.B. "Vanadium derivatives act as growth factor- mimetic compounds upon differentiation and proliferation of osteoblast-like UMR106 cells". Molecular and Cellular Biochemistry, 145 (2): 97-102 (1995).

Cortizo, A.M.; Molinuevo, M.S.; Barrio, D.A.; Bruzzone, L. "Osteogenic activity of vanadyl (IV)-ascorbate complex: evaluation of its mechanisms of action". International Journal of Biochemistry \& Cell Biology, 38 (7): 1171-1180 (2006).

Cortizo, M.C.; De Mele, M.F.; Cortizo, A.M. "Metallic dental material biocompatibility in osteoblast like cells: correlation with metal ion release". Biological Trace Element Research, 100 (2):151-68 (2004).

Cortizo, M.S.; Molinuevo, M.S.; Cortizo, A.M. "Biocompatibility and biodegradation of polyester and polyfumarate based-scaffolds for bone tissue engineering" Journal of Tissue Engineering and Regenerative Medicine, 2(1):33-42(2008).

Costa Martinez, E.; Escobar Ivirico, J.L.; Munoz Criado, I.; Gomez Ribelles, J.L.; Monleon Pradas, M.; Salmeron Sanchez, M. "Effect of poly(L-lactide) surface topography on the morphology of in vitro cultured human articular chondrocytes". Journal of Materials Science: Materials in Medicine, 18 (8):1627- 1632 (2007).

Costa-Pinto, A. R.; Salgado, A. J.; Correlo, V. M.; Sol, P.; Bhattacharya, M.; Charbord, P.; Reis, R. L.; Neves, N.M. "Adhesion, proliferation and osteogenic differentiation of a mouse mesenchymal stem cell line (BMC9) seeded on novel melt-based 
chitosan/polyester 3D porous scaffolds". Tissue Engineering Part A, 14(6):1049-1057 (2008).

Coutinho, D.F.; Pashkuleva, I.H.; Alves, C.M.; Marques, A.P.; Neves, N.M.; Reis, R.L. "The Effect of Chitosan on the In Vitro Biological Performance of Chitosan-Poly (butylene succinate) Blends". Biomacromolecules, 9(4):1139-1145 (2008).

Dalby, M.J.; Childs, S.; Riehle, M.O.; Johnstone, H.J.H.; Affrossman, S.; Curtis, A.S.G. "Fibroblast reaction to island topography: changes in cytoskeleton and morphology with time". Biomaterials, 24(6): 927-935 (2003).

Denkbas, E.B.; Seyyal, M.; Piskin E. "5-Fluorouracil loaded chitosan microspheres for chemoembolization". Journal of Microencapsulation, 16(6):741-749 (1999).

Deschaseaux, F.; Sensébé, L.; Heymann D. "Mechanisms of bone repair and regeneration. Trends in Molecular Medicine", 15: 417-429(2009).

Doherty P.J.; Williams, R.L.; Williams, D.; Lee, A.J.C. (Eds). Biomaterial-Tissue Interfaces: Second Consensus Conference on Definitions in Biomaterials, Chester 1991. Amsterdam: Elsevier (1992).

Dunstan, C. R.; Blair, J.M.; Zhou, H.M; Seibel, J. "6.21 - Bone, Mineral, Connective Tissue Metabolism". Comprehensive Medicinal Chemistry II. Editor-in-Chief: David Triggle, John Taylor. 6: 495-520 (2007).

Duplomb, L.; Dagouassat, M.; Jourdon, P.; Heymann, D. “Concise review: embryonic stem cells: a new tool to study osteoblast and osteoclast differentiation". Stem Cells, 25(3): 544-552(2007).

Ezra, A.; Golomb, G. "Administration routes and delivery systems of bisphosphonates for the treatment of bone resorption". Advanced Drug Delivery Reviews, 42(3):175195(2000).

Fakhry, A.; Schneider, G. B.; Zaharias, R.; Senel, S. "Chitosan supports the initial attachment and spreading of osteoblasts preferentially over fibroblasts". Biomaterials, 25(11): 2075-2079(2004).

Fauchex, C.; Verron, E.; Soueidan, A.; Josse, S.; Arshad, M.D.; Janvier, P.; Pilet, P.; Bouler, J.M.; Bujoli, B.; Guicheux, J. "Controlled release of bisphosphonate from a calcium phosphate biomaterial inhibits osteoclastic resorption in vitro". Journal of Biomedical Materials Research. Part A, 89(1):46-56 (2009). 
Ferguson, C.; Alpern, E.; Miclau, T.; Helms, J.A. "Does adult fracture repair recapitulate embryonic skeletal formation?". Mechanisms of Development, 87(1-2): 57-66 (1999).

Fernandez, J.M.; Molinuevo, M.S.; Cortizo, A.M.; McCarthy, A.D.; Cortizo, M.S. "Characterization of Poly(epsilon-caprolactone)/Polyfumarate Blends as Scaffolds for Bone Tissue Engineering". Journal of biomaterials science. Polymer edition, 21(10):1297312(2010).

Fernandez, J. M.; Molinuevo, M. S.; Cortizo, M. S.; Cortizo, A. M. "Development of an osteoconductive PCL-PDIPF-hydroxyapatite composite scaffold for bone tissue engineering". Journal of Tissue Engineering and Regenerative Medicine, n/a. doi: 10.1002/term.394 (2011).

Filipovic-Grcic, J.; Perissutti, B.; Moneghini, M.; Voinovich, D; Martinac, A.; Jalsenjak, I. "Spray-dried carbamazepine-loaded chitosan and HPMC microspheres: preparation and characterisation". Journal of Pharmacy and Pharmacology, 55(7): 921-931 (2003).

Fleisch,H.; Russell, R.G.G.; Francis, M.D. "Diphosphonates inhibit formation of calcium phosphate crystals in vitro and pathological calcification in vivo". Science, 165:12621264(1969).

Flores-Figueroa, E; Montesinos, J.J.; Mayani, H. "Células troncales mesenquimales: historia, biología y aplicación clínica". Revista de Investigación Clínica, 58(5): 498511(2006).

Frith, J.C.; Mönkkönen, J.; Russell, R.G.G.; Blackburn, G.M.; Rogers, M.J. “Clodronate and liposome-encapsulated clodronate are metabolized to a toxic ATP analogue, adenosine $5^{\prime}$-( $\beta, \gamma$-dichloromethylen) triphosphate, by mammalian cells in vitro". Journal of Bone and Mineral Research, 12:1358-1367(1996).

Frost, $\boldsymbol{H}$. "A new direction for osteoporosis research: a review and proposal". Bone, 12: 429-437 (1991).

Fuchs, J.R.; Nasseri, B.A.; Vacanti, J.P. "Tissue engineering: a 21st century solution to surgical reconstruction" The Annals of Thoracic Surgery, 72:577-591 (2001).

Gangoiti, M. V.; Cortizo, A. M.; Arnol' V.; Felice, J.I.; McCarthy, A.D. "Opposing effects of bisphosphonates and advanced glycation end-products on osteoblastic cells". European Journal of Pharmacology, 600(1-3):140-147(2008). 
García Cruz D.M.; Ivirico J.L.E.; Gomes, M.M; Gomes Ribelles, J.L.G.; Sánchez, M.S.; Reis, R.L.; Mano, J.F. "Chitosan microparticles as injectable scaffolds for tissue engineering". Journal of Tissue Engineering and Regenerative Medicine, 2(6):378- 380 (2008a).

García Cruz D.M.; Coutinho, D.F.; Costa Martinez, E.; Mano, J.F.; Gómez Ribelles, J.L.; Salmerón Sánchez, M. "Blending polysaccharides with biodegradable polymers. II. Structure and biological response of chitosan/polycaprolactone blends". Journal of Biomedical Materials Research Part B: Applied Biomaterials, 87(2):544-54(2008b).

García Cruz D.M.; Coutinho, D.F.; Mano, J.F.; Gómez Ribelles, J.L.; Salmerón Sánchez, M. "Physical interactions in macroporous scaffolds based on poly ( $\varepsilon$-caprolactone)/chitosan semi-interpenetrating polymer networks". Polymer, 50(9): 2058-2064(2009).

Garkhal, K.; Verma, S.; Tikoo, K.; Kumar, N. "Surface modified poly(L-lactide-co- $\varepsilon-$ caprolactone) microspheres as scaffold for tissue engineering" Journal of Biomedical Materials Research Part A Materials in Medicine, 82(3): 747- 756 (2007).

Gartner, L. P.; Hiatt J. L. “Capítulo 7: Cartílago y hueso”. Texto Atlas de histología 2a edición, Mc Graw Hill Interamericana, 127-151(2002).

Geddes, A.D.; D'Souza, S.M.; Ebetino, F.H.; Ibbotson, K.J. "Bisphosphonates: structureactivity relationships and therapeutic implications". Journal of Bone and Mineral Research, 8:265-306 (1994).

Giuliani, N.; Pedrazzoni, M.; Negri, G.; Passeri, G.; Impicciatore, M.; Girasole, G. "Bisphosphonates stimulate formation of osteoblast precursors and mineralized nodules in murine and human bone marrow cultures in vitro and promote early osteoblastogenesis in young and aged mice in vivo". Bone, 22(5):455-461 (1998).

Godbey, W. T.; Atala, A. "In vitro systems for tissue engineering". Annals of the New York Academy of Sciences, 961:10-26 (2002).

Golomb, G.; Levi, M.; Van Gelder J M. "Controlled Release of Bisphosphonate from a Biodegradable Implant: Evaluation of Release Kinetics and Anticalcification Effect". Journal of Applied Biomaterials, 3(1): 23-28 (1992).

Golub, E.E. "Role of Matrix Vesicles in Biomineralization". Biochimica et Biophysica Acta, (12): 1592-1598 (2009).

Gomes, M. E.; Godinho, J. S.; Tchalamov, D.; Cunha, A. M.; Reis R. L. “Alternative tissue engineering scaffolds based on starch: processing methodologies, morphology, 
degradation and mechanical properties". Materials Science and Engineering: C Materials for Biological Applications, 20(1-2):19-26 (2002).

Gori, F.; Hofbauer, L.C.; Dunstan, C.R.; Spelsberg, T.C.; Khosla, S.; Riggs B.L. "The expression of osteoprotegein and RANK ligand and the support of osteoclast formation by stromal-osteoblast lineage cells is developmentally regulated". Endocrinology, 141(12):4768-4776 (2000).

Hamilton, V.; Yuan, Y.; Rigney, D. A.; Chesnutt, B. M.; Puckett, A. D.; Ong, J. L.; Yang, Y.; Haggard, W. O.; Elder, S. H.; Bumgardner, J. D. "Bone cell attachment and growth on well-characterized chitosan films". Polymer International, 56(5): 641-647(2007).

Helander, I.; Nurmiaho-Lassila, E.; Ahvenainen, R.; Rhoades, J.; Roller, S. "Chitosan disrupts the barrier properties of the outer membrane of Gram-negative bacteria". International Journal of Food Microbiology, 71: 235-44 (2001).

Hench, L.L.; Wilson, J. "Surface-active biomaterials". Science 226: 630-636 (1984).

Henriksen, I.; Green, K.L.; Smart, J.D.; Smistad, G.; Karlsen, J. "Bioadhesion of hydrated chitosan: an in vitro and in vivo study". International Journal of Pharmaceutics, 145(12):231-240 (1996).

Herrero J.E. "Biological Biomaterials". Anales de Química International Edition, 93(1): Suppl 32 (1997).

Hessle, L.; Johnson, K.A.; Anderson, H.C.; Narisawa, S.; Sali, A.; Goding, J.W.; Terkeltaub, R.; Millan, J.L. "Tissue-nonspecific alkaline phosphatase and plasma cell membrane glycoprotein-1 are central antagonistic regulators of bone mineralization". Proceedings of the National Academy of Sciences of the United States of America, 99(14):9445-9449 (2002).

Hill, P.A.; Orth, M. "Bone remodeling". British journal of orthodontics, 25(2): 101-107 (1998).

Hirano, S.; Itakura, C.; Seino, H.; Akiyama, Y.; Nonaka, I.; Kanbara, N.; Kanakami, T.; Arai, K.; Kinumaki, T. "Chitosan as an ingredient for domestic animal feeds". Journal of Agricultural and Food Chemistry, 38(5):1214-1217 (1990).

Hirano, S.; Tsuchida, H.; Nagao, N. "N-acetylation in chitosan and the rate of its enzymatic hydrolysis". Biomaterials, 10(8): 574-576(1989). 
Holland, T.A.; Mikos, A.G. "Biodegradable polymeric scaffolds. Improvements in bone tissue engineering through controlled drug delivery". Advances in Biochemical Engineering/Biotechnology,Tissue engineering I. 102:161-185(2006).

Holtrop, M. E.; King, G. J. "The ultrastructure of the osteoclast and its functional implications". Clinical Orthopaedics and Related Research, 123:177-196 (1977).

Hsieh, C.Y.; Tsai, S.P.; Wang, D.M.; Chang, Y.N.; Hsieh, H.J. "Preparation of gammaPGA/chitosan composite tissue engineering matrices". Biomaterials, 26(28): 56176523(2005).

Hsu, S.; Whu, S.W.; Tsai, C.L.; Wu, Y.H.; Chen, H.C.; Hsieh, K.H. "Chitosan as Scaffold Materials: Effects of Molecular Weight and Degree of Deacetylation". Journal of Polymer Research, 11(2): 141-147 (2004).

Huang,Y.C.; Onyeri, S.; Siewe,M.; Moshfeghian, A.; Madihally, S.V. "In vitro characterization of chitosan-gelatin scaffolds for tissue engineering". Biomaterials, 26(36):7616-27(2005b).

Huang, Y.C.; Huang, Y.Y.; Huang, C.C., Liu, H.C. "Manufacture of porous polymer nerve conduits through a lyophilizing and wire-heating process" Journal of Biomedical Materials Research Part B: Applied Biomaterials, 74(1): 659-664 (2005a).

Hughes, D.E.; Wright, K.R.; Uy, H.L.; Sasaki, A.; Yoneda, T., Roodman, G.D.; Mundy, G.R.; Boyce, B.F. "Bisphosphonates promote apoptosis in murine osteoclasts in vitro and in vivo". Journal of Bone and Mineral Research, 10(10):1478-1487(1995).

Hutchison, C.; Pilote, M.; Lévesque, M.; Roy, S. "The axolotl limb: a model for bone development, regeneration and fracture healing". Bone, 40(1):45-56(2007).

Ignatius, A.; Blessing, H.; Liedert, A.; Schmidt, C.; Neidlinger-Wilke, C.; Kaspar, D.; Friemert, B.; Claes, L. "Tissue engineering of bone: effects of mechanical strain on osteoblastic cells in type I collagen matrices". Biomaterials, 26(3):311-318(2005).

Im, G.I.; Qureshi, S.A.; Kenney, J.; Rubash, H.E.; Shanbhag, A.S. "Osteoblast proliferation and maturation by bisphosphonates". Biomaterials, 25(18):4105-15(2004).

Itoh, F.; Aoyagi, S.; Furihata-Komatsu, H.; Aoki, M.; Kusama, H.; Kojima, M.; Kogo, H. "Clodronate stimulates osteoblast differentiation in ST2 and MC3T3-E1 cells and rat organ cultures". European Journal of Pharmacology, 477(1): 9-16 (2003). 
Izquierdo, R.; Garcia-Giralt, N.; Rodriguez, M.T.; Cáceres, E.; García, S.J.; Gómez Ribelles, J.L.; Monleón Pradas, M.; Monllau, J.C.; Suay, J. "Biodegradable PCL scaffolds with an interconnected spherical pore network for tissue engineering". Journal of Biomedical Materials Research Part A, 85(1): 25-35 (2008).

Jung, A.; Bisaz, S.; Fleisch, H. "The binding of pyrophosphate and two diphosphonates on hydroxyapatite crystals". Calcified Tissue Research, 11(4):269-80 (1973).

Kartsogiannis, V.; Ng, K.W. "Cell lines and primary cell cultures in the study of bone cell biology". Molecular and Cellular Endocrinology, 228(1-2):79-102 (2004).

Kawakami, T.; Antoh, M.; Hasegawa, H.; Yamagishi, T.; Ito, M.; Eda, S. "Experimental study on osteoconductive properties of a chitosan-bonded hydroxyapatite self-hardening paste". Biomaterials, 13(11): 759-563(1992).

Khan, T.; Peh, K.; Ching, H. "Mechanical bioadhesive strength and biological evaluations of chitosan films for wound dressing". Journal of Pharmacy \& Pharmaceutical Sciences., 3(3): 303-311 (2000).

Khor, E.; Lim, L.Y. "Implantable applications of chitin and chitosan". Biomaterials, 24(13): 2339-2349 (2003).

Kim, I.Y.; Seo, S.J.; Moon, H.S.; Yoo, M.K.; Park, I.Y.; Kim, B.C.; Cho, C.S. "Chitosan and its derivatives for tissue engineering applications". Biotechnology Advances, 26(1):1-21 (2008).

Kurita, K.; Kaji, Y.; Mori, T.; Nishiyama, Y. "Enzymatic degradation of beta-chitin: susceptibility and the influence of deacetylation". Carbohydrate Polymer, 42(1): 19-21 (2000).

Kwan Tat, S.; Padrines, M.; Théoleyre, S.; Heymann, D.; Fortun, Y.; "IL-6, RANKL, TNFa/IL-1: interrelations in bone resorption pathophysiology". Cytokine \& Growth Factor Reviews 15(1):49-60 (2004).

Langer, R.; Vacanti J.P. “Tissue Engineering”. Science, 260 (5110): 920-926 (1993).

Lee, S.H.; Shin H. "Matrices and scaffolds for delivery of bioactive molecules in bone and cartilage tissue engineering". Advanced Drug Delivery Reviews, 59(4-5): 339-359 (2007).

Leong, J. C. Y. "Bone and cartilage transplant". Journal of Hong Kong Medical Association, 45(2):130-135 (1993). 
Li J.; Pan, J.; Zhang L.; Guo, X.; Yu, Y. "Culture of primary rat hepatocytes within porous chitosan scaffolds". Journal of Biomedical Materials Research Part A. Materials in Medicine, 67(3): 938-943 (2003).

Li, X.; Jin, L.; Balian, G.; Laurencin, C.T.; Greg Anderson, D. “Demineralized bone matrix gelatin as scaffold for osteochondral tissue engineering". Biomaterials, 27(11):24262433(2006).

Li, Z.; Ramay, H.R.; Hauch, K.D.; Xiao, D.; Zhang, M. “Chitosan-alginate hybrid scaffolds for bone tissue engineering". Biomaterials, 26(18):3919-3928(2005).

Liam, J.B.; Stein, G.S. "Concepts of osteoblast growth and differentiation: basis for modulation of bone cell development and tissue formation". Critical Reviews in Oral Biology \& Medicine, 3(3):269-305 (1992).

Liechty, W.B.; Kryscio, D.R.; Slaughter, B.V.; Peppas. N. A. “Polymers for Drug Delivery Systems". Annual Review of Chemical and Biomolecular Engineering, 1:149-173(2010).

Lim, S.T.; Martin, G.P.; Berry, D.J.; Brown, M.B.; "Preparation and evaluation of the in vitro drug release properties and mucoadhesion of novel microspheres of hyaluronic acid and chitosan". Journal of Controlled Release, 66(2-3):281-92 (2000).

Lopez-Perez, P. M.; Marques, A. P.; Da Silva, R. M. P.; Pashkuleva, I.; Reis, R. L. "Effect of chitosan membrane surface modification via plasma induced polymerization on the adhesion of osteoblast-like cells". Journal of Materials Chemistry, 17(38): 4064-4071 (2007).

Ma, P.X. "Tissue Engineering". Encyclopedia of Polymer Science and Technology. Part 3, 3rd Edition. Mark H.F. (Ed.) John Wiley \& Sons, Inc. 12 (9-12): 261-291 (2004a).

Ma, P.X. "Scaffolds for tissue fabrication". Materials Today, 7(5): 30-40 (2004b).

Ma, Z.; Yeoh, H.H.; Lim, L.Y. "Formulation pH modulates the interaction of insulin with chitosan nanoparticles" Journal of Pharmaceutical Sciences, 91(6):1396-1404 (2002).

Madihally, S.V.; Matthew, H.W.T. "Porous chitosan scaffolds for tissue engineering". Biomaterials, 20(12): 1133-1142(1999).

Malafaya, P.B.; Pedro, A.J.; Peterbauer, A.; Gabriel, C.; Redl, H.; Reis, R.L. "Chitosan particles agglomerated scaffolds for cartilage and osteochondral tissue engineering 
approaches with adipose tissue derived stem cells". Journal of Materials Science: Materials in Medicine, 16(12): 1077-1085 (2005).

Malafaya, P.B.; Silva, G.A.; Reis, R.L. "Natural-origin polymers as carriers and scaffolds for biomolecules and cell delivery in tissue engineering applications", Advanced Drug Delivery Reviews 59(4-5): 207-233 (2007).

Mano, J.F.; Silva, G.A.; Azevedo, H.S.; Malafaya, P.B.; Sousa, R.A.; Silva, S.S.; Boesel, L.F.; Oliveira, J.M.; Santos, T.C.; Marques, A.P.; Neves, N.M.; Reis, R.L. "Natural origin biodegradable systems in tissue engineering and regenerative medicine: present status and some moving trends" Journal of the Royal Society Interface, 4(17): 999-1030 (2007).

Mathov, I. M.; Plotkin, L. I.; Sgarlata, C. L.; Leoni, J.; Bellido, T. "Extracellular signal regulated kinases and calcium channels are involved in the proliferative effect of bisphosphonates on osteoblastic cells in vitro". Journal of Bone and Mineral Research, 16(11): 2050-2056 (2001).

Marks Jr., S.C.; Hermey, D.C. "The Structure and Development of Bone". Principles of Bone Biology, 1st Ed, John P. Bilezikian, Lawrence G. Raisz and G.A. Rodan (Eds.) Academic Press, San Diego. Cap 1: 3-15 (1996).

Marks Jr., S.C.; Poppoff, S.N. "Bone Cell Biology: The Regulation of development, structure, and function in the skeleton". American Journal of Anatomy, 183: 1-44 (1988).

Martin, T. J.; Ingleton, P. M.; Coulton, L. A.; Melick, R. A. "Metabolic Properties of Hormonally Responsive Osteogenic Sarcoma Cells". Clinical Orthopaedics \& Related Research: Section II: Basic Science and Pathology, 140:247-254 (1979).

Martínez Palau, M. "Síntesis, estructura y aplicaciones de poliésteres secuenciales derivados de ácido glicólico y $\omega$-hidroxiácidos". PhD Thesis. Universitat Politécnica de Catalunya. $410 \mathrm{p}$.

Martini, F.H.; Timmons, M.J.; Tallitsch, R.B. "The skeletal System: Osseous Tissue and Skeletal Structure". Human Anatomy. $6^{\circ}$ Ed. Pearson Education. Benjamin Cummings Publishing Company. (2009) Cap 5: 912 p.

Martino, AD.; Sittinger, M.; Risbud, M.V. "Chitosan: a versatile biopolymer for orthopaedic tissue-engineering". Biomaterials, 26(30):5983-5990 (2005). 
McCarthy, A.D.; Etcheverry, S.B.; Bruzzone, L.; Cortizo, A.M.; "Effects of advanced glycation end-products on the proliferation and differentiation of osteoblast-like cells". Molecular and Cellular Biochemistry, 170(1-2): 43-51 (1997).

Mei, N.; Chen, G.; Zhou, P.; Chen, X.; Shao, Z.Z.; Pan, L.F.; Wu, C.G. "Biocompatibility of Poly(epsilon-caprolactone) scaffold modified by chitosan- the fibroblasts proliferation in vitro". Journal of Biomaterials Applications, 19(4): 323-339 (2005).

Mi, F.L.; Shyu, S.S.; Wong, T.B.; Jang, S.F.; Lee, S.T.; Lu, K.T. “Chitosan-polyelectrolyte complexation for the preparation of gel beads and controlled release of anticancer drug. II. Effect of pH-dependent ionic crosslinking or interpolymer complex using tripolyphosphate or polyphosphate as reagent". Journal of Applied Polymer Science, 74(5): 1093-1107(1999).

Mi, F.L.; Sung, H.W.; Shyu, S.S.; Su, C.C.; Peng, C.K. "Synthesis and characterization of biodegradable TPP/genipin co-crosslinked chitosan gel beads". Polymer, 44(21): 6521$6530(2003)$

Molinuevo, M.S.; Bruzzone, L.; Cortizo, A.M. "Alendronate induces anti-migratory effects and inhibition of neutral phosphatases in UMR106 osteosarcoma cells". European Journal of Pharmacology, 562 (1-2):28-33 (2007).

Montembault, A.; Viton, C.; Domard, A. "Rheometric study of the gelation of chitosan in aqueous solution without cross-linking agent". Biomacromolecules, 6(2):653-662(2005).

Mouriño, V.; Boccaccini, A.R. "Bone tissue engineering therapeutics: controlled drug delivery in three-dimensional scaffolds". Journal of the Royal Society. Interface,7(43):209227(2010).

Mundy G.R. "Bone Resorbing Cells". Primer on the Metabolic Bone Diseases and Disorders of Mineral Metabolism, Second Edition. Favus M.J.,ed. New York: Raven Press, 25-32 (1993).

Murakami, H.; Takahashi, N.; Sasaki, T.; Udagawa, N.; Tanaka, S.; Nakamura, I.; Zhang, D.; Barbier,A.; Suda,T. "A possible mechanism of the specific action of bisphosphonates on osteoclasts: tiludronate preferentially affects polarized osteoclasts having ruffled borders". Bone, 17(2):137-44(1995).

Muzzarelli, R.A.A. "Human enzymatic activities related to the therapeutic administration of chitin derivatives". Cellular and Molecular Life Sciences, 53(2):131-140 (1997). 
Muzzarelli R.A.A. "Chitins and chitosans for the repair of wounded skin, nerve, cartilage and bone". Carbohydrate Polymers, 76(2): 167-182 (2009).

Muzzarelli, R. A. A.; Zucchini, C.; Ilari, P.; Pugnaloni, A.; Mattioli-Belmonte, M.; Biagini, G.; Castaldini, C. "Osteoconductive properties of methylpyrrolidinone chitosan in an animal model". Biomaterials, 4(12): 925-929(1993).

Nair, L.S.; Laurencin, C.T. "Polymers as Biomaterials for Tissue Engineering and Controlled Drug Delivery". Advances in Biochemical Engineering /Biotechnology,Tissue Engineering I. 102: 47-90 (2006).

Ng, C. S.; Teoh, S. H.; Chung, T. S.; Hutmacher, D. W. "Simultaneous biaxial drawing of poly (epsilon-caprolactone) films". Polymer, 41(15):5855-5864(2000).

Nieto, A.; Balas, F.; Colilla, M.; Manzano, M.; Vallet-Regí, M. "Functionalization degree of SBA-15 as key factor to modulate sodium alendronate dosage". Microporous and Mesoporous Materials, 116(1-3): 4-13 (2008).

Nishikawa, M.; Akatsu, T.; Katayama, Y.; Yasutomo, Y.; Kado, S.; Kugai, N.; Yamamoto, M.; Nagata ,N. "Bisphosphonates act on osteoblastic cells and inhibit osteoclast formation in mouse marrow cultures". Bone, 18(1):9-14 (1996).

No, H.K.; Kim, S.D.; Kim, D.S.; Kim, S.J.; Meyers, S.P. "Effect of physical and chemical treatments on chitosan viscosity". Journal of Korean Society for Chitin and Chitosan, 4:177-83 (1999).

Noble, J.E.; Bailey, M.J.A. "Chapter 8.Quantitation of Protein". Methods in Enzymology, 463: 73-95(2009).

Nunthanid, J.; Puttipipatkhachorn, S.; Yamamoto, K.; Peck, G.E. "Physical properties and molecular behavior of chitosan films". Drug Development and Industrial Pharmacy, 27:143-57(2001).

Ochiuz, L.; Peris J.E. "Preparation and Characterisation of Alendronate-Loaded Chitosan Microparticles Obtained Through the Spray Drying Technique". Medicinal Chemistry, 5(2): 191-196 (2009).

Oliveira, B. F.; Santana, M. H. A.; Ré, M. I. "Spray-Dried Chitosan Microspheres CrossLinked with D, L-glyceraldehyde as a Potential Drug Delivery System: Preparation and Characterization". Brazilian Journal of Chemical Engineering, 22(3): 353-360 (2005). 
Oliveira, S.M.; Amaral, I.F.; Barbosa, M.A.; Teixeira, C.C. "Engineering Endochondral Bone: In Vitro Studies". Tissue Engineering Part A, 15(3): 625-634(2009).

Pangburn, S.H.; Trescony, P.V.; Heller, J. "Lysozyme degradation of partially deacetylated chitin, its films and hydrogels". Biomaterials, 3(2): 105-108(1982).

Panzavolta, S.; Torricelli, P.; Bracci, B.; Fini, M.; Bigi, A. "Alendronate and Pamidronate calcium phosphate bone cements: setting properties and in vitro response of osteoblast and osteoclast cells". Journal of Inorganic Biochemistry, 103(1):101-106 (2009).

Papachroni, K.K.; Karatzas, D.N.; Papavassiliou, K.A.; Basdra, E.K.; Papavassiliou, A.G. "Mechanotransduction in osteoblast regulation and bone disease". Trends in Molecular Medicine, 15(5): 208-216 (2009).

Pappapoulos S. E. "Bisphosphonates: how do they work?". Best Practice \& Research Clinical Endocrinology \& Metabolism, 22(5): 831-847 (2008).

Parfitt, A.M. "Osteonal and hemi-osteonal remodeling: the spatial and temporal framework for signal traffic in adult human bone." Journal of Cellular Biochemistry, 55(3): 273-286 (1994).

Partridge, N.C.; Alcorn, D.; Michelangeli, V.P.; Ryan, G.; Martin, T.J. "Morphological and biochemical characterization of four clonal osteogenic sarcoma cell lines of rat origin". Cancer Research, 43(9): 4308-4312(1983).

Partridge, N.C.; Dickson, C.A.; Kopp, K.; Teitelbaum, S.L.; Crouch, E.C.; Kahn, A.J. "Parathyroid Hormone Inhibits Collagen Synthesis at Both Ribonucleic Acid and Protein Levels in Rat Osteogenic Sarcoma Cells". Molecular Endocrinolology, 3(2): 232-239 (1989).

Patashnik, S.; Rabinovich, L.; Golomb, G. "Preparation and evaluation of chitosan microspheres containing bisphosphonates". Journal of Drug Targering, 4(6):371-80 (1997).

Peppas, N.A.; Langer, R. “New challenges in biomaterials". Science, 263(5154):1715-1720 (1994).

Peppas,N.A.; Bures,P.; Leobandung,W; Ichikawa,H. "Hydrogels in pharmaceutical formulations". European Journal of Pharmaceutics and Biopharmaceutics, 50 (1): 27-46 (2000). 
Pitt C.G. "Poly- $\varepsilon$-caprolactone and its copolymers". Biodegradable polymers as drug delivery systems. Chasin, M.; Langer, R. (Eds). New York: Marcel-Dekker, Inc. Cap.3: 71120 (1990).

Pittenger, M.F.; Mackay, A.M.; Beck, S.C.; Jaiswal, R.K.; Douglas, R.; Mosca, J.E.; Moorman, M.A.; Simonetti, D.W.; Craig, S.; Marshak, D.R. "Multilineage potential of adult human mesenchymal stem cells". Science, 284 (5411): 143-147(1999).

Plotkin, L.I.; Weinstein, R.S.; Parfitt, A.M.; Roberson, P.K.; Manolagas, S.C.; Bellido, T. "Prevention of osteocyte and osteoblast apoptosis by bisphosphonates and calcitonin". Journal of Clinical Investigation, 104(10):1363-1374 (1999).

Plotkin, L.I.; Manolagas, S.C.; Bellido, T. "Dissociation of the pro-apoptotic effects of bisphosphonates on osteoclasts from their anti-apoptotic effects on osteoblasts/osteocytes with novel analogs". Bone, 39 (3):443-452(2006).

Puzas J.E. "The osteoblast". Primer on the metabolic bone diseases and disorders of mineral metabolism, $2^{\circ}$ Edition. Favus M.J. ed. New York: Raven Press, 15-20 (1993).

Quarles, L.D.; Yohay, D.A.; Lever, L.W.; Caton, R.; Wenstrup, R.J. “Distinct proliferative and differentiated stages of murine MC3T3-E1 cells in culture: an in vitro model of osteoblast development". Journal of Bone and Mineral Research, 7(6): 683-692 (1992).

Ravi Kumar, M.N.V.; Muzarelli, R.A.A.; Muzarelli, C.; Sashiwa, H.; Domb, A.J. "Chitosan chemistry and pharmaceutical perspectives". Chemical Reviews ,104 (12): 60176084(2004).

Rinaudo M. "Chitin and chitosan: Properties and applications". Progress in Polymer Science, 31(7): 603-632(2006).

Rinaudo, M.; Pavlov, G.; Desbriéres, J. "Influence of acetic acid concentration on the solubilization of chitosan". Polymer, 40(25): 7029-7032(1999).

Robey, P.G. "Bone Matrix Proteoglycans and Glycoproteins". Principles of Bone Biology, 1st Ed, John P. Bilezikian, Lawrence G. Raisz and G.A. Rodan (Eds.) Academic Press, San Diego. Cap. 12: 155-166 (1996).

Rogers, M.J. "From molds and macrophages to mevalonate: a decade of progress in understanding the molecular mode of action of bisphosphonates". Calcified Tissue International, 75(6):451-61 (2004). 
Rogers, M.J.; Watts, D.J.; Russell, R.G. "Overview of bisphosphonates". Cancer, 80(suppl 8: Skeletal Complications of Malignancy): 1652-1660 (1997).

Rosen, C.J.; Kesenich, C.R. "Comparative clinical pharmacology and therapeutic use of bisphosphonates in metabolic bone diseases". Drugs , 51(4): 537-51(1996).

Ross, J.M. "Cell-Extracellular Matrix Interactions". Frontiers in Tissue Engineering. Patrick, C.W.; Mikos ,A.G.; Mc Intre, L. eds. Oxford: Elsevier Science Ltd. 15-27(1998).

Rossert, J.; De Crombrugghe, B. "Type I Collagen: Structure, Synthesis, and Regulation". Principles of Bone Biology, 1st Ed, John P. Bilezikian, Lawrence G. Raisz and G.A. Rodan (Eds.) Academic Press, San Diego, Cap 10: 127-142 (1996).

Ruel-Gariépy, E.; Chenite, A.; Chaput, C.; Guirguis, S.; Leroux, J. "Characterization of thermosensitive chitosan gels for the sustained delivery of drugs". International Journal of Pharmaceutics, 203(1-2):89-98(2000).

Russell, R.G.; Rogers, M.J. "Bisphosphonates: from the laboratory to the clinic and back again". Bone, 25(1):97-106 (1999).

Russell R.G. "Bisphosphonates: Mode of Action and Pharmacology". Pediatrics, 119(2):150-152 (2007).

Sachlos, E.; Czernuszka, J.T. "Making Tissue Engineering Scaffolds Work. Review on the Application of Solid Freeform Fabrication Technology to the Production of Tissue Engineering Scaffolds". European Cells and Materials, 5:29-40(2003).

Sáez, V.; Hernáez, E.; López, L. “Liberación Controlada de Fármacos. Aplicaciones Biomédicas". Revista Iberoamericana de Polímeros, 4(2):111-122 (2003).

Sahni, M.; Guenther, H.L.; Fleisch, H.; Collin, P.; Martin T.J. "Bisphosphonates act on rat bone resorption through the mediation of osteoblasts". Journal of Clinical Investigation, 91(5):2004-2011(1993).

Salgado, A.J.; Coutinho, O.P.; Reis, R.L. "Bone Tissue Engineering: State of the Art and Future Trends". Macromolecular Bioscience, 4(8): 743-765 (2004).

Santos, C.; Seabra, P.; Veleirinho, B.; Delgadillo, I.; Lopes da Silva, J.A. "Acetylation and molecular mass effects on barrier and mechanical properties of shortfin squid chitosan membranes". European Polymer Journal, 42(12): 3277-3285 (2006). 
Sarasam, A.R.; Madihally, S. V. "Characterization of Chitosan-Polycaprolactone Blends for Tissue. Engineering Applications". Biomaterials, 26 (27): 5500-5508 (2005).

Sarasam, A.R.; Krishnaswamy, R.K.; Madihally, S.V. "Blending Chitosan with Polycaprolactone: Effects on Physicochemical and Antibacterial Properties". Biomacromolecules, 7(4): 1131-1138 (2006).

Sato, M.; Grasser, W.; Endo, N.; Akins, R.; Simmons, H.; Thompson, D.D., et al. "Bisphosphonate action. Alendronate localization in rat bone and effects on osteoclast ultrastructure". Journal of Clinical Investigation, 88(6):2095-2105 (1991).

Schagemann, J. C.; Chung, H. W.; Mrosek, E.H.; Stone, J.J.; Fitzsimmons, J.S.; O'Driscoll, S.W.; Reinholz, G. G. "Poly- $\varepsilon$-caprolactone/gel hybrid scaffolds for cartilage tissue engineering". Journal of Biomedical Materials Research Part A, 93(2):454-463 (2010).

Schenk, R.; Eggli, P.; Fleisch, H.; Rosini, S. "Quantitative morphometric evaluation of the inhibitory activity of new aminobisphosphonates on bone resorption in the rat". Calcified Tissue International; 38(6):342-349 (1986).

Seol, Y. J.; Lee, J. Y.; Park, Y. J.; Lee, Y. M.; Young-Ku; Rhyu, I. C.; Lee, S. J.; Han, S.B.; Chung, C.P. "Chitosan sponges as tissue engineering scaffolds for bone formation". Biotechnology Letters, 26 (13): 1037-1041(2004).

Shalak, R.; Fox C.P. "Preface" Tissue Engineering. Shalak, R.; Fox, C.P. (eds). New York: Alan R. Liss, 26-29 (1988).

She, H.; Xiao, X.; Liu, R. "Preparation and characterization of polycaprolactone-chitosan composites for tissue engineering applications". Journal of Materials Science, 42(19): 8113-8119 (2007).

Shigemasa, Y.; Saito, K.; Sashiwa, H.; Saimoto, H. "Enzymatic degradation of chitins and partially deacetylated chitins". International Journal of Biological Macromolecules, 16(1):43-49 (1994).

Shinoda, H.; Adamek, G.; Felix, R.; Fleisch, H.; Schenk, R.; Hagan, P. "Structure-activity relationships of various bisphosphonates". Calcified Tissue International, 35:87-99 (1983).

Shu, X.Z.; Zhu, K.J.“Controlled drug release properties of ionically crosslinked chitosan beads: the influence of anion structure". International Journal of Pharmaceutics, 233(12): 217-225(2002a). 
Shu, X.Z.; Zhu K.J. "The influence of multivalent phosphate structure on the properties of ionically cross-linked chitosan films for controlled drug release". European Journal of Pharmaceutics and Biopharmaceutics, 54(2): 235-243(2002b).

Sietsema, W.K.; Ebetino, F.H.; Salvagno, A.M.; Bevan, J.A. "Antiresortive dose-response relationships across three generations of bisphosphonates". Drugs Under Experimental \& Clinical Research, 15(9):389-396(1989).

Sikavitsas, V.I.; Temenoff, J. S.; Mikos A. G. "Biomaterials and bone mechanotransduction II". Biomaterials, 22(19): 2581-2593 (2001).

Sokolsky-Papkov, M.; Agashi, K.; Olaye, A.; Shakesheff, K.; Domb, A.J. "Polymer carriers for drug delivery in tissue engineering", Advanced Drug Delivery Reviews 59(4-5): 187206 (2007).

Sorlier, P.; Denuziere, A.; Viton, C.; Domard, A. "Relation between the Degree of Acetylation and the electrostatic properties of chitin and chitosan". Biomacromolecules, 2(3): 765-772(2001).

Srinatha, A.; Pandit, J. K.; Singh, S. "Ionic Cross-linked Chitosan Beads for Extended Release of Ciprofloxacin: In vitro Characterization". Indian Journal of Pharmaceutical Sciences, 70 (1):16-21 (2008).

Stein, G.S.; Liam, J.B. "Molecular mechanisms mediating proliferation/differentiation interrelationships during progressive development of the osteoblast phenotype". Endocrinology Reviews, 14(4):424-442(1993).

Storm, T.; Steiniche, T.; Thamsborg, G.; Melsen, F. "Changes in bone histomorphometry after long-term treatment with intermittent, cyclic etidronate for postmenopausal osteoporosis". Journal of Bone \& Mineral Research, 8(2):199-208 (1993).

Suh, J.K.F.; Matthew, H.W.T. "Application of chitosan-based polysaccharide biomaterials in cartilage tissue engineering: a review". Biomaterials, 21(24): 2589-2598 (2000).

Suphasiriroj, W.; Yotnuengnit, P.; Surarit, R.; Pichyangkura, R. "The fundamental parameters of chitosan in polymer scaffolds affecting osteoblasts (MC3T3-E1)". Journal of Material Science. Materials in Medicine, 20(1):309-20 (2009).

Tietz, N.W.; Rinker, A.D.; Shaw, L.M. "International Federation of Clinical Chemistry (IFCC) methods for the measurement of catalytic concentration of enzymes. Part 5: IFCC methods for alkaline phosphatase (orthophosphoric-monoester phosphohydrolase, 
alkaline optimum, EC 3.1.3.1)". Journal of Clinical Chemistry \& Clinical Biochemistry, 21(11): 731-748 (1983).

Tiwary, A.K.; Rana, V. "Cross-Linked Chitosan Films: Effect of Cross-Linking Density on Swelling Parameters". Pakistan Journal of Pharmaceutical Sciences, 23(4): 443-448 (2010).

Tomihata K.; Ikada Y. "In vitro and in vivo degradation of films of chitin and its deacetylated derivatives". Biomaterials, 18(7): 567-575 (1997).

Triffit, J. T. "The Stem cell of the osteoblast". Principles of Bone Biology, 1st Ed, John P. Bilezikian, Lawrence G. Raisz and G.A. Rodan (Eds.) Academic Press, San Diego Cap. 4:3950 (1996).

Tullberg-Reinert, H.; Jundt, G. "In situ measurement of collagen synthesis by human bone cells with a Sirius red-based colorimetric microassay: effects of transforming growth factor beta2 and ascorbic acid 2-phosphate". Histochemistry and Cell Biology, 112(4): 271-276(1999).

Tuzlakoglu, K.; Alves, C.M.; Mano, J.F.; Reis, R.L. "Production and characterization of chitosan fibers and 3-D fiber mesh scaffolds for tissue engineering applications". Macromolecular Bioscience, 4(8): 811-819(2004).

Uhrich, K.E.; Cannizzaro, S.M.; Langer, R.S.; Shakesheff, K.M. "Polymeric systems for controlled drug release". Chemical Reviews, 99(11):3181-3198(1999).

Vaisman, D. N.; McCarthy, A. D.; Cortizo, A. M. "Bisphosphonates affect the growth, differentiation and cytoskeleton of UMR106 osteoblasts in culture". Osteoporosis International, 15(Supl.1):133 (2004).

Vaisman, D. N.; McCarthy, A. D.; Cortizo, A. M. "Bone-Specific Alkaline Phosphatase Activity Is Inhibited by Bisphosphonates. Role of Divalent Cations". Biological Trace Element Research, 104: 131-140 (2005).

Vårum, K. M.; Ottøy, M. H.; Smidrød, O. "Water-solubility of partially N-acetylated chitosans as a function of $\mathrm{pH}$ : Effect of chemical composition and depolymerization". Carbohydrate Polymers, 25(2): 65-70 (1994).

Vitte, C.; Fleisch, H.; Guenther, H.L. "Bisphosphonates induce osteoblasts to secrete an inhibitor of osteoclast-mediated resorption". Endocrinology 137:2324-2333(1996). 
Wang, J.W.; Hon, M.H. "Effects of sugar cross-linking agents and thermal treatment on the culture of fibroblasts in vitro on a (PEG/ chitosan) membrane". Journal of Biomaterials Science, Polymer Edition, 14(2):119-137 (2003).

Wan, Y.; Lu, X.; Dalai, S.; Zhang, J. "Thermophysical properties of polycaprolactone/chitosan blend membranes". Thermochimica Acta, 487(1-2): 33-38 (2009).

Watanabe, J.; Ishihara, K. "Change in cell adhesion property on cytocompatible interface using phospholipid polymer grafted with poly ( $D, L$-lactic acid) segment for tissue engineering". Science and Technology of Advanced Materials, 4(6): 539-544 (2003).

Weiner, S.; Wagner, H.D. "The Material Bone: Structure Mechanical Function Relations". Annual Review of Materials Science, 28: 271-298 (1998).

Whyte, M. P. “ALP in hypophosphatasia”. Endocrine Reviews, 15(4): 439-461 (1994).

Wiesmann, H.P.; Meyer ,U.; Plate, U.; Hohling, H.J. "Aspects of collagen mineralization in hard tissue formation". International Review of Cytology, 242:121-156 (2005).

Wiliams, J.M.; Adewunmi, A.; Scheck, R.M.; Flanagan, C.L.; Krebsbach, P.H.; Feinberg, S.E. "Bone tissue engineering using polycaprolactone scaffolds fabricated via selective laser sintering" Biomaterials, 26(23): 4817-4827 (2005).

Wu, C.S. "A comparison of the structure, thermal properties, and biodegradability of polycaprolactone/chitosan and acrylic acid grafted polycaprolactone/chitosan". Polymer, 46(1): 147-155(2005).

Wu, Y.C.; Shaw, S.Y.; Lin, H.R.; Lee, T.M.; Yang, C.Y. "Bone tissue engineering evaluation based on rat calvaria stromal cells cultured on modified PLGA scaffolds." Biomaterials, 27:896-904 (2006).

Wu,H.; Wan, Y.; Dalai, S.; Zhang, R. "Response of rat osteoblasts to policaprolactona/chitosan blend porous scaffolds". Journal of Biomedical Materials Research Part A, 92 (1):238-245(2010).

Xiao, Y.M.; Li, D.X.; Chen, X.N.; Lu, J.; Fan, H.S.; Zhang, X.D. "Preparation and cytocompatibility of chitosan-modified polylactide". Journal of Applied Polymer Science, 110(1): 408-412 (2008). 
Yaszemski, M.J.; Payne, R.G.; Hayes, W.C.; Langer, R.; Mikos, A.G. "Evolution of bone transplantation: molecular, cellular and tissue strategies to engineering human bone". Biomaterials, 17(2): 175-185(1996).

Yi, H.; Wu, L.Q.; Bentley, W. E.; Ghodssi, R.; Rubloff, G. W.; Culver, J. N.; Payne, G. F. "Biofabrication with Chitosan". Biomacromolecules, 6(6): 2881-2894 (2005). 
Trabajos publicados

$y$

presentaciones a congresos

en el marco

del trabajo de tesis. 


\section{TRABAJOS PUBLICADOS Y PRESENTACIONES A CONGRESOS EN EL MARCO DEL TRABAJO DE TESIS}

\section{- Participación en Congresos - Encuentros - Jornadas y Simposios:}

- "Estudio y aplicación de quitina, un polímero derivado de fuentes naturales". Berghoff, C.F.; Cortizo, M.S. y Alessandrini, J.L. I Foro de Estudiantes de Biología del Mercosur, Para un Desarrollo Sustentable. Ciudad de Hernandarias, Paraguay, 2 al 7 de Octubre de 2005.

- "Solid State and Solution properties of $\beta$-chitin from Illex argentinus squid pen". Berghoff, C.F.; Cortizo, M.S. y Alessandrini, J.L. IV Simposio Iberoamericano de Quitina. Ciudad de Natal, Brasil, 6 al 9 de Mayo de 2007.

- "Aislamiento y Caracterización de Quitina de Pluma de Calamar". Berghoff, C.F. Jornadas de Becarios del INIFTA (Instituto de Investigaciones Fisicoquímicas Teóricas y Aplicadas) INIFTA, UNLP, La Plata 23-26 de octubre 2007.

- "Longitud de persistencia y masa molar de quitina mediante viscometría capilar". Berghoff C.F ; Cortizo M. S., Alessandrini. J. L. IV Simposio Argentino-Chileno de polímeros. (Archipol 2007). Viña del Mar, Chile, 2-5 de diciembre de 2007.

- "Caracterización de Quitosano de Illex argentinus". Berghoff, C.F. Jornadas de Becarios del INIFTA (Instituto de Investigaciones Fisicoquímicas Teóricas y Aplicadas) INIFTA, UNLP, La Plata 7-10 de octubre 2008.

- "Evaluación de Matrices Mixtas de Quitosano y Poli-ع-Caprolactona en Ingeniería de Tejido Óseo". Berghoff C.F ; Cortizo M. S.,Cortizo M.A. Reunión Anual SAIC-SAFIS 2008. Mar del Plata 19 - 22 de noviembre de 2008.

- "Caracterización y propiedades de quitosano obtenido de calamar Illex argentinus". Berghoff, C.F., Amarilla F. E., Cortizo M. S., Alessandrini J.L. Fronteras en fisicoquímica. Un 
enfoque interdisciplinario. 60 Aniversario (1948-2008) de Actividades en el Campo de la Fisicoquímica INIFTA La Plata, 24-28 de noviembre de 2008.

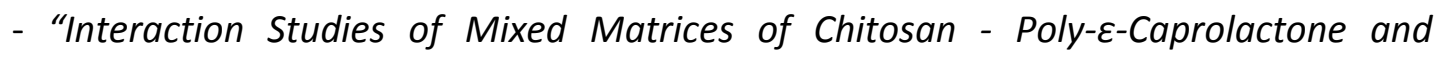
Alendronate for Bone Tissue Engineering". Berghoff C.F.; Cortizo M.S.; Cortizo A.M. 9th International Conference of the European Chitin Society. Isla de San Servolo, Venecia, Italia, 23-26 de mayo de 2009.

- "Interaction Studies of Cross-linked chitosan/PعCL Scaffolds with Osteoblasts". Berghoff C.F.; Cortizo M.S.; Cortizo A.M. V Simposio Argentino-Chileno de polímeros (Archipol 2009). Los Cocos, Córdoba, Argentina, 18-21 de octubre de 2009.

- "Aplicaciones Biomédicas del Quitosano". Berghoff, C.F. Jornadas de Becarios del INIFTA (Instituto de Investigaciones Fisicoquímicas Teóricas y Aplicadas) INIFTA, UNLP, La Plata 13-16 de octubre 2009.

- Trabajos publicados en revistas periódicas:

-Cortizo, M.S.; Berghoff, C.F.; Alessandrini, J.L. "Characterization of Chitin from Illex argentinus squid pen" Carbohydrate Polymers 74: 10-15 (2008).

- Berghoff C.F ; Cortizo M.S. ; Cortizo A.M. "Interaction Studies of Mixed Matrices of Chitosan -Poly- $\varepsilon$ - Caprolactone and Alendronate for Bone Tissue Engineering". Advances in Chitin Science. Volume XI. Proceedings of the 9th International Conference of the European Chitin Society (2009). 